\begin{abstract}
UNIVERSIDADE DE BRASÍLIA
FACULDADE UnB GAMA/ FACULDADE DE TECNOLOGIA PROGRAMA DE PÓS-GRADUAÇÃO EM INTEGRIDADE DE MATERIAIS DA ENGENHARIA
\end{abstract}

\title{
ESTUDO ANALÍTICO E NUMÉRICO DO DESEMPENHO ACÚSTICO DE SILENCIADORES REATIVOS NA PRESENÇA DE ESCOAMENTO MÉDIO INCOMPRESSÍVEL
}

GABRIELA CRISTINA CÂNDIDO DA SILVA

ORIENTADORA: Prof ${ }^{a}$ Dr(a). Maria Alzira de Araújo Nunes

\author{
DISSERTAÇÃO DE MESTRADO EM INTEGRIDADE DE \\ MATERIAIS \\ DA ENGENHARIA
}

PUBLICAÇÃO: FGA.DM - 036A/2016

BRASÍLIA/DF: 08/2016 
UNIVERSIDADE DE BRASÍLIA

FACULDADE UnB GAMA/FACULDADE DE TECNOLOGIA

PROGRAMA DE PÓS-GRADUAÇÃO EM INTEGRIDADE DE MATERIAIS DA ENGENHARIA

\section{ESTUDO ANALÍTICO E NUMÉRICO DO DESEMPENHO ACÚSTICO DE SILENCIADORES REATIVOS NA PRESENÇA DE ESCOAMENTO MÉDIO INCOMPRESSÍVEL}

GABRIELA CRISTINA CANDIDO DA SILVA

DisSERTAÇÃo DE MESTRAdo SUBMETIDA AO PROGRAMA DE PÓSGRADUAÇÃO EM INTEGRIDADE DE MATERIAIS DA ENGENHARIA DA FACULDADE DE TECNOLOGIA DA UNIVERSIDADE DE BRASÍLIA, COMO PARTE DOS REQUISITOS NECESSÁRIOS PARA A OBTENÇÃO DO GRAU DE MESTRE.

APROVADA POR:

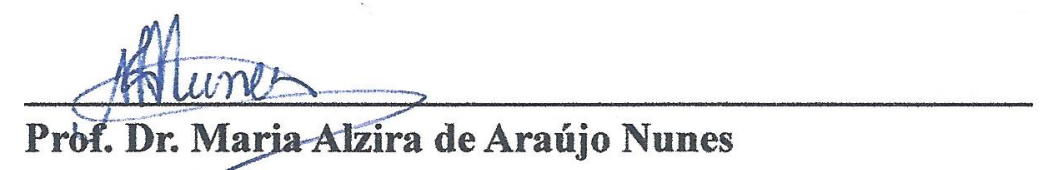

Prof. Dr. Maria-Alzira de Araújo Nunes

(Orientador)

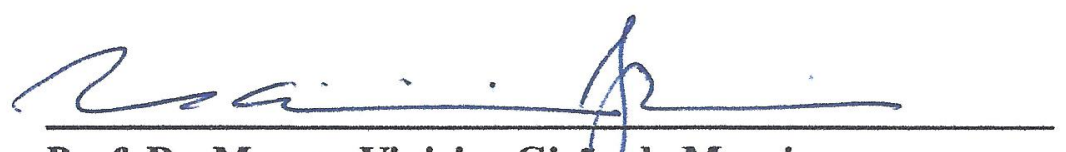

Prof. Dr. Marcus Vinicius Girâd de Morais

(Examinador Interno)

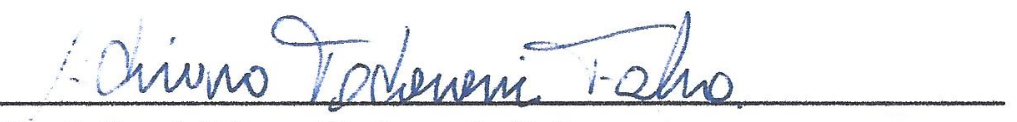

Prof. Dr. Adriano Todorovic Fabro

(Examinador Externo)

Brasília, 04 de agosto de 2016. 


\section{FICHA CATALOGRÁFICA}

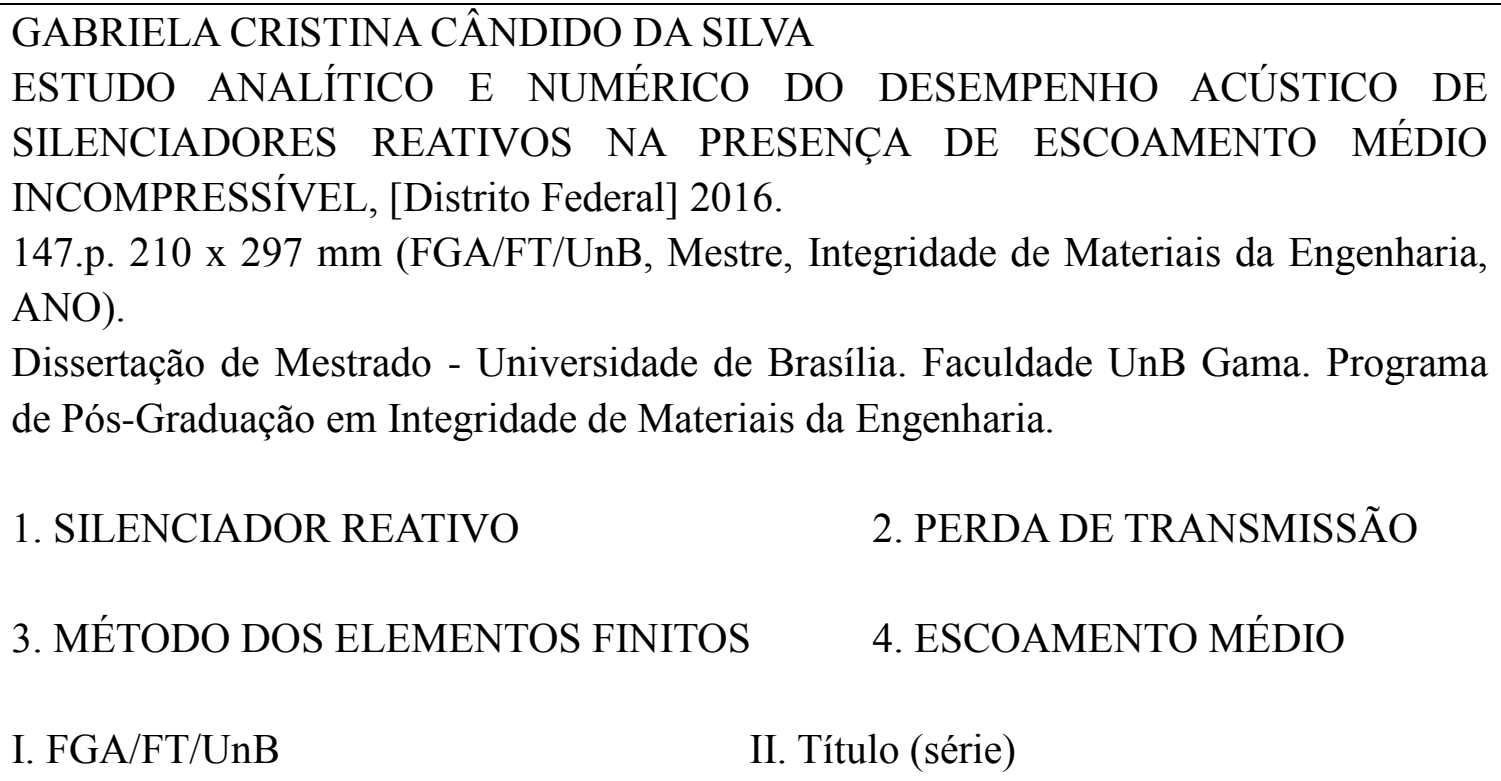

Dissertação de Mestrado - Universidade de Brasília. Faculdade UnB Gama. Programa de Pós-Graduação em Integridade de Materiais da Engenharia.

1. SILENCIADOR REATIVO

3. MÉTODO DOS ELEMENTOS FINITOS

I. FGA/FT/UnB

2. PERDA DE TRANSMISSÃO

4. ESCOAMENTO MÉDIO

II. Título (série)

\section{REFERÊNCIA BIBLIOGRÁFICA}

SILVA, G. C. C. (2016). ESTUDO ANALÍTICO E NUMÉRICO DO DESEMPENHO ACÚSTICO DE SILENCIADORES REATIVOS NA PRESENÇA DE ESCOAMENTO MÉDIO INCOMPRESSÍVEL. Dissertação de Mestrado em Integridade de Materiais da Integridade da Engenharia, Publicação 036A./2016, Faculdade UnB Gama/FT/Universidade de Brasília, DF, 147.p.

\section{CESSÃO DE DIREITOS}

AUTOR: GABRIELA CRISTINA CÂNDIDO DA SILVA

TÍTULO: ESTUDO ANALÍTICO E NUMÉRICO DO DESEMPENHO ACÚSTICO DE SILENCIADORES REATIVOS NA PRESENÇA DE ESCOAMENTO MÉDIO INCOMPRESSÍVEL

GRAU: Mestre ANO: 2016

É concedida à Universidade de Brasília permissão para reproduzir cópias desta dissertação de mestrado e para emprestar ou vender tais cópias somente para propósitos acadêmicos e científicos. $\mathrm{O}$ autor reserva outros direitos de publicação e nenhuma parte desta dissertação de mestrado pode ser reproduzida sem a autorização por escrito do autor.

GABRIELA CRISTINA CÂNDIDO DA SILVA

CONDOMÍNIO DAS PALMEIRAS, RUA 11, CASA 10

72426-300 Brasília, DF - Brasil. 
Aos meus pais 


\section{AGRADECIMENTO}

Agradeço aos meus pais, meus maiores parceiros, por acreditar nas minhas escolhas e fazer tudo o que for possível para que eu alcance meus objetivos.

Ao Israel, meu namorado, que está sempre ao meu lado, me incentivando, me ouvindo, e que foi essencial para chegar até aqui.

À minha orientadora, professora Maria Alzira, por participar com dedicação de todas as etapas desse trabalho, e por todos os conselhos fundamentais para meu crescimento acadêmico e pessoal.

Ao Professor Jhon, e aos colegas do laboratório GMSA, que ofereceram toda a ajuda necessária na etapa de simulação CFD.

Ao suporte da LMS Virtual.lab e Ansys, que foram solícitos em responder minhas dúvidas.

Agradeço também ao Flick, meu companheiro fiel. 


\section{RESUMO}

O objetivo desse trabalho é apresentar uma metodologia para estimativa analítica e numérica do desempenho acústico de silenciadores reativos na presença de escoamento médio incompressível em seu interior. Inicialmente, a perda de transmissão (TL) de quatro modelos de silenciadores foi estimada sem a presença de escoamento. A análise analítica foi realizada pelo método da matriz de transferência e também por equações analíticas, avaliando diferentes fatores de correção. A análise numérica foi realizada utilizando o método de elementos finitos em dois softwares comerciais: Ansys Mechanical ${ }^{\circledR} 16.0$ e LMS Virtual.lab ${ }^{\circledR}$ 13.5. Os resultados numéricos e analíticos apresentaram boa concordância. Na segunda etapa, considerou-se a presença de fluxo adotando três valores distintos para velocidade do escoamento. $\mathrm{Na}$ análise numérica foi obtido o campo de velocidade de fluxo no interior do silenciador através de simulação CFD, considerando regime permanente e utilizando o software comercial Ansys $\mathrm{CFX}^{\circledR}$ 16.0. Os dados de velocidade de fluxo são importados no Virtual.lab ${ }^{\circledR}$, onde integram a formulação de elementos finitos para determinação da TL. Essa metodologia não avalia os efeitos da viscosidade do escoamento na propagação do som, mas fornece uma distribuição de velocidade no interior do silenciador mais realista e detalhada, que não é considerada na análise analítica. Os resultados revelam uma maior sensibilidade da TL ao escoamento com aumento da descontinuidade geométrica do silenciador. Pelo método numérico, verifica-se que a amplitude de atenuação diminui com 0 aumento da velocidade de fluxo, porém a frequência de máxima atenuação se mantém a mesma.

Palavras-chaves: silenciador reativo; perda de transmissão; método de elementos finitos; método da matriz de transferência; escoamento médio. 


\begin{abstract}
The aim of this paper is to present a methodology for analytical and numerical estimation of acoustic performance of reactive silencers in the presence of incompressible mean flow. At the first step, the transmission loss (TL) of four types of silencers was estimated with no mean flow. The analytical analysis was performed by the transfer matrix method and by analytical equations, evaluating different correction factors. Numerical analysis was performed using the finite element method in two commercial softwares: Ansys Mechanical® 16.0 and 13.5 Virtual.Iab® LMS. The numerical and analytical results presented good agreement. In the second step, It was considered the presence of mean flow. Three different flow velocities were adopted. In numerical analysis, the 3D mean flow field is computed by firstly using computational fluid dynamic performed by the software Ansys CFX ${ }^{\circledR} 16.0$ and then the obtained mean flow data are imported to an acoustic solution undertaken using FEM using the software Virtual.lab ${ }^{\circledR}$. The numerical and analytical results did not show good agreement, but show greater sensitivity TL to flow with increased geometric discontinuity muffler. This methodology does not evaluate the viscous effect of mean flow on sound propagation but gives a more realistic and detailed flow velocity distribution inside the silencers, which is not considered by the analytical method. The results show that the geometric discontinuities tends to be more sensitive to the mean flow. The amplitude attenuation decreases with increasing flow rate, but the frequency of maximum attenuation stays the same.
\end{abstract}

Keywords: reactive muffler; transmission loss; finite element method; transfer matrix method; mean flow 


\section{LISTA DE FIGURAS}

Figura 1 - (a) Silenciador dissipativo para aplicação automotiva (34) (b) Silenciador reativo para aplicação industrial (2) ........................................... 21

Figura 2 - (a) Silenciador ativo (35) (b) Princípio de funcionamento da técnica de controle ativo 22

Figura 3 - Exemplo de silenciadores reativos (a) Aplicação industrial (2) (b) Dispositivo utilizado em escapamento de veículos automotivos (3) ................. 22

Figura 4 - Silenciador reativo para motores industriais e sua curva de desempenho em função do diâmetro [2] .................................................... 23

Figura 5 - Exemplos de silenciadores reativos com geometria mais complexa [8] 24

Figura 6 - Modos de propagação da onda em um duto uniforme circular [39] 42

Figura 7 - Modo acústico de propagação da onda em um duto com uma placa no interior (40) 44

Figura 8 - Redução de Ruído (NR) [1] ...................................................... 45

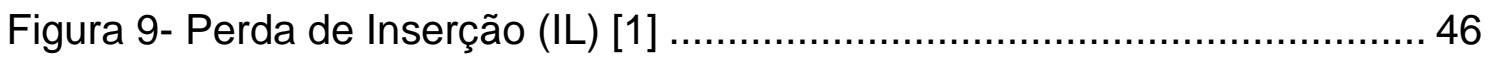

Figura 10 - Perda de Transmissão (TL) [1] ............................................. 46

Figura 11 - (a) Analogia com a velocidade de volume (b) analogia com a

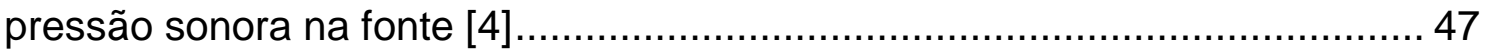

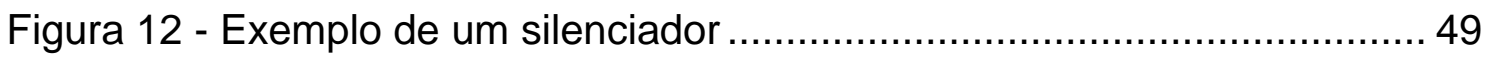

Figura 13 - Representação da velocidade de particulada provocada pela súbita mudança da área da seção transversal de dutos [39]. 50 
Figura 14 - Fator de correção da extremidade de um duto 51

Figura 15 - Duto uniforme com fluxo médio 52

Figura 16 - Principais tipos de duto estendido: (a) Duto Estendido na Saída, (b) Duto Estendido na Entrada, (c) Sistema com Expansão Reversa e (d) Sistema com Contração Reversa. 53

Figura 17 - Duto com abertura lateral (Quarter-Wave-Tube). 55

Figura 18- Descontinuidades geométricas: (a) Súbita contração e (b) Súbita expansão. 56

Figura 19 - Método da decomposição 61

Figura 20- Resumo do estudo analítico-numérico desenvolvido 64

Figura 21 - Modelos de silenciadores reativos adotados neste trabalho: (a) QWT - modelo I, (b) câmara de expansão simples - modelo II, (c) câmara de expansão com duto de entrada estendido - modelo III e (d) câmara de expansão com dutos estendidos - modelo IV. 65

Figura 22 - Fluxograma do Método da Matriz de Transferência 67

Figura 23 - Decomposição do silenciador em elementos básicos 69

Figura 24 - Perda de Transmissão do modelo I 71

Figura 25 - Decomposição do modelo II em elementos básicos (sem fator de correção) 72

Figura 26 - Decomposição do modelo II em elementos básicos (com fator de correção) 73

Figura 27 - TL do modelo II calculada com MMT 74 
Figura 28 - TL do modelo Il calculada com a equação analítica 75

Figura 29- TL do modelo II calculada por MMT e equação analítica com fator de correção de Karal 76

Figura 30 - Decomposição do modelo III em elementos básicos 77

Figura 31 - TL do modelo III calculada pelo MMT 78

Figura 32 - TL do modelo III calculada pelo MMT e equação analítica com fator de correção de Karal 79

Figura 33- Decomposição do modelo IV em elementos básicos 80

Figura 34 - TL do modelo IV pelo MMT. 81

Figura 35 - TL para o modelo IV calculada pelo MMT e Equação analítica com fator de correção de Karal 83

Figura 36 - Metodologia adotada para avaliação do desempenho de silenciadores reativos utilizando o método de elementos finitos 84

Figura 37- Detalhes da metodologia numérica via Ansys ${ }^{\circledR}$ (a) Meio fluído 2D (b) Meio fluído 3D (c) Pressão no duto de entrada (símbolo em verde) (d) Terminação anecóica no duto de saída (símbolo em vermelho) 86

Figura 38 - Geometria do Elemento (a) FLUID29 (b) FLUID30 [60]. 87

Figura 39 - Envelope acústico dividido em grupos de elementos e 10 points (em amarelo) 89

Figura 40- Detalhes das condições de contorno (a) Velocidade unitária no duto de entrada (símbolo em vermelho) (d) Terminação anecóica no duto de saída (símbolo em azul) 89 
Figura 41 - Malha em elementos finitos do modelo I nas análises (a) Ansys ${ }^{\circledR} 2 \mathrm{D}$

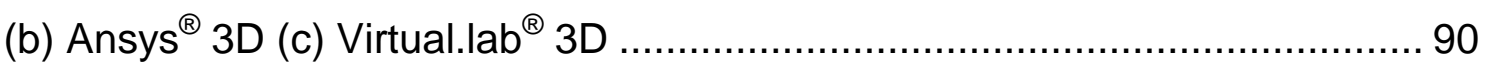

Figura 42 - TL do modelo I pelo método de elementos finitos .......................... 91

Figura 43 - Comparação da TL do modelo I obtida pelo MMT com fator de correção de Ji e obtida pelo MEF no Ansys ${ }^{\circledR}$................................................... 92

Figura 44 - Comparação da TL do modelo I obtida pelo MMT e obtida pelo MEF no Virtual.lab ${ }^{\circledR}$...... 93

Figura 45- Malha em elementos finitos do modelo II no Ansys ${ }^{\circledR}$ nas análises (a) 2D (b) 3D fracionada e (c) 3D ................................................................. 93

Figura 46 - Malha em elementos finitos do modelo II utilizadas no Virtual.lab ${ }^{\circledR}$

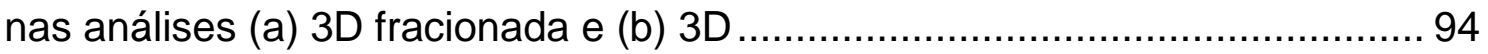

Figura 47 - TL do modelo Il obtida pelo MEF no Ansys ${ }^{\circledR}$................................ 95

Figura 48 - TL do modelo II obtida pelo MEF no Virtual.lab ${ }^{\circledR}$.......................... 96

Figura 49 - Comparação da TL do modelo II obtida pelo MMT com fator de

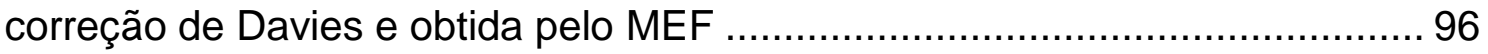

Figura 50 - Malha em elementos finitos do modelo III utilizadas no Ansys ${ }^{\circledR}$ nas

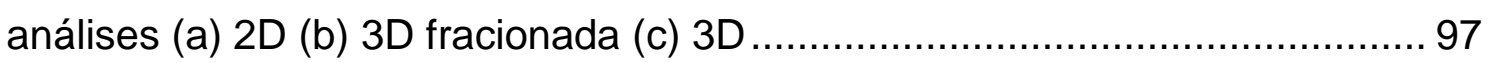

Figura 51 - Malha em elementos finitos do modelo III utilizadas no Virtual.lab ${ }^{\circledR}$ nas análises (a) 3D fracionada (b) 3D 97

Figura 52 - Detalhe da malha para representar o duto estendido ................... 98

Figura 53 - TL do modelo III obtida pelo MEF no Ansys ${ }^{\circledR}$.............................. 98

Figura 54 - Comparação entre a TL do modelo II obtida pelo MMT com fator de correção de Davies com MEF no Ansys ${ }^{\circledR}$ modelo 3D 99 
Figura 55 - TL do modelo III obtida pelo Virtual.lab ${ }^{\circledR}$ 100

Figura 56 - Comparação das TL do modelo III obtidas pelo MMT e pelo MEF no Virtual.lab ${ }^{\circledR}$ com modelo 3D 101

Figura 57 - Comparação das TL do modelo III obtidas pelo MMT e pelo MEF no Virtual.lab ${ }^{\circledR}$ com modelo 3D fracionado 101

Figura 58 - Malha em elementos finitos do modelo IV utilizados no Ansys ${ }^{\circledR}$ nas análises (a) 2D (b) 3D fracionada e (c) 3D 102

Figura 59 - Malha em elementos finitos do modelo IV utilizados no Virtual.lab ${ }^{\circledR}$ nas análises (a) 2D (b) 3D fracionada e (c) 3D 102

Figura 60 - Malha 3D do modelo IV: (a) Contorno da malha utilizada no Ansys ${ }^{\circledR}$ e (b) vista em corte da malha utilizada no Virtual.lab ${ }^{\circledR}$ 103

Figura 61 - TL do modelo IV obtido por MEF no Ansys ${ }^{\circledR}$ 103

Figura 62 - Comparação entre a TL do modelo III obtida pelo MMT com fator de correção de Davies com MEF no Ansys ${ }^{\circledR}$ modelo 3D 105

Figura 63 - TL do modelo III obtida por MEF no Virtual.lab ${ }^{\circledR}$ 105

Figura 64 - Comparação entre a TL obtida pelo MMT com fator de correção de Davies com MEF no Virtual.lab ${ }^{\circledR}$ modelo 3D 106

Figura 65 - Comparação da TL do modelo IV obtida no Ansys ${ }^{\circledR}$ modelo 3D variando a espessura dos dutos estendidos 107

Figura 66 - Comparação da TL do modelo IV obtida no Virtual.lab ${ }^{\circledR}$ modelo 3D fracionado variando a espessura dos dutos estendidos 107

Figura 67 - TL obtida pelo MMT sem considerar fator de correção variando a velocidade de escoamento 110 
Figura 68 - TL obtida para o modelo II pelo MMT com fator de correção de Davies variando a velocidade de escoamento 110

Figura 69 - TL obtida para o modelo II pelo MMT com fator de correção de Karal variando a velocidade de escoamento.

Figura 70 - TL obtida para o modelo II pelo MMT com fator de correção de Torregrossa variando a velocidade de escoamento 111

Figura 71 - TL obtida pelo MMT para velocidade de $10 \mathrm{~m} / \mathrm{s}$ 112

Figura 72 - TL obtida para o modelo III pelo MMT sem fator de correção variando a velocidade de escoamento 113

Figura 73 - TL do modelo III obtida pelo MMT com fator de correção de Davies variando a velocidade de escoamento 114

Figura 74 - TL do modelo III obtida pelo MMT com fator de correção de Karal variando a velocidade de escoamento 114

Figura 75 - TL do modelo III obtida pelo MMT com fator de correção de Torregrossa variando a velocidade de escoamento 115

Figura 76 - TL do modelo III obtida pelo MMT para velocidade de $10 \mathrm{~m} / \mathrm{s}$.... 116

Figura 77 - TL do modelo IV obtida pelo MMT sem fator de correção variando a velocidade de escoamento

Figura 78 - TL do modelo IV obtida pelo MMT com fator de correção de Davies variando a velocidade de escoamento 117

Figura 79 - TL do modelo IV obtida pelo MMT com fator de correção de Karal variando a velocidade de escoamento 118

Figura 80 - TL do modelo IV obtida pelo MMT com fator de correção de Torregrossa variando a velocidade de escoamento 118 
Figura 81 - TL do modelo IV obtida pelo MMT com fator de correção de Kang \& Ji e Chaitanya \& Munjal variando a velocidade de escoamento

Figura 82 - TL do modelo IV obtida pelo MMT para velocidade de $10 \mathrm{~m} / \mathrm{s} \ldots .120$

Figura 83 - Fluxograma da metodologia para estimativa da TL em silenciadores reativos considerando a presença de escoamento 121

Figura 84 - Geometria dos silenciadores no DesignModeler (a) modelo II (b) modelo III e (c) modelo IV

Figura 85 - Malha em CFD do modelo II (a) vista isométrica e (b) vista em corte 124

Figura 86 - Malha em CFD do modelo III (a) vista isométrica e (b) vista em corte 125

Figura 87 - Malha em CFD do modelo IV (a) vista isométrica e (b) vista em corte 125

Figura 88 - Contorno de velocidade obtido para o modelo II com velocidade de entrada de (a) $10 \mathrm{~m} / \mathrm{s}$ (b) $30 \mathrm{~m} / \mathrm{s}$ e (c) $60 \mathrm{~m} / \mathrm{s}$ 126

Figura 89- Contorno de velocidade obtido para o modelo III com velocidade de entrada de (a) $10 \mathrm{~m} / \mathrm{s}$ (b) $30 \mathrm{~m} / \mathrm{s}$ e (c) $60 \mathrm{~m} / \mathrm{s}$ 127

Figura 90 - Contorno de velocidade obtido para o modelo IV com velocidade de entrada de (a) $10 \mathrm{~m} / \mathrm{s}$ (b) $30 \mathrm{~m} / \mathrm{s}$ e (c) $60 \mathrm{~m} / \mathrm{s}$ 127

Figura 91 - Comparação entre o contorno de velocidade na malha CFD e malha acústica para o modelo III 129

Figura 92 - TL do modelo II variando a velocidade de escoamento 130

Figura 93 - Comparação da TL obtida pelo MMT e MEF para o modelo II com velocidade de fluxo de $10 \mathrm{~m} / \mathrm{s}$ 131 
Figura 94 - Distribuição da pressão sonora (dB) do modelo II em $1398 \mathrm{~Hz}(\mathrm{a})$ sem escoamento e com velocidade de fluxo de (b) $10 \mathrm{~m} / \mathrm{s}$, (c) $30 \mathrm{~m} / \mathrm{s}$ e (d) 60 $\mathrm{m} / \mathrm{s}$

Figura 95 - TL do modelo III variando a velocidade de escoamento 133

Figura 96 - Comparação da TL obtida pelo MMT e MEF para o modelo III com velocidade de fluxo de $10 \mathrm{~m} / \mathrm{s}$ 134

Figura 97 - Distribuição da pressão sonora (dB) no modelo III em $1398 \mathrm{~Hz}(\mathrm{a})$ sem escoamento e com velocidade de fluxo de (b) $10 \mathrm{~m} / \mathrm{s}$, (c) $30 \mathrm{~m} / \mathrm{s}$ e (d) 60 $\mathrm{m} / \mathrm{s}$ 135

Figura 98 - TL do modelo IV variando a velocidade de escoamento 135

Figura 99 - Comparação da TL obtida pelo MMT e MEF para o modelo IV com velocidade de fluxo de $10 \mathrm{~m} / \mathrm{s}$ 137

Figura 100 - Distribuição da pressão sonora (dB) no modelo IV em $432 \mathrm{~Hz}$ (a) sem escoamento e com velocidade de fluxo de (b) $10 \mathrm{~m} / \mathrm{s}$, (c) $30 \mathrm{~m} / \mathrm{s}$ e (d) 60 $\mathrm{m} / \mathrm{s}$ 137 


\section{LISTA DE TABELAS}

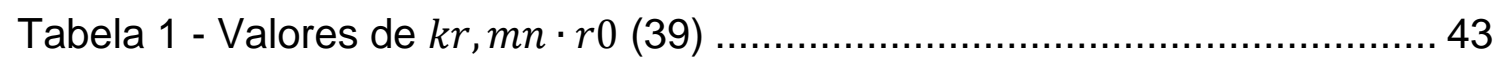

Tabela 2- Coeficiente de Pressão de Estagnação K (13)................................ 53

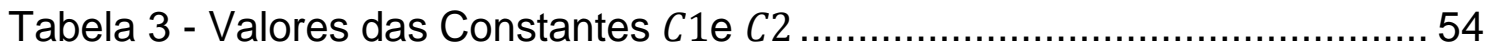

Tabela 4 - Quadro-resumo com matrizes de transferência de elementos comuns que compõem silenciadores reativos............................................. 57

Tabela 5 - Frequências de corte dos dutos que compõem os silenciadores .... 67

Tabela 6 - Etapas para cálculo do TL utilizando o Método da Matriz de

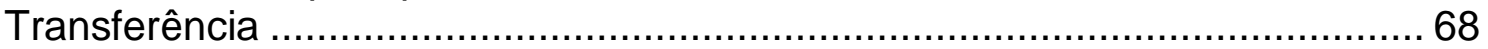

Tabela 7 - Fatores de Correção para o modelo I............................................ 70

Tabela 8 - Frequências e amplitudes de ressonância de acordo com cada fator

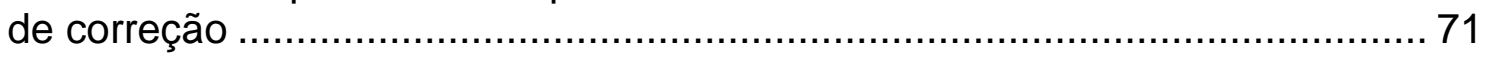

Tabela 9 - Fatores de correção para camâra de expansão simples.................. 73

Tabela 10 - Frequência e amplitude dos pontos de máximo dos domos da TL

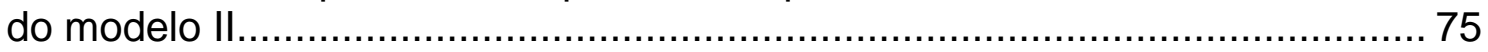

Tabela 11 - Frequência e amplitude do pico de atenuação obtido para cada

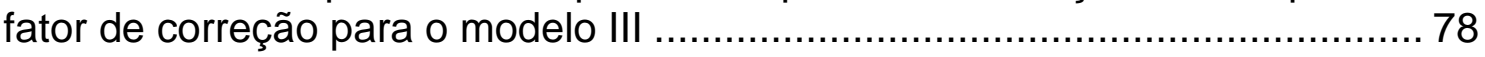

Tabela 12 - Fatores de correção para o modelo IV ........................................... 81

Tabela 13 - Frequência e amplitude dos picos de atenuação obtidos para cada

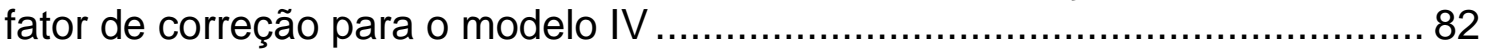

Tabela 14 - Etapas da metodologia numérica para estimativa numérica da TL

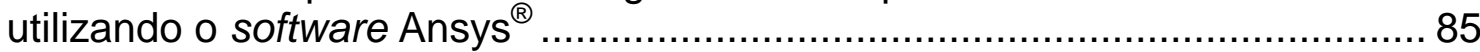

Tabela 15 - Etapas da metodologia numérica para estimativa numérica da TL

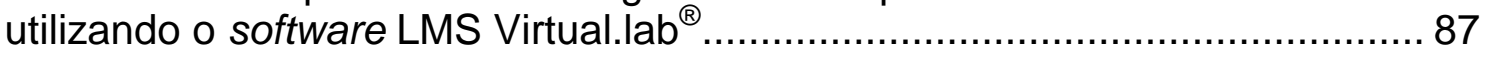

Tabela 16 - Propriedades das malhas em elementos finitos do modelo I e tempo de processamento ............................................................................... 91

Tabela 17 - Valores de frequência de ressonância e amplitude obtidos com 0 MEF 
Tabela 18 - Propriedades das malhas em elementos finitos e tempo de

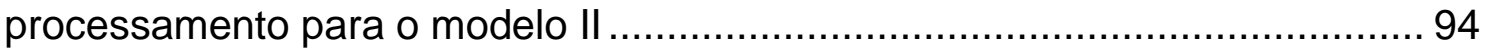

Tabela 19 - Propriedades das malhas em elementos finitos e tempo de processamento para o modelo III .............................................................. 97

Tabela 20 - Valores de frequência e amplitude dos picos de atenuação do modelo III obtido pelo MEF no Ansys ${ }^{\circledR}$........................................................... 99

Tabela 21 - Valores de frequência e amplitude dos picos de atenuação obtidos para o modelo III pelo MEF no Virtual.lab ${ }^{\circledR}$.................................................... 100

Tabela 22 - Propriedades das malhas em elementos finitos e tempo de processamento do modelo IV ............................................................... 102

Tabela 23 - Valores de frequência e amplitude dos picos de atenuação obtidos para o modelo IV pelo MEF no Ansys ${ }^{\circledR}$..................................................... 104

Tabela 24 - Valores de frequência e amplitude dos picos de atenuação obtidos para o modelo IV pelo MEF no Virtual.lab ${ }^{\circledR}$.................................................. 106

Tabela 25 - Frequências de corte circunferencial e radial para velocidade de 60 $\mathrm{m} / \mathrm{s}$ 109

Tabela 26 - Número de Reynolds para cada modelo de câmara de expansão em função da velocidade do escoamento

Tabela 27- Etapas da metodologia para simulação CFD do escoamento em um silenciador reativo utilizando o CFX

Tabela 28- Composição da malha CFD de cada modelo de silenciador 125

Tabela 29 - Tempo de simulação CFD em função da velocidade de entrada 126

Tabela 30- Valores de frequência e amplitude do pico de atenuação da TL do modelo III 133

Tabela 31- Valores de frequência e amplitude dos picos de atenuação da TL do modelo IV 


\section{LISTA DE SIGLAS}

1D - Unidimensional

2D - Bidimensional

3D- Tridimensional

CFD - Computacional Fluid Dynamics

IL - Insertion Loss (Perda de Inserção)

MEC - Método dos Elementos de Contorno

MEF - Método dos Elementos Finitos

MFV - Método dos Volumes Finitos

MMT - Método da Matriz de Transferência

NR - Noise Reduction (Redução de ruído)

QWT - Quarter-wave-tube

TL - Transmission Loss (Perda de Transmissão) 


\section{ÍNDICE}

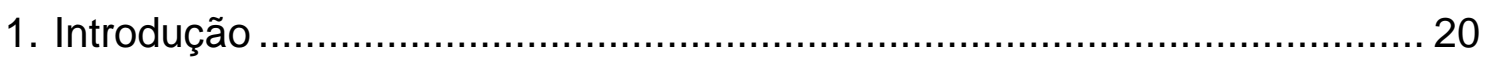

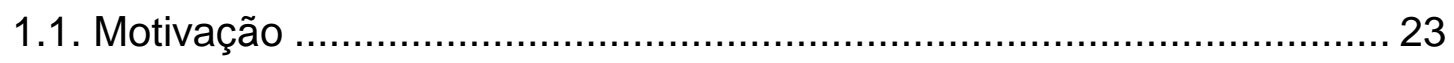

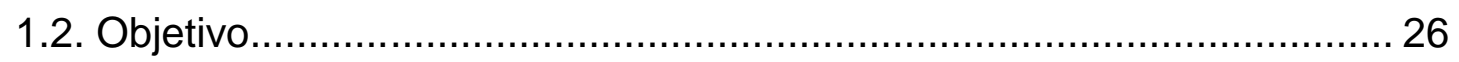

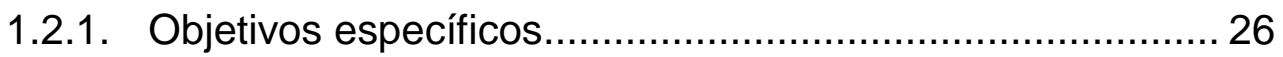

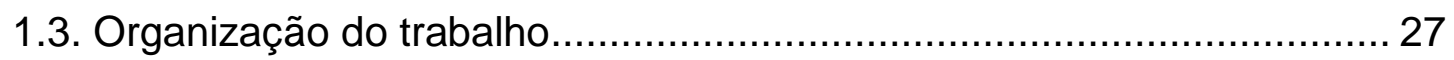

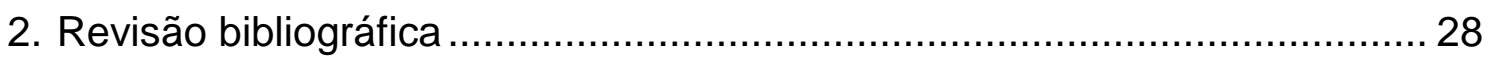

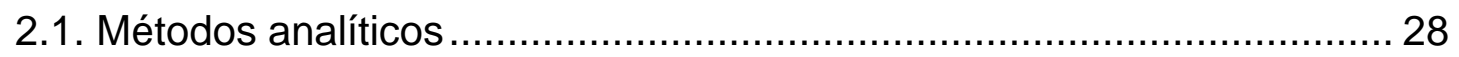

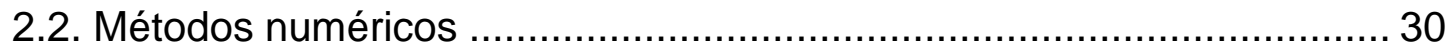

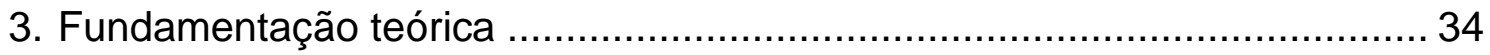

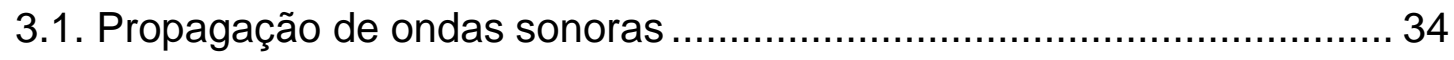

3.1.1. Equação da continuidade de massa ................................ 35

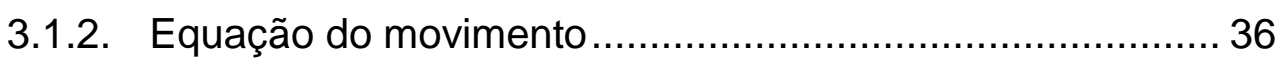

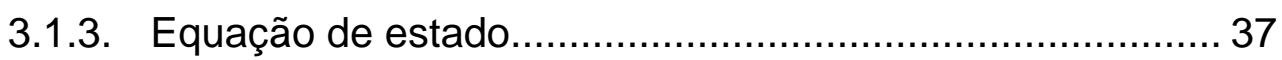

3.1.4. Irrotacionalidade e funções potenciais ............................. 38

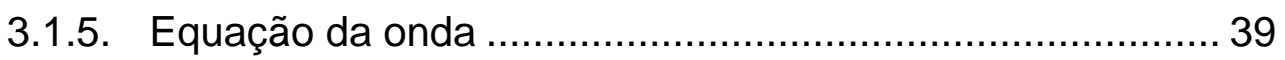

3.1.6. Modos acústicos de propagação de ondas em dutos de seção transversal circular.......................................................................... 41

3.2. Parâmetros para avaliação do desempenho acústico ............................ 44

3.2.1. Redução de ruído - Noise Reduction (NR) ....................... 45

3.2.2. Perda de inserção - Insertion Loss (IL)............................. 45

3.2.3. Perda de transmissão - Transmission Loss (TL) ............... 46

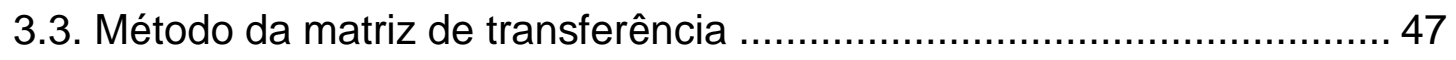

3.3.1. Fator de correção da extremidade de um tubo....................50 
3.3.2. Matriz de transferência para dutos de seção uniforme ....... 51

3.3.3. Matriz de transferência para dutos estendidos ................... 52

3.3.4. Matriz de transferência para tubo fechado na abertura

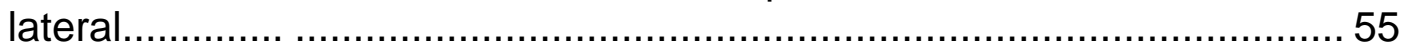

3.3.5. Matriz de transferência para expansão e contração súbita 56

3.4. Método dos elementos finitos (MEF) 58

3.4.1. Modelagem em elementos finitos do potencial de

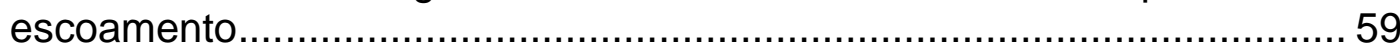

3.4.2. Modelagem em elementos finitos do potencial acústico..... 59

3.4.3. Método da decomposição ............................................... 61

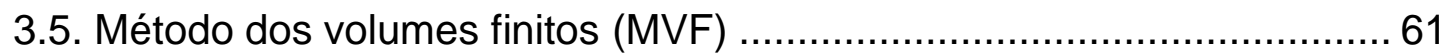

4. Modelagem e simulação do desempenho acústico de silenciadores reativos 64

4.1. Estimativa da perda de transmissão na ausência de escoamento .........66

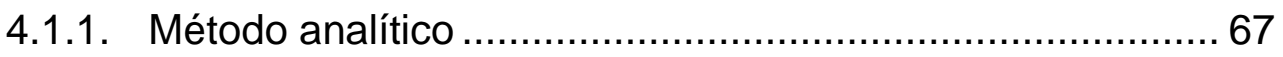

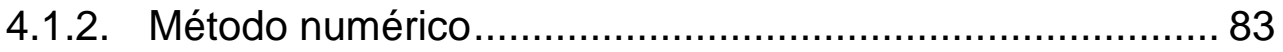

4.2. Estimativa da perda de transmissão na presença de escoamento ...... 108

4.2.1. Método analítico ......................................................... 108

4.2.2. Método numérico......................................................... 120

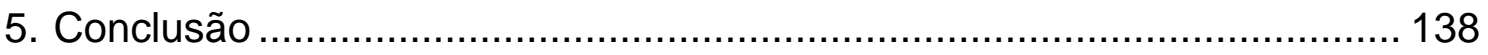

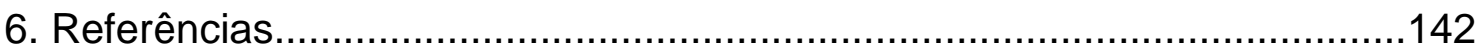




\section{INTRODUÇÃO}

O ruído gerado por sistemas mecânicos, domésticos e industriais, é atualmente uma das principais fontes de poluição sonora com impacto significativo na perda de qualidade de vida da população, podendo causar, inclusive, efeitos nocivos à saúde do ser humano.

As fontes de ruído são muito diversas, podendo citar como exemplos os motores de combustão interna presentes em veículos automotores, os compressores industriais que fornecem ar comprimido para ferramentas industriais, os compressores de sistemas de refrigeração que são responsáveis pelos ciclos termodinâmicos e os sistemas de ventilação e exaustão industrial, entre outros [1].

Este contexto provocou o surgimento de leis ambientais mais rigorosas e aumentou a demanda por máquinas e equipamentos mais silenciosos. Dessa forma, um dos principais desafios da indústria se tornou o desenvolvimento de estratégias para eliminar os ruídos ou reduzi-los para níveis aceitáveis. Uma das soluções adotadas é o uso de filtros acústicos, chamado de silenciadores.

Os silenciadores são classificados como ativos ou passivos. Os silenciadores passivos ainda são subdivididos em duas categorias: dissipativos e reativos (ou reflexivos) [30], conforme Figura 1.

O silenciador dissipativo (Figura 1(a)) é composto por dutos ou câmaras que são revestidos com materiais acústicos que absorvem a energia acústica e a transformam em calor. Este tipo de silenciador é útil quando a fonte produz ruído em uma faixa ampla de frequência e é particularmente eficaz em altas frequências. Mas precauções especiais devem ser tomadas se o fluxo de gás apresenta alta velocidade e temperatura e se contém partículas ou é corrosivo [31]. O sistema dissipativo perde o seu desempenho com o tempo, devido ao arraste de partículas do material acústico pela passagem dos gases e pelo craqueamento do mesmo, gerando uma barreira contra a absorção sonora. 
O silenciador reativo (Figura 1(b)) consiste em conjuntos de elementos tubulares de dimensões transversais variadas com câmaras de volumes e formas diferentes. Utiliza a geometria para criar mudanças de impedância acústica para refletir a maior parte da energia acústica de volta para a fonte [32]. Este silenciador é econômico e requer pouca manutenção, sendo eficiente em baixas frequências, especialmente para atenuação de ruído de frequências discretas (tons puros) ou ainda na presença de fluxo de gás quente, com partículas ou de alta velocidade.

Entretanto, após a frequência de corte, quando começa a propagação de ondas sonoras tridimensionais, o desempenho do silenciador deteriora significativamente [33]. Na prática, é comum a combinação de silenciadores dissipativos e reativos, visando um sistema de atenuação mais eficiente, que contemple vantagens de ambos.

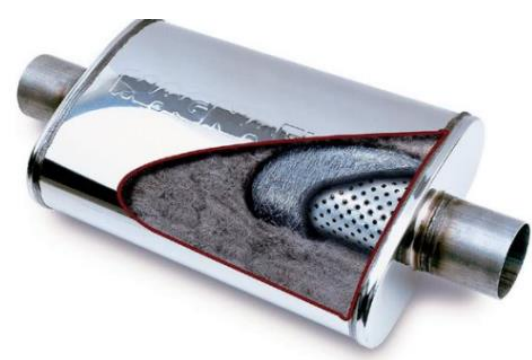

(a)

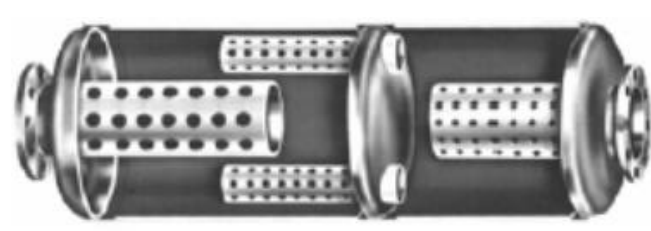

(b)

Figura 1 - (a) Silenciador dissipativo para aplicação automotiva (34) (b) Silenciador reativo para aplicação industrial (2)

Os silenciadores ativos utilizam-se do princípio da interferência destrutiva de ondas. A Figura 2(a) mostra um modelo de silenciador ativo e a Figura 2(b) está ilustrando a metodologia de funcionamento de um controle ativo - uma onda de pressão inversa é gerada através de dispositivos eletrônicos para atenuar ou até mesmo eliminar o ruído proveniente do motor. Estes silenciadores ainda estão em fase de pesquisa e possuem a grande vantagem de não causarem perda de potência pelo seu emprego [1]. 

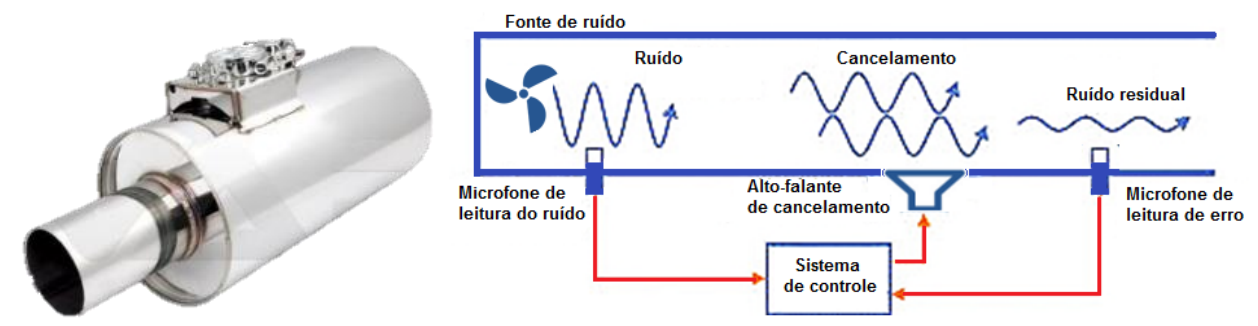

Figura 2 - (a) Silenciador ativo (35) (b) Princípio de funcionamento da técnica de controle ativo

Conforme as características apresentadas, os silenciadores reativos se revelam como uma alternativa atraente para diversas aplicações. Como exemplo, a Figura 3(a) mostra um silenciador utilizado em uma planta industrial e a Figura 3(b) apresenta um silenciador para uso em escapamento de veículos automotivos. São dispositivos de controle que podem ser altamente eficazes e de baixo custo, se corretamente dimensionados (4). Em geral, são construídos e dimensionados através de métodos parcialmente teóricos e largamente empíricos.

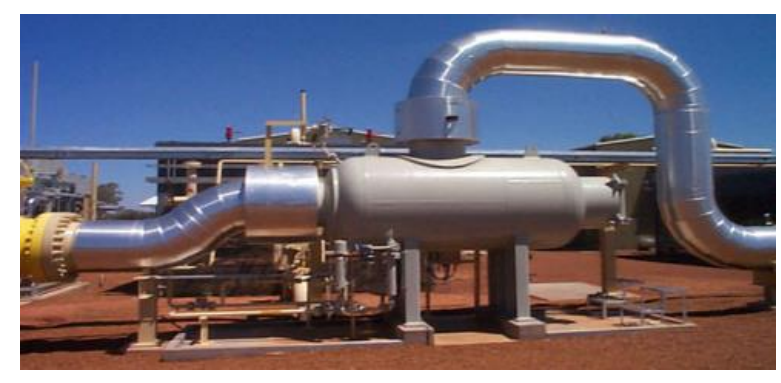

(a)

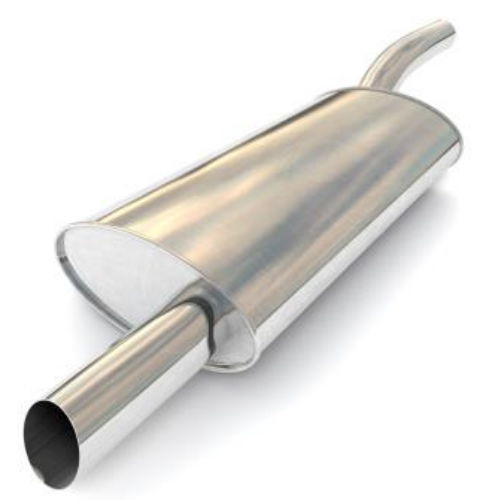

(b)

Figura 3 - Exemplo de silenciadores reativos (a) Aplicação industrial (2) (b) Dispositivo utilizado em escapamento de veículos automotivos (3)

A maior desvantagem dos procedimentos empíricos são sua inflexibilidade ao desenvolvimento e otimização de silenciadores, os quais acabam não atendendo completamente os requisitos de qualidade exigidos pelos consumidores e legislações. Os modelos teóricos inicialmente desenvolvidos eram limitados a geometrias simples e à propagação de ondas 
planas. Dessa forma, não era possível representar com proximidade os fenômenos de onda existentes nos silenciadores [5].

Porém, com o avanço tecnológico ocorreu o surgimento de uma variedade de técnicas computacionais, tornando possível predizer 0 desempenho acústico de silenciadores com maior rapidez e precisão, ainda na fase de projeto por meio da análise numérica. Isto possibilitou a fabricação de silenciadores mais eficientes, compactos e de menor custo, aliados a um menor tempo de desenvolvimento, que é um requisito fundamental [1].

\subsection{MOTIVAÇÃO}

Para construção de um silenciador, diversos parâmetros devem ser avaliados: faixa de frequência na qual o dispositivo deve atuar, máxima atenuação e limitações de espaço físico para sua instalação. A Figura 4 ilustra um silenciador para motores industriais, ao lado da sua curva de desempenho (perda de inserção - insertion loss) variando em função do diâmetro.

No processo usual de desenvolvimento de silenciadores, diversos protótipos são construídos e testados, gastando-se assim muito tempo e dinheiro até obter o modelo que atenda a todos os requisitos. A alta competitividade e o curto ciclo de vida do produto tornam crucial abreviar 0 tempo de desenvolvimento.
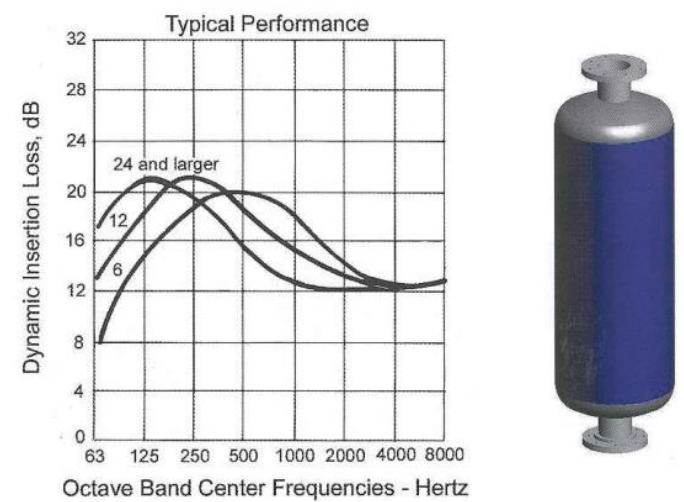

Figura 4 - Silenciador reativo para motores industriais e sua curva de desempenho em função do diâmetro [2] 
Com o avanço na teoria de filtros acústicos surgiram métodos analíticos unidimensionais, como o método da Matriz de Transferência (MMT), utilizado para avaliar o desempenho acústico de silenciadores, sem a necessidade de construção de modelos físicos [6]. Apesar de uma metodologia bem consolidada, ela contempla um número bem reduzido de configurações geométricas, relativamente simples, e os resultados estão limitados à frequência de propagação de ondas planas [7].

Atualmente, os silenciadores possuem formas mais complexas (Figura 5). Isto provoca o surgimento de ondas não planas, com a propagação simultânea de ondas nas direções axiais e radiais, quando a excitação atinge a faixa de frequência em que o comprimento de onda é menor que a maior dimensão da seção transversal do silenciador [1]
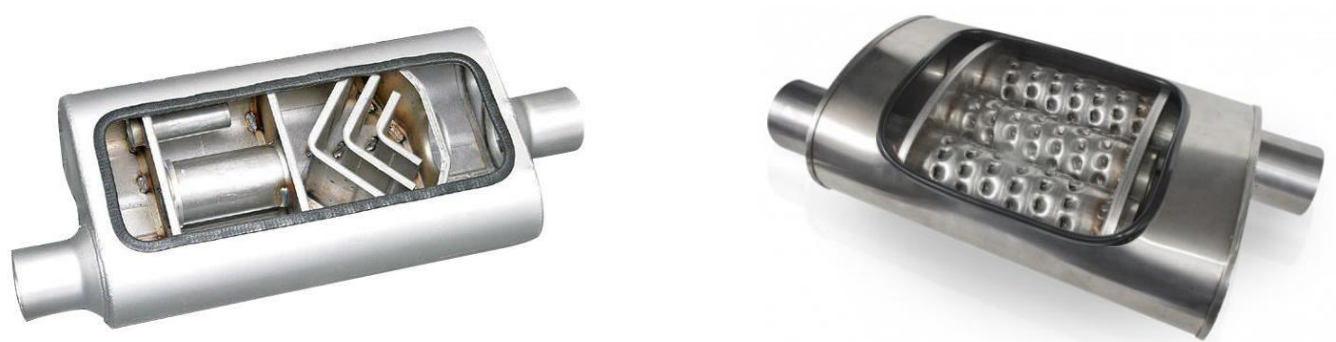

Figura 5 - Exemplos de silenciadores reativos com geometria mais complexa [8]

Então, a teoria unidimensional não pode ser aplicada, pois os resultados apresentam diferenças significativas ao compará-los com resultados experimentais. Os métodos analíticos envolvem uma álgebra complexa e não são viáveis para filtros com geometrias irregulares e complexas.

A metodologia capaz de substituir o método analítico é a simulação numérica computacional, tornando assim possível predizer o desempenho acústico dos silenciadores com maior rapidez e precisão. Os métodos numéricos não são restritos a modelos unidimensionais e podem ser adaptados a qualquer geometria, principalmente devido aos softwares destinados a desenho assistido por computador (CAD) existentes hoje no mercado. 
O Método dos Elementos Finitos (MEF) é um dos mais empregados para prever a performance acústica de silenciadores. A precisão dos resultados está relacionada com a discretização adequada do modelo e da correta implementação das condições de contorno. Em geral, considera algumas hipóteses de simplificação, as quais facilitam a análise numérica, pois diminuem o tempo de processamento e requerem recursos computacionais menos sofisticados. Dentre estas simplificações, tem-se, por exemplo, inexistência de fluxo de gases no interior do silenciador.

Contudo, a presença do fluxo pode modificar o desempenho acústico, em comparação com um silenciador sem fluxo [9]. Portanto, não considerar o meio fluído quando este está presente no silenciador, pode conduzir a resultados errôneos. Porém, muitas vezes, este efeito só é detectado durante os testes experimentais em bancadas, de forma que o silenciador deve voltar para fase de projeto, incidindo, novamente, em custo de tempo e dinheiro, reduzindo uma das vantagens obtidas com o uso de análises numéricas.

Nesse sentido, a simulação numérica via dinâmica de fluído computacional (CFD - computational fluid dynamics) representa uma alternativa, visto que permite a análise de fluidos, inclusive em geometrias complexas. Com isso, as características de desempenho de silenciadores podem ser determinadas de forma mais precisa, ainda na fase de desenvolvimento.

Este tipo de simulação pode demandar um grande esforço computacional, e exige conhecimento técnico específico para manipulá-la. Entretanto, ainda assim é uma opção atrativa, no sentido de reduzir a quantidade de testes experimentais em silenciadores com a presença de fluido, que são onerosos e de difícil realização.

Neste contexto, este trabalho apresenta uma metodologia numérica para estimar a perda de transmissão de atenuadores acústicos reativos considerando a presença de um fluido incompressível no seu interior. São 
adotadas quatro configurações geométricas de silenciadores. Primeiramente, foi realizada a análise sem considerar a presença de fluxo nos softwares comerciais Ansys Mechanical $^{\circledR} 16.0$ e LMS Virtual.lab ${ }^{\circledR}$ 13.5. Esta etapa foi realizada com intuito de validar o modelo numérico por comparação com resultados analíticos obtidos com o método da matriz de transferência, e também por equações disponíveis na literatura, dentro da faixa de frequência cuja teoria da propagação de ondas planas é válida.

$\mathrm{Na}$ segunda etapa, considera-se a presença de um escoamento de fluido incompressível, cujo campo de velocidade de fluxo é obtido por simulação CFD em regime permanente no software Ansys $C F X^{\circledR}$ 16.0. Estes dados são importados no Virtual.lab ${ }^{\circledR}$, para os modelos já simulados na etapa anterior, onde integram a formulação de elementos finitos para análise do desempenho acústico do silenciador. A fim de avaliar os efeitos do escoamento, são realizadas análises para três velocidades de entrada distintas $(10 \mathrm{~m} / \mathrm{s}, 30 \mathrm{~m} / \mathrm{s}$ e $60 \mathrm{~m} / \mathrm{s})$, nas quais a condição de incompressibilidade do fluido ainda é mantida.

\subsection{OBJETIVO}

O objetivo deste trabalho é apresentar uma metodologia para estimativa analítica e numérica do desempenho acústico, especificamente a perda de transmissão, de silenciadores reativos na presença de escoamento médio incompressível em seu interior.

\subsubsection{Objetivos Específicos}

São objetivos específicos deste trabalho:

- Modelagem analítica utilizando o método da matriz de transferência para determinação da perda de transmissão considerando a ausência e a presença de escoamento de fluido no interior do silenciador. ; 
- Estudo, avaliação e análise dos diferentes fatores de correção utilizados para modelagem no MMT das extremidades dos dutos que compõem o silenciador.

- Determinação da perda de transmissão de silenciadores reativos, sem a presença de fluxo, utilizando o método de elementos finitos em dois softwares comerciais: Ansys Mechanical ${ }^{\circledR}$ e LMS Virtual.lab ${ }^{\circledR}$

- Obtenção do campo de velocidade de fluxo no interior do silenciador através de simulação CFD, considerando regime permanente e utilizando para isto o software comercial Ansys $\mathrm{CFX}^{\circledR}$;

- Implementação de uma metodologia que integre o método de elementos finitos com análise CFD para determinação da perda de transmissão, considerando a presença de escoamento no interior do silenciador.

\subsection{ORGANIZAÇÃO DO TRABALHO}

No capítulo 2 é apresentada uma revisão bibliográfica de trabalhos relevantes sobre a avaliação do desempenho de silenciadores acústicos reativos, considerando ou não a presença de escoamento, que serviram para nortear a consolidação da metodologia proposta neste trabalho.

Conceitos importantes para a fundamentação teórica sobre silenciadores acústicos, métodos analíticos e métodos numéricos para estimativa do desempenho acústico são apresentados no capítulo 3.

O capítulo 4 apresenta a metodologia proposta neste trabalho, bem como os resultados obtidos. Para melhor compreensão este capítulo é dividido em dois tópicos: sem considerar fluxo interno e com fluxo.

Por fim, o capítulo 5 mostra as conclusões desse estudo e propõe trabalhos futuros. 


\section{REVISÃO BIBLIOGRÁFICA}

Neste capítulo será feita uma breve revisão bibliográfica de técnicas disponíveis para avaliação do desempenho acústico de silenciadores acústicos, considerando ou não a presença de escoamento. É apresentado o método analítico de Matriz de Transferência (MMT) e os principais métodos numéricos: Método de Elementos Finitos (MEF) e Método de Elementos de Contorno (MEC).

\subsection{MÉTODOS ANALÍTICOS}

As propriedades de silenciadores acústicos começaram a ser calculadas utilizando a analogia de circuitos elétricos no final dos anos 50 , em trabalhos publicados por Igarashi et al. [10,11]. Nessa abordagem, a pressão acústica e velocidade de massa são descritas analogamente à voltagem e corrente, respectivamente, e são relacionadas antes e após o silenciador através de uma multiplicação de matrizes referente a cada elemento básico formador do silenciador. A matriz de transferência, também conhecida como matriz dos quatro polos, é composta por quatro elementos que representam cada seção básica.

Para considerar os efeitos do fluxo, um novo conjunto de variáveis foi introduzido por Munjal [12]: pressão convectiva e velocidade de massa convectiva e então a expressão para perda de inserção de silenciadores veiculares com fluxo de gases foi determinada.

Como resultado de anos de pesquisa, Munjal [13] apresenta o desenvolvimento teórico de matrizes de transferência de uma variedade de elementos que compõem silenciadores reativos, como dutos uniformes, dutos perfurados, entre outros. Em seguida, diversos trabalhos foram realizados no sentido de desenvolver teoricamente matrizes de transferência para diferentes tipos de subsistemas de silenciadores [14-16]. 
A partir de então, diversas matrizes de transferência passaram a estar disponíveis na literatura, facilitando a avaliação do desempenho de diferentes configurações de silenciadores reativos por este método. Nesse sentido, Thieme [4] calculou a perda de transmissão sonora em silenciadores automotivos utilizando o MMT e comparou com resultados obtidos por análise experimental, alcançando boa concordância entre eles. Nesse estudo também se alterou, teoricamente, a geometria de cada elemento básico, bem como as variáveis de temperatura e velocidade de fluxo do ar. Os resultados indicaram que a resposta do sistema é sensível perante estas modificações.

Gerges et al. [6] aplicaram o MMT para calcular numericamente a TL de diferentes configurações de silenciadores, considerando meio estacionário. Os resultados foram comparados com aqueles obtidos em uma bancada experimental. Foi obtida boa concordância entre os resultados, com divergências, esperadas, próximo à frequência de corte. Os resultados numéricos mostraram, ainda, que a extensão do tubo de entrada de uma câmara de expansão simples aumenta os picos da perda de transmissão e amplia as bandas de frequência de atenuação.

Ainda em 2005, Panigrahi e Munjal [17] desenvolveram um algoritmo genérico, com base no método da matriz de transferência, para estudar a propagação de ondas em sistemas rígidos, interconectados por silenciadores acústicos. No algoritmo, as equações de continuidade de velocidade e de equilíbrio de pressão são interconectadas, para cada elemento, usando uma matriz de conectividade, que é resolvida para obter-se a matriz de transferência global. Os resultados foram validados por comparação da perda de transmissão obtida com modelos de elementos finitos e por análises experimentais disponíveis na literatura. No entanto, o algoritmo não considera o efeito da presença de escoamento no desempenho dos sistemas acústicos.

Mais recentemente, Chen [18] propôs a otimização do desempenho de um filtro acústico utilizando algoritmo genético baseado no método da matriz de transferência. A função-objetivo da otimização era maximizar a perda de 
transmissão, variando as dimensões estruturais do silenciador. Com o modelo final proposto foi alancada uma redução de $21,32 \mathrm{~dB}$.

\subsection{MÉTODOS NUMÉRICOS}

Embora 0 método da matriz de transferência seja de fácil implementação, a determinação das matrizes de elementos de diversos segmentos de um silenciador pode tornar-se uma atividade laboriosa, e sua aplicação deixa de ser atraente, quando a geometria é irregular e quando são consideradas ondas tridimensionais. Nesse sentido, abordagens utilizando métodos computacionais têm sido desenvolvidas para estudo de silenciadores acústicos.

A aplicação de métodos numéricos para avaliação do desempenho de silenciadores iniciou em 1975, quando Young e Crocker [5] apresentaram uma técnica baseada no método de elementos fintos para predição da perda de transmissão de silenciadores. O método foi aplicado para uma câmara de expansão simples, tratada como um sistema bidimensional, utilizando elementos retangulares e os resultados foram validados por comparação com as predições da teoria de onda plana, mostrando a funcionalidade do método.

No ano seguinte, os mesmos autores aplicaram o método para avaliar diversos modelos de câmaras de fluxo reverso [7], e obtiveram bons resultados quando comparados com medições experimentais. Neste mesmo ano, Craggs (19), utilizando-se de uma formulação com elementos hexaédricos, analisou a perda de transmissão e perda de inserção de diversas configurações de silenciadores.

Segundo Alfredson e Davies [9], o desempenho acústico de um sistema reativo é superestimado caso os efeitos do escoamento sejam desconsiderados. Desta forma, em 1982, Peat [20] apresentou uma técnica baseada no MEF análoga à utilizada por Young e Crocker [5], porém aplicada a 
um modelo matemático tridimensional que inclui a influência de escoamentos com baixo número de Mach sobre o desempenho do atenuador.

A partir do final da década de 1980, procurando superar as dificuldades relativas à aplicabilidade do MEF em análises tridimensionais, técnicas numéricas baseadas no método dos elementos de contorno começaram a ser desenvolvidas. Zhenlin et al [21] sugeriram um método através do MEC para determinação dos quatro parâmetros da matriz de transferência de uma câmara de expansão considerando apenas os efeitos convectivos de um fluxo uniforme para calcular a perda de transmissão. Os resultados foram validados por comparação com resultados presentes na literatura e apresentaram boa concordância. Ji et al. [22] utilizaram a mesma abordagem, porém considerando fluxo não uniforme e baixo número de Mach.

Selamet e Ji [23] demonstraram com o MEC as vantagens de se estenderem os dutos de entrada e de saída de um silenciador de câmara de expansão simples através da otimização de seus comprimentos com os modelos axissimétricos. No ano seguinte, os mesmo autores estudaram [24], aplicando o MEC, a influência do posicionamento dos dutos de entrada e de saída juntamente com a informação de fase das ondas incidentes no desempenho de silenciadores com dois dutos de entrada e um de saída. Porém, ambos os trabalhos não consideram a presença de escoamento.

Mais recentemente, com o aumento da capacidade de processamento numérico, a dinâmica de fluidos computacional passou a ser utilizada como ferramenta para avaliação de silenciadores acústicos. Broatch et al. [25] realizaram a simulação em CFD do campo acústico 3D de um silenciador. Neste método as equações que governam o modelo foram resolvidas no domínio do tempo. A excitação do sistema é feita por um pulso de ar a alta pressão que atravessa o silenciador e então seu desempenho é avaliado a partir da determinação das amplitudes complexas do pulso de pressão incidente, refletido e transmitido. Os resultados do CFD obtiveram boa concordância para baixas e médias frequências comparadas com uma análise 
de elementos finitos tradicional, entretanto, o tempo computacional foi significativamente maior.

Liu e Ji [26] aplicaram o mesmo modelo do campo acústico de Broatch et al. [24], porém sobreposto ao campo de escoamento. Em seguida, uma nova simulação é feita, sem impor a excitação acústica. A diferença entre os resultados é a pressão acústica no domínio do tempo, a partir da qual é possível determinar a TL. Dessa forma, é possível avaliar os efeitos convectivos e dissapativos do escoamento no desempenho do silenciador. $O$ comprimento do tubo de saída deve ser suficientemente grande para que os registos de pressão transmitida não sejam contaminados por reflexões indesejáveis. Sendo assim, o custo e esforço computacional desta metodologia são significativamente elevados. Além de que exigem conhecimento mais específico em CFD.

Como uma alternativa, Gardner et al. [27] descrevem um processo automatizado utilizando um código aberto de CFD para calcular as variações de temperatura e campo de fluxo. Estes resultados são, então, utilizados em um modelo de elementos finitos para prever o desempenho acústico de um silenciador. Um estudo de caso é apresentado e os resultados são comparados com resultados experimentais simples demonstrando a precisão do método para um silenciador considerando fluxo e elementos perfurados.

Os efeitos do fluxo também podem avaliados experimentalmente, e os dados utilizados em um modelo em MEF, conforme proposto por Lee e Bolton [28]. Em seus estudos avaliaram um silenciador com elementos microperfurados e foi verificado que as baixas velocidades de fluxo consideradas não influenciaram a perda de transmissão na faixa de frequência de interesse.

Ou ainda, os dados de velocidade de fluxo podem advir de uma simulação CFD do escoamento em regime permanente, conforme avaliado por Fan e Guo [29]. Esta metodologia não avalia o efeito da viscosidade do 
escoamento no desempenho do silenciador, mas considera a distribuição não uniforme de velocidade. Os resultados foram comparados com resultados experimentais e apresentam boa aproximação. Este trabalho apresentou grande contribuição para o desenvolvimento metodologia que será proposta nos próximos capítulos. 


\section{FUNDAMENTAÇÃO TEÓRICA}

Neste capítulo serão introduzidos conceitos importantes para o entendimento da metodologia proposta neste trabalho. Primeiramente será apresentada a formulação da equação da onda, que rege a propagação da onda sonora no interior dos silenciadores acústico e ainda, a teoria de modos acústicos, visto que os métodos analíticos são restritos à propagação de ondas planas. A seguir, são mostrados os parâmetros de avaliação do desempenho de silenciadores acústicos.

Então, apresentam-se os métodos adotados para estimativa do desempenho dos silenciadores. Inicia-se com a teoria do método da matriz de transferência, bem como o equacionamento das matrizes de transferência utilizadas nesse trabalho. Em seguida, a fundamentação teórica do método de elementos finitos para solução de problemas de acústica por meio da equação da onda. E, por último, uma introdução ao conceito do método dos volumes finitos, que é utilizado na simulação CFD para solução do problema de fluido.

\subsection{PROPAGAÇÃO DE ONDAS SONORAS}

O som é um fenômeno ondulatório, que se caracteriza por propagar energia ao longo da direção de propagação da onda, não ocorrendo 0 transporte de massa [36]

Todo fenômeno ondulatório apresenta um ou mais parâmetros físicos que variam periodicamente no tempo. No caso de uma onda sonora, os deslocamentos das partículas fluidas constituem tal variação, os quais levam a oscilações de pressão. Como essas oscilações ocorrem na mesma direção de propagação da onda, diz-se que o som é uma onda longitudinal.

A principal grandeza física envolvida na propagação sonora é a pressão sonora, a qual é definida como sendo a diferença entre a pressão total e a pressão média do meio fluido. Esta última corresponde à pressão existente na ausência de perturbação acústica. 
De forma análoga, a velocidade de escoamento é definida como sendo a diferença entre a velocidade total e a velocidade média do escoamento. Esta última corresponde à velocidade existente na ausência de perturbação do escoamento.

A fim de avaliar a propagação sonora, o estabelecimento das seguintes equações é necessário [37]: Equação da continuidade de massa; Equação de movimento e Equação de estado.

\subsubsection{Equação da continuidade de massa}

A equação geral da continuidade em três dimensões, a qual está representada a seguir:

$\frac{\partial \rho}{\partial t}+\vec{\nabla} \cdot\left[\rho\left(\vec{u}^{F}+\vec{u}^{A}\right)\right]=0$

em que $\rho$ é a densidade do meio, $\vec{u}^{F}$ é a parcela da velocidade das partículas fluidas devido ao escoamento e a $\vec{u}^{A}$ é a parcela da velocidade das partículas fluidas devido à excitação acústica $A$ velocidade foi desmembrada em duas parcelas com intuito de obter equações aplicáveis a problemas de propagação sonora em dutos considerando a existência de escoamento de fluido no mesmo.

Ou, expandindo:

$\frac{\partial \rho}{\partial t}+\rho\left(\vec{\nabla} \cdot \vec{u}^{A}\right)+(\overrightarrow{\nabla \rho}) \cdot \vec{u}^{A}+\rho\left(\vec{\nabla} \cdot \vec{u}^{F}\right)+(\overrightarrow{\nabla \rho}) \cdot \vec{u}^{F}=0$

Assumindo que as variações na densidade do meio sejam muito pequenas, pode-se desprezar o terceiro termo da Eq.(2) e concluir que $\rho \approx \rho_{0}$, sendo $\rho_{0}$ a densidade do meio na ausência de perturbação acústica.

Para que esta hipótese seja válida, é necessário que duas condições sejam cumpridas: as ondas sonoras devem ser de baixa amplitude, bem como 
a velocidade do escoamento ser suficientemente pequena de maneira a situálo dentro da faixa de incompressibilidade. Segundo FOX e McDONALD [38], para que esta última condição seja atendida, o número de Mach deve ser inferior ao valor aproximado de 0,3 .

Atendidas estas exigências, a Eq.(2) simplifica-se para equação de continuidade de massa para pequenas variações de densidade, dada por:

$\frac{\partial \rho}{\partial t}+\rho_{0}\left(\vec{\nabla} \cdot \vec{u}^{A}\right)+\rho_{0}\left(\vec{\nabla} \cdot \vec{u}^{F}\right)+(\overrightarrow{\nabla \rho}) \cdot \vec{u}^{F}=0$

Supondo ainda que o escoamento seja permanente, ou seja, que o vetor $\vec{u}^{F}$ independe da variável tempo, pode-se dividir a Eq.(3) em duas equações utilizando uma separação de variáveis, obtendo assim:

$$
\begin{aligned}
& \rho_{0}\left(\vec{\nabla} \cdot \vec{u}^{F}\right)=0 \\
& \frac{\partial \rho}{\partial t}+\rho_{0}\left(\vec{\nabla} \cdot \vec{u}^{A}\right)+(\overrightarrow{\nabla \rho}) \cdot \vec{u}^{F}=0
\end{aligned}
$$

A Eq.(4) e (5) expressam a condição de continuidade de massa em relação ao escoamento de fluido e à propagação sonora, respectivamente.

\subsubsection{Equação do movimento}

Assumindo a inexistência de efeitos dissipativos devidos à viscosidade do fluido e forças de campo desprezíveis, a equação do movimento é dada por:

$$
\vec{\nabla}\left(p^{A}+p^{F}\right)+\left\{\frac{\partial\left(\vec{u}^{F}+\vec{u}^{A}\right)}{\partial t}+\left[\left(\vec{u}^{F}+\vec{u}^{A}\right) \cdot \vec{\nabla}\right]\left(\vec{u}^{F}+\vec{u}^{A}\right)\right\} \rho=0
$$

onde $p^{A}$ é a pressão sonora e $p^{F}$ é a pressão do meio fluído na ausência de perturbação acústica.

Pela a hipótese de escoamento permanente, tem-se que $\frac{\partial \vec{u}^{F}}{\partial t}=0$ e de pequenas variações na densidade do meio, a Eq.(6) simplifica-se para: 
$\vec{\nabla}\left(p^{A}+p^{F}\right)+\left\{\frac{\partial \vec{u}^{A}}{\partial t}+\left[\left(\vec{u}^{F}+\vec{u}^{A}\right) \cdot \vec{\nabla}\right]\left(\vec{u}^{F}+\vec{u}^{A}\right)\right\} \rho_{0}=0$

A fim de simplificá-la, será adotada a hipótese de que o campo de velocidade $\vec{u}^{F}+\vec{u}^{A}$ é irrotacional; isto implica em afirmar que $\vec{\nabla} \times\left(\vec{u}^{F}+\vec{u}^{A}\right)=$ 0. Desta forma, a Eq.(7) simplifica-se para:

$$
\vec{\nabla}\left(p^{A}+p^{F}\right)+\rho_{0}\left\{\frac{\partial \vec{u}^{A}}{\partial t}+\vec{\nabla}\left(\vec{u}^{A}+\vec{u}^{F}\right)+\frac{1}{2}\left(\vec{u}^{F} \cdot \vec{u}^{F}\right)\right\}=0
$$

A Eq.(8) é a equação de movimento para fluidos não-viscosos na ausência de forças de campo. Esta expressão ainda carrega consigo as seguintes hipóteses: pequenas variações na densidade do meio, escoamento permanente e campo de velocidade irrotacional.

Como se admite a hipótese de escoamento permanente, tanto o vetor $\vec{u}^{F}$ quanto $o$ escalar $p^{F}$ independem da variável tempo. Assim, pode-se dividir a Eq.(8) em duas equações utilizando uma separação de variáveis, obtendo:

$$
\begin{aligned}
& \vec{\nabla} p^{F}+\rho_{0} \frac{1}{2}\left(\vec{u}^{F} \cdot \vec{u}^{F}\right)=0 \\
& \vec{\nabla} p^{A}+\rho_{0}\left[\frac{\partial \vec{u}^{A}}{\partial t}+\vec{\nabla}\left(\vec{u}^{A}+\vec{u}^{F}\right)\right]=0
\end{aligned}
$$

A Eq.(9) e Eq.(10) expressam a condição de equilíbrio dinâmico em relação ao escoamento de fluido e à propagação sonora, respectivamente.

\subsubsection{Equação de Estado}

A relação entre pressão, volume e temperatura para um gás perfeito é dada pela lei dos gases:

$$
p \cdot V=m \cdot R \cdot T
$$


onde $R$ é uma constante dependente da massa molar do gás e $m$ é a massa do sistema.

Assumindo um processo adiabático e pequenas variações de densidade, chega-se a seguinte equação:

$\left(\frac{\partial p^{A}}{\partial \rho}\right)_{S}=\gamma \frac{p_{0}}{\rho_{0}}=c^{2}$

em que $p^{A}=p-p_{0}$ é a pressão sonora, $p_{0}=p^{F}$ é a pressão de equilíbrio, $\rho_{0}$ é a densidade de equilíbrio. $\gamma$ é a razão entre o calor específico a pressão constante e o calor específico a volume constante; $c$ é a velocidade do som no meio. $O$ índice $s$ enfatiza que tal relação é válida apenas para processos isoentrópicos.

Integrando a Eq. (12), tem-se:

$p^{A}=c^{2} \rho+A$

onde $A$ é uma constante.

Se $p^{A}=0$ tem-se $\rho=\rho_{0}$, logo $A=-c^{2} \rho_{0}$. Então, a equação anterior reduz-se a:

$p^{A}=c^{2}\left(\rho-\rho_{0}\right)$

Esta é a equação de estado, sendo válida para gases perfeitos, processos isoentrópicos e pequenas variações de densidade.

\subsubsection{Irrotacionalidade e Funções Potenciais}

Ao assumir a irrotacionalidade do campo de velocidade $\vec{u}^{F}+\vec{u}^{A}$, este pode ser considerado como sendo o gradiente de uma função escalar $\phi$, denominda função potencial, ou seja: 
$\vec{u}^{F}+\vec{u}^{A}=-\vec{\nabla} \phi$

O sinal negativo foi utilizado de forma arbitrária a fim de indicar que o fluxo de massa ocorre no sentido do potencial decrescente.

Foi assumida a hipótese de escoamento permanente, dessa forma, pode-se desmembrar a função $\phi$ em duas parcelas: uma independente do tempo, correspondendo ao escoamento; e outra dependente do tempo, referente à propagação sonora. Logo:

$$
\begin{aligned}
& \vec{u}^{F}=-\vec{\nabla} \phi^{F} \\
& \vec{u}^{A}=-\vec{\nabla} \phi^{A}
\end{aligned}
$$

Substituindo a Eq. (16) na Eq. (4):

$$
\nabla^{2} \phi^{F}=0
$$

onde $\nabla^{2}$ é o Operador Laplaciano.

A Eq.(18) rege o comportamento de escoamentos irrotacionais e incompressíveis. Note que a hipótese de escoamento permanente implicou no desacoplamento entre os fenômenos acústicos e o escoamento.

Conforme será tratado mais adiante, para a solução da equação que rege a propagação sonora, é necessário que a Eq. (18) já tenha sido resolvida.

\subsubsection{Equação da onda}

A equação de onda é aquela que rege a propagação sonora. Combinando-se a equação da continuidade com as de movimento e de estado, obtém-se: 


$$
\nabla^{2} p^{A}-\frac{1}{c^{2}} \frac{\partial^{2} p^{A}}{\partial t^{2}}-\frac{1}{c^{2}}+\frac{\partial\left(\vec{u}^{F}+\vec{\nabla} p^{A}\right)}{\partial t}+\rho_{0} \nabla^{2}\left(\vec{u}^{F}+\vec{u}^{A}\right)=0
$$

Conforme pode ser observado, seu último termo contém o vetor correspondente à flutuação de velocidade $\vec{u}^{A}$. Portanto, tem-se uma equação $\mathrm{e}$ duas variáveis acústicas: $\vec{u}^{A}$ e $p^{A}$. Sendo assim, é necessário expressá-la em termos de apenas uma variável acústica. Isto é feito utilizando o potencial acústico de velocidade, $\phi^{A}$.

A relação entre $\phi^{A}$ e $\vec{u}^{A}$ é dada pela Eq. (17) a relação entre $\phi^{A}$ e $p^{A}$ é dada por:

$$
p^{A}=\rho_{0}\left(\frac{\partial \phi^{A}}{\partial t}-\vec{\nabla} \phi^{A} \cdot \vec{\nabla} \phi^{F}\right)
$$

Neste trabalho, serão realizadas análises apenas no domínio da frequência. Desta forma, $\phi^{A}$ será uma função harmônica, assumindo a seguinte forma:

$\phi^{A}=\Phi^{A} e^{i \omega t}$

onde $\Phi^{A}$ é a amplitude do potencial acústico, sendo independente da variável tempo, e $\omega$ é a frequência angular da excitação acústica.

Substituindo as Eq. (16), (17) e (20) na Eq. (19), realizando uma integração em relação à variável tempo e substituindo a Eq. (21), chega-se a equação de onda aplicável a análises no domínio da frequência e expressa em termos das funções potenciais:

$\nabla^{2} \Phi^{A}+k^{2} \Phi^{A}+\frac{2 i k}{c}\left(\vec{\nabla} \phi^{F} \cdot \vec{\nabla} \Phi^{A}\right)-\frac{1}{c^{2}} \vec{\nabla} \phi^{F} \cdot\left[\vec{\nabla}\left[\left(\vec{\nabla} \phi^{F} \cdot \vec{\nabla} \Phi^{A}\right)\right]\right]=0$

onde $k=\frac{\omega}{c}$ é o número de onda. 
A solução desta equação fornece os valores de $\Phi^{A}$ em cada ponto do domínio. Entretanto, antes de solucionar a Eq.(22), é necessário resolver a Eq.(18) a qual fornecerá $\phi^{F}$ a fim de ser utilizado na equação de onda.

Após a obtenção de $\Phi^{A}$, é necessário determinar as variáveis acústicas que são realmente de interesse, ou seja, a pressão sonora e a velocidade acústica, que são dadas, respectivamente, pelas seguintes relações:

$$
\begin{aligned}
& \vec{u}^{A}=-\left(\vec{\nabla} \Phi^{A}\right) e^{i \omega t} \\
& p^{A}=\rho_{0}\left(i \omega \Phi^{A}-\vec{\nabla} \Phi^{A} \cdot \vec{\nabla} \phi^{F}\right) e^{i \omega t}
\end{aligned}
$$

Um caso particular que pode ser considerado é quando a velocidade de escoamento é nula ( $\vec{u}^{F}=0$ ). Quando esta condição é satisfeita, diz-se que o meio é estacionário e a referida equação se reduz a forma mais conhecida da equação da propagação de onda, também denominada Equação de Helmholtz:

$$
\nabla^{2} p^{A}-\frac{1}{c^{2}} \frac{\partial^{2} p^{A}}{\partial t^{2}}=0
$$

\subsubsection{Modos Acústicos de Propagação de Ondas em Dutos de Seção Transversal Circular}

Os dutos são os elementos básicos e essenciais no projeto de silenciadores. Portanto, a análise da propagação de ondas em seu interior é de grande relevância para predizer o comportamento acústico de silenciadores.

Para uma excitação acústica harmônica em um tubo reto na ausência de escoamento, a solução da Eq.(21) é dada por [39]:

$$
p^{A}=\sum_{m=0}^{\infty} \sum_{n=0}^{\infty} p_{m n}^{A}
$$

onde: 
$p_{m n}^{A}=J_{m}\left(k_{r, m n} r\right)\left(C_{1, m n} e^{-i z k_{z, m n}}+C_{2, m n} e^{-i z k_{z, m n}}\right)\left(C_{3, m n} e^{-i m \theta}+e^{-i m \theta}\right) e^{i \omega t}$

$k_{r}^{2}=k^{2}-k_{z}^{2}$

$J_{m}$ é a função de Bessel de primeira espécie de ordem $m ; C_{1, m n}, C_{2, m n}$ e $C_{3, m n}$ são constantes dependentes de $m$ e de $n$, as quais são determinadas pelas condições de contorno do problema. $k_{r, m n}$ e $k_{z, m n}$ são constantes relativas à propagação sonora nas direções radial e longitudinal.

Cada par de valores $m$ e $n$ corresponde a um modo de oscilação, sendo que $m$ indica o modo como a pressão sonora varia com o ângulo $\theta$, e $n$ indica $o$ modo como a pressão sonora varia na direção radial $r$. Dependendo da freqüência de excitação, cada um destes modos expressos por $(m, n)$ poderá ou não ser propagado. Como exemplo, a Figura 6 ilustra os modos de propagação de baixa ordem em um duto uniforme circular.

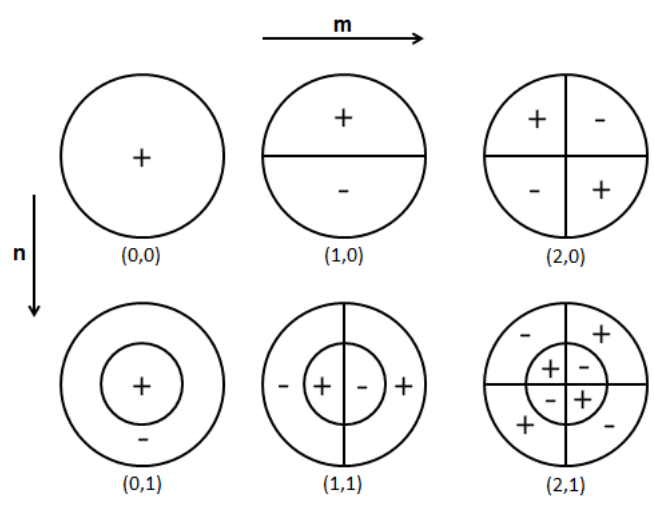

Figura 6 - Modos de propagação da onda em um duto uniforme circular [39]

Se, para um determinado modo, $k_{z}$ for um número imaginário, o valor da pressão sonora correspondente a este modo $\left(p_{m n}^{A}\right)$ apresentará um decrescimento exponencial na variável $z$, conforme pode ser constatado pela Eq.(26). Portanto, tem-se um modo evanescente não propagativo e conclui-se que apenas modos cujos valores de $k_{z}$ forem reais serão propagados. Assim, pela Eq.(28), um dado modo $(m, n)$ se propagará sem atenuação se: 
$k>k_{r, m n}$

Ou seja,

$\omega>c \cdot k_{r, m n}$

A partir da Eq. (30) é possível estabelecer a frequência de corte $f_{m n}$, abaixo da qual não é possível que o modo se propague:

$f_{m n}=\frac{c k_{r, m n}}{2 \pi}$

Os valores de $k_{r, m n} \cdot r_{0}$ podem ser obtidos utilizando a Tabela 1, em que $r_{0}$ é o raio da seção transversal do duto.

Tabela 1 - Valores de $k_{r, m n} \cdot r_{0}$ [39]

\begin{tabular}{lcccc}
\hline & \multicolumn{5}{c}{$\mathbf{m}$} \\
\cline { 2 - 5 } $\mathbf{n}$ & $\mathbf{0}$ & $\mathbf{1}$ & $\mathbf{2}$ & $\mathbf{3}$ \\
\hline $\mathbf{0}$ & 0 & 3,83 & 3,05 & 4,20 \\
\hline $\mathbf{1}$ & 1,84 & 5,33 & 6,71 & 8,02 \\
\hline $\mathbf{2}$ & 3,05 & 8,54 & 9,97 & 13,17 \\
\hline $\mathbf{3}$ & 4,20 & 11,71 & 13,17 & 14,59 \\
\hline
\end{tabular}

Desta forma, para haver somente propagação de ondas sonoras planas, correspondente ao modo $(0,0)$, deve-se tomar o menor valor não nulo de $k_{r, m n}$, que corresponde a $m=1$ e $n=0$. Portanto:

$k_{r, m n}=\frac{1,84}{r_{0}}$

Substituindo a Eq. (32) na Eq. (31) e obtêm-se a frequência de corte que garante a propagação apenas de ondas planas em um meio estacionário:

$f_{1,0}=\frac{c \cdot 1,84}{2 \pi \cdot r_{0}}$ 
A Figura 7 mostra o modo acústico de propagação da onda para frequência de $177,12 \mathrm{~Hz}$ em um duto com uma placa no interior. Observa-se a propagação de ondas planas no interior das cavidades formadas pelo conjunto placa-duto. Nas demais regiões, é possível notar que a frequência de análise está acima da primeira frequência de corte do duto, e por isso ocorre a propagação de modos de alta ordem.

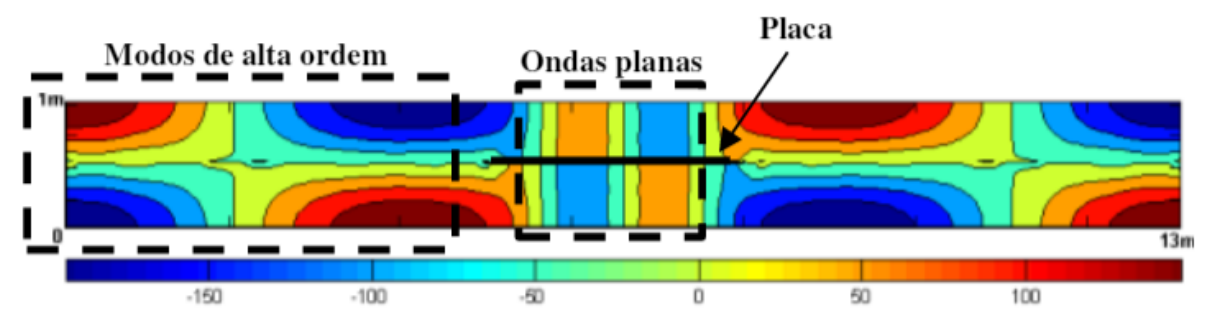

Figura 7 - Modo acústico de propagação da onda em um duto com uma placa no interior (40)

Quando a propagação sonora ocorre em um meio não estacionário, as frequências de corte não mais podem ser calculadas pela Eq.(34), devendo ser ajustadas por um fator de correção de $\left(\sqrt{1-M^{2}}\right)$, [13].

Portanto, a frequência de corte que garante a propagação apenas de ondas planas, considerando um escoamento uniforme ao longo do tubo, é dada por:

$f_{1,0}=\frac{c \cdot 1,84}{2 \pi \cdot r_{0}} \cdot \sqrt{1-M^{2}}$

em que $M=\frac{\left|\vec{u}^{F}\right|}{C}$

\subsection{PARÂMETROS PARA AVALIAÇÃO DO DESEMPENHO ACÚSTICO}

O desempenho acústico de um silenciador é medido e caracterizado através da análise da Redução de Ruído - Noise Reduction (NR), Perda de Inserção - Insertion Loss (IL) e Perda de Transmissão - Transmission Loss (TL). A seleção adequada do parâmetro de desempenho é essencial para obter conclusões corretas sobre a eficácia do filtro acústico. 


\subsubsection{Redução de Ruído - Noise Reduction (NR)}

O parâmetro Redução de Ruído (NR) é definido como a diferença entre os níveis de pressão sonora em dois pontos arbitrários, um antes do silenciador e outro após (Figura 8).

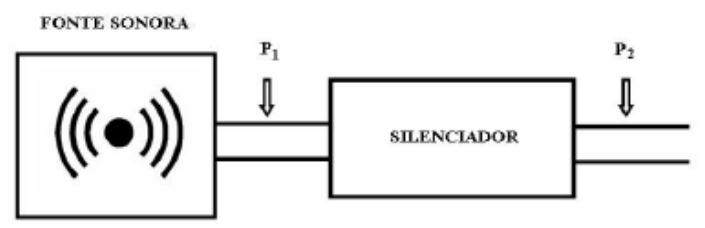

Figura 8 - Redução de Ruído (NR) [1]

A redução de ruído pode ser obtida por [13]:

$N R=20 \cdot \log \left|\frac{p_{1}}{p_{2}}\right|=L_{P 1}-L_{p 2} \quad(\mathrm{~dB})$

onde $p_{1}$ e $p_{2}$ são a pressão sonora em $(\mathrm{Pa})$ antes e após o silenciador respectivamente e $L_{P 1}$ e $L_{p 2}$ são o nível de pressão sonora em (dB) antes e após o silenciador respectivamente.

Apesar da NR ser de fácil medição a sua utilidade é bastante limitada uma vez que não faz distinção entre ondas refletidas e transmitidas, e ainda o nível de pressão sonora é facilmente influenciado pelas condições ambientais [40].

\subsubsection{Perda de Inserção - Insertion Loss (IL)}

O parâmetro Perda de Inserção (IL) é definido como a diferença entre o nível de potência acústica irradiada num mesmo ponto do sistema de exaustão sem silenciador e com silenciador (Figura 9).

A perda de inserção pode ser calculada por [13]:

$$
I L=20 \cdot \log \left|\frac{W_{1}}{W_{2}}\right|=L_{W 1}-L_{W 2} \quad(\mathrm{~dB})
$$




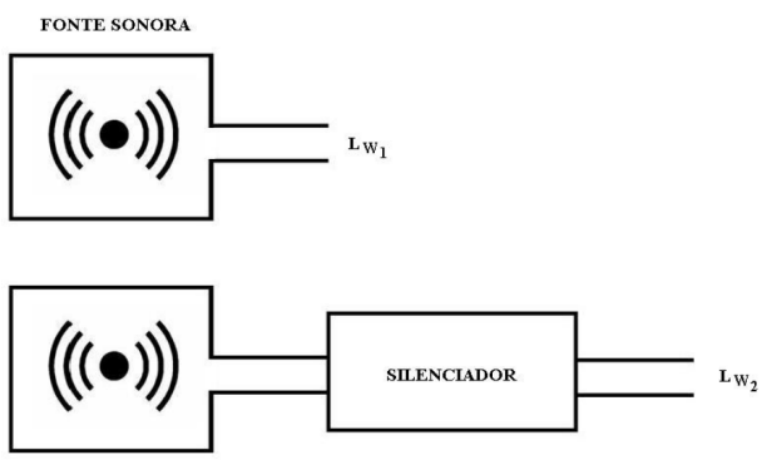

Figura 9- Perda de Inserção (IL) [1]

onde $w_{1}$ e $w_{2}$ são a potência sonora (W) sem e com o silenciador respectivamente e $L_{W 1}$ e $L_{W 2}$ são o nível de potência sonora irradiada (dB) com e sem o silenciador respectivamente.

Para estimativa analítica da IL é necessário conhecer previamente a impedância da fonte e a impedância de radiação, por isso este tipo de cálculo pode ser difícil de prever numericamente. Como resultado, a IL é geralmente determinada experimentalmente [31].

\subsubsection{Perda de Transmissão - Transmission Loss (TL)}

O parâmetro Perda de Transmissão (TL) é definido como a diferença entre o nível de potência sonora incidente no silenciador e a o nível de potência sonora transmitida para saída do sistema na presença de uma terminação anecóica, ou seja, sem presença de ondas refletidas no silenciador (Figura 10).

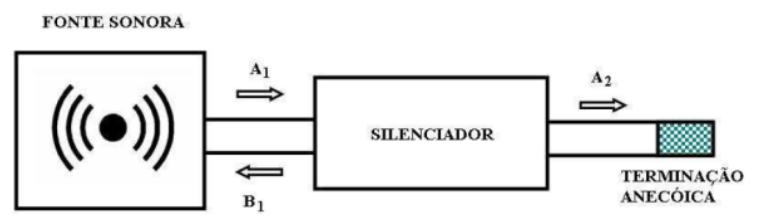

Figura 10 - Perda de Transmissão (TL) [1]

A perda de transmissão pode ser calculada por [13]:

$$
T L=10 \cdot \log \left|\frac{S_{1} A_{1}^{2}}{S_{2} A_{2}^{2}}\right|=L_{W i}-L_{W t} \quad(\mathrm{~dB})
$$


onde $s_{1}$ e $s_{2}$ são a área $\left(\mathrm{m}^{2}\right)$ do duto de entrada e saída, respectivamente; $A_{1}^{2}$ e $A_{2}^{2}$ são a amplitude da onda complexa $\left(\mathrm{Pa}^{2}\right)$ na entrada e saída do silenciador, respectivamente; $B_{1}$ é a amplitude de onda complexa $(\mathrm{Pa})$ refletida da entrada do silenciador; $L_{W i}$ é o nível de potência sonora $(\mathrm{dB})$ incidente na entrada do silenciador e $L_{W t}$ é o nível de potência sonora $(\mathrm{dB})$ transmitida após o silenciador.

A TL é uma característica intrínseca da geometria do silenciador que independe da fonte sonora ou do comprimento dos dutos de entrada e saída. Sua medição experimental é pouco viável, visto que a terminação anecóica é dificilmente encontrada na prática, entretanto, é de fácil simulação numérica, tornando simples o cálculo analítico. Devido a tais características, a perda de transmissão foi adotada como parâmetro do desempenho dos silenciadores neste trabalho.

\subsection{MÉTODO DA MATRIZ DE TRANSFERÊNCIA}

O conceito do método da matriz de transferência baseia-se na analogia eletroacústica para cálculo das propriedades de silenciadores. Assume-se que o meio é estacionário e a propagação de ondas unidimensionais. Dessa forma a pressão sonora $p$ e a velocidade de volume $v$ em qualquer lugar do elemento podem ser representadas pela soma das ondas incidentes e refletidas.

Então, de acordo com [13] um circuito elétrico análogo pode ser usado onde a pressão é análoga à voltagem e a velocidade de volume à corrente. $\mathrm{A}$ Figura 11(a) representa uma analogia com a velocidade de volume e Figura 11 (b) com a pressão sonora da fonte.

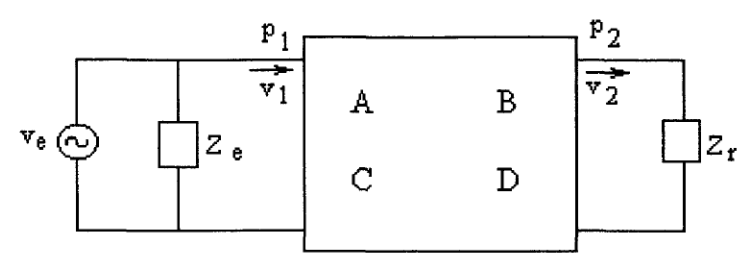

(a)

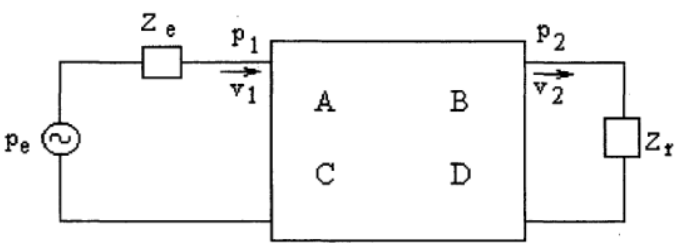

(b)

Figura 11 - (a) Analogia com a velocidade de volume (b) analogia com a pressão sonora na fonte [4] 
Este circuito equivalente pode ser representado com o uso de quatro parâmetros da seguinte maneira:

$\left[\begin{array}{l}p_{1} \\ v_{1}\end{array}\right]=\left[\begin{array}{ll}A & B \\ C & D\end{array}\right]\left[\begin{array}{c}p_{2} \\ v_{2}\end{array}\right]$

onde os pares $\left(p_{1}, v_{1}\right)$ e $\left(p_{2}, v_{2}\right)$ representam a pressão sonora e velocidade na entrada e saída, respectivamente. $A, B, C$ e $D$ são os quatro parâmetros que são determinados resolvendo a equação da onda com condições de contorno dadas por:

$$
\begin{aligned}
& A=\left.\frac{p_{1}}{p_{2}}\right|_{v_{2}=0, v_{1}=1} \\
& B=\left.\frac{p_{1}}{v_{2}}\right|_{p_{2}=0, v_{1}=1} \\
& C=\left.\frac{v_{1}}{p_{2}}\right|_{v_{2}=0, v_{1}=1} \\
& D=\left.\frac{v_{1}}{v_{2}}\right|_{p_{2}=0, v_{1}=1}
\end{aligned}
$$

O sistema obedece ao princípio da reciprocidade, portanto $A D-B C=1$, o qual é um teste usual feito com os valores da matriz dos quatro pólos [42].

A fim de contabilizar o efeito de convecção do fluxo médio incompressível, foi definido um novo conjunto de variáveis de estado - pressão convectiva, $p_{c}$, e velocidade da massa convectiva, $v_{c}$ - para substituir as variáveis clássicas de pressão acústica $p$ e velocidade acústica de massa $v$. Descobriu-se que os dois conjuntos de variáveis estão relacionadas linearmente uns aos outros [12]. Através dessas variáveis de estado convectivas, o método da matriz de transferência foi estendido para a avaliação de um silenciador com um fluxo significativo. Este foi significativamente superior à do método anterior, que envolvia solução simultânea de um grande número de equações algébricas com coeficientes complexos. 
Um silenciador real é composto de vários elementos, tais como câmaras simples, expansão e contração súbita, tubos estendidos e perfurados. Cada elemento possui uma matriz de transferência particular. Então para determinar um parâmetro acústico de um silenciador completo deve-se estabelecer uma relação entre cada elemento e sua matriz de transferência. Assim, se vários componentes do sistema estão conectados juntos de maneira seriada, então a matriz de transferência do sistema completo é dada pelo produto individual das matrizes do sistema [4].

Por exemplo, considerando o silenciador ilustrado na Figura 12, o qual possui um duto estendido, uma câmara de expansão e um ressonador concêntrico, a matriz de transferência do sistema completo é dada pelo produto das seis matrizes do sistema, conforme Eq. (43).

$\left[\begin{array}{c}p_{0} \\ v_{0}\end{array}\right]=\left[\begin{array}{ll}A & B \\ C & D\end{array}\right]\left[\begin{array}{c}p_{7} \\ v_{7}\end{array}\right]$

onde:

$\left[\begin{array}{ll}A & B \\ C & D\end{array}\right]=\left[\begin{array}{ll}A_{1} & B_{1} \\ C_{1} & D_{1}\end{array}\right]\left[\begin{array}{ll}A_{2} & B_{2} \\ C_{2} & D_{2}\end{array}\right]\left[\begin{array}{ll}A_{3} & B_{3} \\ C_{3} & D_{3}\end{array}\right]\left[\begin{array}{ll}A_{4} & B_{4} \\ C_{4} & D_{4}\end{array}\right]\left[\begin{array}{ll}A_{5} & B_{5} \\ C_{5} & D_{5}\end{array}\right]\left[\begin{array}{ll}A_{6} & B_{6} \\ C_{6} & D_{6}\end{array}\right]$

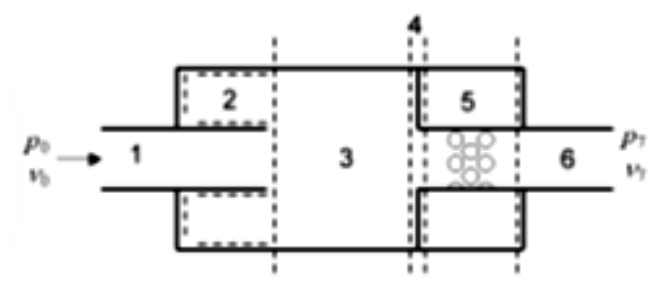

Figura 12 - Exemplo de um silenciador

Ao fim do item 3.4 é apresentado um quadro-resumo com as matrizes de transferências dos principais subsistemas utilizados neste trabalho.

A perda de transmissão da Eq. (37) pode ser reescrita em função dos quatro parâmetros (A, B, C e D) da matriz de transferência [10,12]: 
$T L=20 \cdot \log \left(\frac{1}{2} \cdot\left(Y_{1} / Y_{2}\right)^{1 / 2} \cdot\left|A+B / Y_{2}+Y_{1} \cdot C+\left(Y_{1} / Y_{2}\right) D\right|\right)+10 \cdot \log \left(\frac{S_{1}}{S_{2}}\right)$

sendo $Y_{1}$ e $Y_{2}$, respectivamente, as impedâncias características do tubo de entrada e saída do silenciador $\left(\rho_{0} c / S\right)$.

De acordo com Munjal [13], para tubos conduzindo gases quentes de exaustão, é mais apropriado lidar com a velocidade de "massa" acústica. Sendo assim, a correspondente impedância característica adotada nas próximas páginas, será denotada como $Y_{0}$ por conveniência, onde:

$Y_{0}=c / S$

\subsubsection{Fator de Correção da Extremidade de um Tubo}

Quando dois tubos de diferentes áreas de seção transversal se juntam para formar um sistema de transmissão acústico, a existência de súbitas descontinuidades da área provocam efeitos de ondas 3D, como ilustra a Figura 13. Esses efeitos estão associados à geração de modos evanescentes, mesmo para frequências inferiores a menor frequência de corte.

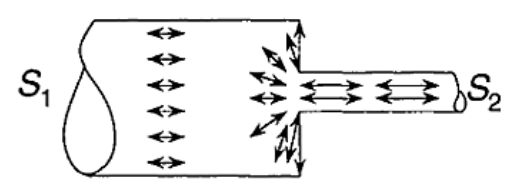

Figura 13 - Representação da velocidade de particulada provocada pela súbita mudança da área da seção transversal de dutos [39].

Esse fenômeno constitui uma parte importante do campo sonoro e pode ser interpretado no coeficiente de reflexão como um comprimento adicional necessário para considerar o deslocamento de fase entre as ondas incidentes e refletidas, denominado fator de correção (Figura 14). 


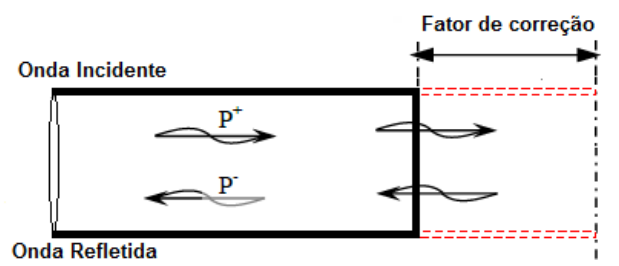

Figura 14 - Fator de correção da extremidade de um duto

O fator de correção pode ainda ser modelado como um salto de impedância acústica na área da descontinuidade [43]:

$\mathrm{Z}_{\text {descontinuidade }}=\mathrm{Z}_{2}-i \omega m$

onde $m=k \Delta l / \rho / S_{1}$ e $l_{f c}$ é o fator de correção.

O fator de correção depende, entre outros fatores, da geometria do duto e da frequência de análise. Vários autores [44-51] propuseram em seus estudos diferentes equações para fatores de correção, obtidas por cálculos analíticos e numéricos, a fim de obter o melhor ajuste com resultados experimentais.

Então, para a correta avaliação dos silenciadores pelo método da matriz de transferência, é necessário considerar o comprimento efetivo $l^{\prime}$ dos tubos localizados em áreas de descontinuidade geométrica, que corresponde à soma do comprimento físico $l$ e o fator de correção $l_{f c}$.

É importante ressaltar que, em análises numéricas, estes aspectos já são automaticamente considerados durante a modelagem do problema, não sendo necessária a adição de nenhuma correção na geometria do sistema.

\subsubsection{Matriz de Transferência para Dutos de Seção Uniforme}

Considera-se um simples duto de seção uniforme (Figura 15) com pressão acústica $p$ e velocidade de massa $v$ e a correspondente impedância característica do duto $Y_{0}$. Para um meio viscoso e fluxo médio incompreensível e turbulento, Munjal [13] definiu as seguintes relações: 


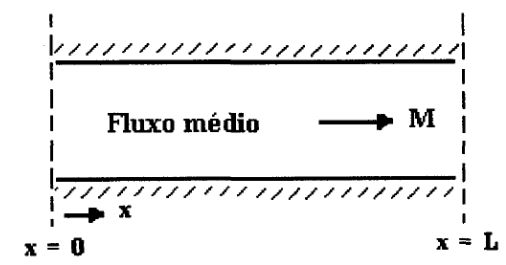

Figura 15 - Duto uniforme com fluxo médio

$p(x)=\left(A e^{-i k c x}+B e^{i k c x}\right) \cdot e^{i \cdot M \cdot k_{c} \cdot x}$

$v(x)=\left(A e^{-i k c x}+B e^{i k c x}\right) \cdot e^{i \cdot M \cdot k_{c} \cdot x} / Y^{\prime}$

onde:

$Y^{\prime}=Y_{0} \cdot\{1-i \propto(M)\} / k$

$\propto(M)=\propto+F M / 2 d$

sendo $F$ o fator de fricção de Froude (ver [13]); e $d$ o diâmetro do tubo.

Considerando um meio não viscoso $\left(Y^{\prime}=Y_{0}\right)$, tem-se a matriz de transferência para um duto uniforme:

$\left[\begin{array}{ll}A & B \\ C & D\end{array}\right]=e^{-i \cdot M \cdot k_{c} \cdot l}\left[\begin{array}{cc}\cos \left(k_{c} l\right) & i \cdot Y_{0} \cdot \sin \left(k_{c} l\right) \\ \left(1 / Y_{0}\right) \cdot \sin \left(k_{c} l\right) & \cos \left(k_{c} l\right)\end{array}\right]$

onde $k_{c}=1 /\left(1-M^{2}\right)$.

\subsubsection{Matriz de Transferência para Dutos Estendidos}

A Figura 16 ilustra os quatro tipos principais de ressonadores com duto estendido [13]: 


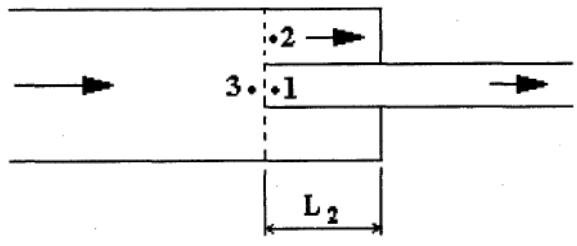

(a)

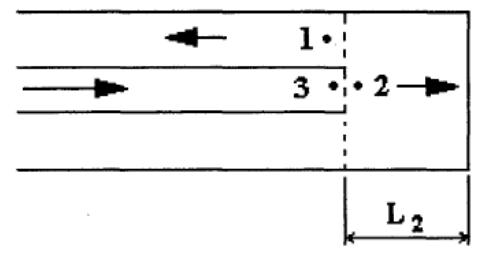

(c)

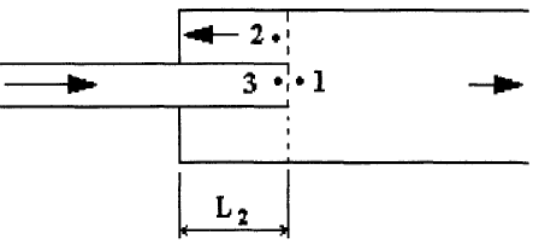

(b)

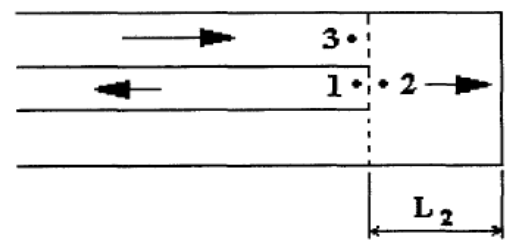

(d)

Figura 16 - Principais tipos de duto estendido: (a) Duto Estendido na Saída, (b) Duto Estendido na Entrada, (c) Sistema com Expansão Reversa e (d) Sistema com Contração Reversa

Quando o fluxo do fluído (gases de exaustão) passa por uma mudança de área, uma parte da energia acústica é convertida em calor, aumentando então a sua entropia [13]. Este aumento pode ser mensurado por um parâmetro dito coeficiente de perda da pressão de estagnação para fluxos incompreensíveis K. A Tabela 2 mostra este coeficiente, medido por [13], para fluxos fixos e para vários tipos de descontinuidades:

Tabela 2- Coeficiente de Pressão de Estagnação K [13]

\begin{tabular}{cc}
\hline Elemento & $\mathbf{K}$ \\
\hline Duto Estendido na Saída & $\left(1-S_{1} / S_{3}\right) / 2$ \\
\hline Duto Estendido na Entrada & {$\left[\left(S_{1} / S_{3}\right)-1\right]^{2}$} \\
\hline Sistema com Expansão Reversa & $\left(S_{1} / S_{3}\right)^{2}$ \\
\hline Sistema com Contração Reversa & 0,5 \\
\hline
\end{tabular}

onde $S_{1}$ é área da seção transversal no ponto $1\left(\mathrm{~m}^{2}\right)$ e $\mathrm{S}_{3}$ e área da seção transversal no ponto $3\left(\mathrm{~m}^{2}\right)$.

De acordo com Munjal [13], a matriz de transferência de cada um dos quatro tipos de dutos estendidos, em termos das variáveis conectivas, é:

$$
\left[\begin{array}{l}
p_{c, 3} \\
v_{c, 3}
\end{array}\right]=\left[\begin{array}{ll}
A_{11} & A_{12} \\
A_{21} & A_{22}
\end{array}\right]\left[\begin{array}{c}
p_{c, 1} \\
v_{c, 1}
\end{array}\right]
$$


Em que:

$$
\begin{aligned}
A_{11}= & 1-\frac{K M_{1}^{2}}{1-M_{1}^{2}} \\
A_{12}= & \frac{K M_{1} Y_{1}}{1-M_{1}^{2}} \\
A_{21}= & \frac{-S_{3} A_{11}-C_{1} S_{1}\left(1-\frac{(\gamma-1) M_{1}^{4}}{1-M_{1}^{2}}\right)+\frac{C_{2} S_{2} Z_{2}(\gamma-1) K M_{1}^{3}}{\left(1-M_{1}^{2}\right) Y_{1}}}{C_{2} S_{2} Z_{2}+S_{3} M_{3} Y_{3}} \\
A_{22}= & \frac{-S_{3} A_{12}-C_{1} S_{1} M_{1} Y_{1}\left(1-\frac{(\gamma-1) M_{1}^{2}}{1-M_{1}^{2}}\right)+C_{2} S_{2} Z_{2}\left(1-\frac{(\gamma-1) M_{1}^{2}}{1-M_{1}^{2}}\right)}{C_{2} S_{2} Z_{2}+S_{3} M_{3} Y_{3}}
\end{aligned}
$$

onde $S_{1}, S_{2}$ e $S_{3}$ são as áreas da seção transversal $\left(\mathrm{m}^{2}\right)$ nos pontos 1,2 e 3, respectivamente; $K$ é o coeficiente de perda dada na Tabela $1 ; \gamma$ é relação de calor específico $=1,402 ; M_{1}$ e $M_{3}$ número de Mach nos pontos 1 e 3 respectivamente; $Y_{1}, Y_{2}$ e $Y_{3}$ são as impedâncias característica do tubo nos pontos 1, 2 e 3 , dado por $c / S$; $k$ é o número de ondas; $Z_{2}=-i Y_{2} \cot (k L)$ é a impedância do ressonador para sistema rígido, em que $L$ é o comprimento do tubo. Os valores para os constantes $C_{1}$ e $C_{2}$ são dados pela Tabela 3:

Tabela 3 - Valores das Constantes $C_{1}$ e $C_{2}$

\begin{tabular}{ccc}
\hline Elemento & $\mathbf{C}_{\mathbf{1}}$ & $\mathbf{C}_{\mathbf{2}}$ \\
\hline Duto Estendido na Saída & -1 & -1 \\
\hline Duto Estendido na Entrada & -1 & +1 \\
\hline Sistema com Expansão Reversa & +1 & -1 \\
\hline Sistema com Contração Reversa & +1 & -1
\end{tabular}

A relação entre as variáveis conectivas e a pressão acústica e velocidade acústica de massa é dada por: 
$p_{c}=p+M Y_{0} v$

$v_{c}=v+p M / Y_{0}$

Reescrevendo a Eq. (34) em termos da pressão acústica e velocidade acústica de massa, obtém-se:

$\left[\begin{array}{l}p_{c, 3} \\ v_{c, 3}\end{array}\right]=\left[\begin{array}{ll}A & B \\ C & D\end{array}\right]\left[\begin{array}{c}p_{1} \\ v_{1}\end{array}\right]$

onde:

$\left[\begin{array}{ll}A & B \\ C & D\end{array}\right]=\left[\begin{array}{cc}1 & -M_{3} Y_{3} \\ -M_{3} / Y_{3} & 1\end{array}\right]\left[\begin{array}{ll}A_{11} & A_{12} \\ A_{21} & A_{22}\end{array}\right]\left[\begin{array}{cc}1 & -M_{1} Y_{1} \\ -M_{1} / Y_{1} & 1\end{array}\right]$

\subsubsection{Matriz de Transferência para Tubo Fechado na Abertura Lateral}

A Figura 17 ilustra um duto fechado na abertura lateral (em inglês quarte-wave-tube-QWT).

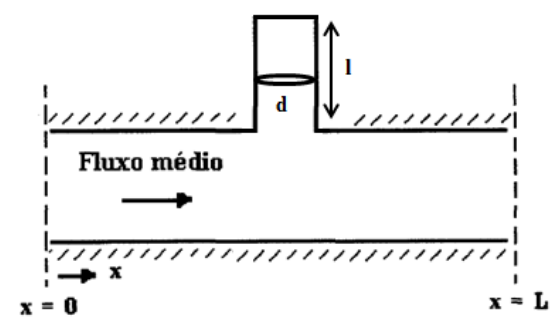

Figura 17 - Duto com abertura lateral (Quarter-Wave-Tube)

Um duto com abertura lateral pode ser considerado como uma impedância ramificada, cuja matriz de transferência é dada por [13]:

$\left[\begin{array}{ll}A & B \\ C & D\end{array}\right]=\left[\begin{array}{cc}1 & 0 \\ \frac{1}{Z_{r}} & 1\end{array}\right]$

em que $Z_{r}=-i Y_{2} \cot \left(k l_{q w t}\right)$ é a impedância de um tubo com a extremidade fechada. 


\subsubsection{Matriz de Transferência para Expansão e Contração Súbita}

A Figura 18 ilustra os dois tipos de descontinuidades ou mudanças bruscas de área que podem ser encontrados:

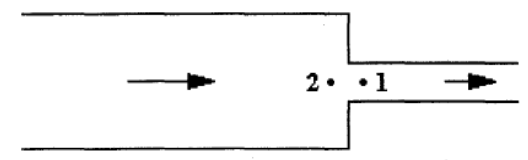

(a)

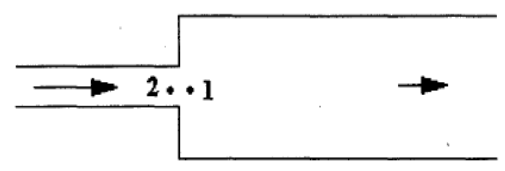

(b)

Figura 18- Descontinuidades geométricas: (a) Súbita contração e (b) Súbita expansão

Assume-se que este sistema é um caso particular do sistema com duto estendido na entrada e na saída, respectivamente. Sendo assim, a matriz de transferência é igual à Eq.(61), com a diferença que o comprimento $L_{2}$ nestes casos é igual à zero, e considerando que o ponto 3 é agora o ponto 2 deste novo sistema. Nesta análise, é suposto que qualquer pressão sonora possível na mudança de área foi devida a uma variação de entropia.

Munjal [13] apresentou uma matriz de transferência diferenciada, por considerar que a mudança de área pode excitar modos acústicos de alta ordem. Assim, a matriz de transferência para contração e expansão súbita é dada por:

$\left[\begin{array}{ll}A & B \\ C & D\end{array}\right]=\left[\begin{array}{cc}1 & i \omega L \\ 0 & 1\end{array}\right]$

em que $L=8 \cdot\left(1-\frac{r}{R}\right) /\left(3 r \pi^{2}\right)$, onde $r$ é o raio do duto menor e $R$ é o raio do duto maior $(\mathrm{m})$.

A Tabela 4 apresenta um quadro-resumo com as matrizes de transferências dos elementos apresentados. 
Tabela 4 - Quadro-resumo com matrizes de transferência de elementos comuns que compõem silenciadores reativos

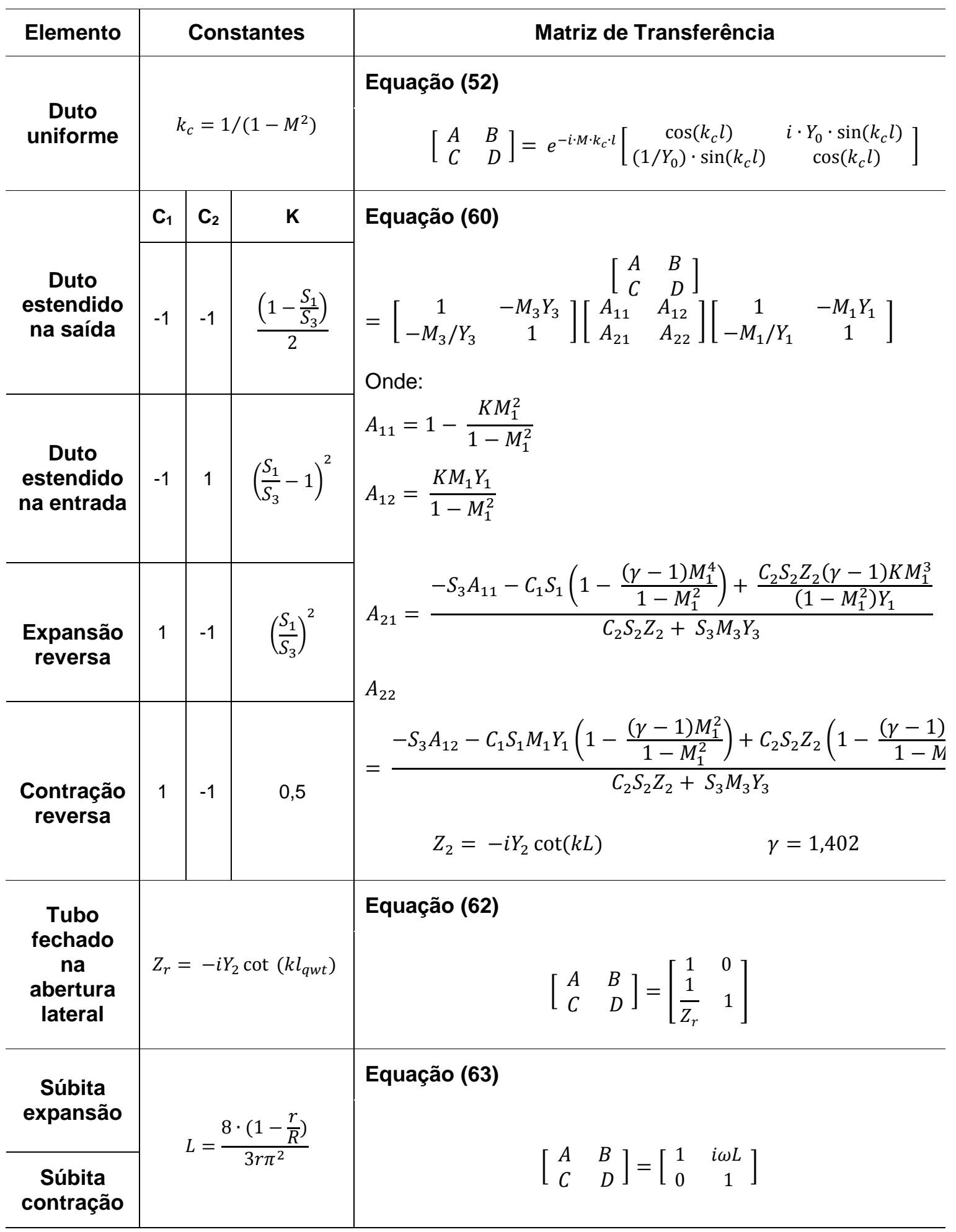




\subsection{MÉTODO DOS ELEMENTOS FINITOS (MEF)}

O Método dos Elementos Finitos (MEF) foi desenvolvido primeiramente para análise estrutural em aviões na década de 50 e somente em 1975 iniciaram-se os estudos da propagação de ondas em silenciadores com Young e Crocker, na predição da perda de transmissão de uma câmara de expansão simples [5].

A aplicação do MEF exige que o domínio do problema seja dividido em subdomínios, os quais também são denominados "elementos finitos", sendo o conjunto de elementos chamado de "malha". Ao processo de subdivisão dá-se o nome de discretização, sendo que, a convergência dos resultados e o tempo computacional estão diretamente relacionados com o número de elementos finitos empregados. Além disso, cada elemento é definido a partir de determinados pontos, chamados "nós" do elemento.

O Método de Galerkin é um caso particular do método dos resíduos ponderados, utilizando para derivar as equações de elementos finitos diretamente das equações diferenciais que governam o problema. O item 3.1 apresentou a equação que rege a propagação tridimensional de ondas acústicas em meios não estacionários, repetida aqui por conveniência:

$$
\nabla^{2} \Phi^{A}+k^{2} \Phi^{A}+\frac{2 i k}{c}\left(\vec{\nabla} \phi^{F} \cdot \vec{\nabla} \Phi^{A}\right)-\frac{1}{c^{2}} \vec{\nabla} \phi^{F} \cdot\left[\vec{\nabla}\left[\left(\vec{\nabla} \phi^{F} \cdot \vec{\nabla} \Phi^{A}\right)\right]\right]=0
$$

Nota-se que o potencial referente ao escoamento $\left(\Phi^{F}\right)$ também aparece na equação, sendo, portanto, necessário solucionar primeiro a Eq.(18) para só então resolver a equação da propagação sonora.

A formulação de Garlekin deve ser aplicada cada uma destas expressões a fim de se obter as equações em elementos finitos [52]. Estas equações serão apresentadas, mas suas formulações não serão discutidas com profundidade, visto que não é foco deste trabalho desenvolver um 
programa computacional para utilizar o MEF, mas sim utilizar aplicativos comerciais, nos quais tais equações já estão implementadas.

\subsubsection{Modelagem em elementos finitos do potencial de escoamento}

Considerando o domínio $\Omega$ com contorno $\Gamma$, o modelo em elementos finitos do potencial de escoamento estacionário é obtido selecionando um conjunto de funções de interpolação:

$\phi^{F}(x, y, z)=\boldsymbol{N}(x, y, z) \boldsymbol{\Phi}_{F}$

onde $\Phi_{F}$ é o vetor de incógnita do elemento e $\boldsymbol{N}(x, y, z)$ é o vetor de funções de forma.

O gradiente pode ser avaliado como:

$\nabla \phi^{F}(x, y, z)=\boldsymbol{B}(x, y, z) \boldsymbol{\Phi}_{F}$

em que $\boldsymbol{B}(x, y, z)$ contem as derivadas cartesianas das funções de forma.

Substituindo nas funções peso, determinadas pelo Método de Galerkin, chaga-se ao sistema de equações algébricas simultâneas:

$\boldsymbol{K}_{F} \cdot \Phi_{F}=C_{F} \cdot \Psi_{F n}$

onde $\boldsymbol{K}_{\boldsymbol{F}}=\int_{\Omega} \boldsymbol{B}^{T} \cdot \boldsymbol{B} d \Omega$ corresponde a matriz de rigidez, $\boldsymbol{C}_{\boldsymbol{F}}=\int_{\Omega} \boldsymbol{N}^{T} \cdot \boldsymbol{N} d \Gamma$ corresponde a matriz de acoplamento e $\boldsymbol{\Psi}_{F n}$ é o vetor de gradientes normais do potencial de velocidade ao longo do contorno.

\subsubsection{Modelagem em elementos finitos do potencial acústico}

De maneira análoga, o modelo em elementos finitos do potencial acústico é obtido selecionando um conjunto de funções de interpolação: 
$\phi^{A}(x, y, z)=N(x, y, z) \Phi_{A}$

$\nabla \phi^{A}(x, y, z)=\boldsymbol{B}(x, y, z) \Phi_{A}$

Substituindo nas funções peso, determinadas pelo Método de Galerkin, chaga-se ao sistema de equações algébricas simultâneas:

$$
\left(\boldsymbol{K}_{A}+i \omega \boldsymbol{D}_{A}-\omega \boldsymbol{M}_{A}\right) \cdot \boldsymbol{\Phi}_{F}=\boldsymbol{C}_{A} \cdot \boldsymbol{\Psi}_{A n}
$$

Sendo:

$$
\begin{aligned}
& \boldsymbol{K}_{\boldsymbol{A}}=\int_{\Omega} \boldsymbol{B}^{T} \cdot \boldsymbol{D} \cdot \boldsymbol{B} d \Omega+\int_{\Omega} \boldsymbol{N}^{T} \cdot \boldsymbol{G} \cdot \boldsymbol{B} d \Omega \\
& \boldsymbol{M}_{\boldsymbol{A}}=\int_{\Omega} \frac{\boldsymbol{N}^{T} \cdot \boldsymbol{N}}{a^{2}} d \Omega \\
& \boldsymbol{D}_{\boldsymbol{A}}=\int_{\Omega} \frac{2}{a^{2}} \boldsymbol{N}^{T} \cdot u_{0} \cdot \boldsymbol{B} d \Omega \\
& \boldsymbol{C}_{\boldsymbol{A}}=\int_{\Omega} \boldsymbol{N}^{T} \cdot \boldsymbol{N}\left(\boldsymbol{n}^{T} \cdot(\boldsymbol{D} \cdot \boldsymbol{n})\right) d \Gamma
\end{aligned}
$$

em que $\boldsymbol{\Psi}_{F n}$ é o vetor de gradientes normais do potencial de velocidade acústica, $a^{2}=c^{2}+(\gamma-1)\left(\frac{\partial \phi^{F}}{\partial t}+\frac{u^{2}}{2}\right)$.

No caso particular em que a velocidade de fluxo é zero, $\boldsymbol{D}$ se reduz a uma matriz unitária e $\boldsymbol{G}$ a uma matriz nula. Então, as matrizes anteriores se resumem:

$$
\begin{aligned}
& \boldsymbol{K}_{\boldsymbol{A}}=\int_{\Omega} \boldsymbol{B}^{T} \cdot \boldsymbol{B} d \Omega \\
& \boldsymbol{M}_{\boldsymbol{A}}=\int_{\Omega} \frac{\boldsymbol{N}^{T} \cdot \boldsymbol{N}}{a^{2}} d \Omega \\
& \boldsymbol{D}_{\boldsymbol{A}}=0 \\
& \boldsymbol{C}_{\boldsymbol{A}}=\int_{\Omega} \boldsymbol{N}^{T} \cdot \boldsymbol{N} d \Gamma
\end{aligned}
$$


Essas expressões correspondem à análise com meio estacionário, ou seja, sem presença de escoamento.

\subsubsection{Método da decomposição}

Ao final da análise por elementos finitos obtêm-se a pressão sonora em cada nó que compõem a malha. A partir desses dados, foi adotado o Método da Decomposição (Figura 19) para cálculo da perda de transmissão dos silenciadores.

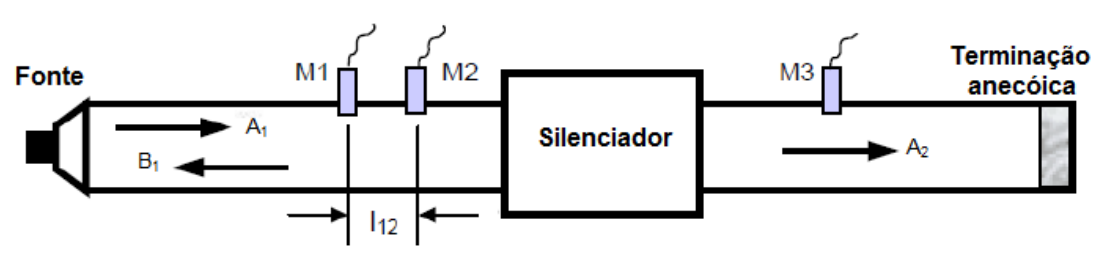

Figura 19 - Método da decomposição

Por este método, o autoespectro da onda incidente, $A_{1}$ e da onda transmitida $A_{2}$ são calculados por [53]:

$$
\begin{aligned}
& A_{1}(f)=\frac{S_{11}+S_{22}-2 C_{12} \cos \left(k l_{12}\right)+2 Q_{12} \operatorname{sen}\left(k l_{12}\right)}{4 \operatorname{sen}^{2}\left(k l_{12}\right)} \\
& A_{2}(f)=S_{33}
\end{aligned}
$$

onde $S_{11}, S_{22}$ e $S_{33}$ são o auto espectro da pressão acústica total nos nós 1, 2 e 3 respectivamente; $Q_{12}$ e $C_{12}$ são as partes real e imaginária do espectro cruzado entre os nós 1 e 2 respectivamente; $k$ é o número de onda e $I_{12}$ é a distância entre os nós 1 e 2.

Então, para calcular a perda de transmissão do silenciador, basta substituir as Eq.(79) e (80) na Eq. (37).

\subsection{MÉTODO DOS VOLUMES FINITOS (MVF)}

O método dos volumes finitos é utilizado por simulação de dinâmica de fluídos computacional para solução das equações governantes de transporte. 
Não é objetivo desta seção discutir com profundidade o método. Sua aplicação neste trabalho restringe-se ao uso de software comercial para simulação do escoamento dentro de silenciadores reativos de geometrias relativamente simples, a fim de obter os valores de velocidade de fluxo, que serão considerados na análise acústica, pelo método de elementos finitos. Para uma análise detalhada do método numérico recomenda-se a consulta a literatura específica desta área [54,55].

No MVF o domínio de solução é dividido em número finito de volumes de controle (VC) não sobrepostos, que podem ser irregulares no tamanho e na forma. A formulação do método se baseia no princípio de conservação de uma determinada quantidade física expressa pelas equações governativas sobre qualquer VC. Os valores de determinada variável são armazenados no centroide dos volumes de controle. As equações discretizadas da variável dependente são obtidas integrando a equação governativa sobre cada um dos volumes de controle no domínio [56].

As equações que governam o escoamento de fluidos são as equações de conservação da massa, quantidade de movimento e de energia [54], escritas no sistema cartesiano de coordenadas, seguintes:

$$
\begin{aligned}
& \frac{\partial \rho}{\partial t}+\frac{\partial}{\partial x_{j}}\left(\rho u_{j}\right)=0 \\
& \frac{\partial}{\partial t}\left(\rho u_{i}\right)+\frac{\partial}{\partial x_{j}}\left(\rho u_{i} u_{j}\right)=-\frac{\partial P}{\partial x_{j}}+\frac{\partial}{\partial x_{j}}\left(\mu \frac{\partial u_{i}}{\partial x_{j}}\right)+S^{u_{i}} \\
& \frac{\partial}{\partial t}(\rho T)+\frac{\partial}{\partial x_{j}}\left(\rho u_{j} T\right)=\frac{\partial}{\partial x_{j}}\left(\frac{k}{C_{p}} \frac{\partial T}{\partial x_{j}}\right)+S^{T}
\end{aligned}
$$

Problemas com escoamentos laminares são de fácil solução analítica, o que não ocorre com problemas de escoamento turbulentos, de forma que a turbulência precisa ser modelada. Uma das maneiras de se definir a turbulência 
foi proposta por Reynolds pelo processo de médias das equações de NavierStokes (RANS - Reynolds Averaged Navier - Stokes).

Com essa abordagem surge um termo de tensão não-linear, conhecido por tensão de Reynolds, que requer modelação adicional para fechar as equações RANS e levou à criação de diferentes modelos de turbulência. Existem diversos modelos de turbulência baseados nas equações RANS. Dentre eles destaca-se o modelo $k-\varepsilon$, que trabalha com a energia cinética turbulenta, $k$, e a taxa de dissipação da energia cinética turbulenta, $\varepsilon$. Esse modelo é bastante utilizado na indústria, por ser de fácil implementação, barato em termos de custo computacional e por possuir boa estabilidade [57].

Neste trabalho, para as simulações CFD foi utilizado o software Ansys $C F{ }^{\circledR} 16.0$, o qual é baseado no método de volumes finitos, e o modelo de $k-\varepsilon$ é utilizado para representar a turbulência do escoamento. O CFX é um compõem a plataforma ANSYS Workbench ${ }^{\circledR}$, que permite a integração de vários ambientes, dentre eles o DesignModeler e Meshing, que foram utilizados para gerar a geometria e malha do silenciador, respectivamente

No próximo capítulo, a metodologia proposta neste trabalho para avaliação do desempenho de silenciadores acústicos é apresentada, bem como os resultados e discussão. 


\section{MODELAGEM E SIMULAÇÃO DO DESEMPENHO ACÚSTICO DE SILENCIADORES REATIVOS}

Conforme dito no item 3.2.3, o parâmetro utilizado neste trabalho para estudar o desempenho acústico de cada atenuador de ruído é a perda por transmissão. Esta é uma propriedade intrínseca do silenciador, sendo independente da amplitude da excitação acústica e das características dos demais elementos existentes no sistema, tais como as impedâncias de radiação e da fonte sonora.

A Figura 20 resume a metodologia do estudo analítico-numérico desenvolvido nesse trabalho para avaliação do desempenho de silenciadores reativos:

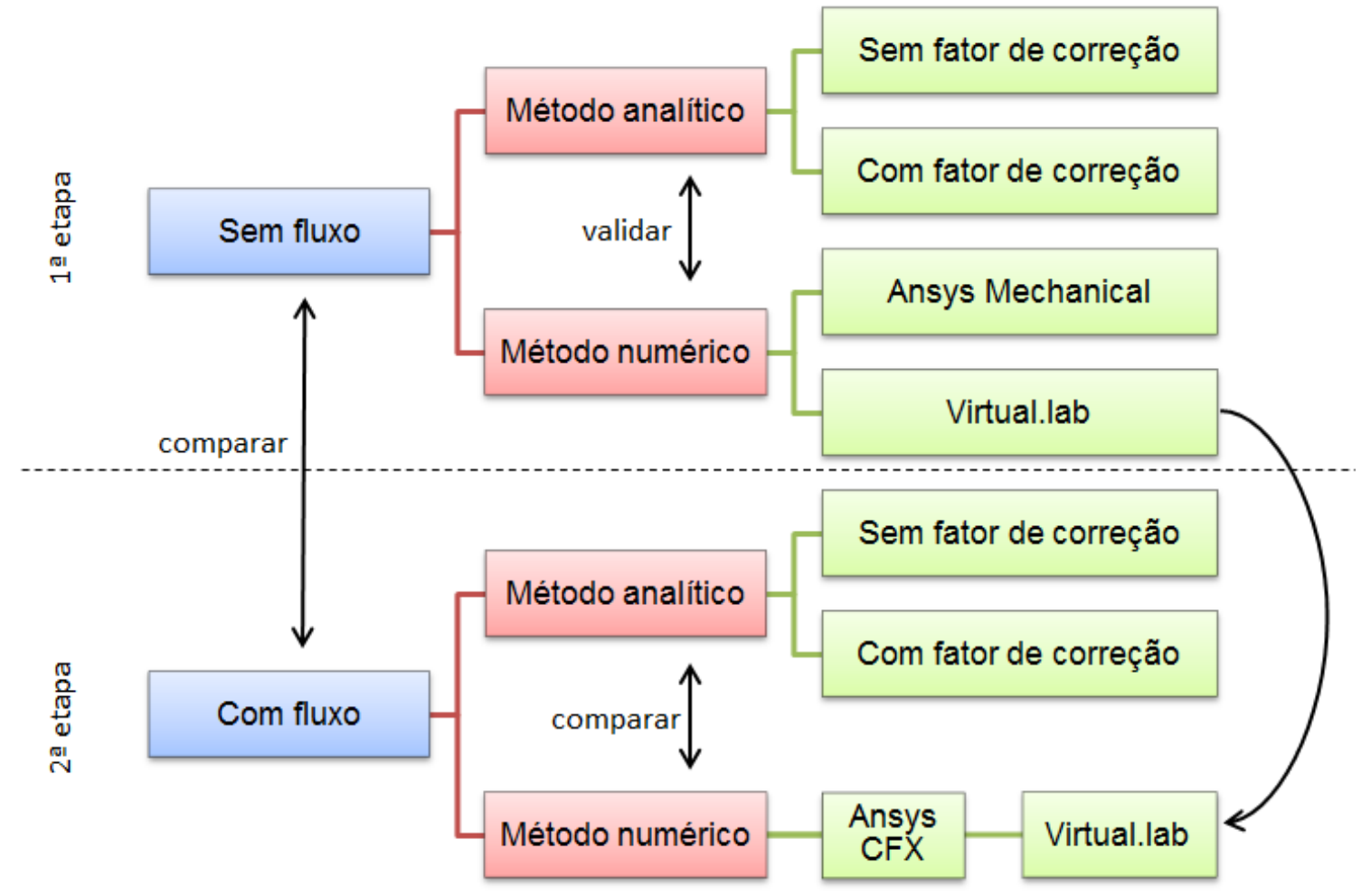

Figura 20- Resumo do estudo analítico-numérico desenvolvido

Como observado no fluxograma, na primeira etapa a perda de transmissão foi estimada numericamente, sem considerar a presença fluxo, por métodos analíticos e pelo método dos elementos finitos utilizando os softwares 
Ansys ${ }^{\circledR}$ e Virtual.lab ${ }^{\circledR}$. Essa etapa é importante para validar o modelo numérico com resultados obtidos a partir de métodos analíticos, cuja análise sem escoamento já é bem consolidada. Por isso, foram adotados quatro modelos clássicos silenciadores reativos, cuja solução analítica é extensamente conhecida.

A Figura 21 apresenta os quatro modelos de silenciadores, sendo eles: Modelo I - QWT; Modelo II - câmara de expansão simples, Modelo III - câmara de expansão com duto de entrada estendido e Modelo IV - câmara de expansão com dutos estendidos.

As dimensões geométricas, em milímetros, foram definidas a partir de revisão bibliográfica $[4,29,51]$, permitindo assim, ao longo do desenvolvimento da metodologia, comparação com resultados obtidos pela literatura e artigos publicados.

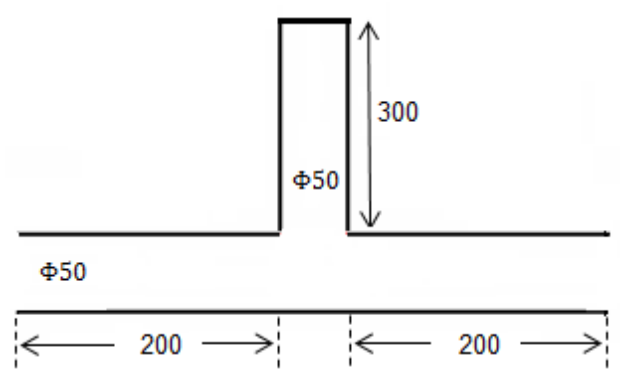

(a)

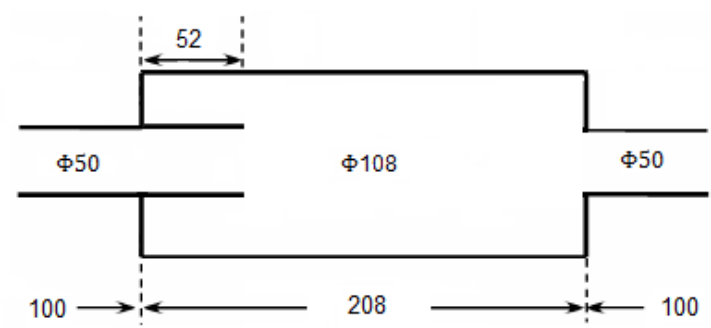

(c)

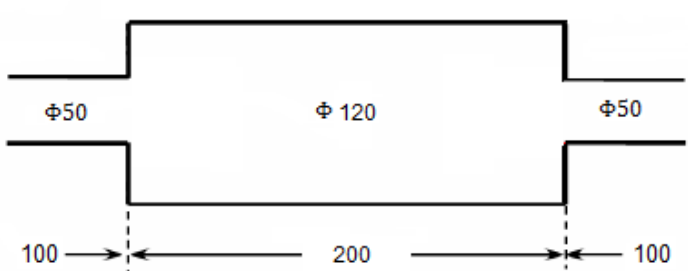

(b)

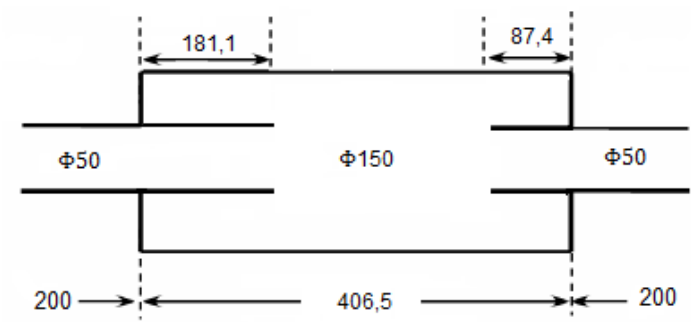

(d)

Figura 21 - Modelos de silenciadores reativos adotados neste trabalho: (a) QWT - modelo I, (b) câmara de expansão simples - modelo II, (c) câmara de expansão com duto de entrada estendido - modelo III e (d) câmara de expansão com dutos estendidos - modelo IV.

Na segunda etapa, é feita a análise considerando a presença de fluxo. $\mathrm{O}$ campo de velocidade é obtido por simulação CFD no software CFX. Os 
resultados são importados no modelo em elementos finitos do Virtual.lab ${ }^{\circledR}$, desenvolvido na etapa anterior, para então os efeitos do escoamento sejam considerados no desempenho do silenciador.

Os resultados são comparados com a análise analítica, em que é possível considerar a velocidade de fluxo, adotando o número de Mach diferente de zero. Porém os efeitos da distribuição da velocidade de fluxo ao longo do silenciador não são avaliados.

Nas análises analíticas, foram considerados diferentes fatores de correção disponíveis na literatura, para cálculo do comprimento efetivo do duto, conforme abordado no item 3.3.1.

Nos próximos itens, estas etapas serão discutidas de forma mais detalhada.

\subsection{ESTIMATIVA DA PERDA DE TRANSMISSÃO NA AUSÊNCIA DE ESCOAMENTO}

Esta seção apresenta a modelagem para estimativa da $T L$ de silenciadores acústicos, considerando o meio estacionário, ou seja, ausência de fluxo.

Primeiramente, conforme mostrado no fluxograma da Figura 20, o desempenho dos silenciadores foi calculado por métodos analíticos. Foi feita a análise unidimensional pelo o método da matriz de transferência, avaliando diferentes fatores de correções para cálculo do comprimento efetivo, disponíveis na literatura. Também foram empregadas equações analíticas, disponíveis na literatura, para o cálculo da perda de transmissão.

Em seguida, foi realizada a análise com o método de elementos finitos utilizando dois softwares comerciais distintos: Ansys Mechanical ${ }^{\circledR}$, em sua versão 16.0, e LMS Virtual.lab ${ }^{\circledR}$, em sua versão 13.5. 
Para permitir a comparação entre o MMT e o MEF, os resultados foram avaliados em uma faixa de frequência abaixo da primeira frequência de corte, em que a hipótese de propagação sonora unidimensional é válida. A primeira frequência de corte, calculada pela Eq. (33), de cada modelo de silenciador é mostrada na Tabela 5.

Tabela 5 - Frequências de corte dos dutos que compõem os silenciadores

\begin{tabular}{cc}
\hline Duto & Frequência de corte \\
\hline Modelo I & $4017 \mathrm{~Hz}$ \\
\hline Modelo II & $1647 \mathrm{~Hz}$ \\
\hline Modelo III & $1860 \mathrm{~Hz}$ \\
\hline Modelo IV & $1339 \mathrm{~Hz}$ \\
\hline
\end{tabular}

\subsubsection{Método Analítico}

A Figura 22 apresenta um fluxograma com as etapas da metodologia para cálculo da perda de transmissão de silenciadores reativos utilizando 0 método da matriz de transferência. A descrição de cada etapa é apresentada na Tabela 6.

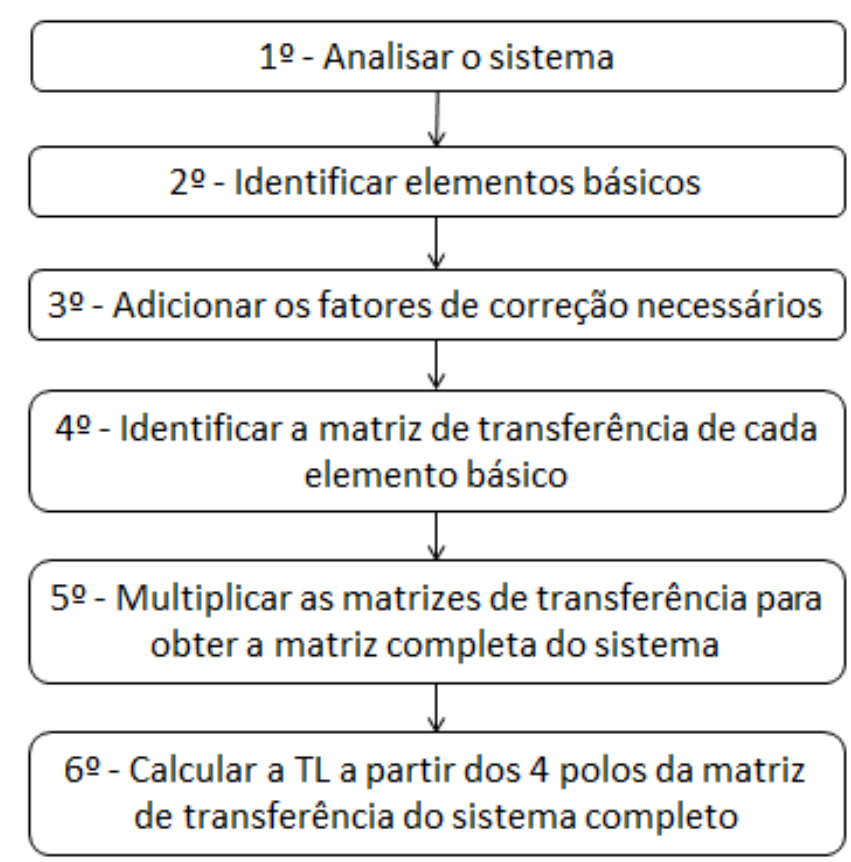

Figura 22 - Fluxograma do Método da Matriz de Transferência 
Tabela 6 - Etapas para cálculo do TL utilizando o Método da Matriz de Transferência

\begin{tabular}{|c|c|}
\hline Etapa & Descrição \\
\hline $1^{a}$ - Analisar o sistema & $\begin{array}{l}\text { - Observar geometria, dimensões e definir a } \\
\text { menor frequência de corte dos dutos que o } \\
\text { compõem; }\end{array}$ \\
\hline $2^{\mathrm{a}}$ - Identificar os elementos básicos & $\begin{array}{l}\text { - Classificar quais os elementos básicos que } \\
\text { compõem o silenciador, por exemplo: duto de } \\
\text { seção uniforme; súbita contração; súbita } \\
\text { expansão; duto perfurado; duto fechado na } \\
\text { abertura lateral, etc. }\end{array}$ \\
\hline $\begin{array}{l}\text { 3a - Adicionar os fatores de correção } \\
\text { necessários }\end{array}$ & $\begin{array}{l}\text { - Quando existirem descontinuidades } \\
\text { geométricas, identificar o fator de correção } \\
\text { apropriado e calcular o comprimento efetivo; } \\
\text { - Considerar o número de Mach igual à zero nas } \\
\text { matrizes de transferência; }\end{array}$ \\
\hline $\begin{array}{l}4^{\mathrm{a}}-\text { Identificar a matriz de } \\
\text { transferência de cada elemento } \\
\text { básico }\end{array}$ & $\begin{array}{l}\text { - Identificar na literatura a matriz de transferência } \\
\text { de cada elemento definido na } 2^{2} \text { etapa. Para } \\
\text { este trabalho, todas as matrizes utilizadas } \\
\text { podem ser consultadas na Tabela } 4 \text {; }\end{array}$ \\
\hline $\begin{array}{l}5^{\mathbf{a}} \text { - Multiplicar as matrizes de } \\
\text { transferência para obter a matriz } \\
\text { completado sistema }\end{array}$ & $\begin{array}{l}\text { - Esta etapa foi realizada no programa Matlab }{ }^{(} \text {; } \\
\text { - Multiplicar as matrizes de transferência } \\
\text { identificadas na } 3^{\text {a }} \text { etapa. }\end{array}$ \\
\hline $\begin{array}{l}5^{a} \text { - Calcular a TL a partir dos quatro } \\
\text { polos da matriz de transferência do } \\
\text { sistema completo }\end{array}$ & $\begin{array}{l}\text { - Esta etapa foi realizada no programa Matlab }{ }^{(} ; \\
\text {- Substituir os quatro polos da matriz de } \\
\text { transferência determinada na etapa anterior na } \\
\text { equação da Perda de Transmissão, Eq. (45) }\end{array}$ \\
\hline
\end{tabular}

\subsubsection{Modelo I}

A presença de um tubo fechado na abertura lateral (Figura 21(a)) muda a impedância na região onde ele se localiza, de forma que parte da energia sonora incidente é refletida de volta para a fonte. Este filtro é do tipo para banda, já bastante conhecido, cuja equação analítica para cálculo da TL é encontrado na literatura [32]: 
$T L_{Q W T}=10 \log \left[1+0,25 \tan ^{2}\left(k l^{\prime}\right)\right]$

Esse tipo de silenciador opera muito bem em torno da sua frequência de ressonância. Um tubo com a extremidade fechada, no entanto, possui várias frequências de ressonância (teoricamente, um número infinito), definidas por [36]:

$f=\frac{\left(n-\frac{1}{2}\right) c}{2 l} \quad n=1,2,3 \ldots$

onde lé o comprimento do tubo.

O modelo I é composto por três elementos básicos (Figura 23). As matrizes de transferência dos respectivos elementos indicados na figura podem ser consultadas na Tabela 4.

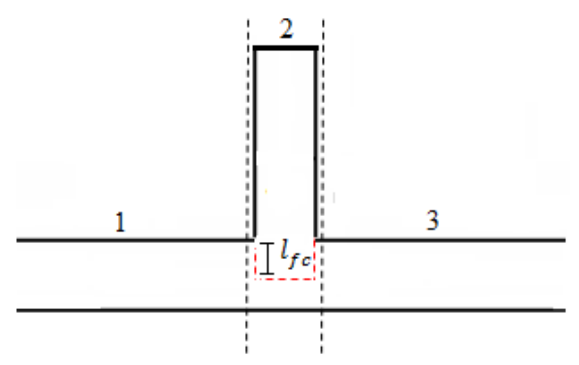

\begin{tabular}{|c|c|c|}
\hline $\mathbf{n}$ & Elemento básico & Matriz de Transferência \\
\hline 1 & Duto de seção uniforme (entrada) & Eq. (52) \\
\hline 2 & Duto fechado na abertura lateral (QWT) & Eq. (62) \\
\hline 3 & Duto de seção uniforme (saída) & Eq. (52) \\
\hline
\end{tabular}

Figura 23 - Decomposição do silenciador em elementos básicos

Devido à descontinuidade de área causada pela inserção de um tubo fechado na abertura lateral do duto é necessário adicionar fator de correção $\left(l_{f c}\right)$, conforme indicado em vermelho na Figura 23, ao comprimento físico do QWT. Os fatores de correção adotados neste trabalho para este modelo de silenciador são apresentados na Tabela 7 . 
Tabela 7 - Fatores de Correção para o modelo I

\begin{tabular}{ccc}
\hline Proposto por & Fator de Correção & Válido para \\
\hline Onorati (48) & $l_{f c}=0,3 r$ & $f<500$ \\
\hline Rayleigh (44) & $l_{f c}=0,85 r$ & $500<f<1500$ \\
\hline Onorati (48) & $l_{f c}=r$ & $f>1500$ \\
\hline Ji (50) & $l_{f c}=0,9326 r-0,6196\left(\frac{r^{2}}{a}\right)$ & $\frac{r}{a}>0,4$ \\
\hline
\end{tabular}

em que $r$ corresponde ao raio do QWT e a corresponde ao raio do duto principal no qual o QWT está instalado.

Após determinar os comprimentos efetivos e matrizes de transferência dos elementos básicos, a metodologia para cálculo da TL foi seguida, conforme Tabela 6. A TL foi calculada para a faixa de frequência de 0 a $2000 \mathrm{~Hz}$.

A Figura 24 apresenta os resultados obtidos com o MMT e também com a aplicação direta da equação analítica do QWT (Eq.(84)), ambos com e sem o fator de correção. Os fatores de correção de Onorati e Rayleigh, de acordo com a restrição da faixa de frequência de análise que cada um apresenta, foram combinados para cobrir a faixa de frequência de 0 a $2000 \mathrm{~Hz}$.

Observa-se que para um mesmo fator de correção, os resultados obtidos por meio do MMT e da equação analítica são equivalentes, demonstrando assim a validade da metodologia do método da matriz de transferência adotada neste trabalho. Porém as curvas se diferem de acordo com o fator de correção adotado, tanto em frequência quanto em amplitude.

A Tabela 8 apresenta as quatro primeiras frequências de ressonância e respectivas amplitudes obtidas para cada fator de correção. A inclusão de tais fatores deslocou os picos de atenuação para esquerda. Essa diferença é significativa ao considerar o projeto de um QWT para aplicações práticas, visto que este dispositivo deve ser ajustado corretamente para ser eficiente na atenuação de um ruído tonal. 


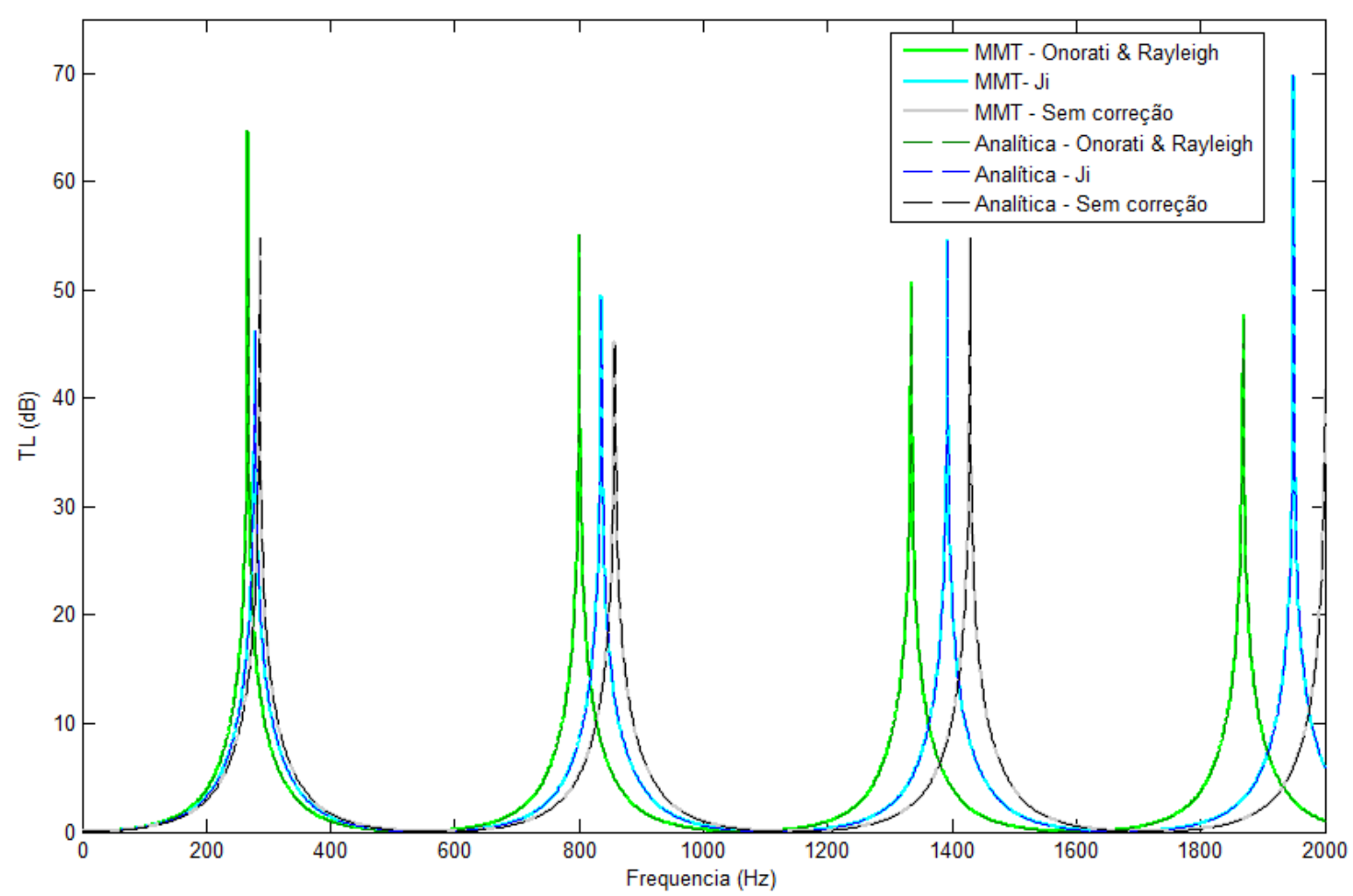

Figura 24 - Perda de Transmissão do modelo I

Tabela 8 - Frequências e amplitudes de ressonância de acordo com cada fator de correção

\begin{tabular}{c|c|c|c|c|c|c}
\cline { 2 - 7 } & \multicolumn{2}{c}{ Sem correção } & \multicolumn{2}{c}{ Onorati \& Rayleigh } & \multicolumn{2}{c}{ Ji } \\
\hline $\mathbf{n}$ & Frequência & Amplitude & Frequência & Amplitude & Frequência & Amplitude \\
\hline $\mathbf{1}$ & $286 \mathrm{~Hz}$ & $54,74 \mathrm{~dB}$ & $267 \mathrm{~Hz}$ & $64,69 \mathrm{~dB}$ & $279 \mathrm{~Hz}$ & $46,23 \mathrm{~dB}$ \\
\hline $\mathbf{2}$ & $858 \mathrm{~Hz}$ & $45,20 \mathrm{~dB}$ & $801 \mathrm{~Hz}$ & $55,14 \mathrm{~dB}$ & $836 \mathrm{~Hz}$ & $49,47 \mathrm{~dB}$ \\
\hline $\mathbf{3}$ & $1429 \mathrm{~Hz}$ & $54,74 \mathrm{~dB}$ & $1335 \mathrm{~Hz}$ & $50,71 \mathrm{~dB}$ & $1393 \mathrm{~Hz}$ & $54,70 \mathrm{~dB}$ \\
\hline $\mathbf{4}$ & $2000 \mathrm{~Hz}$ & $40,76 \mathrm{~dB}$ & $1869 \mathrm{~Hz}$ & $47.78 \mathrm{~dB}$ & $1950 \mathrm{~Hz}$ & $69,88 \mathrm{~dB}$ \\
\hline
\end{tabular}

\subsubsection{Modelo II}

A câmara de expansão simples (Figura 21(a)) é um das formas mais clássicas e simples de silenciador reativo. Seu conceito se baseia na reflexão do som causado pela mudança abrupta da área da seção transversal. É um filtro do tipo para banda. O comprimento da câmara é ajustado para refletir a onda e atenuar a propagação de saída da energia sonora na saída. A equação analítica para cálculo da TL é [30]: 
$T L_{Q W T}=10 \log \left[1+0,25\left(\frac{S_{2}}{S_{1}}-\frac{S_{1}}{S_{2}}\right) \operatorname{sen}^{2}(k l)\right]$

em que $S_{1}$ é a área da seção transversal do duto de entrada e $S_{2}$ é a área da seção transversal da câmara. Os máximos da curva ocorrem em:

$f=\frac{n c}{4 l} \quad n=1,3,5, \ldots$

Em uma primeira análise, o modelo II é composto por cinco elementos: 1) duto de seção uniforme (entrada); 2) súbita expansão; 3) duto de seção uniforme (câmara); 4) súbita contração e 5) duto de seção uniforme (saída), (Figura 25).

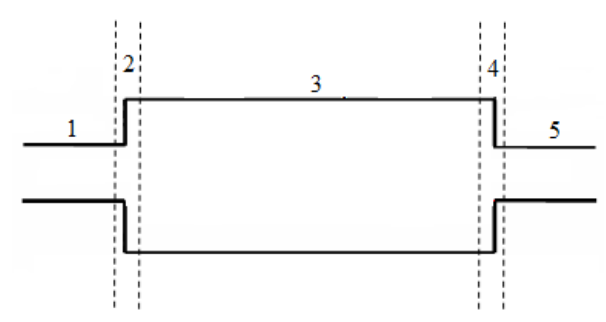

\begin{tabular}{|c|c|c|}
\hline $\mathbf{n}$ & Elemento básico & Matriz de Transferência \\
\hline 1 & Duto de seção uniforme (entrada) & Eq. (52) \\
\hline 2 & Súbita expansão & Eq. (63) \\
\hline 3 & Duto de seção uniforme (câmara) & Eq. (52) \\
\hline 4 & Súbita contração & Eq. (63) \\
\hline 5 & Duto de seção uniforme (saída) & Eq. (52) \\
\hline
\end{tabular}

Figura 25 - Decomposição do modelo II em elementos básicos (sem fator de correção)

Porém, a descontinuidade da área da seção transversal, provocada pela súbita contração e expansão, exige o ajuste do comprimento físico, adicionando o comprimento acústico, conforme ilustrado em vermelho na Figura 26. Devido à adição deste comprimento, a câmara de expansão simples passa a se assemelhar a uma câmara de expansão com dutos estendidos. Assim, o sistema passa a ser composto por novos elementos básicos (Figura 26). As matrizes de transferência dos respectivos elementos indicados na figura podem ser consultadas na Tabela 4. 


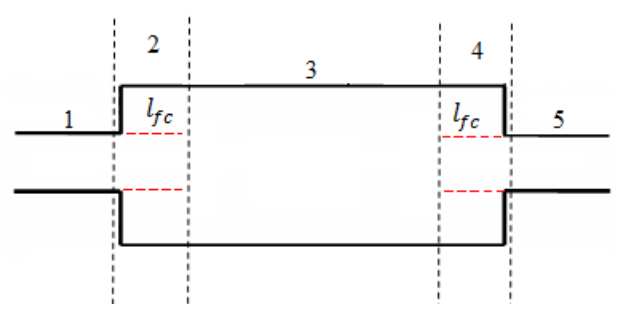

\begin{tabular}{|c|c|c|}
\hline $\mathbf{n}$ & Elemento básico & Matriz de Transferência \\
\hline 1 & Duto de seção uniforme (entrada) & Eq. (52) \\
\hline 2 & Duto estendido & Eq. (60) \\
\hline 3 & Duto de seção uniforme (câmara) & Eq. (52) \\
\hline 4 & Duto estendido & Eq. (60) \\
\hline 5 & Duto de seção uniforme (saída) & Eq. (52) \\
\hline
\end{tabular}

Figura 26 - Decomposição do modelo II em elementos básicos (com fator de correção)

Os fatores de correção adotados neste trabalho para este modelo de silenciador são apresentados na Tabela 9.

Tabela 9 - Fatores de correção para camâra de expansão simples

\begin{tabular}{cccc}
\hline Proposto por & Fator de Correção & Válido para \\
\hline Karal (46) & $\frac{l_{f c}}{r_{1}}=\frac{8}{3 \pi}\left[1-1,238 \frac{r_{1}}{r_{2}}\right]$ & $0<\frac{r_{1}}{r_{2}}<0,5$ \\
\hline Davies (47) & $l_{f c}=0,63 r_{1}\left[1-e^{\left.-\left(\frac{r_{2} / r_{1}-1}{1,5}\right)\right]}\right.$ & $0,5<\frac{r_{1}}{r_{2}}<1$ \\
\hline Torregrosa (49) & $\frac{l_{f c}}{r_{1}}=2\left(0,26148-e^{-\left(1,31906 r_{2} / r_{1}\right)}\right)$ & $0<\frac{r_{1}}{r_{2}}<1$ \\
\hline
\end{tabular}

Como consequência das correções, o comprimento dos tubos de entrada e saída estendem-se por um comprimento $l_{f c}$, e, consequentemente, o comprimento da câmara é reduzido em $2 l_{f c}$.

Após determinar os comprimentos efetivos e matrizes de transferência dos elementos básicos, a metodologia para cálculo da TL foi seguida, conforme Tabela 6. A TL foi calculada para a faixa de frequência de 0 a $1500 \mathrm{~Hz}$. Também foi avaliada sem considerar nenhum fator correção. Os resultados são mostrados na Figura 27. 


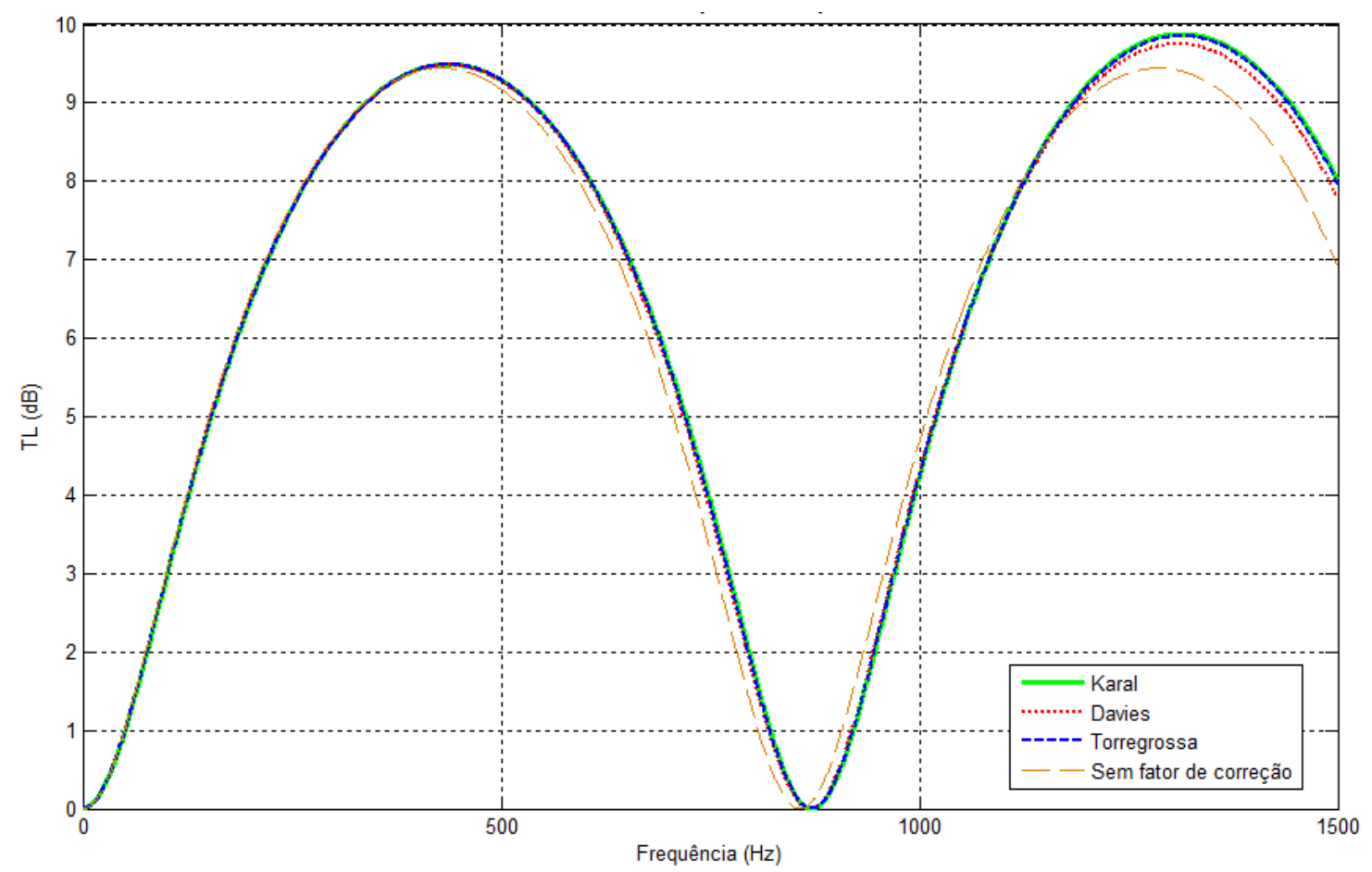

Figura 27 - TL do modelo II calculada com MMT

Em baixas frequências (até $450 \mathrm{~Hz}$ ), os resultados obtidos com correção e sem correção são próximos. Entretanto, começam a se distinguir à medida que a frequência aumenta. As curvas obtidas com fator de correção de Karal e Torregrossa são muito próximas.

A Tabela 10 apresenta a frequência e amplitude dos pontos de máximo de cada um dos domos das curvas. A curva sem fator de correção exibe comportamento de domos repetitivos, dessa forma, os dois pontos de máximo ocorrem na mesma amplitude $(9,44 \mathrm{~dB})$.

Para os três fatores de correção, a frequência em que ocorre o primeiro ponto de máximo $(n=1)$ é a mesma $(433 \mathrm{~Hz})$ e os valores de amplitude são muito próximos. O padrão de domos repetitivo não é mantido: a amplitude do segundo domo aumenta em relação ao primeiro. A curva de Karal é a que apresenta o maior aumento $(0,40 \mathrm{~dB})$ e Davies o menor $(0,27 \mathrm{~dB})$. 
Tabela 10 - Frequência e amplitude dos pontos de máximo dos domos da TL do modelo II

\begin{tabular}{c|c|c|c|c|c|c|c|c}
\cline { 2 - 8 } \multicolumn{2}{c|}{ Sem correção } & \multicolumn{2}{c|}{ Karal } & \multicolumn{2}{c}{ Torregrossa } & \multicolumn{2}{c}{ Davies } \\
\hline $\mathbf{n}$ & Freq. & Amp. & Freq. & Amp. & Freq. & Amp. & Freq. & Amp. \\
\hline $\mathbf{1}$ & $428 \mathrm{~Hz}$ & $9,44 \mathrm{~dB}$ & $433 \mathrm{~Hz}$ & $9,49 \mathrm{~dB}$ & $433 \mathrm{~Hz}$ & $9,49 \mathrm{~dB}$ & $433 \mathrm{~Hz}$ & $9,48 \mathrm{~dB}$ \\
\hline $\mathbf{2}$ & $1286 \mathrm{~Hz}$ & $9,44 \mathrm{~dB}$ & $1311 \mathrm{~Hz}$ & $9,89 \mathrm{~dB}$ & $1308 \mathrm{~Hz}$ & $9,85 \mathrm{~dB}$ & $1303 \mathrm{~Hz}$ & $9,75 \mathrm{~dB}$ \\
\hline
\end{tabular}

A Figura 28 apresenta as TL obtidas a partir da aplicação direta da equação analítica, Eq. (86), considerando também os fatores de correção.

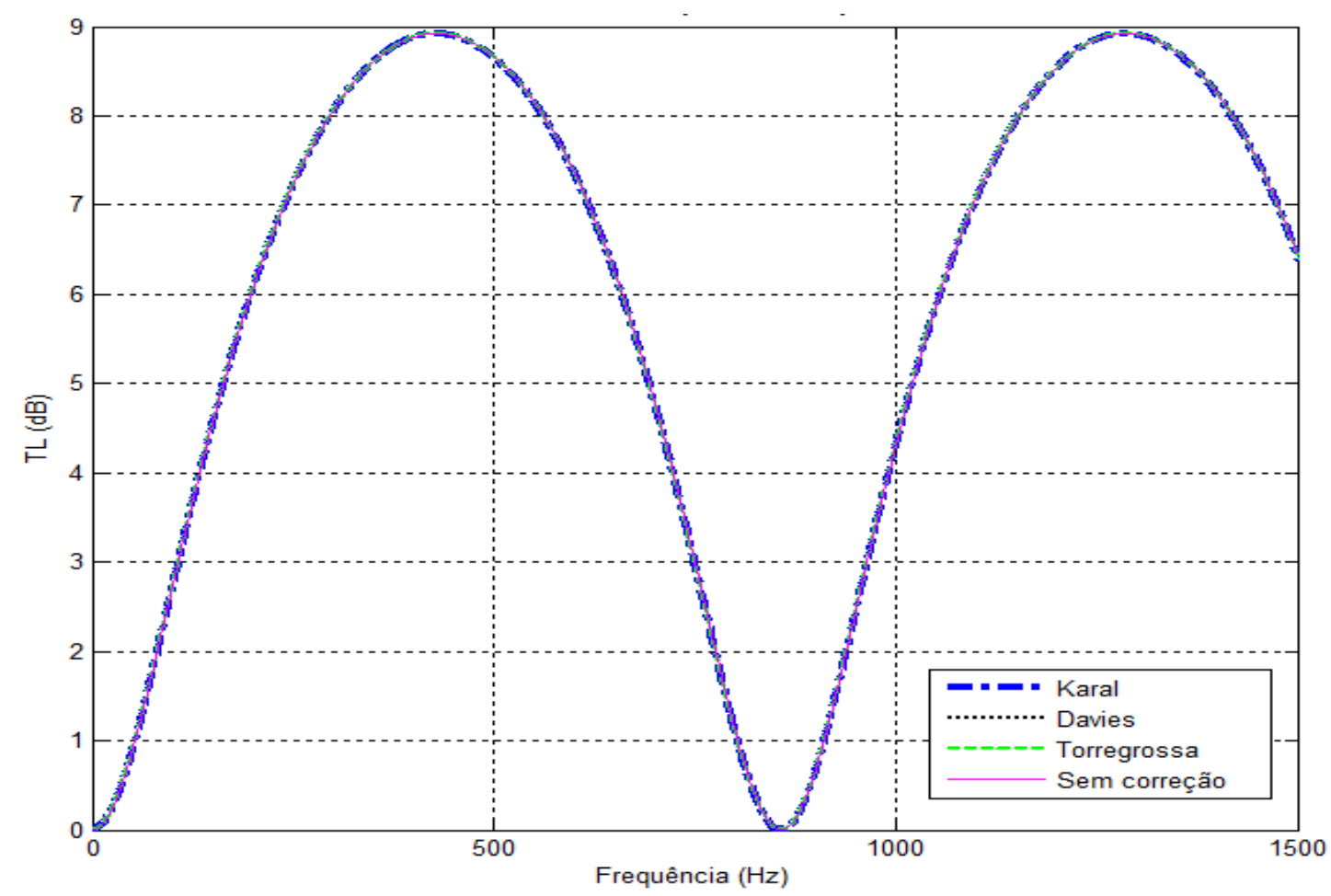

Figura 28 - TL do modelo II calculada com a equação analítica

Conclui-se que a equação que não é sensível à inclusão do comprimento acústico, uma vez que as curvas obtidas sem correção e com diferentes fatores de correção são as mesmas. Os dois pontos de máximo da curva (extraídos do gráfico e também calculados pela Eq. (87)) ocorrem em 428 $\mathrm{Hz}$ e $1286 \mathrm{~Hz}$, ambos em 8,9 dB. Nota-se que são as mesmas frequências obtidas para a TL calculada pelo MMT sem fator de correção (Figura 27) 
Já a Figura 29 apresenta comparação entre o MMT utilizando o fator de correção sugerido por Karal e equação analítica. Embora as curvas tenham a mesma forma, o aumento da amplitude dos pontos máximos da curva de Karal fica mais evidente.

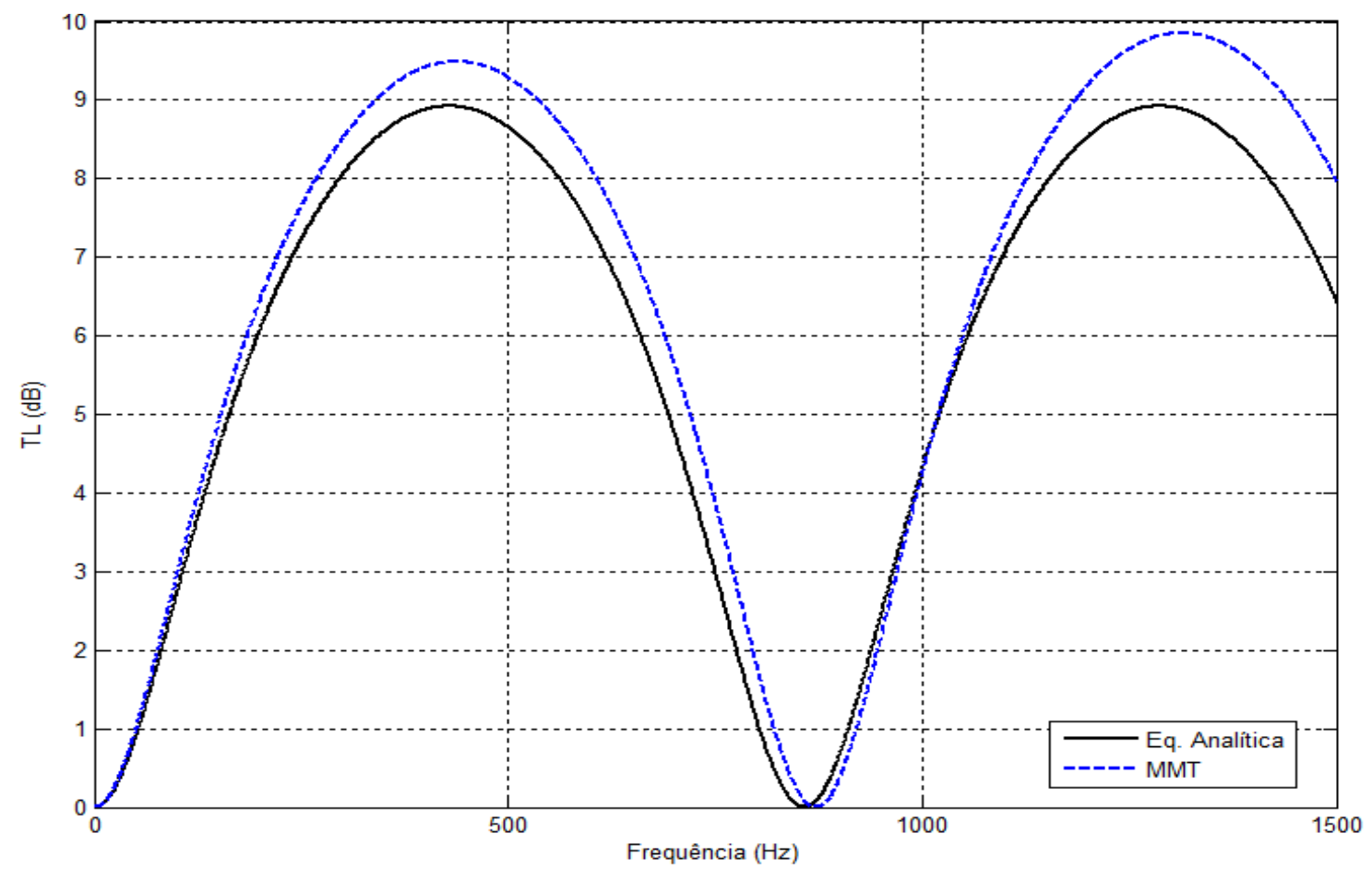

Figura 29- TL do modelo II calculada por MMT e equação analítica com fator de correção de Karal

\subsubsection{Modelo III}

A extensão do duto de entrada, Figura 21(c), representa o primeiro passo para melhorar o desempenho acústico de uma câmara de expansão. Neste caso, a perda de transmissão na câmara é dada pela seguinte equação [37]:

$$
\begin{aligned}
T L=20 \log \left\{\frac{1}{4 m}\right. & \mid\left[(m+1)+i(m-1) \tan \left(k l^{\prime} e e\right)\right][(m+1) \\
& \left.+i(m-1) \tan \left(k l^{\prime} e d\right)\right] e^{i k\left(l^{\prime} c^{-l^{\prime}} e e^{-l^{\prime}} e d\right)} \\
& \left.+(m-1)^{2}\left[1-\tan \left(k l^{\prime} e e\right)\right]\left[1-\tan \left(k l^{\prime}{ }_{e d}\right)\right] e^{-i k\left(l^{\prime} c^{-l^{\prime}} e e-l^{\prime} e d\right)} \mid\right\}
\end{aligned}
$$


em que $m$ é a razão entre o raio da câmara principal e o raio do duto de entrada/saída, $l_{e e}^{\prime}$ é o comprimento efetivo da extensão do duto de entrada, $l^{\prime}{ }_{e d}$ é o comprimento efetivo da extensão do duto de saída e $l^{\prime}{ }_{c}$ é o comprimento efetivo da câmara.

O modelo III é composto por cinco elementos básicos (Figura 30). As matrizes de transferência dos respectivos elementos indicados na figura podem ser consultadas na Tabela 4.

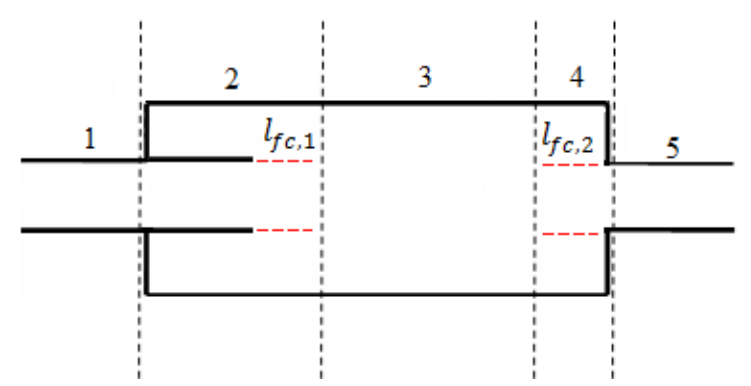

\begin{tabular}{|c|c|c|}
\hline $\mathbf{n}$ & Elemento básico & Matriz de Transferência \\
\hline 1 & Duto de seção uniforme (entrada) & Eq. (52) \\
\hline 2 & Duto estendido & Eq. (60) \\
\hline 3 & Duto de seção uniforme (câmara) & Eq. (52) \\
\hline 4 & Duto estendido & Eq. (52) \\
\hline 5 & Duto de seção uniforme (saída) & Eq) \\
\hline
\end{tabular}

Figura 30 - Decomposição do modelo III em elementos básicos

Devido às descontinuidades geométricas, é necessário adicionar 0 comprimento acústico nas duas extremidades internas dos dutos de entrada e saída, indicados em vermelho na Figura 30, a fim de considerar os efeitos não unidimensionais. Neste caso, foram empregados os mesmos fatores de correção do modelo II (Tabela 9).

Ressalta-se que o comprimento efetivo da câmara de expansão é reduzido em relação ao comprimento físico devido aos fatores de correção. Tendo identificado as matrizes de transferência dos elementos, e respectivos comprimentos efetivos, é possível calcular a TL, pelo MMT. 
Para esta configuração, a teoria da onda plana é válida para faixa de frequência de 0 a $1860 \mathrm{~Hz}$. Entretanto, na Figura 31, os resultados são mostrados na faixa de frequência de $0 \mathrm{a} 2500 \mathrm{~Hz}$, apenas para permitir melhor visualização.

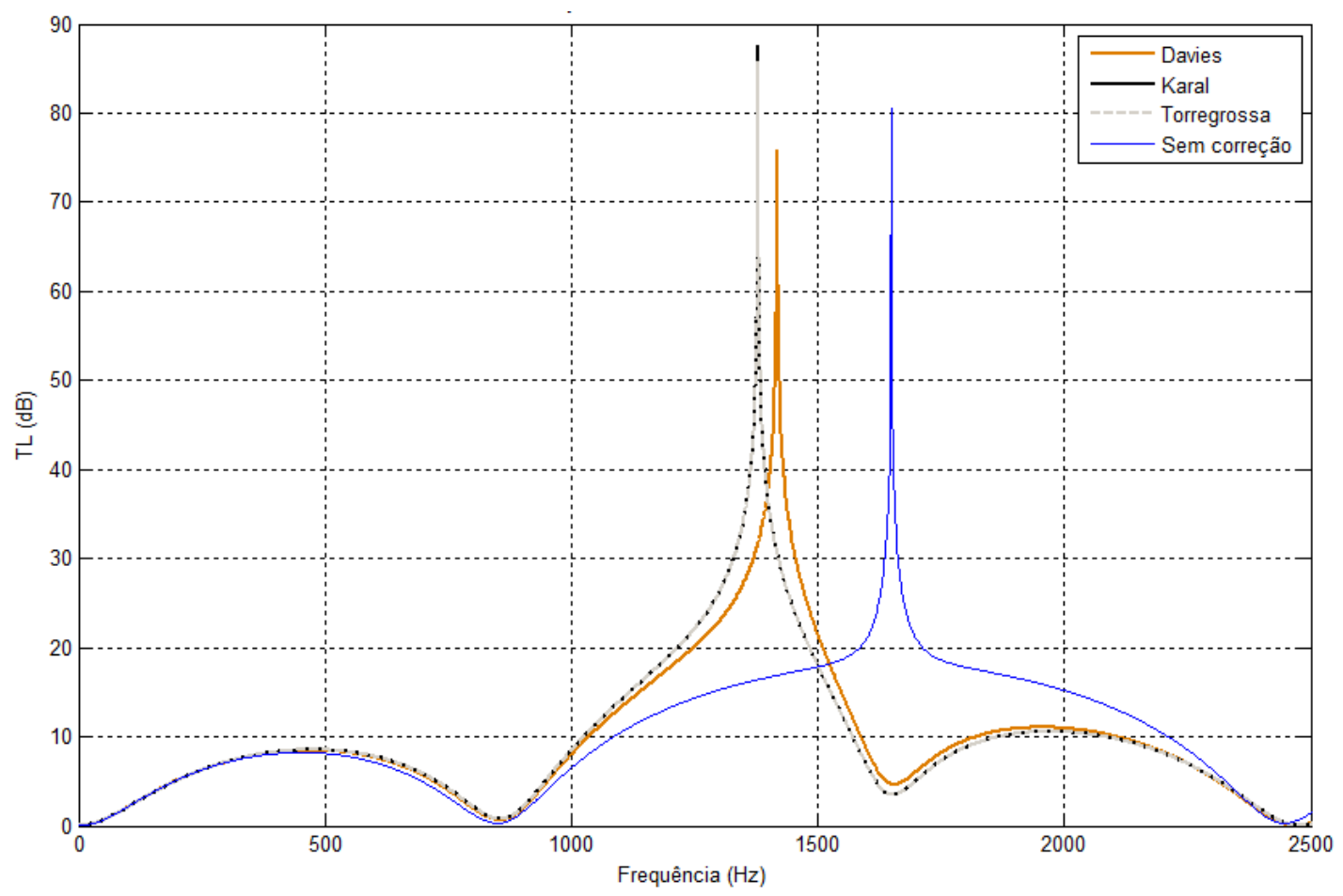

Figura 31 - TL do modelo III calculada pelo MMT

A TL em câmaras de expansão com extremidade estendida exibe um comportamento resultante da superposição de domos e picos de atenuação sonora. Para frequências inferiores à de corte o número de domos é igual ao apresentado por câmaras de expansão simples. Os picos de atenuação são devidos às áreas que se formam entre a câmara e as extremidades estendidas.

A Tabela 11 apresenta a frequência e amplitude do pico de ressonância de cada uma das curvas de TL.

Tabela 11 - Frequência e amplitude do pico de atenuação obtido para cada fator de correção para o modelo III

\begin{tabular}{ccc}
\hline Fator de correção & Frequência & Amplitude \\
\hline Davies & $1418 \mathrm{~Hz}$ & $75,84 \mathrm{~dB}$ \\
\hline
\end{tabular}




\begin{tabular}{cll}
\hline Karal & $1379 \mathrm{~Hz}$ & $87,64 \mathrm{~dB}$ \\
\hline Torregrossa & $1379 \mathrm{~Hz}$ & $85,81 \mathrm{~dB}$ \\
\hline Sem fator de correção & $1649 \mathrm{~Hz}$ & $80,61 \mathrm{~dB}$ \\
\hline
\end{tabular}

As curvas obtidas com 0 fator de correção sugerido por Karal e Torregrossa são próximas e apresentam o pico de atenuação na mesma frequência, com pouca diferença em amplitude $(1,81 \mathrm{~dB})$. O fator de correção proposto por Davies resultou em uma curva com o mesmo comportamento das citadas anteriormente, porém com o pico de ressonância um pouco deslocado para direita. Já o comportamento da curva de TL calculada sem fator de correção se difere notadamente das demais.

A Figura 32 mostra a TL calculada com o MMT e com aplicação da equação analítica (Eq. (88)) . Como exemplo foi adotado o fator de correção de Karal. Verifica-se que os picos de atenuação sonora previstos por ambas as curvas ocorrem nas mesmas frequências, apesar da diferença entre elas.

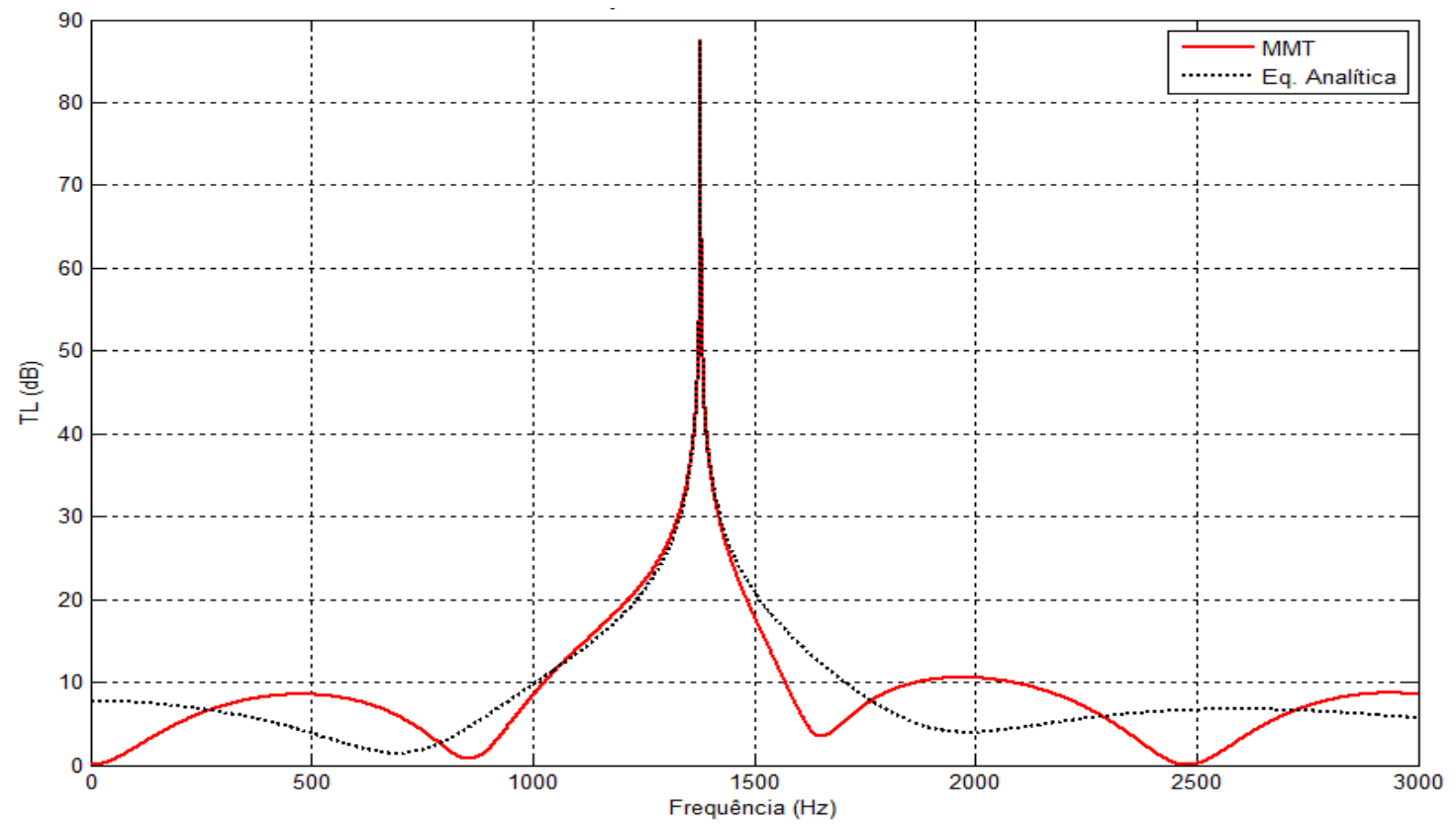

Figura 32 - TL do modelo III calculada pelo MMT e equação analítica com fator de correção de Karal 


\subsubsection{Modelo IV}

Câmaras de expansão simples podem ter a aplicação limitada devido à presença de decaimentos periódicos ao longo da curva da perda de transmissão. Nesse sentido, a extensão dos dutos de entrada e saída (Figura 21(d)) podem representar uma solução viável para melhorar o desempenho do silenciador.

O modelo IV é composto por cinco elementos básicos (Figura 33). As matrizes de transferência dos respectivos elementos indicados na figura podem ser consultadas na Tabela 4. A descontinuidade da seção transversal exige a correção do comprimento das extensões de entrada e saída, conforme ilustrado em vermelho, para contabilizar os efeitos das ondas tridimensionais que não são considerados na análise de ondas planas.

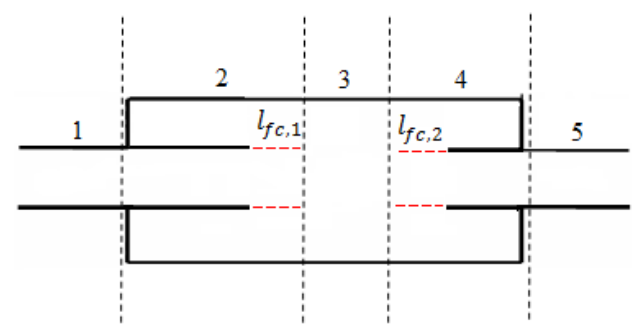

\begin{tabular}{|c|c|c|}
\hline $\mathbf{n}$ & Elemento básico & Matriz de Transferência \\
\hline 1 & Duto de seção uniforme (entrada) & Eq. (52) \\
\hline 2 & Duto estendido & Eq. (60) \\
\hline 3 & Duto de seção uniforme (câmara) & Eq. (52) \\
\hline 4 & Duto estendido & Eq. (60) \\
\hline 5 & Duto de seção uniforme (saída) & Eq. (52) \\
\hline
\end{tabular}

Figura 33- Decomposição do modelo IV em elementos básicos

Os fatores de correção $\left(l_{f c}\right)$ adotados para este modelo foram os mesmos utilizados para o modelo II (Tabela 9) e também os fatores apresentados na Tabela 12, específicos para dutos estendidos. 
Tabela 12 - Fatores de correção para o modelo IV

\begin{tabular}{c|c|c}
\hline Proposto por & Fator de Correção & Válido para \\
\hline Kang \& Ji (58) & $l_{f c}=r_{1}\left(0.6165-\frac{0.7046 r_{1}}{r_{2}}+0.2051 e^{\left(\frac{-3.4453 l_{\text {ext }}}{2 r_{1}}\right)}\right.$ & $\frac{r_{1}}{r_{2}}<0.51$ \\
\hline $\begin{array}{l}\text { Chaitanya e } \\
\text { Munjal (51) }\end{array}$ & $\left.-\frac{0.3749 r_{1}}{r_{2}} e^{\left(\frac{-2.6023 l_{\text {ext }}}{2 r_{1}}\right)}\right)$ & \\
\hline
\end{tabular}

em que $f_{r}$ é a frequência de ressonância do silenciador, que pode ser determinada experimentalmente ou por análise numérica. As frequências de ressonância deste modelo foram determinadas experimentalmente e por análise de elementos finitos por Chaitanya e Munjal [51], sendo $426,5 \mathrm{~Hz}$ e 853 $\mathrm{Hz}$, obtendo assim os valores das correções da extensão de entrada e saída: $l_{f c, 1}=11,95 \mathrm{~mm}$ e $l_{f c, 2}=13,13 \mathrm{~mm}$, respectivamente.

A Figura 34 apresenta a curva da TL calculada pelo MMT para o modelo IV na faixa de frequência de 0 a $1300 \mathrm{~Hz}$. Apenas para fins comparativos 0 gráfico mostra o resulta obtido para câmara de expansão simples com as mesmas dimensões. . A Tabela 13 registra as frequências e amplitudes dos picos de atenuação para cada fator de correção.

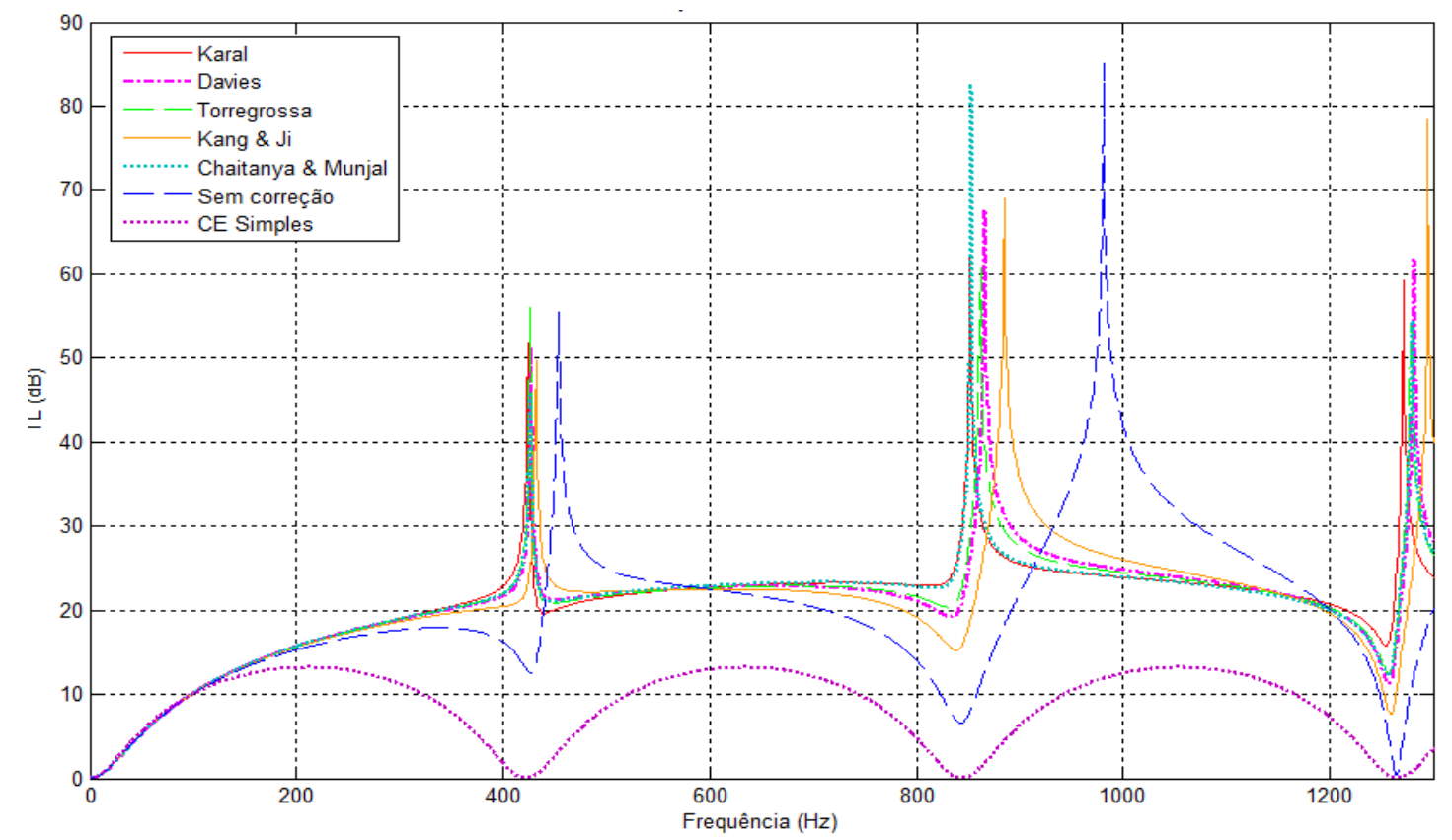

Figura 34 - TL do modelo IV pelo MMT 
Tabela 13 - Frequência e amplitude dos picos de atenuação para cada fator de correção para o modelo IV

\begin{tabular}{c|ccc|c}
\cline { 2 - 5 } & \multicolumn{2}{c}{ 10 pico } & \multicolumn{2}{c}{ 20 pico } \\
\hline Fator de correção & Frequência & Amplitude & Frequência & Amplitude \\
\hline Torregrossa & $426 \mathrm{~Hz}$ & $56,1 \mathrm{~dB}$ & $862 \mathrm{~Hz}$ & $60,7 \mathrm{~dB}$ \\
\hline Karal & $424 \mathrm{~Hz}$ & $51,7 \mathrm{~dB}$ & $852 \mathrm{~Hz}$ & $61,9 \mathrm{~dB}$ \\
\hline Davies & $427 \mathrm{~Hz}$ & $51,2 \mathrm{~dB}$ & $866 \mathrm{~Hz}$ & $67,3 \mathrm{~dB}$ \\
\hline Kang \& Ji & $423 \mathrm{~Hz}$ & $49,7 \mathrm{~dB}$ & $885 \mathrm{~Hz}$ & $68,9 \mathrm{~dB}$ \\
\hline Chaitanya e Munjal & $427 \mathrm{~Hz}$ & $45,6 \mathrm{~dB}$ & $853 \mathrm{~Hz}$ & $82,7 \mathrm{~dB}$ \\
\hline Sem correção & $453 \mathrm{~Hz}$ & $55,5 \mathrm{~dB}$ & $981 \mathrm{~Hz}$ & $85,1 \mathrm{~dB}$ \\
\hline
\end{tabular}

Conforme esperado, tem-se o surgimento de picos de ressonância provocado pela extensão dos dutos. Para as curvas com fator de correção, estes picos ocorrem em frequências próximas daquelas em que ocorre decaimento da TL na câmara de expansão simples. Assim, a faixa de frequência de atuação desse tipo de silenciador é maior.

Em geral, as TL apresentam o mesmo comportamento, entretanto, diferenças expressivas de frequência e amplitude dos picos de atenuação são notadas, principalmente em relação à curva sem fator de correção Comparando os valores do primeiro pico, a diferença em frequência é de até 20 $\mathrm{Hz}$ e 10,5 dB em amplitude. Para o segundo pico, a diferença chega a $129 \mathrm{~Hz}$ e $24,4 \mathrm{~dB}$.

A Figura 35 mostra a TL dada pela solução da equação analítica (Eq.(88)) e obtida com MMT ambas com fator de correção de Karal. Verifica-se que apesar da diferença entre as curvas, os picos de atenuação sonora previstos por ambas ocorrem nas mesmas frequências. 


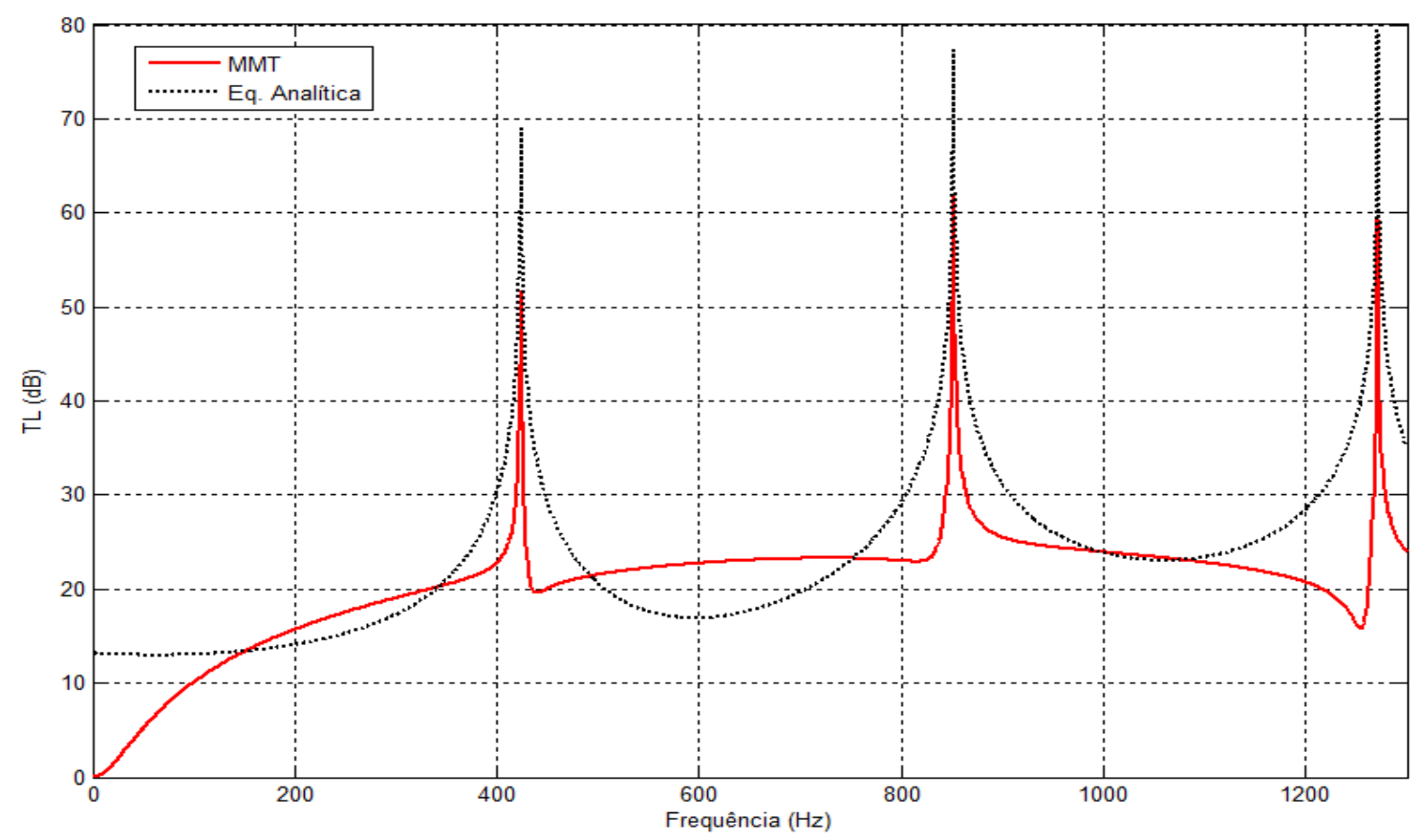

Figura 35 - TL para o modelo IV calculada pelo MMT e Equação analítica com fator de correção de Karal

\subsubsection{Método Numérico}

Esta seção apresenta a metodologia numérica para a estimativa da perda de transmissão de silenciadores reativos usando o método de elementos finitos, sem presença de escoamento. Foram utilizados dois softwares comerciais: Ansys ${ }^{\circledR}$ e LMS Virtual.Lab ${ }^{\circledR}$, a fim de comparar metodologia, resultados e tempo de processamento.

Ambos os softwares permitem a análise em elementos finitos de problemas de acústica, integrando ambientes de pré-processamento, processamento e pós-processamento. Atualmente, na área de Engenharia, o Ansys $^{\circledR}$ é uma ferramenta amplamente utilizada tanto no ambiente industrial como no ambiente acadêmico, incentivada pela maior facilidade de acesso, visto que são fornecidas sem custo licenças para o uso por estudantes. Por outro lado, o Virtual.lab ${ }^{\circledR}$ incorpora a tecnologia de processamento do SYSNOISE, que foi um solver muito utilizando no ambiente industrial e permite redução do tempo computacional. 
No Ansys $^{\circledR}$ foram realizadas análises bi e tridimensionais. No Virtual.lab ${ }^{\circledR}$, análises tridimensionais apenas, uma vez que modelos $2 \mathrm{D}$ não são suportados pelo software. Devido à simetria axial dos três modelos de câmara de expansão avaliados neste trabalho, foram realizadas simulações considerando apenas $1 / 6$ do volume total. Estes modelos são chamados aqui de 3D fracionado. Esta metodologia está esquematizada na Figura 36.

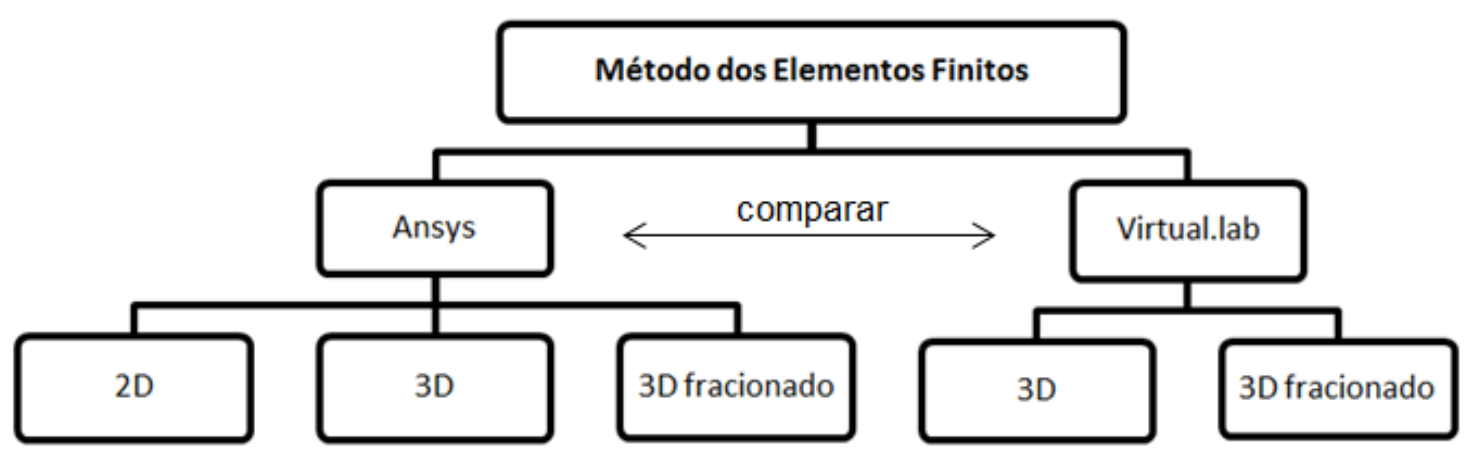

Figura 36 - Metodologia adotada para avaliação do desempenho de silenciadores reativos utilizando o método de elementos finitos

Com relação à malha em elementos finitos, foi adotada uma regra geral que recomenda, em análises acústicas, o uso de seis elementos por comprimento de onda da frequência máxima de análise [59]. Todas as malhas foram geradas automaticamente por ferramentas disponíveis nos próprios softwares.

A fim de viabilizar a comparação de resultados, para cada modelo de silenciador procurou-se manter um número aproximado de nós e elementos entre as malhas utilizadas no Ansys ${ }^{\circledR}$ e no Virtual.lab ${ }^{\circledR}$. E todas as simulações foram realizadas em um mesmo computador, com 6 GB de memória RAM e processador de $2.40 \mathrm{GHz}$.

As faixas de frequência utilizadas na etapa anterior são mantidas, uma vez que os resultados são comparados com aqueles obtidos via MMT. Todas as análises harmônicas foram realizadas com incrementos na frequência de 2 $\mathrm{Hz}$. 
Sobre as propriedades do meio fluído, os seguintes valores são adotados para a pressão de referência, densidade do ar e velocidade de propagação sonora, respectivamente $2 \times 10^{-5} \mathrm{~N} / \mathrm{m}^{2}, 1,21 \mathrm{~kg} / \mathrm{m}^{3}$ e $343 \mathrm{~m} / \mathrm{s}$.

\subsubsection{Metodologia: Ansys ${ }^{\circledR}$}

A Tabela 14 apresenta as etapas da metodologia adotadas neste trabalho para estimativa numérica da perda de transmissão de silenciadores acústicos utilizando o software Ansys ${ }^{\circledR}$.

Tabela 14 - Etapas da metodologia numérica para estimativa numérica da TL utilizando o software Ansys ${ }^{\circledR}$

\begin{tabular}{|c|c|}
\hline Etapa & Descrição \\
\hline $1^{\mathrm{a}}-$ Definir tipo de elemento & $\begin{array}{l}\text { - Utilizar FLUID29 para análise bidimensional ou } \\
\text { FLUID30 para análise tridimensional. }\end{array}$ \\
\hline $2^{\mathbf{a}}-$ Construir modelo acústico & $\begin{array}{l}\text { - Fazer a modelagem da área (Figura } 37(a) \text { ) ou do } \\
\text { volume (Figura } 37(b)) \text { do interior do silenciador. }\end{array}$ \\
\hline $\begin{array}{l}3^{a}-\text { Definir as propriedades do } \\
\text { material }\end{array}$ & $\begin{array}{l}\text { - Inserir valores de densidade do ar, pressão de } \\
\text { referência e velocidade de propagação do som. }\end{array}$ \\
\hline $4^{a}-$ Construir a malha & $\begin{array}{l}\text { - Subdividir o domínio fluído em elementos discretos, } \\
\text { seguindo a regra de, pelo menos, seis elementos } \\
\text { por comprimento de onda. }\end{array}$ \\
\hline $\begin{array}{l}\text { 5a - Definir condições de } \\
\text { contorno }\end{array}$ & $\begin{array}{l}\text { - Para simular a excitação acústica na entrada do } \\
\text { sistema, insere-se pressão unitária (com o comando } \\
\text { PRES) nos nós dos elementos que compõem a } \\
\text { seção transversal da extremidade do duto de } \\
\text { entrada, como mostra a Figura 37(c); } \\
\text { - Para o cálculo da TL, faz-se necessário que o tubo } \\
\text { de saída do sistema possua terminação anecóica. } \\
\text { Para isto insere-se impedância acústica (com o } \\
\text { comando IMPD) com valor igual a um nos nós seção } \\
\text { transversal da extremidade do duto de saída, como } \\
\text { mostra a Figura 37(d) }\end{array}$ \\
\hline
\end{tabular}




\begin{tabular}{|c|c|}
\hline $\begin{array}{l}5^{a}-\text { Realizar analise harmônica } \\
\text { do modelo }\end{array}$ & $\begin{array}{l}\text { - O software resolve a equação da onda (Eq. (25)), } \\
\text { pelo método de elementos finitos. }\end{array}$ \\
\hline $\begin{array}{l}\text { 6⿳亠口冋 - Obter valor da pressão } \\
\text { acústica em três pontos }\end{array}$ & $\begin{array}{l}\text { - Obter o valor real e imaginário da pressão acústica } \\
\text { em três nós: dois antes do silenciador e um após o } \\
\text { silenciador. } \\
\text { - Exportar os valores de pressão em arquivo de } \\
\text { formato txt. }\end{array}$ \\
\hline $\begin{array}{l}\text { 7ㅇ - Calcular a TL pelo método da } \\
\text { decomposição }\left(^{*}\right)\end{array}$ & $\begin{array}{l}\text { - Manipular os valores de pressão sonora para } \\
\text { calcular a TL pelo método da decomposição, } \\
\text { aplicando as Eq.(79) e (80) na Eq. (37). }\end{array}$ \\
\hline
\end{tabular}

${ }^{*}$ Essa etapa foi realizada no software Matlab ${ }^{\circledR}$

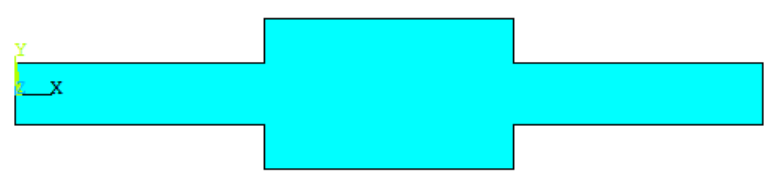

(a)

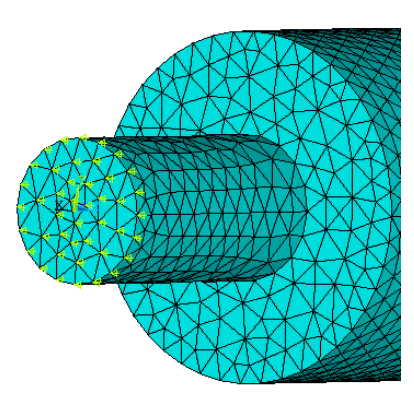

(c)

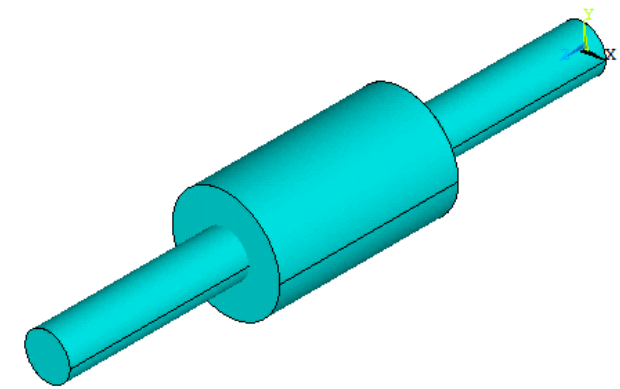

(b)

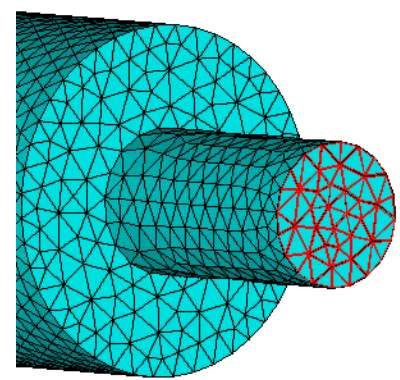

(d)

Figura 37- Detalhes da metodologia numérica via Ansys ${ }^{\circledR}$ (a) Meio fluído 2D (b) Meio fluído 3D (c) Pressão no duto de entrada (símbolo em verde) (d) Terminação anecóica no duto de saída (símbolo em vermelho)

O FLUID29 é um elemento acústico 2D plano, definido por 4 nós. A sua geometria (Figura 38(a)), pode ser quadrilateral ou triangular, na qual os dois últimos nós são coincidentes. Neste trabalho, foi utilizado na forma quadrilateral. Cada nó tem um grau de liberdade de pressão, e dois graus de liberdade translacionais opcionais ao longo dos eixos $\mathrm{x} e \mathrm{y}$. 
O FLUID30 é definido por 8 nós. Pode assumir a forma geométrica de hexaédrico, tetraédrico e prisma (Figura 38(b)). Neste trabalho foi utilizado em sua forma tetraédrica. Cada nó tem um grau de liberdade de pressão, e três graus de liberdade opcionais de translação ao longo dos eixos x, y e z [60].

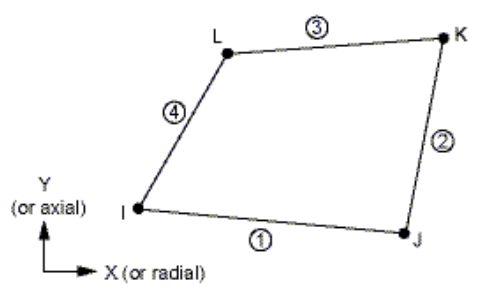

(a)
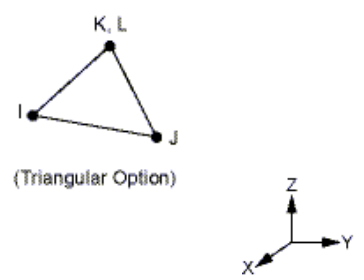

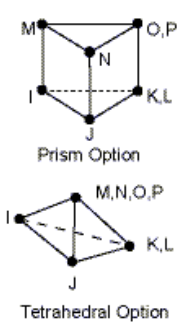

(b)

Figura 38 - Geometria do Elemento (a) FLUID29 (b) FLUID30 [60].

\subsubsection{Metodologia: LMS Virtual.lab ${ }^{\circledR}$}

A Tabela 15 apresenta as etapas da metodologia adotada neste trabalho para estimativa numérica da perda de transmissão de silenciadores acústicos utilizando o software LMS Virtual.lab ${ }^{\circledR}$.

Tabela 15 - Etapas da metodologia numérica para estimativa numérica da TL utilizando o software LMS Virtual.lab ${ }^{\circledR}$

\begin{tabular}{|c|c|}
\hline Etapa & Descrição \\
\hline 1a - Construir modelo acústico & $\begin{array}{l}\text { - Esta etapa é realizada no módulo "Geometry" } \\
\text { - Fazer a modelagem do volume interno do } \\
\text { silenciador. }\end{array}$ \\
\hline $2^{a}-$ Construir a malha & $\begin{array}{l}\text { - Esta etapa é realizada no módulo "Meshing" } \\
\text { - Subdividir o domínio fluído em elementos discretos } \\
\text { tetraédricos, seguindo a regra de, pelo menos, seis } \\
\text { elementos por comprimento de onda. }\end{array}$ \\
\hline $\begin{array}{l}3^{a}-\text { Definir as propriedades do } \\
\text { meio }\end{array}$ & $\begin{array}{l}\text { - Definir os valores de densidade do ar e velocidade } \\
\text { de propagação do som na opção Materials. } \\
\text { - Atribuir tais propriedades à malha de elementos } \\
\text { finitos na opção Propreties. }\end{array}$ \\
\hline
\end{tabular}


- Esta etapa e as próximas são realizadas no módulo "Acoustic Harmonic FEM"

- Definir a malha como malha acústica;

4 - Processar a malha acústica

$5^{\mathbf{a}}-$ Criar grupos de elementos do domínio completo

- Inserir a opção Acoustic Mesh Preprocessing que verifica e corrige a malha, de modo a torná-la adequada para a análise numérica. Também gera o envelope acústico (Acoustic Envelop) necessário para impor as condições de contorno.

- Utilizar a opção Inserting an Auto-Update Group Set para dividir a malha do envelope acústico em grupos, nos quais serão impostas condições de contorno. Cada grupo é representado por uma cor, como pode ser visto na Figura 39

- Para simular a excitação acústica na entrada do sistema, insere-se velocidade unitária (através da opção Panel velocity) no grupo de elementos referentes à seção transversal da extremidade do duto de entrada, criado na etapa anterior, como mostra a Figura 40(a);

6a - Definir condições de contorno
- Para o cálculo da TL, faz-se necessário que o tubo de saída do sistema possua terminação anecóica. Para isto insere-se a propriedade Absorbet panel para estipular a impedância acústica, no valor de $408 \mathrm{~kg} \cdot \mathrm{m}^{-2} \cdot \mathrm{s}^{-1}$ no grupo de elementos referentes à seção transversal da extremidade do duto de saída, criado na etapa anterior como mostra a Figura 40(b);

\section{$7^{\text {a }}$ - Realizar analise harmônica} do modelo

- O software resolve a equação da onda (Eq.(25)), pelo método de elementos finitos.

- Criar três 10 Points escalares (pontos que relacionam um nome a um nó e respectivos graus de liberdade): dois antes do silenciador e um após o silenciador, conforme indicam os pontos amarelos na Figura 39;

- Converter o campo de pressão da análise harmônica em um conjunto de funções, utilizando o 
comando Vector-to-Function Conversion Case para extrair o valor real e imaginário da pressão acústica nos três IO Ponits;

- Exportar os valores de pressão em arquivo de formato txt.

9 - Calcular a TL pelo método da decomposição $\left(^{*}\right)$
- Manipular os valores de pressão sonora para calcular a TL pelo método da decomposição, aplicando as Eq.(79) e (80) na Eq. (37).

${ }^{\star}$ Essa etapa foi realizada no software Matlab ${ }^{\circledR}$

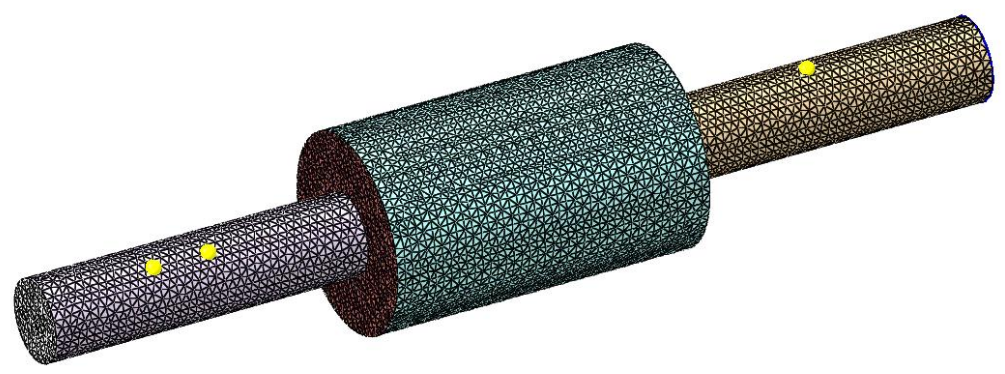

Figura 39 - Envelope acústico dividido em grupos de elementos e 10 points (em amarelo)

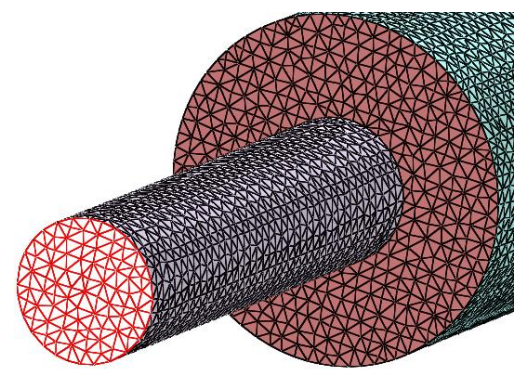

(a)

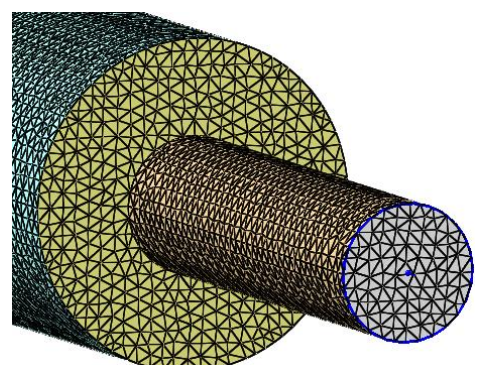

(b)

Figura 40- Detalhes das condições de contorno (a) Velocidade unitária no duto de entrada (símbolo em vermelho) (d) Terminação anecóica no duto de saída (símbolo em azul)

A malha gerada pelo Virtual.lab ${ }^{\circledR}$ é composta por elementos tetraédricos do tipo TETRA4, que são elementos lineares com quatro nós [61].

Ressalta-se que a versão utilizada do Virtual.lab ${ }^{\circledR}$ apresenta uma metodologia mais atualizada, que calcula a perda de transmissão diretamente no software, dispensando a realização da $8^{\underline{a}}$ e $9^{\underline{a}}$ etapa da metodologia 
apresentada, e consequentemente 0 uso de outro programa para implementação do método da decomposição.

Esta metodologia foi aplicada e verificou-se que os resultados são os mesmos daqueles obtidos a partir da metodologia aqui exposta. Contudo, embora mais rápida, apresenta limitações quando se considera a presença de fluxo no sistema, que é objeto de estudo deste trabalho. Por isso, optou-se por não apresentá-la.

\subsubsection{Modelo I}

A Figura 41 apresenta as malhas em elementos finitos utilizadas em cada simulação numérica do modelo I. Visto que essa geometria não apresenta simetria axial, não foi realizada a análise do modelo 3D fracionado. $A$ análise harmônica foi realizada na faixa de frequência de 0 a $2000 \mathrm{~Hz}$.

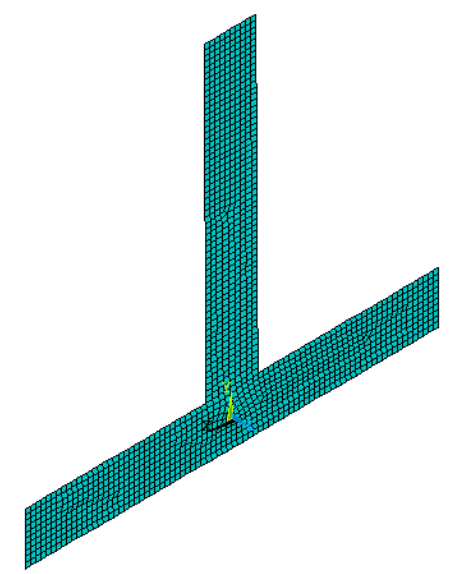

(a)

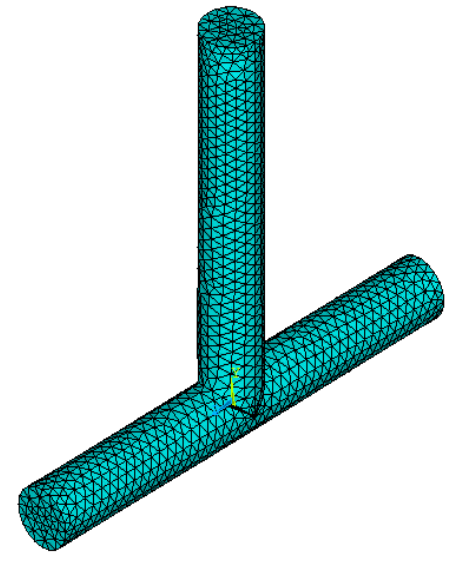

(b)

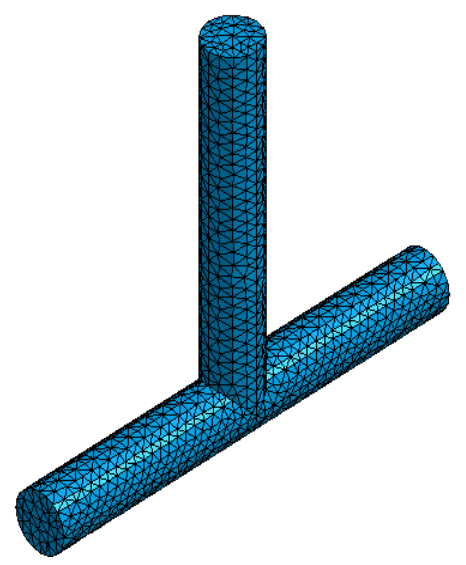

(c)

Figura 41 - Malha em elementos finitos do modelo I nas análises (a) Ansys ${ }^{\circledR} 2 \mathrm{D}$ (b) Ansys ${ }^{\circledR} 3 \mathrm{D}$ (c) Virtual.lab ${ }^{\circledR} 3 \mathrm{D}$

A Tabela 16 mostra o número de nós e elementos de cada malha e também o tempo gasto em cada simulação. Nota-se que o tempo de simulação do modelo 2D no Ansys ${ }^{\circledR}$ e 3D no Virtual.lab ${ }^{\circledR}$ é significativamente menor que o modelo 3D no Ansys ${ }^{\circledR}$. 
Tabela 16 - Propriedades das malhas em elementos finitos do modelo I e tempo de processamento

\begin{tabular}{cccc} 
& 2D & \multicolumn{2}{c}{ 3D } \\
\cline { 2 - 4 } & Ansys $^{\circledR}$ & Ansys $^{\circledR}$ & Virtual.lab $^{\circledR}$ \\
\hline Elemento & 1395 & 15656 & 14546 \\
\hline Nós & 1546 & 3468 & 3468 \\
\hline Tempo & $18 \mathrm{~s}$ & 10 min32s & 01 min46s \\
\hline
\end{tabular}

A Figura 42 mostra os resultados gerados a partir de cada simulação. E a Tabela 17 registra os valores em que ocorrem as frequências de ressonância e respectivas amplitudes, aferidos do gráfico.

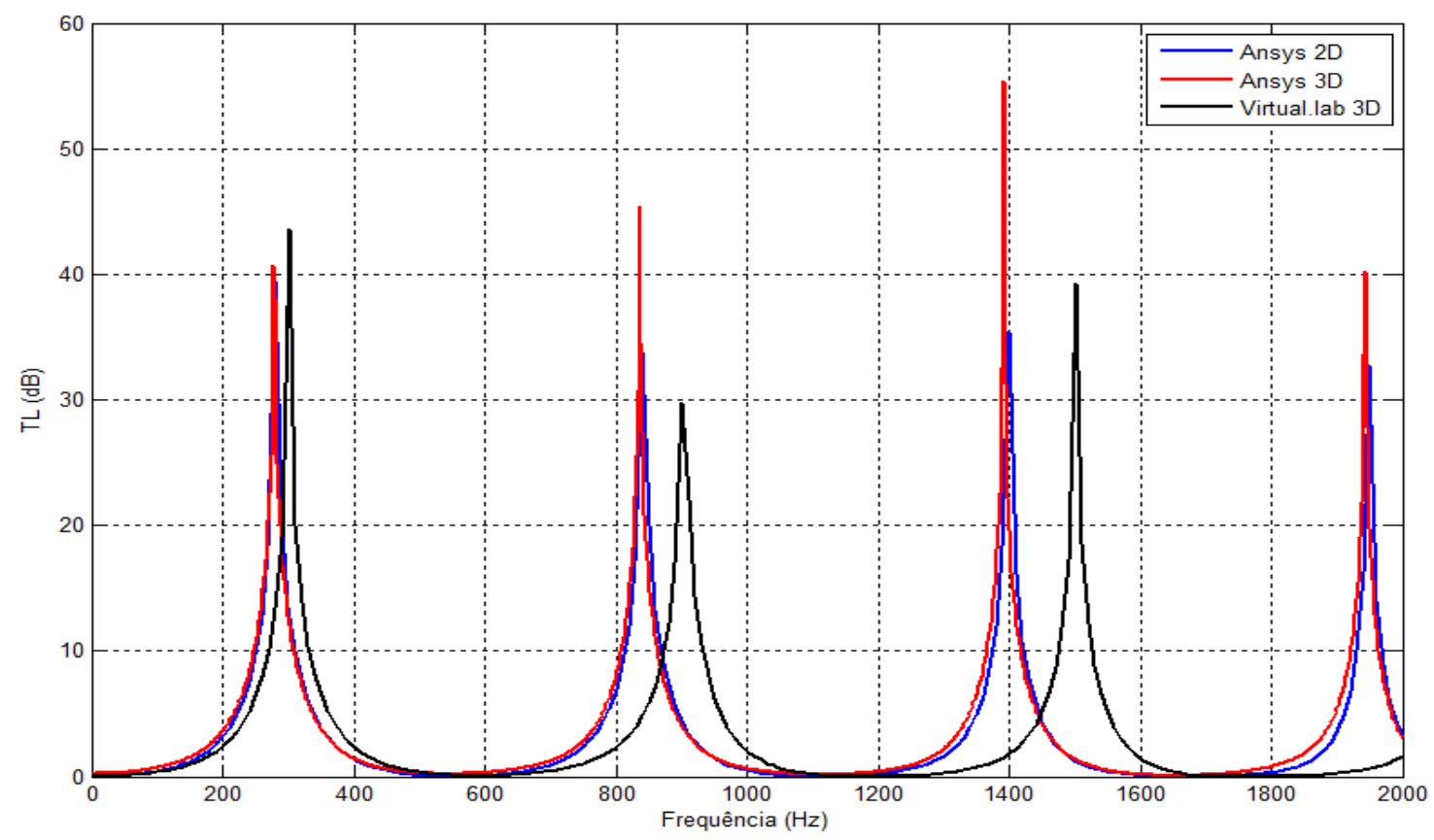

Figura 42 - TL do modelo I pelo método de elementos finitos

Tabela 17 - Valores de frequência de ressonância e amplitude obtidos com o MEF

\begin{tabular}{c|c|c|c|c|cc}
\cline { 2 - 7 } & \multicolumn{2}{c}{ Ansys 2D } & \multicolumn{2}{c|}{ Ansys 3D } & \multicolumn{2}{c}{ Virtual.lab 3D } \\
\hline $\mathbf{n}$ & Frequência & Amplitude & Frequência & Amplitude & Frequência & Amplitude \\
\hline $\mathbf{1}$ & $280 \mathrm{~Hz}$ & $39,54 \mathrm{~dB}$ & $278 \mathrm{~Hz}$ & $40,70 \mathrm{~dB}$ & $301 \mathrm{~Hz}$ & $43,56 \mathrm{~dB}$ \\
\hline $\mathbf{2}$ & $840 \mathrm{~Hz}$ & $33,83 \mathrm{~dB}$ & $836 \mathrm{~Hz}$ & $45,44 \mathrm{~dB}$ & $901 \mathrm{~Hz}$ & $29,71 \mathrm{~dB}$ \\
\hline $\mathbf{3}$ & $1400 \mathrm{~Hz}$ & $35,36 \mathrm{~dB}$ & $1392 \mathrm{~Hz}$ & $55,41 \mathrm{~dB}$ & $1501 \mathrm{~Hz}$ & $39,28 \mathrm{~dB}$ \\
\hline $\mathbf{4}$ & $1950 \mathrm{~Hz}$ & $32,79 \mathrm{~dB}$ & $1944 \mathrm{~Hz}$ & $40,21 \mathrm{~dB}$ & - & -
\end{tabular}


Ao comparar as duas curvas de TL estimadas no Ansys ${ }^{\circledR}$, nota-se que existe boa aproximação entre os valores de frequência e que os valores de amplitude do modelo 2D são subestimados em relação ao 3D. Considera-se a concordância satisfatória, em vista da grande redução do tempo computacional alcançada ao utilizar o modelo bidimensional. Já a curva estimada pelo Virtual.lab ${ }^{\circledR}$ apresenta as frequências de ressonância deslocadas para direita.

Quando os resultados das simulações 3D são comparados com os resultados 1D obtidos pelo MMT, a curva com fator de correção proposto por $\mathrm{Ji}$ apresenta boa aproximação com a curva obtida no Ansys ${ }^{\circledR}$, conforme pode ser visto na Figura 43. Nota-se boa concordância em frequência e que as amplitudes estimadas pelo MMT são superestimadas em relação ao MEF.

Por outro lado, na Figura 44 verifica-se que nenhum dos resultados obtidos pelo MMT se aproxima em amplitude ou em frequência daquele obtido no Virtual.lab ${ }^{\circledR}$.

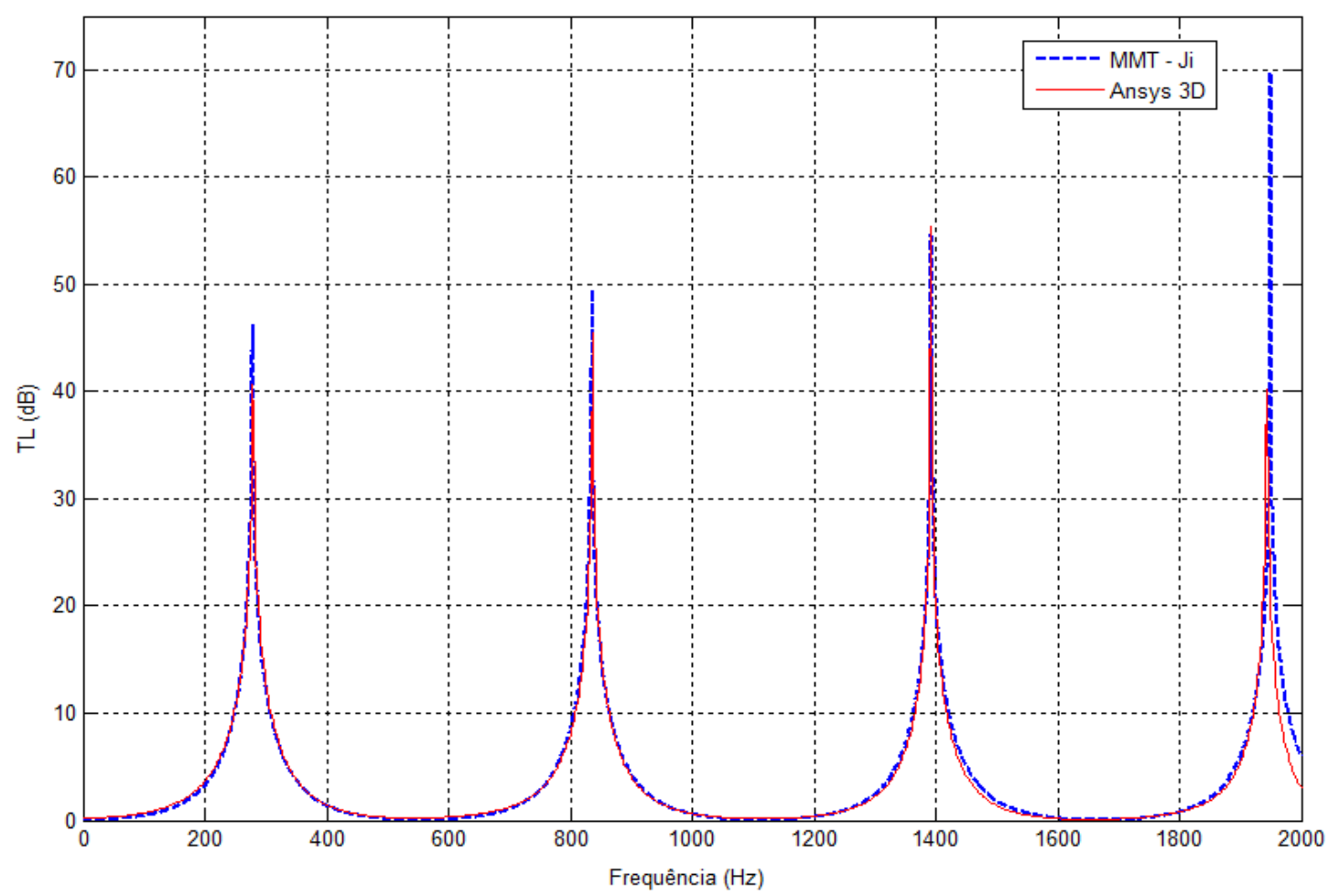

Figura 43 - Comparação da TL do modelo I obtida pelo MMT com fator de correção de Ji e obtida pelo MEF no Ansys ${ }^{\circledR}$ 


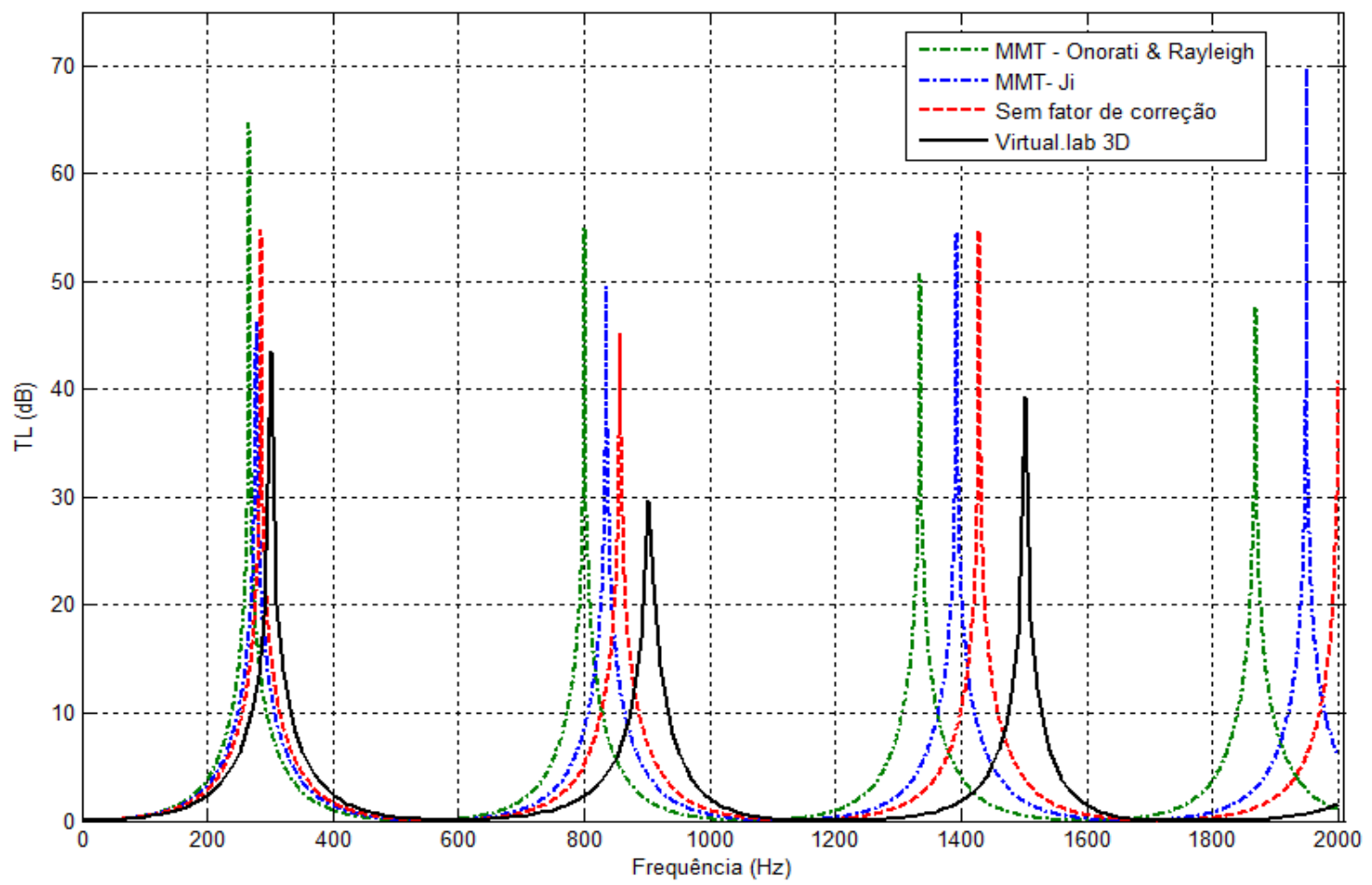

Figura 44 - Comparação da TL do modelo I obtida pelo MMT e obtida pelo MEF no Virtual.lab ${ }^{\circledR}$

\subsubsection{Modelo II}

A Figura 45 mostra as malhas do modelo II utilizadas no Ansys $^{\circledR}$, e a Figura 46 mostra as malhas utilizadas no Virtual.lab ${ }^{\circledR}$. Foi realizada a análise harmônica da câmara de na faixa de frequência de 0 a $1500 \mathrm{~Hz}$.

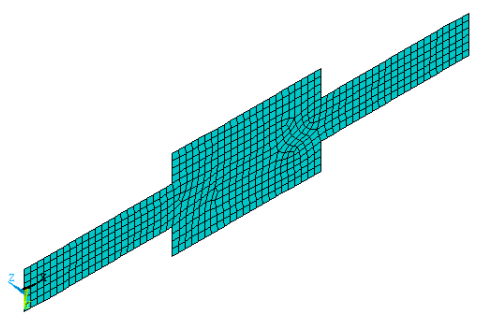

(a)

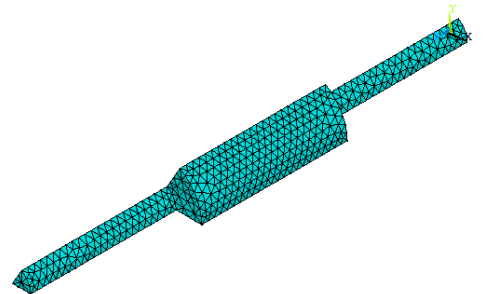

(b)

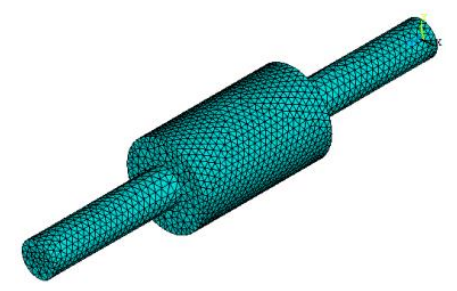

(c)

Figura 45- Malha em elementos finitos do modelo II no Ansys ${ }^{\circledR}$ nas análises (a) 2D (b) 3D fracionada e (c) 3D 


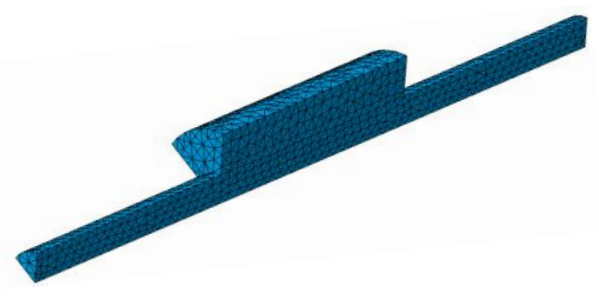

(a)

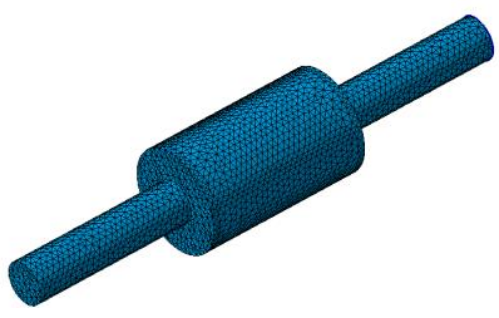

(b)

Figura 46 - Malha em elementos finitos do modelo II utilizadas no Virtual.lab ${ }^{\circledR}$ nas análises (a) 3D fracionada e (b) 3D

A Tabela 18 mostra o número de nós e elementos de cada malha e também o tempo gasto em cada simulação. É possível observar que para um mesmo modelo, o tempo de simulação no Virtual.lab ${ }^{\circledR}$ é expressivamente reduzido em relação a simulação no Ansys ${ }^{\circledR}$.

Tabela 18 - Propriedades das malhas em elementos finitos e tempo de processamento para o modelo II

\begin{tabular}{ccccccc} 
& 2D & \multicolumn{2}{c|}{ 3D fracionado } & \multicolumn{2}{c}{ 3D } \\
\cline { 2 - 6 } & Ansys $^{\circledR}$ & Ansys $^{\circledR}$ & Virtual.lab $^{(}$ & Ansys $^{\circledR}$ & Virtual.lab $\left.^{(}\right)$ \\
\hline Elementos & 599 & 5598 & 5151 & 37454 & 40963 \\
\hline Nós & 683 & 1510 & 11518 & 7425 & 7635 \\
\hline Tempo & $19 \mathrm{~s}$ & 01 min30s & $6 \mathrm{~s}$ & 51 min08s & 04min06s \\
\hline
\end{tabular}

A Figura 47 mostra as curvas de TL geradas a partir das simulações no Ansys $^{\circledR}$. Entre as curvas do modelo 3D completo e 3D fracionado nota-se uma pequena diferença na amplitude do primeiro domo, considerada pouco expressiva, principalmente quando se considera que tempo computacional alcançada ao utilizar o modelo fracionado foi cerca de trinta vezes menor. Já o resultado obtido com a análise 2D apresenta a amplitude muito reduzida em relação as análises 3D, ainda que a curva apresente semelhança na forma e nas frequências de máximo e mínimo. 


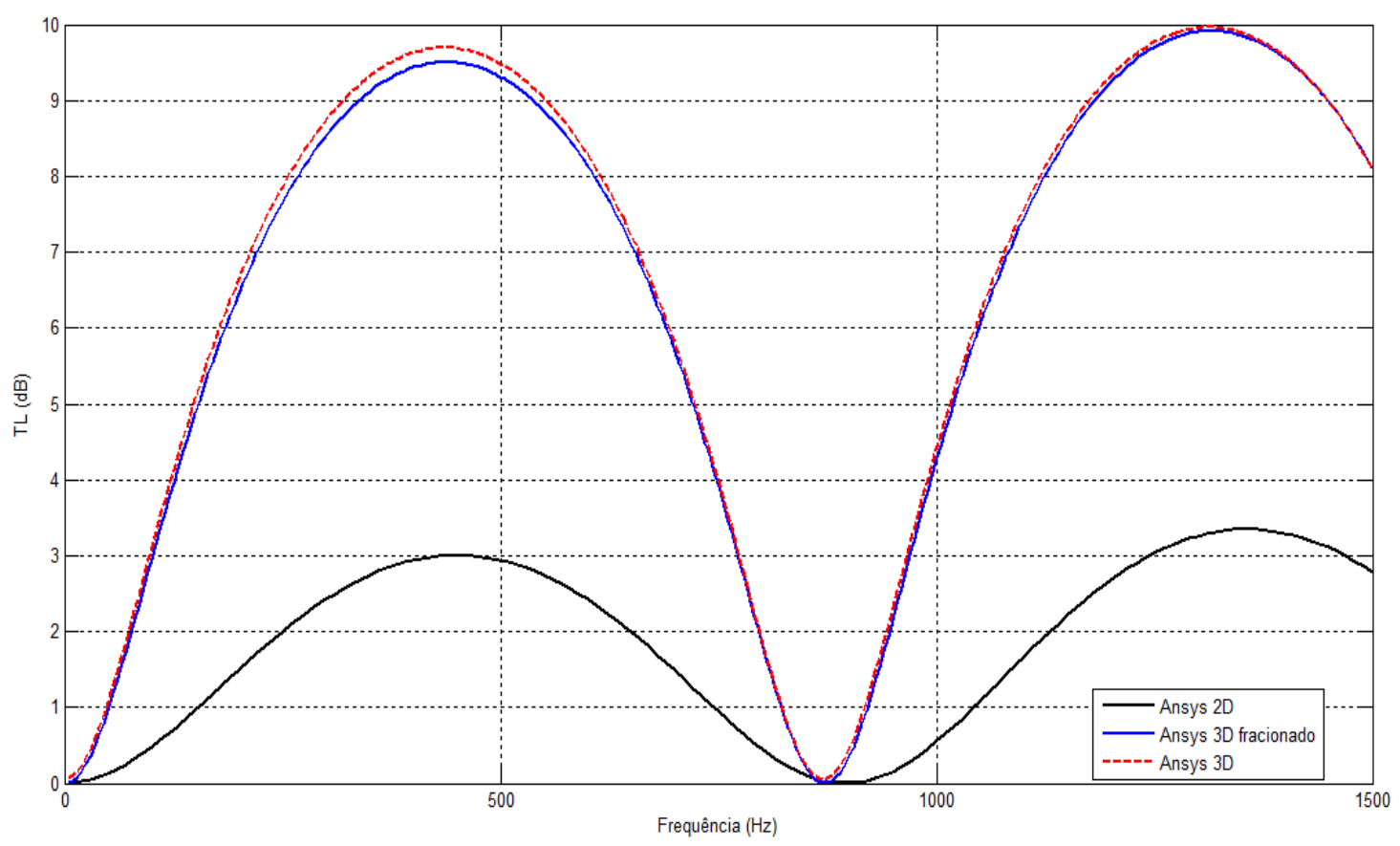

Figura 47 - TL do modelo II obtida pelo MEF no Ansys ${ }^{\circledR}$

A Figura 48 compara as curvas de TL geradas a partir das simulações no Virtual.lab ${ }^{\circledR}$. Os resultados apresentam boa aproximação até $1050 \mathrm{~Hz}$, quando a amplitude do modelo fracionado passa a ser maior que a estimada pelo modelo completo. O tempo de simulação do modelo fracionado foi aproximadamente 2 vezes menor que o do modelo 3D.

Na Figura 49 é possível comparar os resultados das simulações 3D do Ansys $^{\circledR}$ e Virtual.lab ${ }^{\circledR}$. Observa-se boa aproximação até $1050 \mathrm{~Hz}$, quando a amplitude da curva obtida com Ansys ${ }^{\circledR}$ passa a ser maior que a estimada pelo modelo do Virtual.lab ${ }^{\circledR}$. Quando ambas são comparadas com os resultados 1D obtidos pelo MMT, a curva com fator de correção proposto por Davies é a que apresenta melhor aproximação, principalmente em relação a curva obtida com Virtual.lab ${ }^{\circledR}$. 


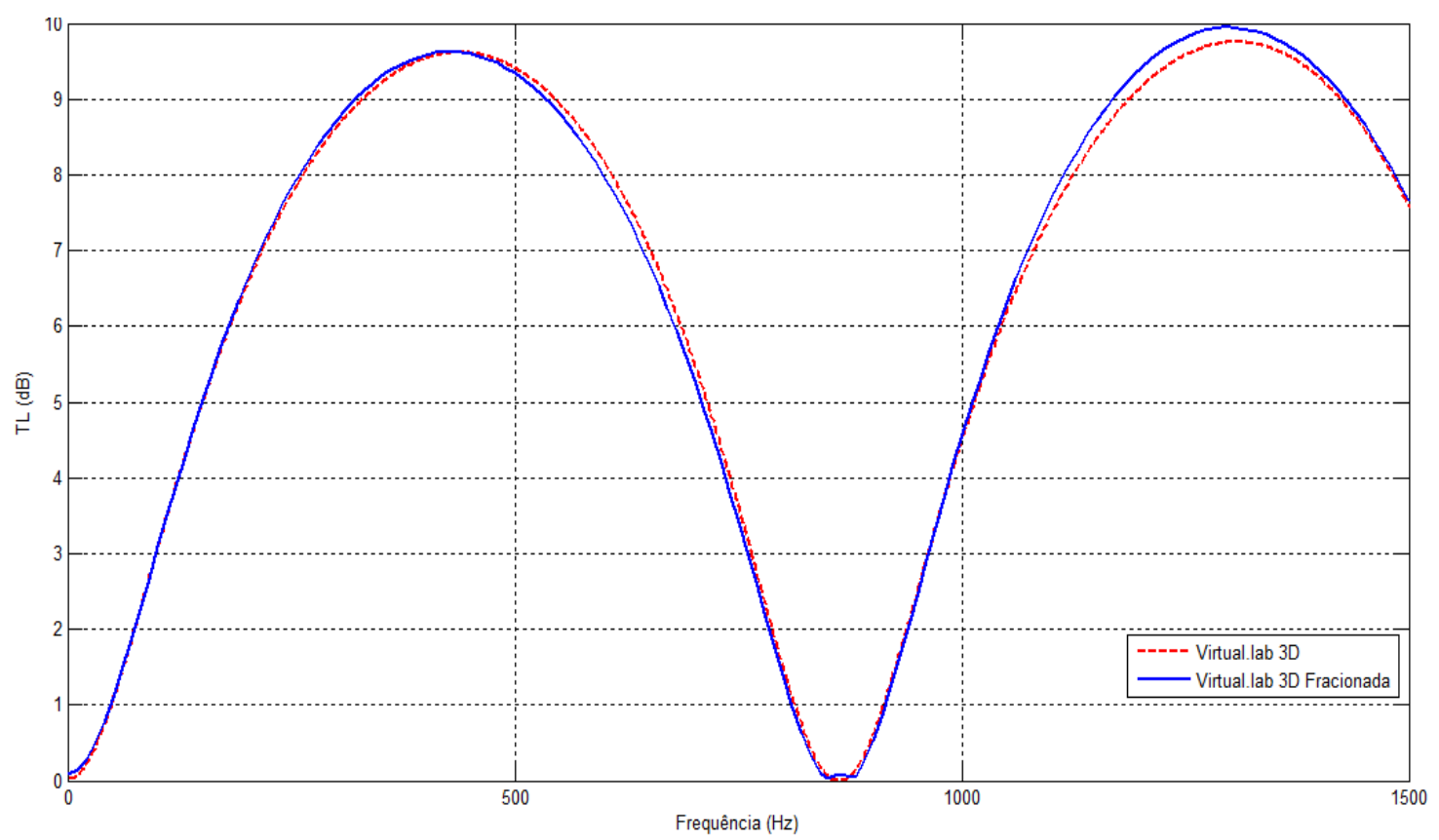

Figura 48 - TL do modelo II obtida pelo MEF no Virtual.lab ${ }^{\circledR}$

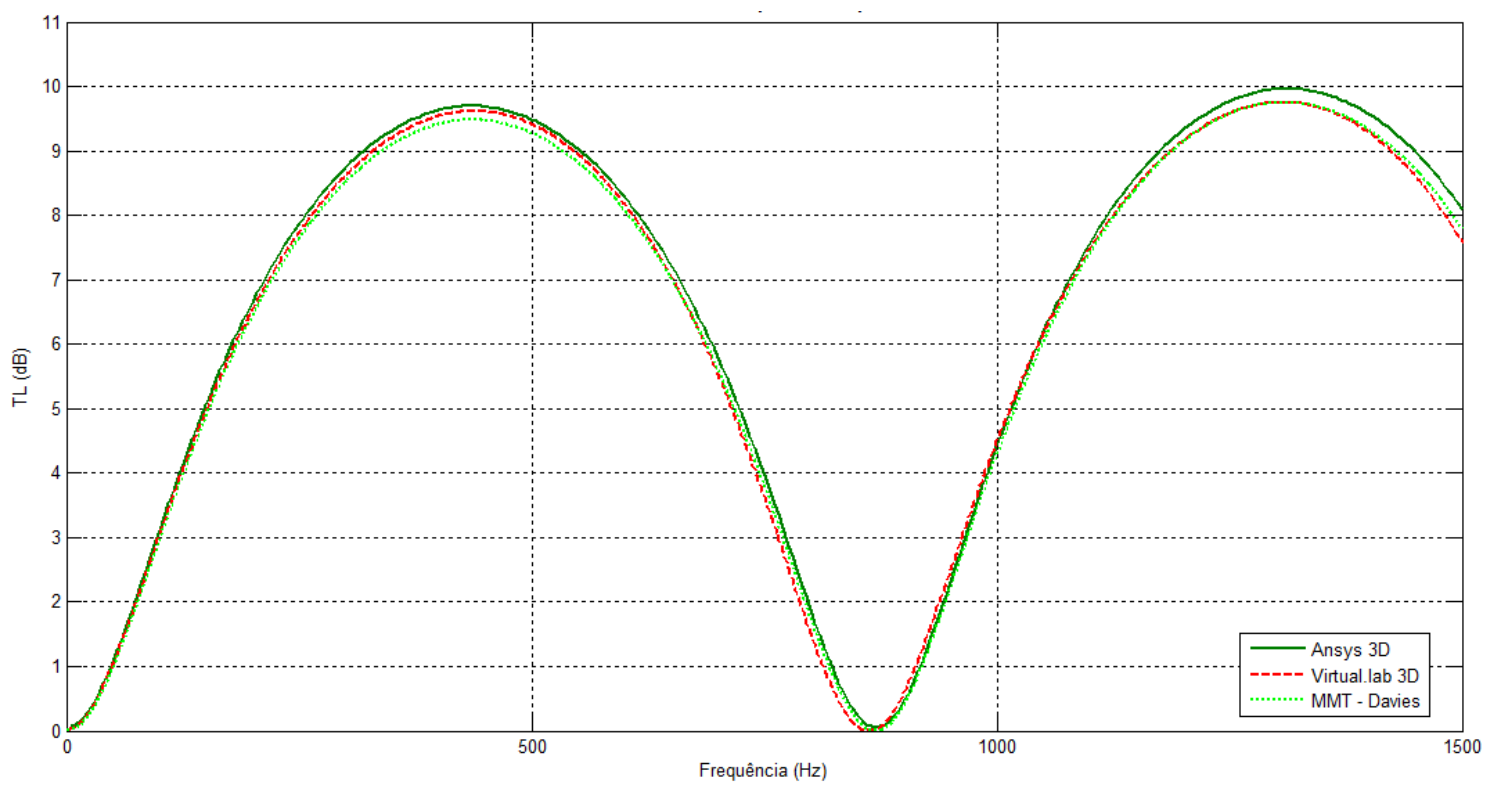

Figura 49 - Comparação da TL do modelo Il obtida pelo MMT com fator de correção de Davies e obtida pelo MEF

\subsubsection{Modelo III}

A Figura 50 mostra as malhas do modelo III utilizadas no Ansys ${ }^{\circledR}$, e a Figura 51 mostra as malhas utilizadas no Virtual.lab ${ }^{\circledR}$. Foi realizada a análise harmônica da câmara de na faixa de frequência de 0 a $2500 \mathrm{~Hz}$. 


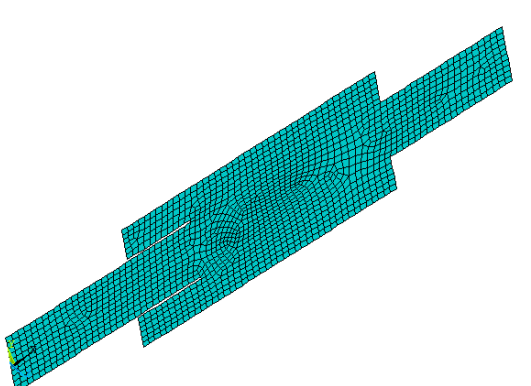

(a)

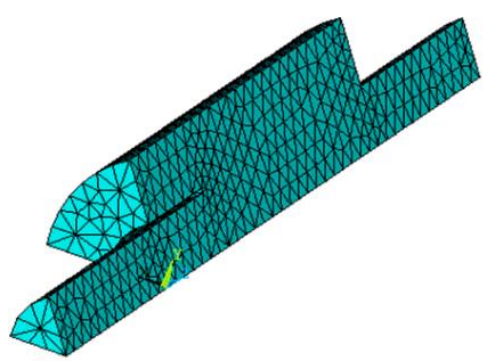

(b)

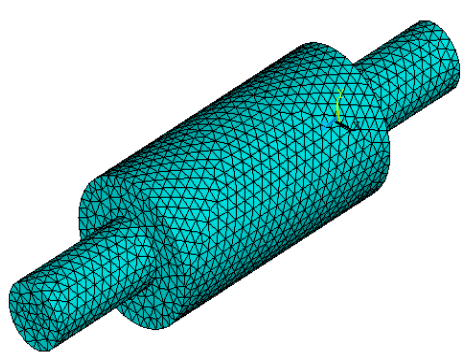

(c)

Figura 50 - Malha em elementos finitos do modelo III utilizadas no Ansys ${ }^{\circledR}$ nas análises (a) 2D (b) 3D fracionada (c) 3D

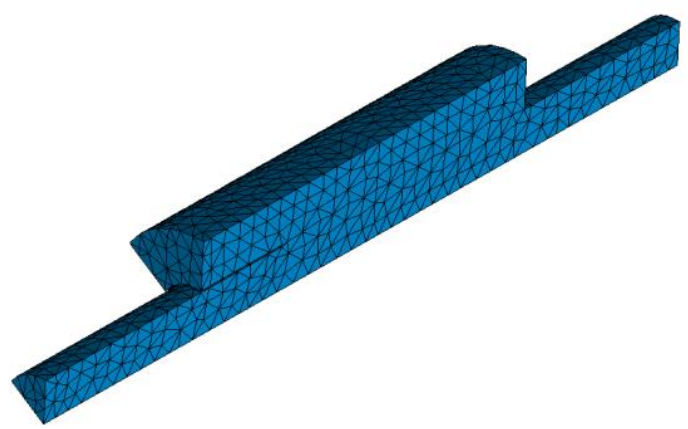

(a)

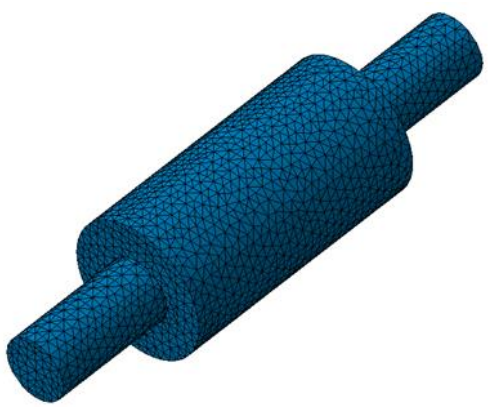

(b)

Figura 51 - Malha em elementos finitos do modelo III utilizadas no Virtual.lab ${ }^{\circledR}$ nas análises (a) 3D fracionada (b) 3D

A Tabela 19 mostra o número de nós e elementos de cada malha e também o tempo gasto em cada simulação. É possível observar que para um mesmo modelo o tempo de simulação no Virtual.lab ${ }^{\circledR}$ é expressivamente reduzido em relação a simulação no Ansys ${ }^{\circledR}$.

Tabela 19 - Propriedades das malhas em elementos finitos e tempo de processamento para o modelo III

\begin{tabular}{ccccccc}
\cline { 2 - 6 } & 2D & \multicolumn{2}{c|}{ 3D fracionado } & \multicolumn{2}{c}{ 3D } \\
\cline { 2 - 6 } & Ansys $^{\circledR}$ & Ansys $^{\circledR}$ & Virtual.lab $^{(}$ & Ansys $^{\circledR}$ & Virtual.lab $\left.^{(}\right)$ \\
\hline Elementos & 1489 & 4679 & 4326 & 32208 & 33863 \\
\hline Nós & 1618 & 1274 & 1221 & 6479 & 7635 \\
\hline Tempo & 02min09s & $13 \min 26 \mathrm{~s}$ & $31 \mathrm{~s}$ & $01 \mathrm{~h} 47 \mathrm{~min} 04 \mathrm{~s}$ & 05min37s \\
\hline
\end{tabular}

Nota-se que, durante a modelagem, foi representada a espessura do duto estendido, que não é ocupada pelo meio acústico no interior da câmara de 
expansão, como mostra a Figura 52. Foi adotado o valor de $2 \mathrm{~mm}$ de espessura.

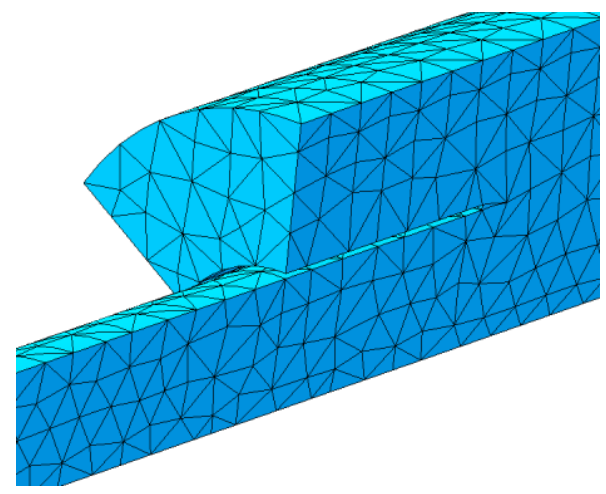

Figura 52 - Detalhe da malha para representar o duto estendido

A Figura 53 mostra as curvas de TL geradas a partir das simulações no Ansys $^{\circledR}$ e a Tabela 20 registra os valores de frequência e amplitude em que ocorre a máxima atenuação.

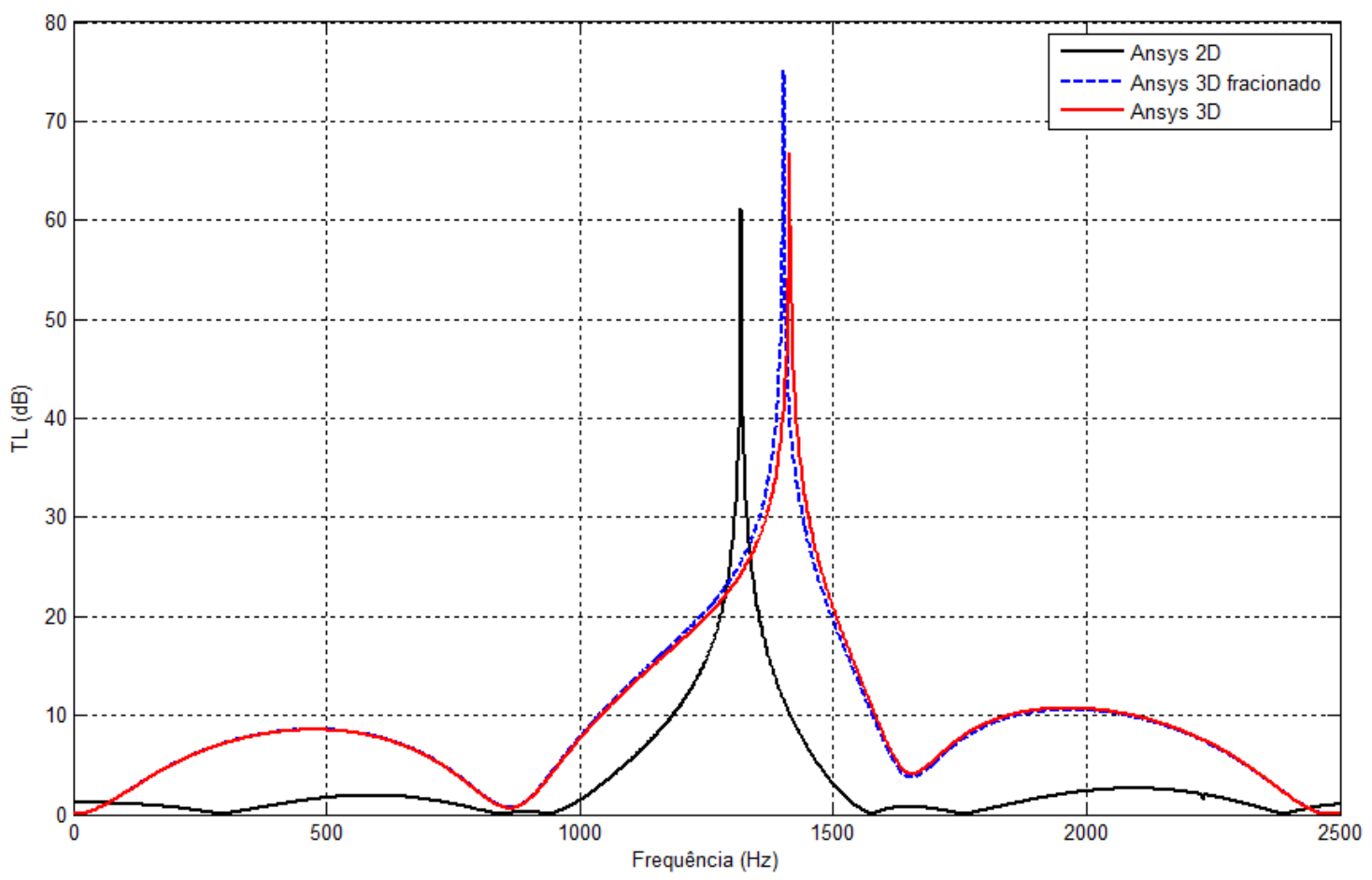

Figura 53 - TL do modelo III obtida pelo MEF no Ansys ${ }^{\circledR}$ 
Tabela 20 - Valores de frequência e amplitude dos picos de atenuação do modelo III obtido pelo MEF no Ansys ${ }^{\circledR}$

\begin{tabular}{ccc}
\hline Modelo & Frequência & Amplitude \\
\hline Ansys 2D & $1318 \mathrm{~Hz}$ & $61,09 \mathrm{~dB}$ \\
\hline Ansys 3D fracionado & $1402 \mathrm{~Hz}$ & $75,04 \mathrm{~dB}$ \\
\hline Ansys 3D & $1414 \mathrm{~Hz}$ & $66,71 \mathrm{~dB}$ \\
\hline
\end{tabular}

Entre as curvas do modelo 3D completo e 3D fracionado nota-se boa concordância, com pequena diferença na frequência e na amplitude no pico de máxima atenuação. Porém considera-se o resultado do modelo fracionado satisfatório, visto que ocorreu uma redução de aproximadamente seis vezes no tempo de processamento.

O resultado obtido com a análise $2 \mathrm{D}$, embora exiba o formato típico do modelo III, apresenta redução expressiva na amplitude dos domos e também na frequência em que ocorre a máxima TL.

Ao comparar a curva do modelo $3 \mathrm{D}$ com os resultados obtidos pelo MMT, a curva com o fator de correção proposto por Davies apresentou boa concordância, principalmente em frequência (Figura 54).

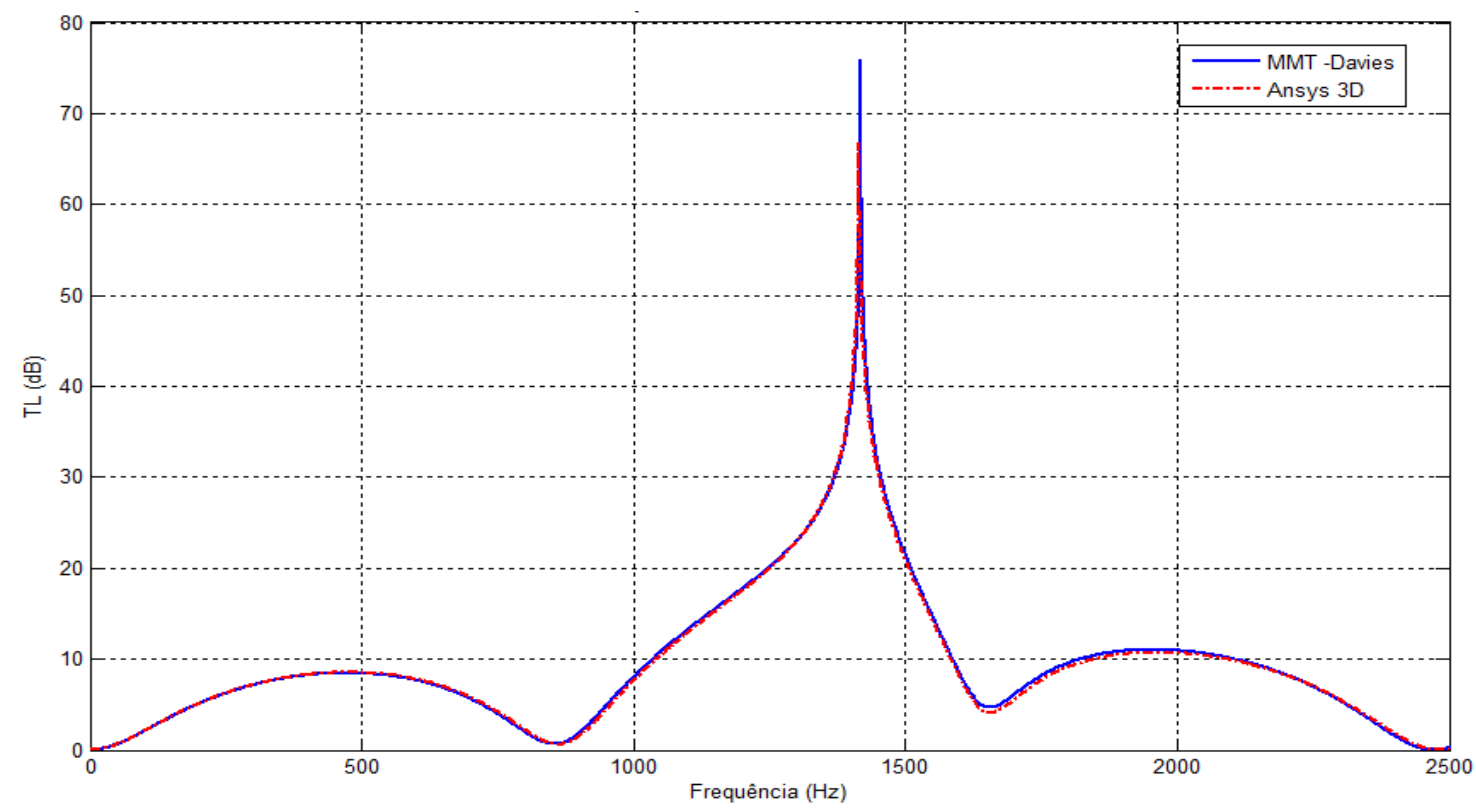

Figura 54 - Comparação entre a TL do modelo II obtida pelo MMT com fator de correção de Davies com MEF no Ansys ${ }^{\circledR}$ modelo 3D 
A Figura 55 compara os resultados obtidos no Virtual.lab ${ }^{\circledR}$ e a Tabela 21 registra os valores de frequência e amplitude em que ocorre a máxima atenuação. Verifica-se que as curvas apresentam o mesmo comportamento, embora a curva do modelo 3D fracionado apresente o pico de máxima atenuação deslocado para direita e em menor amplitude.

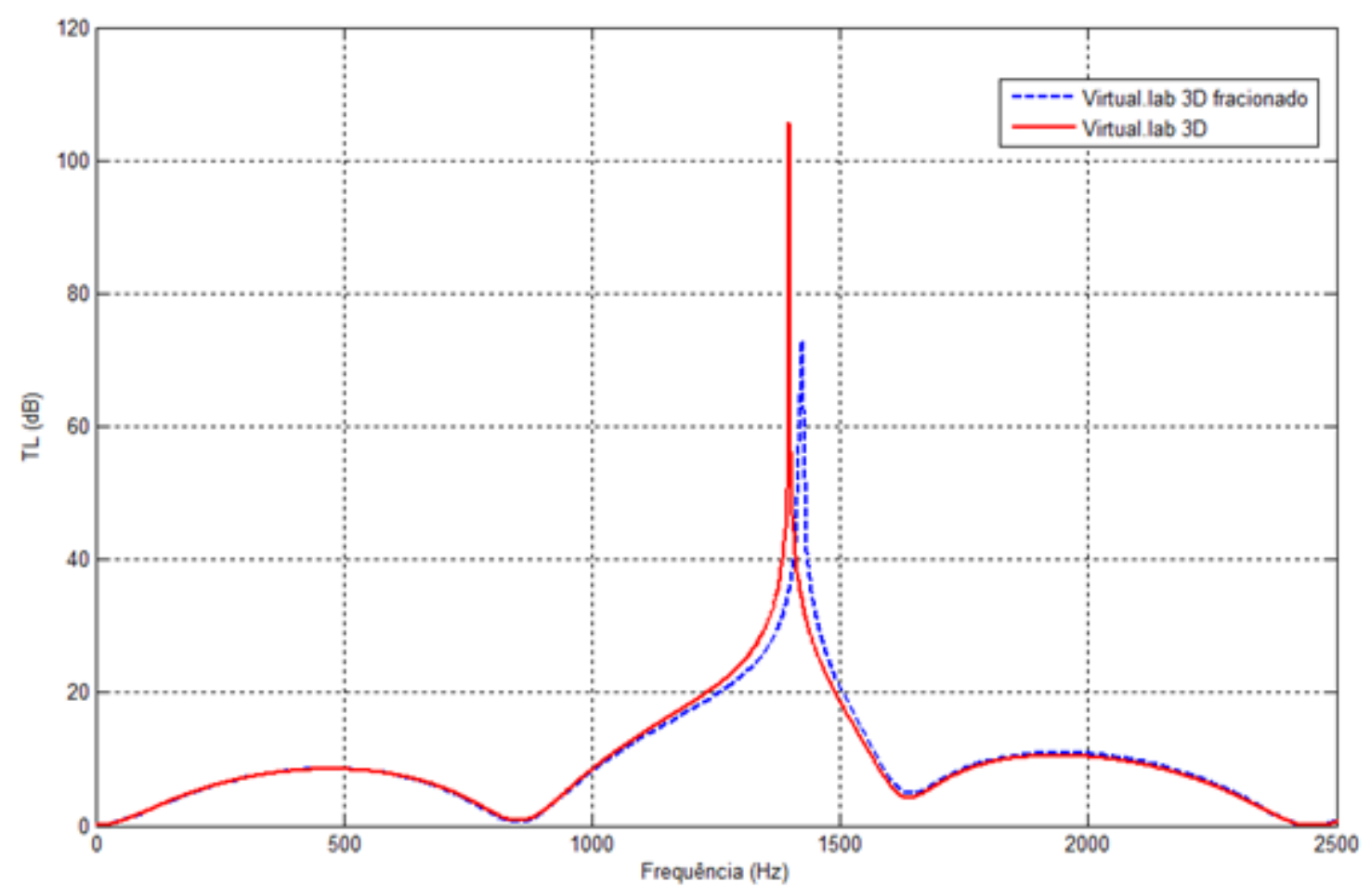

Figura 55 - TL do modelo III obtida pelo Virtual.lab ${ }^{\circledR}$

Tabela 21 - Valores de frequência e amplitude dos picos de atenuação obtidos para o modelo III pelo MEF no Virtual.lab ${ }^{\circledR}$

\begin{tabular}{ccc}
\hline Modelo & Frequência & Amplitude \\
\hline Virtual.lab 3D fracionado & $1421 \mathrm{~Hz}$ & $72,98 \mathrm{~dB}$ \\
\hline Virtual.lab 3D & $1398 \mathrm{~Hz}$ & $105,7 \mathrm{~dB}$ \\
\hline
\end{tabular}

Ao comparar o resultado do modelo 3D com os resultados $1 \mathrm{D}$ obtidos pelo MMT, Figura 56, observa-se que a frequência e amplitude de máxima atenuação obtida pelo Virtual.lab ${ }^{\circledR}$ não foi alcançado com exatidão por nenhum dos fatores de correção adotados. Por outro lado, a curva com fator de correção de Davies revelou concordância significativa com o modelo 3D fracionado (Figura 57). 


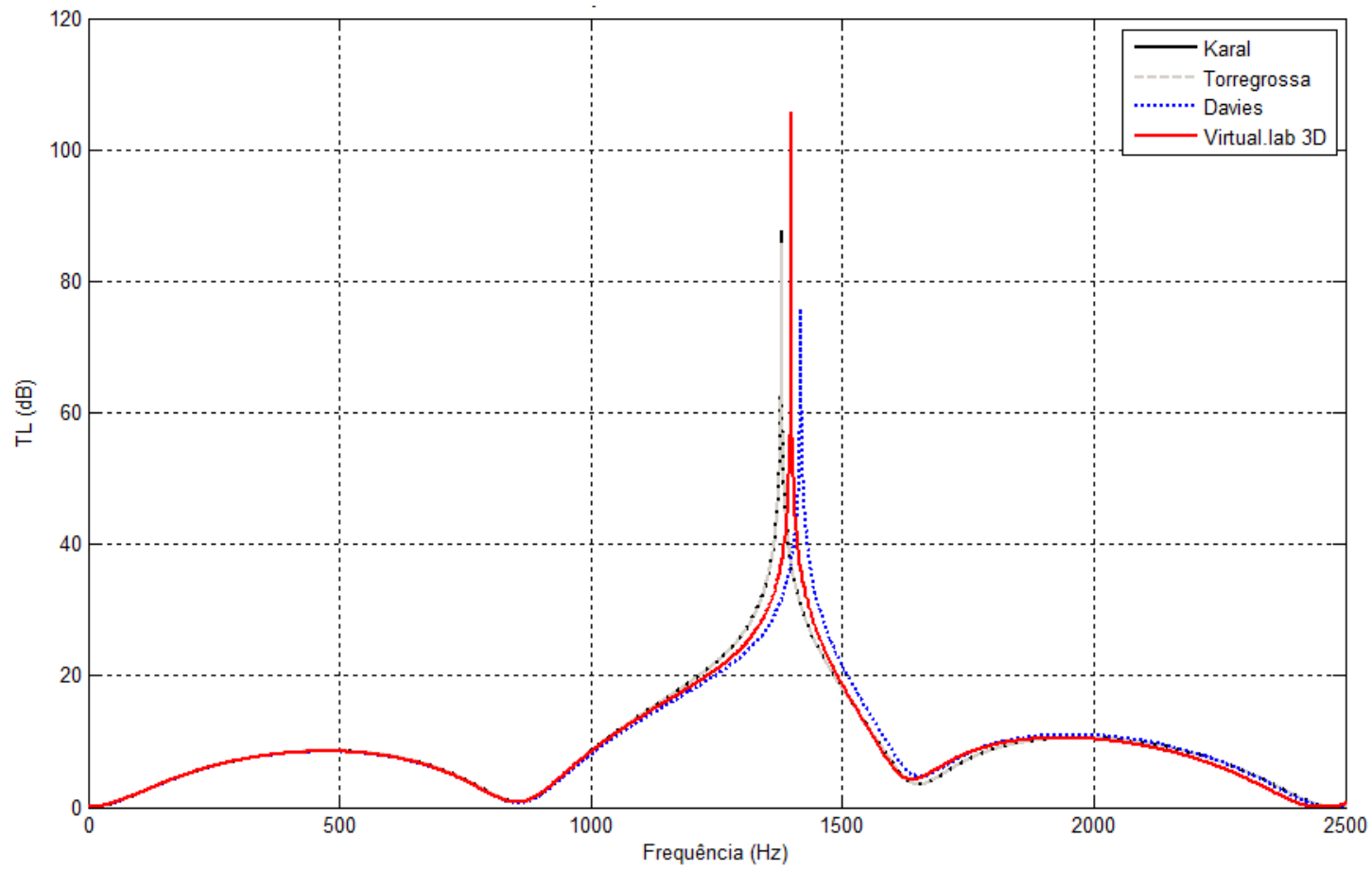

Figura 56 - Comparação das TL do modelo III obtidas pelo MMT e pelo MEF no Virtual.lab ${ }^{\circledR}$ com modelo 3D

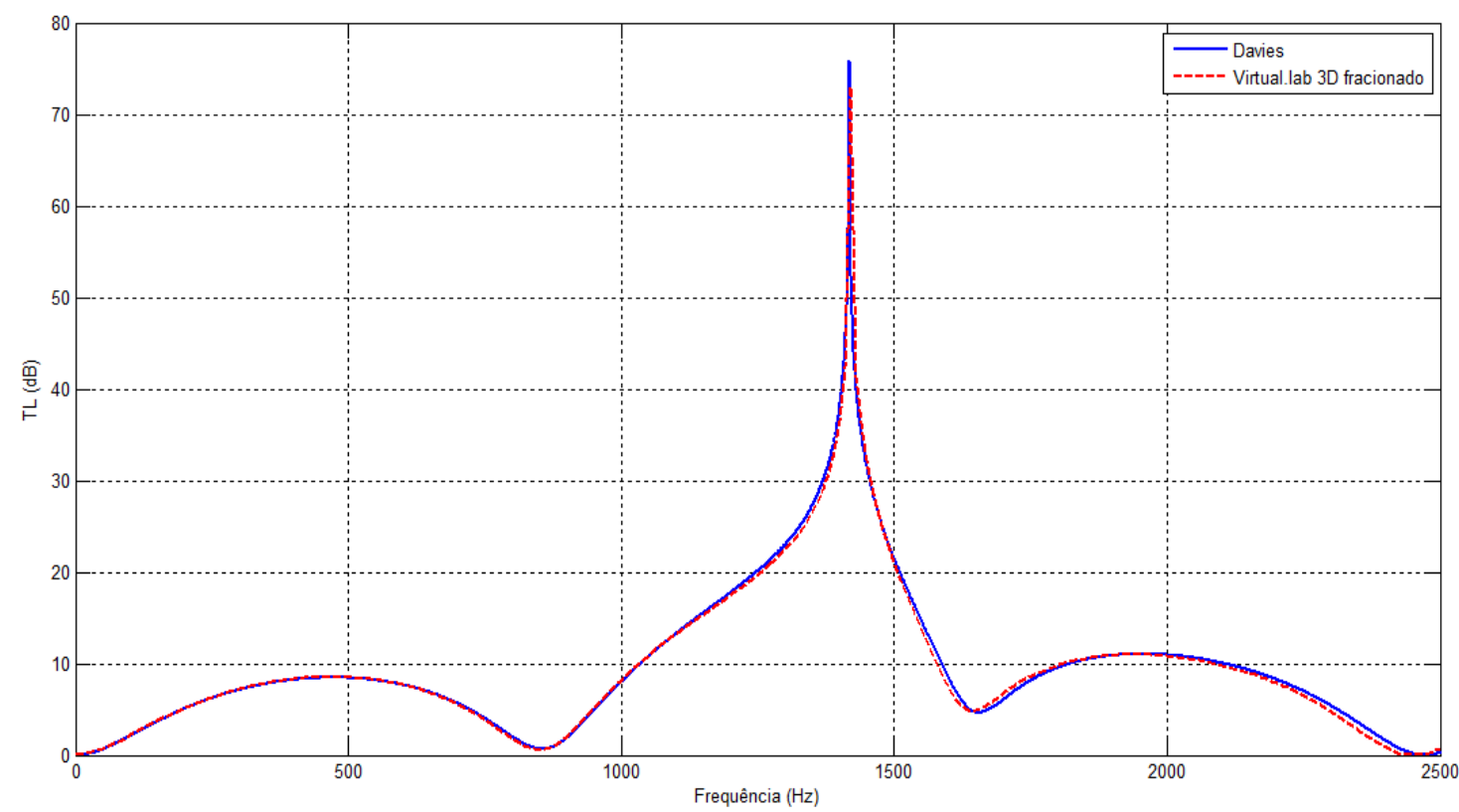

Figura 57 - Comparação das TL do modelo III obtidas pelo MMT e pelo MEF no Virtual.lab ${ }^{\circledR}$ com modelo 3D fracionado 


\subsubsection{Modelo IV}

A Figura 58Figura 50 mostra as malhas do modelo IV utilizadas no Ansys $^{\circledR}$, e a Figura 59 mostra as malhas utilizadas no Virtual.lab ${ }^{\circledR}$. Foi realizada a análise harmônica da câmara de na faixa de frequência de 0 a $1300 \mathrm{~Hz}$.

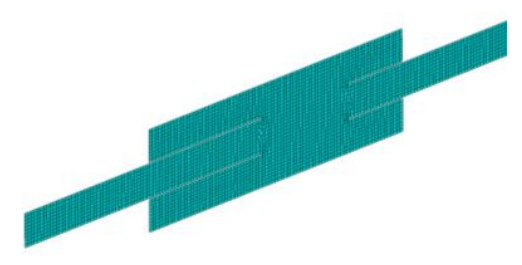

(a)

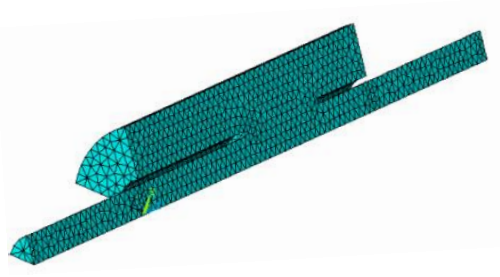

(b)

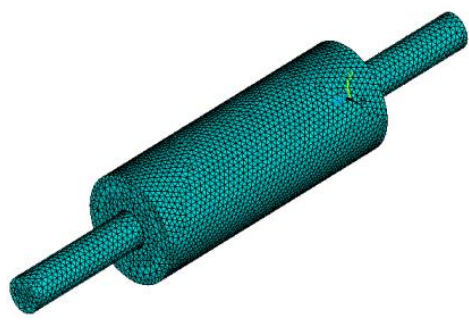

(c)

Figura 58 - Malha em elementos finitos do modelo IV utilizados no Ansys ${ }^{\circledR}$ nas análises (a) 2D (b) 3D fracionada e (c) 3D

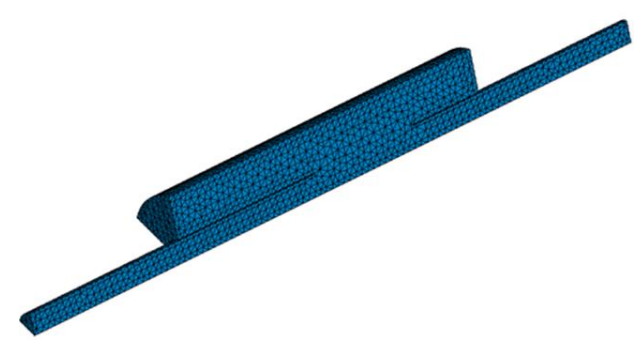

(a)

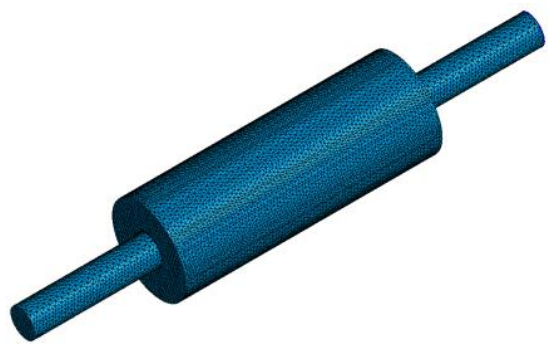

(b)

Figura 59 - Malha em elementos finitos do modelo IV utilizados no Virtual.lab ${ }^{\circledR}$ nas análises (a) 2D (b) 3D fracionada e (c) 3D

A Tabela 22 mostra o número de nós e elementos de cada malha e também o tempo gasto em cada simulação.

Tabela 22 - Propriedades das malhas em elementos finitos e tempo de processamento do modelo IV

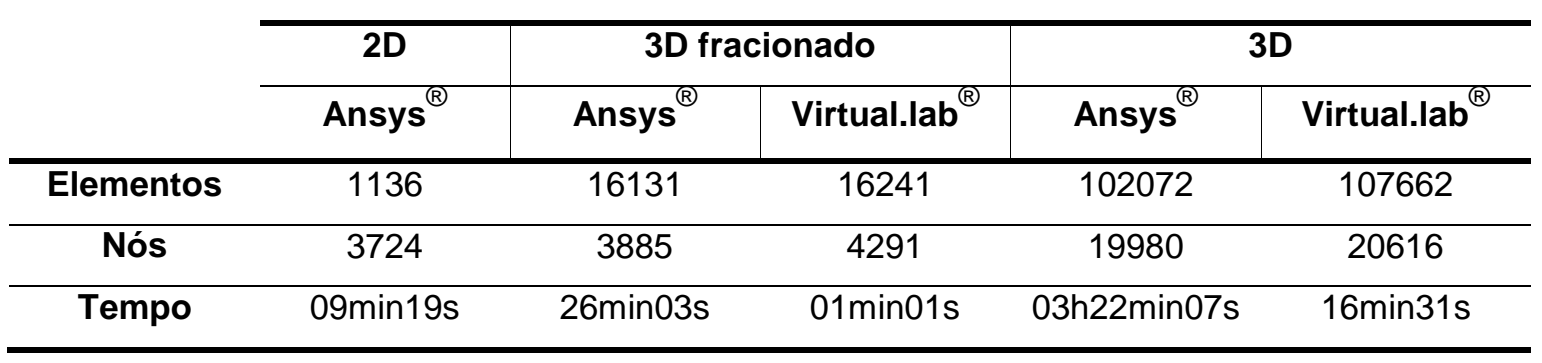


É possível observar que para um mesmo modelo o tempo de simulação no Virtual.lab ${ }^{\circledR}$ é expressivamente reduzido em relação a simulação no Ansys ${ }^{\circledR}$.

Ressalta-se que, durante a modelagem, foram representadas as espessuras dos dutos estendidos, que não são ocupadas pelo meio acústico no interior da câmara de expansão, como pode ser visto na Figura 60. Neste trabalho foi adotado o valor de $2 \mathrm{~mm}$ de espessura.

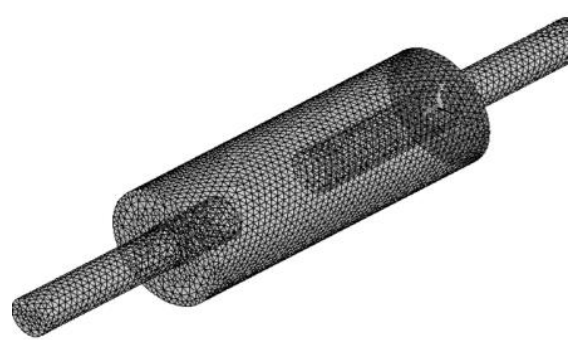

(a)

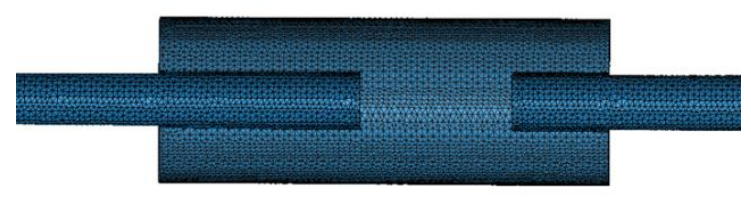

(b)

Figura 60 - Malha 3D do modelo IV: (a) Contorno da malha utilizada no Ansys ${ }^{\circledR}$ e (b) vista em corte da malha utilizada no Virtual.lab ${ }^{\circledR}$

A Figura 61 mostra as curvas de TL geradas a partir das simulações no Ansys ${ }^{\circledR}$ e a Tabela 23 registra os valores de frequência e amplitude em que ocorrem picos de atenuação sonora.

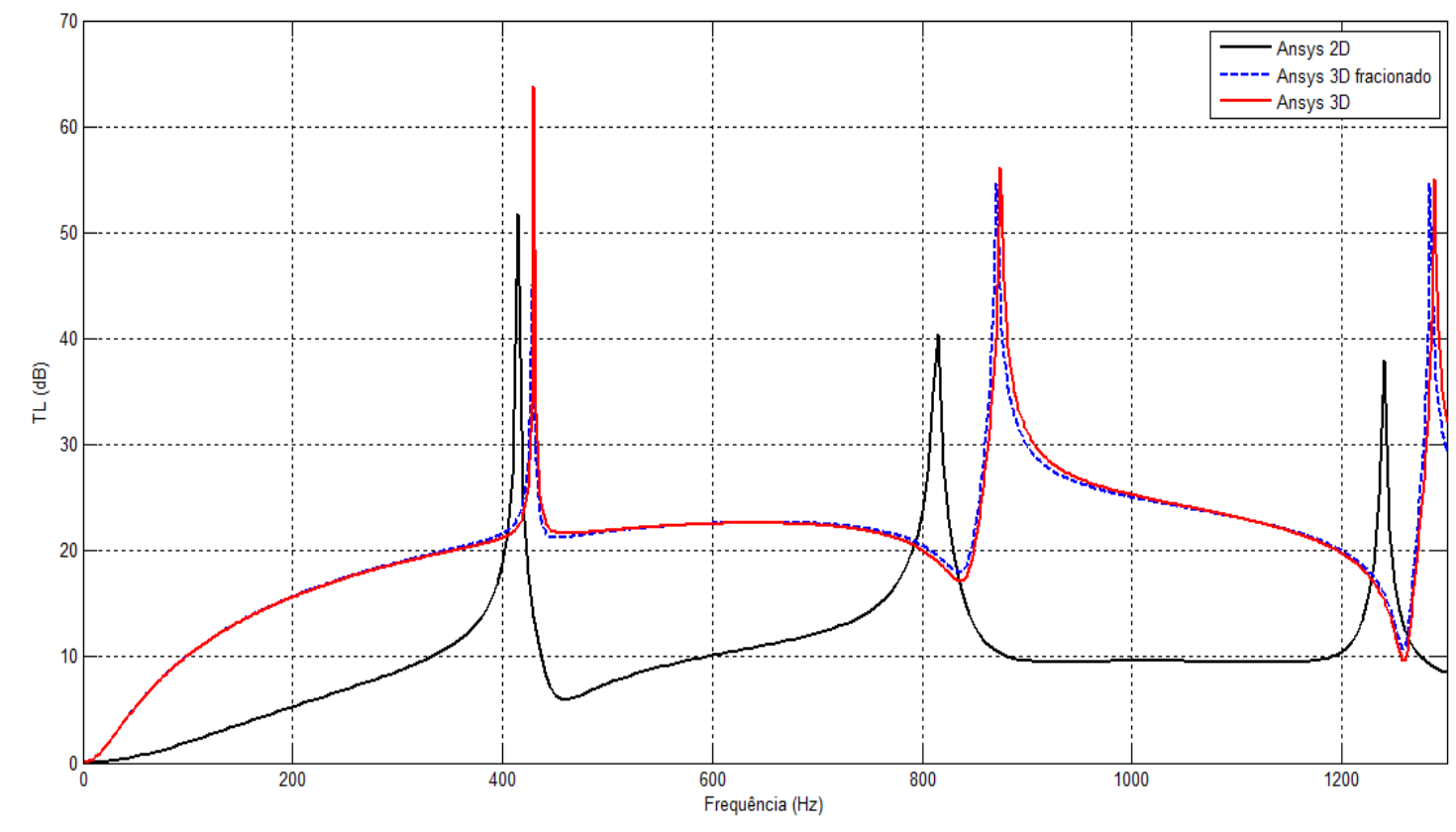

Figura 61 - TL do modelo IV obtido por MEF no Ansys ${ }^{\circledR}$ 
Tabela 23 - Valores de frequência e amplitude dos picos de atenuação obtidos para o modelo IV pelo MEF no Ansys ${ }^{\circledR}$

\begin{tabular}{c|c|c|c|c|cc}
\cline { 2 - 6 } & \multicolumn{2}{c|}{ 1 } & \multicolumn{2}{c}{ 2 } & \multicolumn{2}{c}{} \\
\hline Modelo & Frequência & Amplitude & Frequência & Amplitude & Frequência & Amplitude \\
\hline Ansys 2D & $415 \mathrm{~Hz}$ & $51,78 \mathrm{~dB}$ & $815 \mathrm{~Hz}$ & $40,39 \mathrm{~dB}$ & $1240 \mathrm{~Hz}$ & $37,98 \mathrm{~dB}$ \\
\hline $\begin{array}{c}\text { Ansys 3D } \\
\text { fracionado }\end{array}$ & $428 \mathrm{~Hz}$ & $45,09 \mathrm{~dB}$ & $870 \mathrm{~Hz}$ & $54,56 \mathrm{~dB}$ & $1284 \mathrm{~Hz}$ & $54,64 \mathrm{~dB}$ \\
\hline Ansys 3D & $430 \mathrm{~Hz}$ & $63,82 \mathrm{~dB}$ & $874 \mathrm{~Hz}$ & $56,17 \mathrm{~dB}$ & $1288 \mathrm{~Hz}$ & $55,04 \mathrm{~dB}$ \\
\hline
\end{tabular}

Entre as curvas do modelo 3D completo e 3D fracionado nota-se boa concordância, com pequena diferença na frequência e na amplitude no pico de máxima atenuação. Porém considera-se o resultado do modelo fracionado satisfatório, visto que ocorreu uma redução de aproximadamente sete vezes no tempo de processamento.

O resultado obtido com a análise $2 \mathrm{D}$, embora exiba o formato semelhante ao da câmara de expansão com dutos estendidos, apresenta redução expressiva na amplitude da curva e também nas frequências em que ocorrem picos de atenuação.

Ao comparar a curva do modelo 3D com os resultados 1D obtidos pelo MMT, a curva com o fator de correção proposto por Davies apresentou concordância satisfatória, como pode ser visto na Figura 62.

A Figura 63 compara os resultados obtidos no Virtual.lab ${ }^{\circledR}$ e a Tabela 24 registra os valores de frequência e amplitude em que ocorrem picos de atenuação sonora. Embora apresente diferenças na amplitude e frequência do pico de atenuação, verifica-se boa concordância entre as curvas, principalmente considerando a redução no tempo de processamento adquirida com o modelo 3D fracionado, de cerca de quinze vezes. 


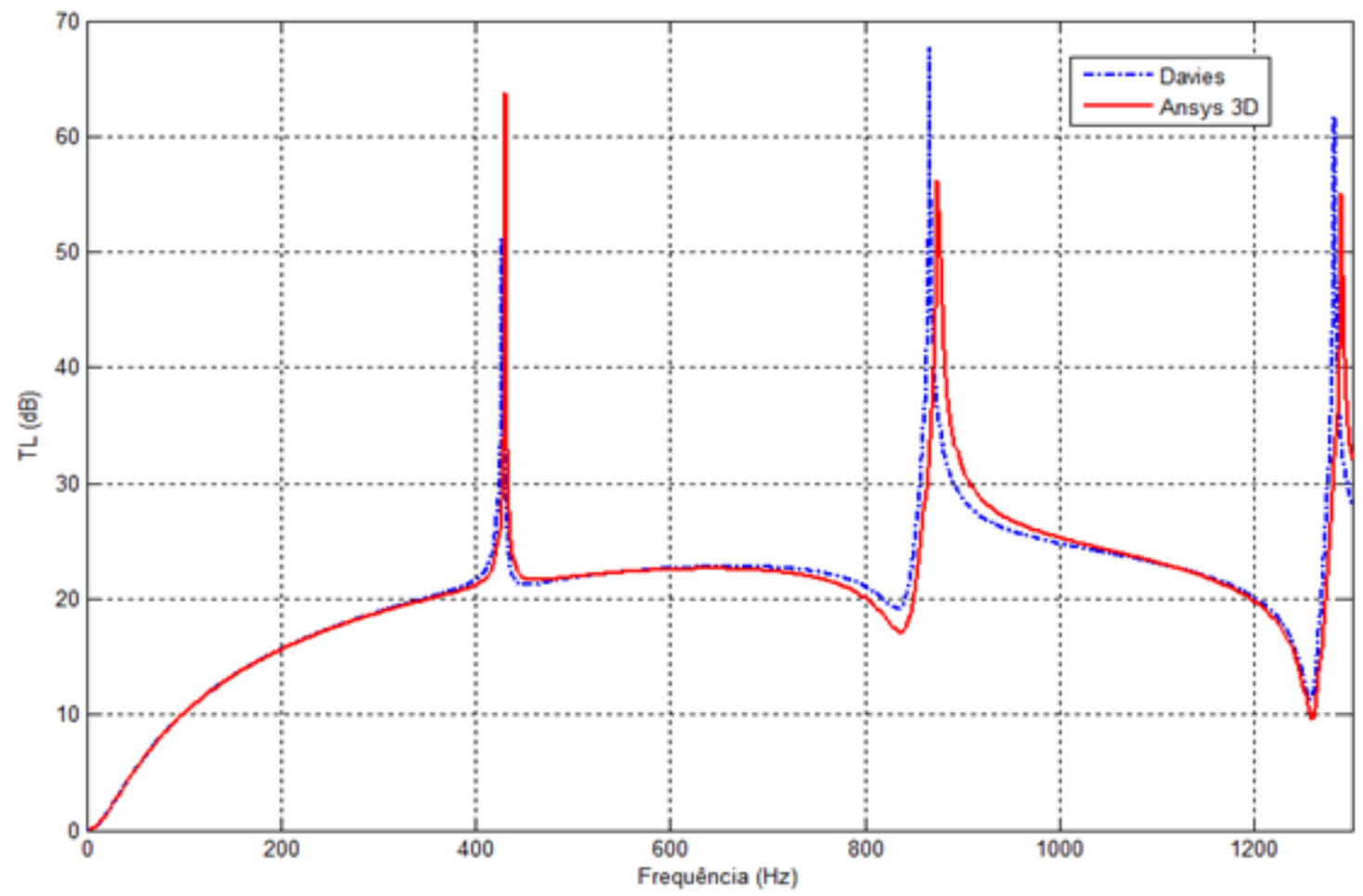

Figura 62 - Comparação entre a TL do modelo III obtida pelo MMT com fator de correção de Davies com MEF no Ansys ${ }^{\circledR}$ modelo 3D

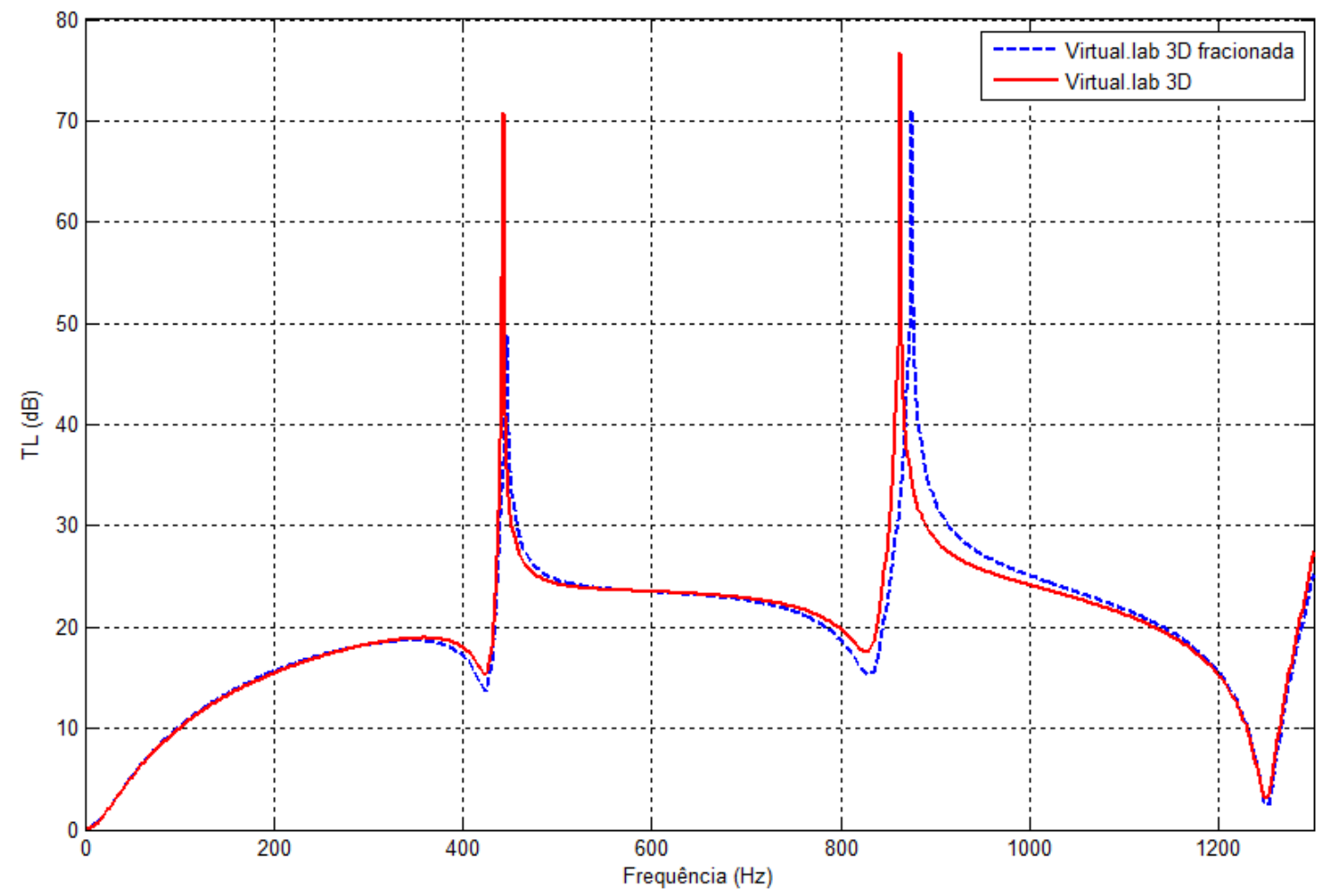

Figura 63 - TL do modelo III obtida por MEF no Virtual.lab ${ }^{\circledR}$ 
Tabela 24 - Valores de frequência e amplitude dos picos de atenuação obtidos para o modelo IV pelo MEF no Virtual.lab

\begin{tabular}{c|c|c|c|c}
\cline { 2 - 5 } & \multicolumn{2}{c}{ 1 } & \multicolumn{2}{c}{$\mathbf{2}$} \\
\hline Modelo & Frequência & Amplitude & Frequência & Amplitude \\
\hline Virtual.lab 3D fracionado & $446 \mathrm{~Hz}$ & $48,79 \mathrm{~dB}$ & $874 \mathrm{~Hz}$ & $71,12 \mathrm{~dB}$ \\
\hline Virtual.lab 3D & $442 \mathrm{~Hz}$ & $70,74 \mathrm{~dB}$ & $862 \mathrm{~Hz}$ & $76,75 \mathrm{~dB}$
\end{tabular}

Dentre as curvas obtidas pela análise unidimensional, com o MMT, a que considera o fator de correção proposto por Torregrossa foi a que apresentou melhor aproximação a curva do modelo 3D do Virtual.lab (Figura $64)$.

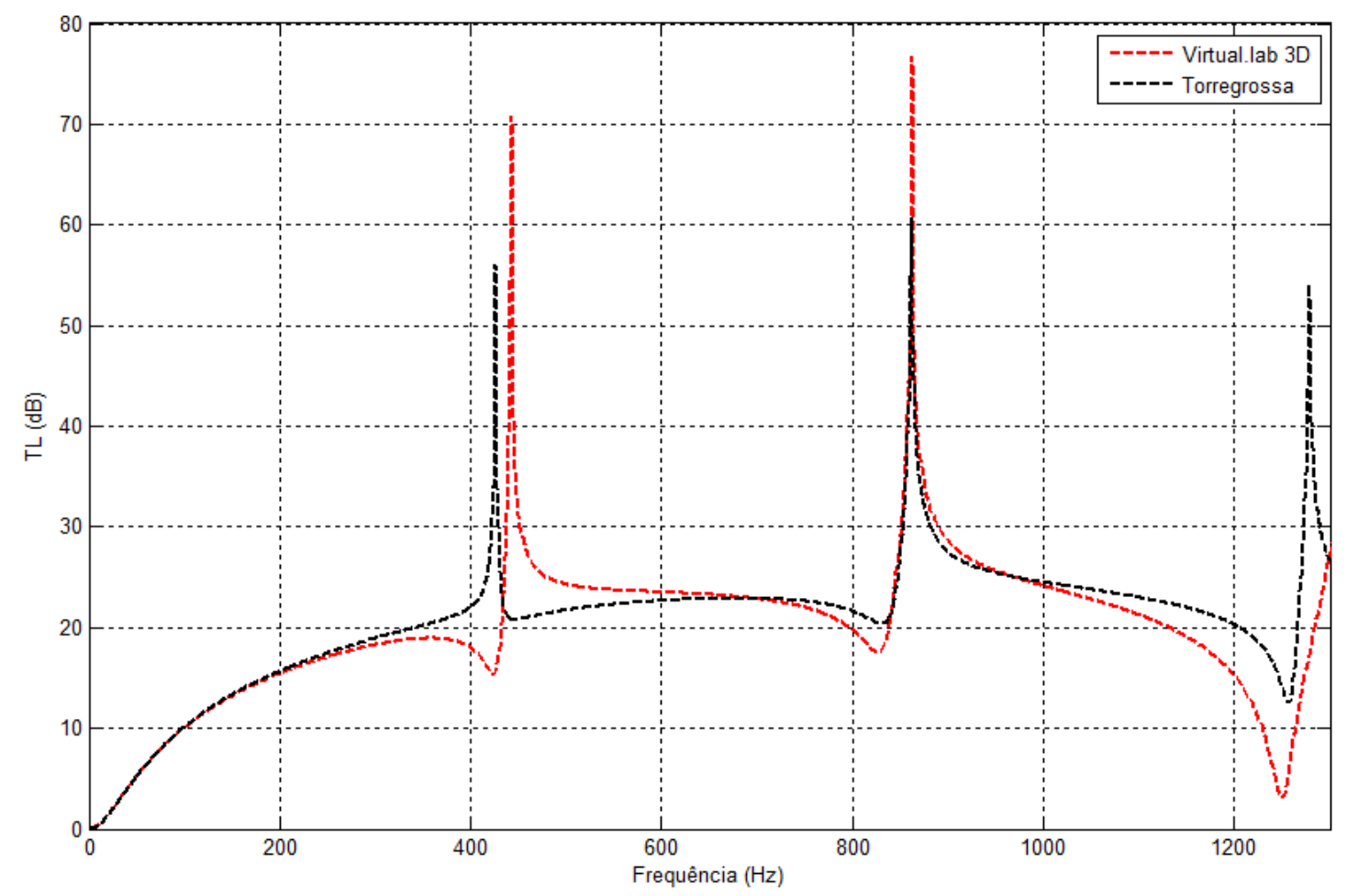

Figura 64 - Comparação entre a TL obtida pelo MMT com fator de correção de Davies com MEF no Virtual.lab ${ }^{\circledR}$ modelo 3D

A fim de avaliar a influência da espessura dos dutos estendidos no interior da câmara de expansão, foi realizada uma nova análise no Ansys ${ }^{\circledR}$, modelo 3D, e no Virtual.lab ${ }^{\circledR}$, modelo 3D fracionado, aumentando a espessura dos dutos para $5 \mathrm{~mm}$. Os resultados são mostrados nas Figura 65 e Figura 66, respectivamente. 


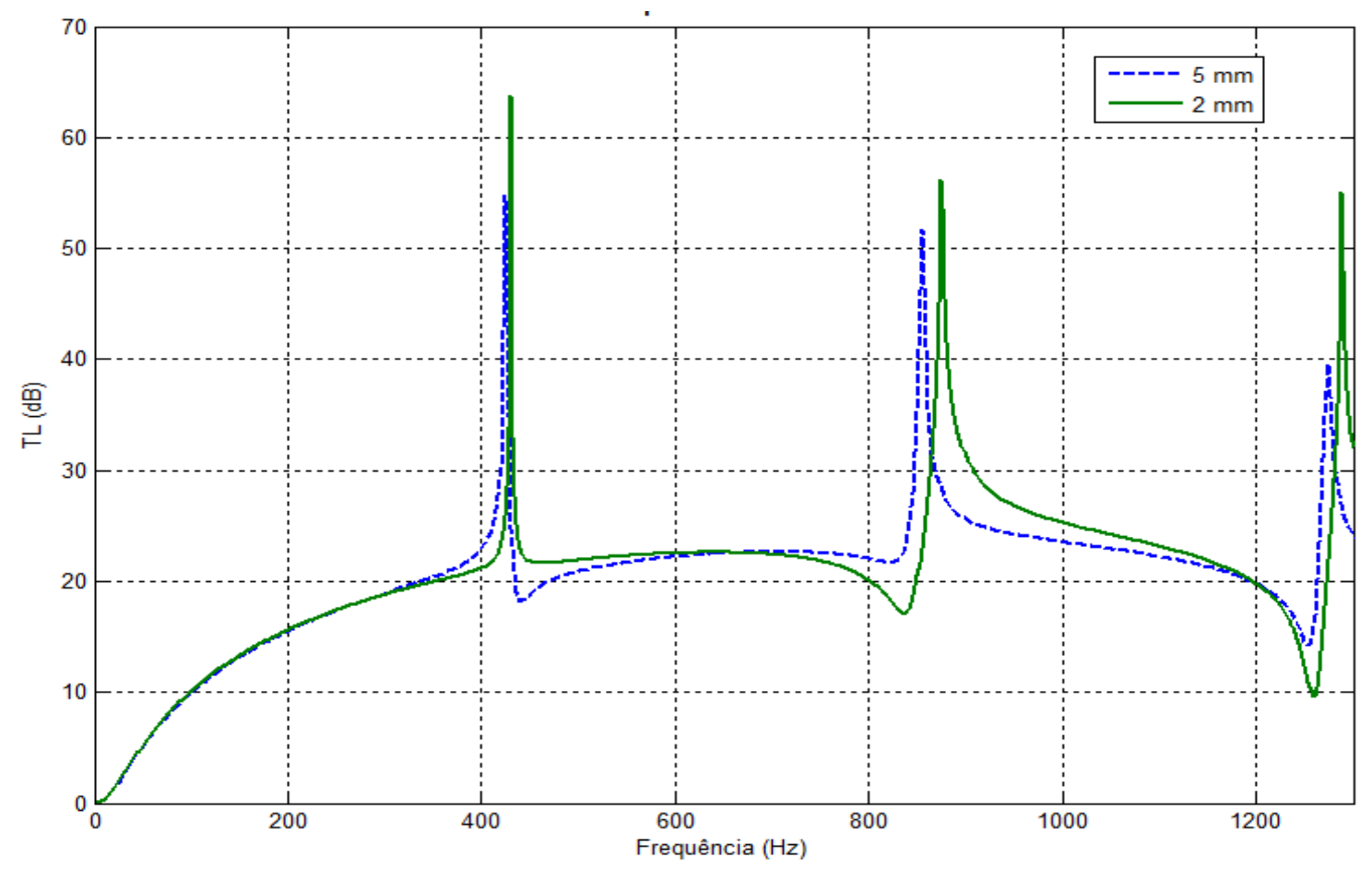

Figura 65 - Comparação da TL do modelo IV obtida no Ansys ${ }^{\circledR}$ modelo 3D variando a espessura dos dutos estendidos

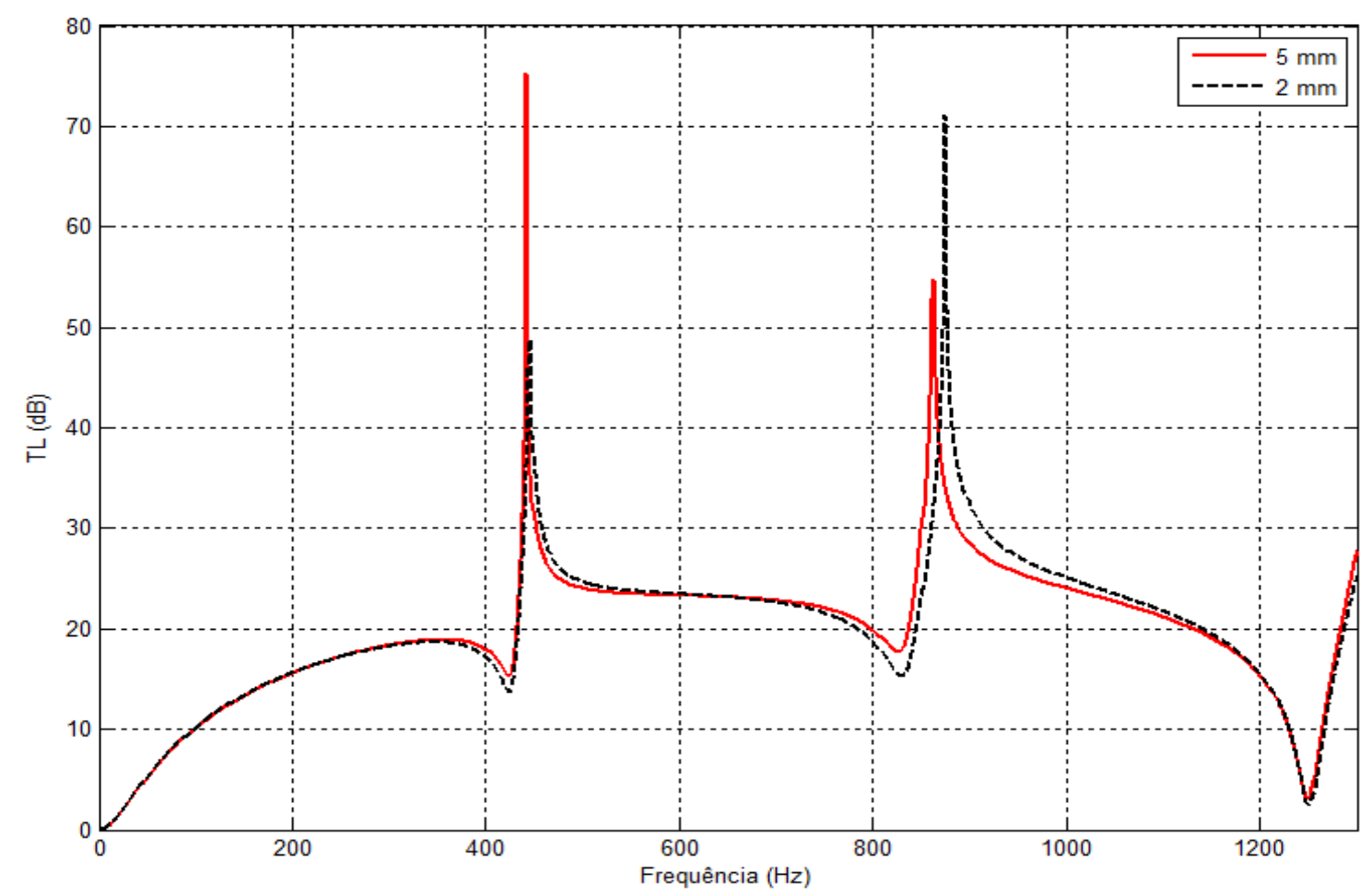

Figura 66 - Comparação da TL do modelo IV obtida no Virtual.lab ${ }^{\circledR}$ modelo 3D fracionado variando a espessura dos dutos estendidos 
Os resultados mostram que a espessura do duto afeta o desempenho do silenciador. Nota-se que em ambos os casos, o aumento da espessura reduziu as frequências em que ocorrem os picos de atenuação. Cabe ressaltar que no método da matriz de transferência esta espessura não é levada em consideração. Sendo assim, este fenômeno deve ser melhor investigado futuramente.

\subsection{ESTIMATIVA DA PERDA DE TRANSMISSÃO NA PRESENÇA DE ESCOAMENTO}

Esta seção apresenta a modelagem para estimar a perda de transmissão de silenciadores acústicos reativos na presença de escoamento. Foi feita a análise unidimensional, pelo método de matriz de transferência, adotando número de Mach diferente de zero. E a análise tridimensional foi realizada combinando o método de volumes finitos em dinâmica de fluido computacional com o método de elementos finitos.

A presença de fluxo foi analisada apenas para os três modelos de câmara de expansão, devido à continuidade longitudinal da geometria, que facilita a convergência da simulação do escoamento. A geometria em " $T$ " do QWT exige recursos mais sofisticados para realizar a dinâmica de fluido computacional, que fogem da abrangência deste trabalho.

A fim de avaliar o efeito da velocidade do fluxo sobre o desempenho do silenciador, foram adotados três valores, sendo eles: $10 \mathrm{~m} / \mathrm{s}, 30 \mathrm{~m} / \mathrm{s}$ e $60 \mathrm{~m} / \mathrm{s}$, cujos respectivos números de Mach são: 0,0294; 0,0882 e 0,1765. Para estas velocidades o escoamento caracteriza-se como incompressível, visto os números de Mach são inferiores ao valor aproximado de 0,3 [38].

\subsubsection{Método Analítico}

A TL considerando a presença de fluxo foi calculada analiticamente pelo MMT seguindo a metodologia exposta na Tabela 6. Porém, agora na $3^{\underline{a}}$ etapa, o número de Mach assume valor diferente de zero nas matrizes de 
transferência $(0,0294 ; 0,0882$ ou 0,1765$)$ - correspondente à velocidade que será avaliada.

Foram aplicados os mesmos fatores de correção da análise sem fluxo, uma vez que não apresentam em sua formulação restrições quanto à presença de escoamento. No entanto, alguns estudos [62] verificam que a influência do fluxo no fator de correção é dependente de diversas condições, tais como a frequência, a velocidade de fluxo, e a presença de uma camada de cisalhamento após a área de descontinuidade.

Conforme foi mostrado no item 3.2.6, a velocidade do fluxo altera a frequência de corte. Sendo assim, para cada velocidade, as frequências de corte foram calculadas conforme a Eq. (34). Para exemplificar, a Tabela 25 mostra os valores de frequência de corte para velocidade de $60 \mathrm{~m} / \mathrm{s}$, que é o caso mais crítico.

Tabela 25 - Frequências de corte circunferencial e radial para velocidade de $60 \mathrm{~m} / \mathrm{s}$

\begin{tabular}{cc}
\hline Duto & Frequência de corte \\
\hline Duto de entrada/saída & $3955 \mathrm{~Hz}$ \\
\hline Modelo II & $1648 \mathrm{~Hz}$ \\
\hline Modelo III & $1831 \mathrm{~Hz}$ \\
\hline Modelo IV & $1318 \mathrm{~Hz}$ \\
\hline
\end{tabular}

Foi verificado que as faixas de frequência em que foram realizadas as análises sem fluxo poderiam ser mantidas, visto que permanecem dentro da validade da hipótese de propagação de ondas planas.

\subsubsection{Modelo II}

A Figura 67 exibe as curvas de perda de transmissão para o modelo II obtidas pelo MMT sem adotar nenhum fator de correção, variando a velocidade do escoamento. 


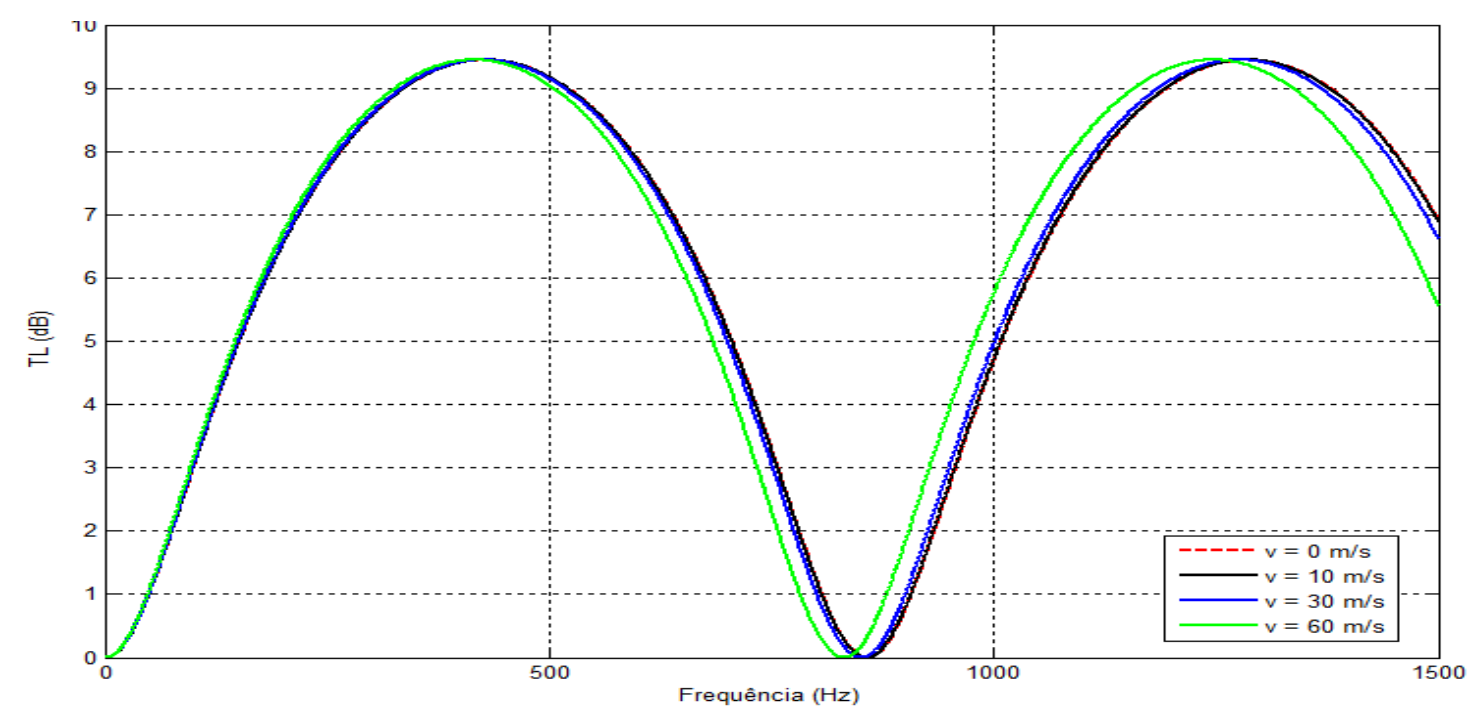

Figura 67 - TL obtida pelo MMT sem considerar fator de correção variando a velocidade de escoamento

Observa-se que apenas o resultado obtido para velocidade de $60 \mathrm{~m} / \mathrm{s}$ apresenta diferença significativa em relação ao resultado sem fluxo: a curva se deslocou para esquerda, entretanto, a amplitude é mantida.

A Figura 68, Figura 69 e Figura 70 mostram os resultados obtidos aplicando os fatores de correção propostos por Davies, Karal e Torregrossa, respectivamente, variando a velocidade do escoamento.

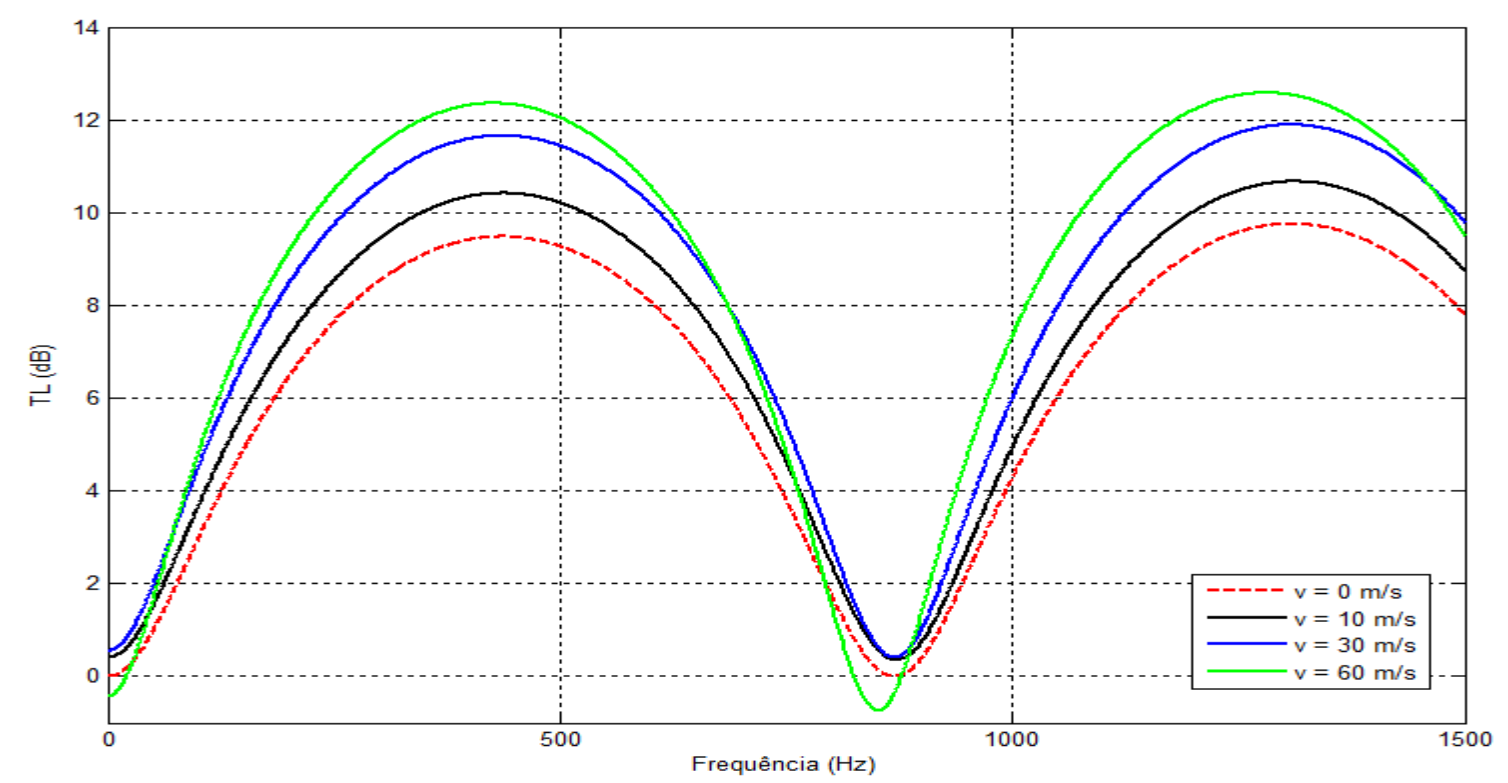

Figura 68 - TL obtida para o modelo II pelo MMT com fator de correção de Davies variando a velocidade de escoamento 


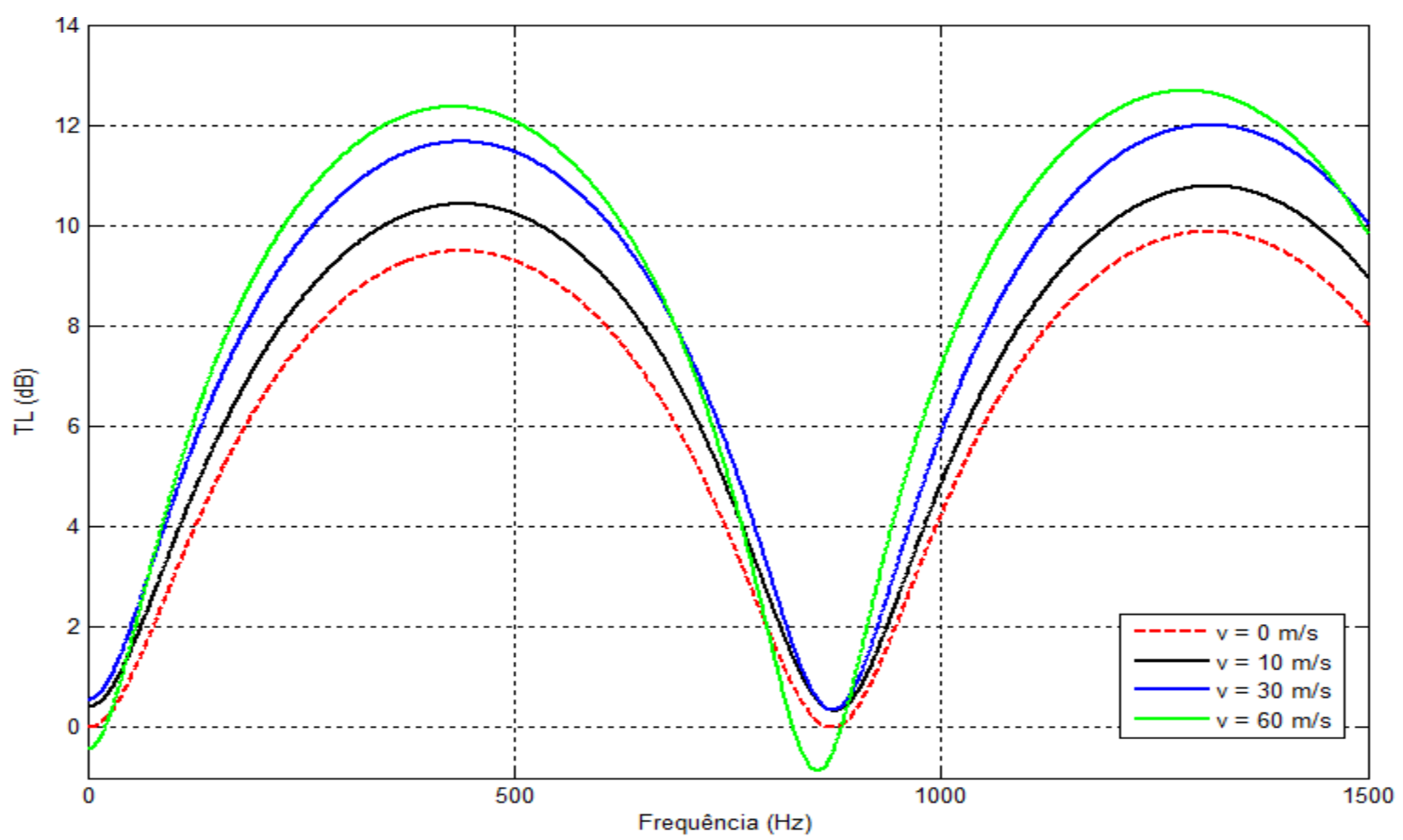

Figura 69 - TL obtida para o modelo II pelo MMT com fator de correção de Karal variando a velocidade de escoamento

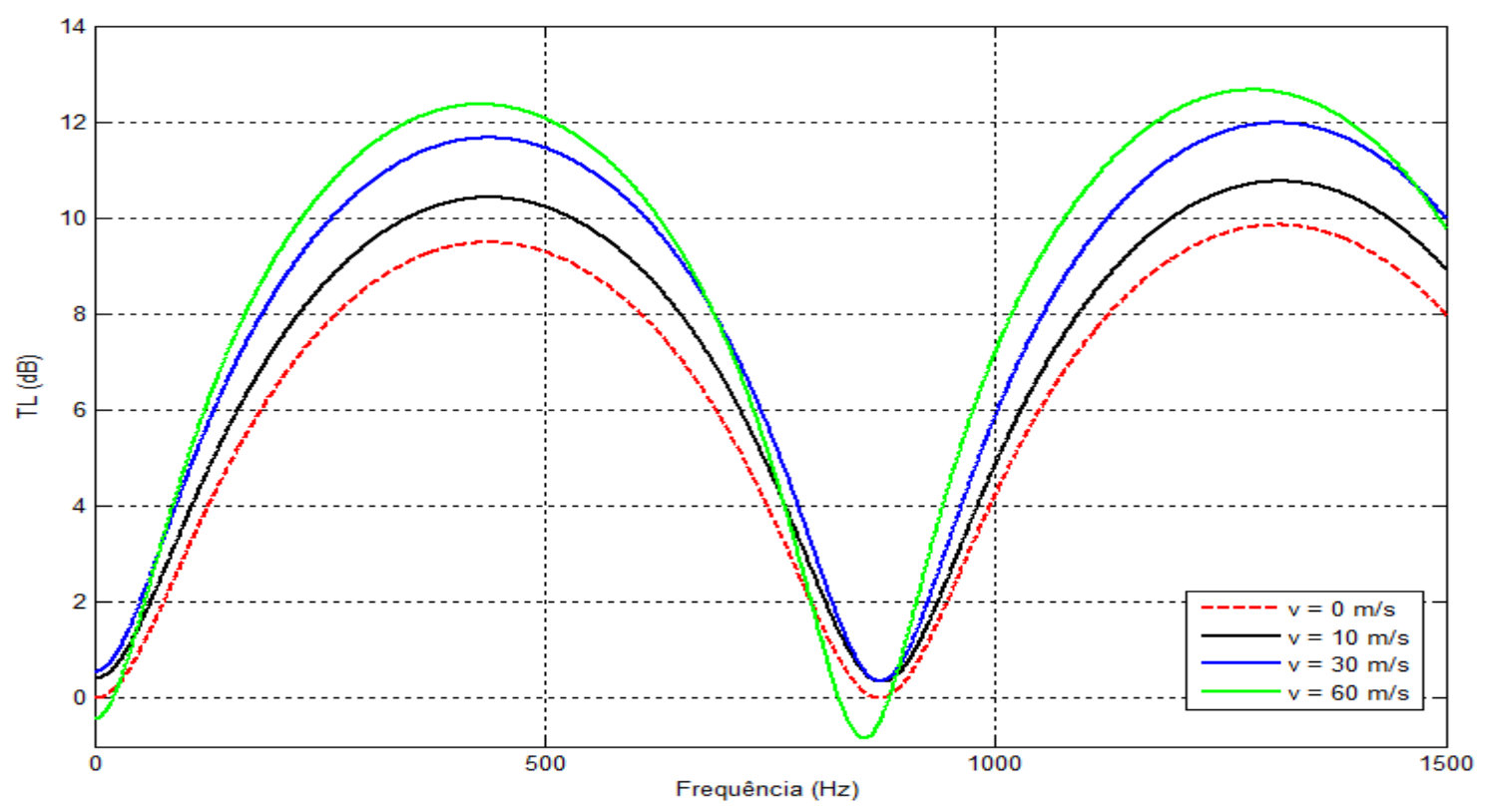

Figura 70 - TL obtida para o modelo II pelo MMT com fator de correção de Torregrossa variando a velocidade de escoamento

Nos três casos observa-se um padrão: a amplitude de atenuação aumenta à medida que a velocidade aumenta. Nota-se ainda que o formato da curva com velocidade de $60 \mathrm{~m} / \mathrm{s}$ se difere das demais, apresentado, inclusive valores negativos, que não possuem significado físico. 
A Figura 71 compara os resultados, para a mesma velocidade $(10 \mathrm{~m} / \mathrm{s})$, obtidos com os diferentes fatores de correção.

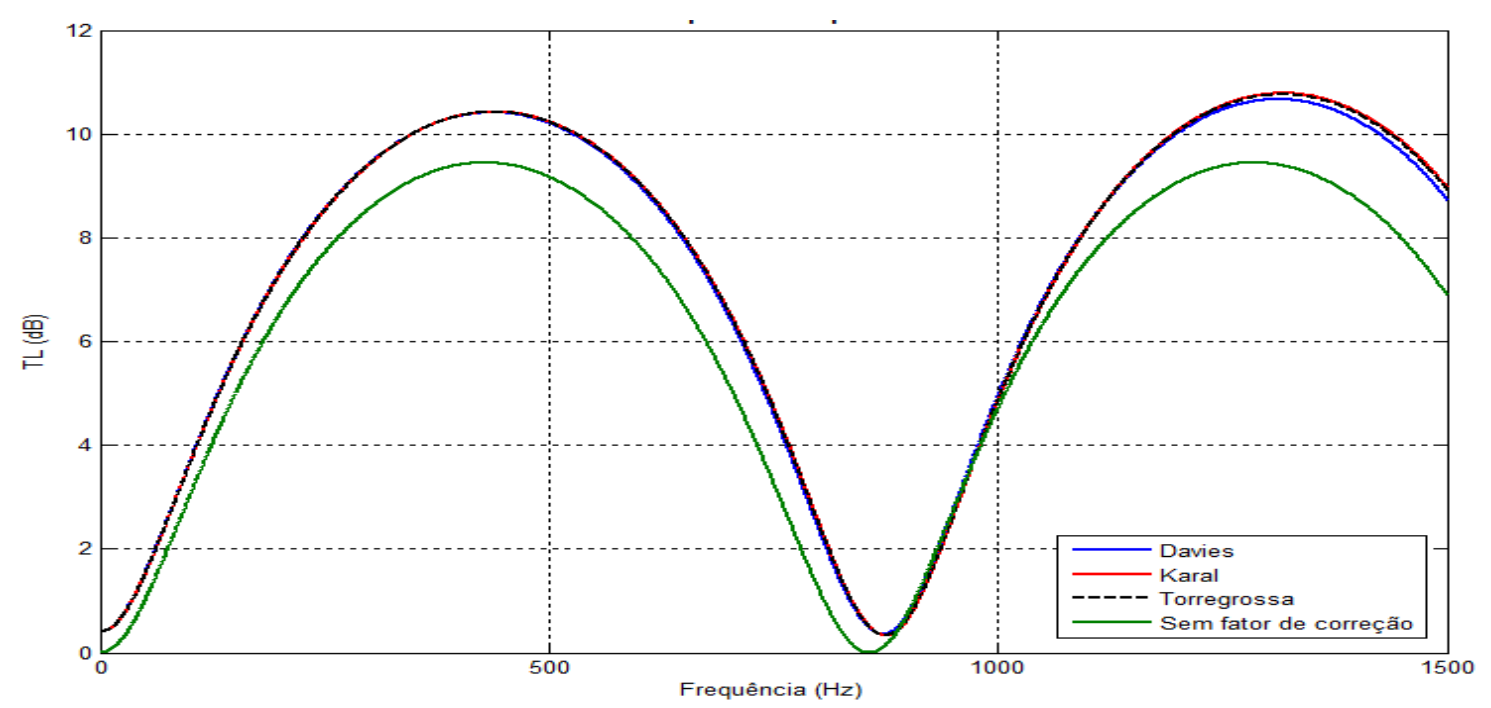

Figura 71 - TL obtida pelo MMT para velocidade de $10 \mathrm{~m} / \mathrm{s}$

É notável a diferença, principalmente em amplitude, entre a curva sem fator de correção e as demais. Ao comparar apenas os resultados que consideram o fator de correção, o comportamento das curvas é muito parecido com aquele obtido na análise sem fluxo. Ou seja, a amplitude do segundo domo aumenta em relação ao primeiro e as curvas obtidas com fator de correção de Karal e Torregrossa são muito próximas.

\subsubsection{Modelo III}

Ressalta-se que os resultados do modelo III são mostrados na faixa de frequência de 0 a $2500 \mathrm{~Hz}$, apenas para efeito de visualização dos resultados. Para este modelo, a teoria de propagação de ondas planas é valida para frequências abaixo de $1831 \mathrm{~Hz}$.

A Figura 72 exibe as curvas de perda de transmissão obtidas pelo MMT sem adotar nenhum fator de correção, variando a velocidade do escoamento. 


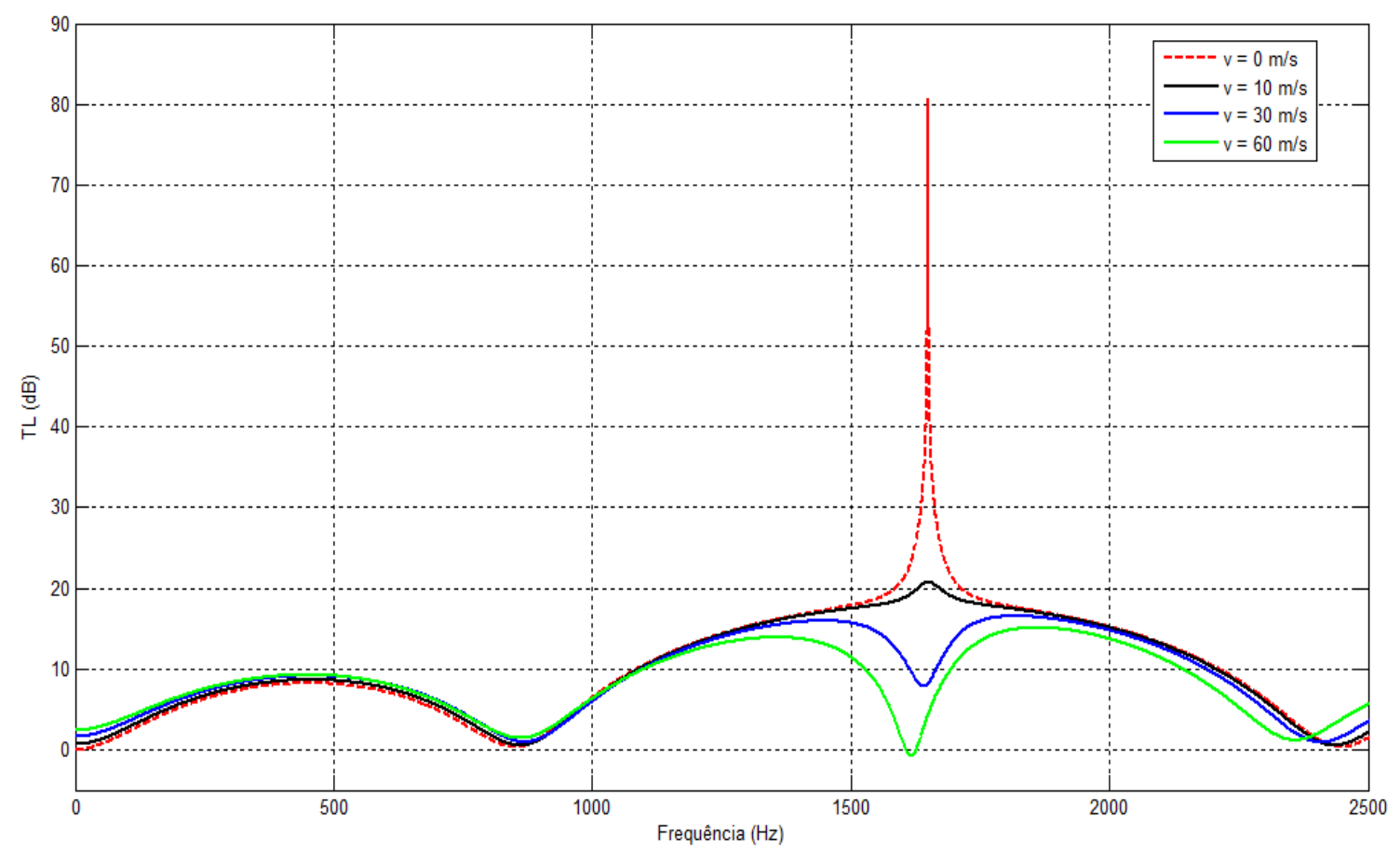

Figura 72 - TL obtida para o modelo III pelo MMT sem fator de correção variando a velocidade de escoamento

Observa-se que a presença do escoamento reduz significativamente a amplitude do pico de atenuação, de tal forma que à medida que a velocidade aumenta, o formato da curva se assemelha mais ao de uma câmara de expansão simples. Nota-se ainda a presença de resultados negativos na curva de $60 \mathrm{~m} / \mathrm{s}$, que não possuem interpretação física.

A Figura 73, Figura 74 e Figura 75 mostram os resultados obtidos aplicando os fatores de correção propostos por Davies, Karal e Torregrossa, respectivamente, variando a velocidade do escoamento. 


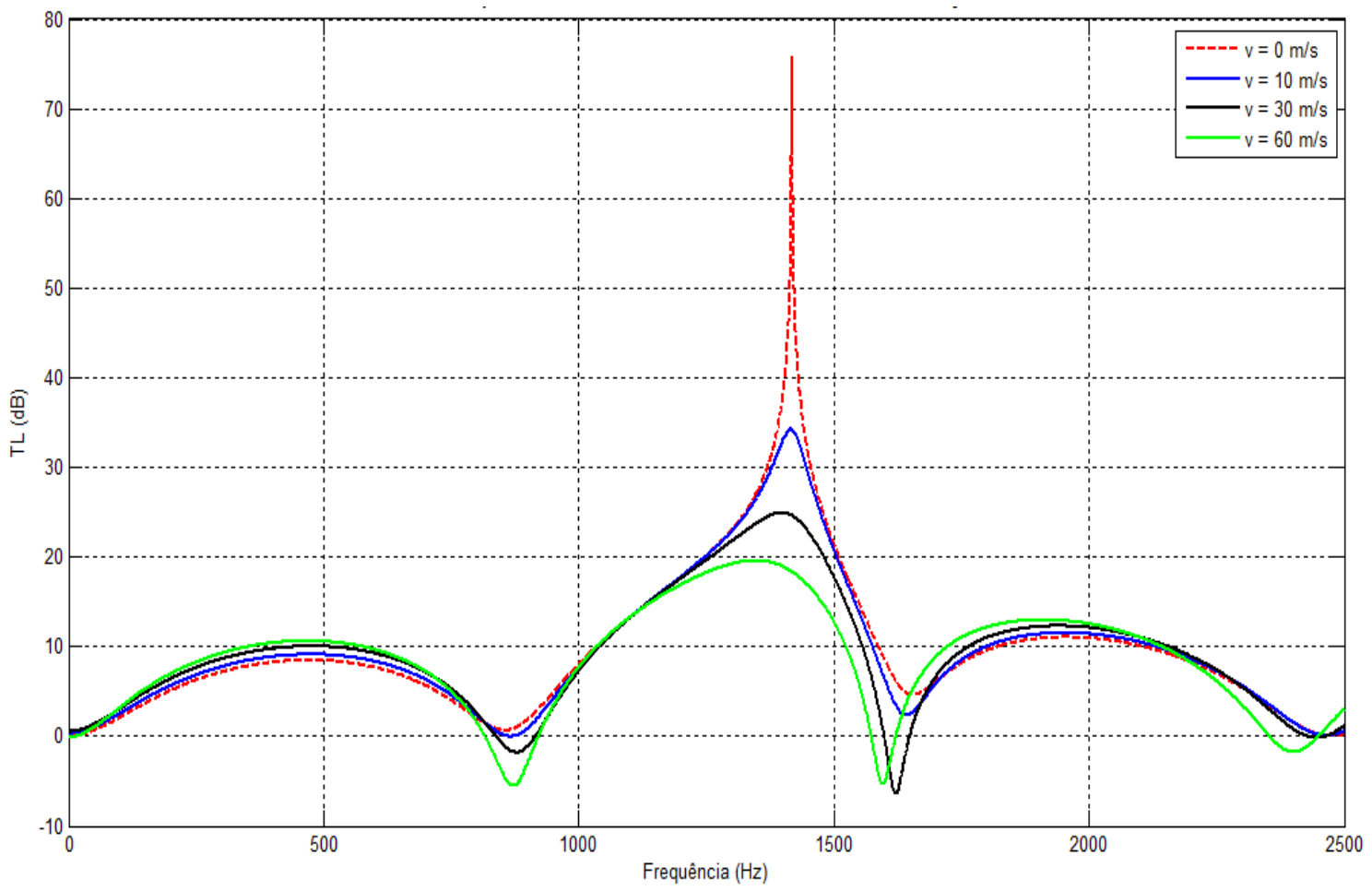

Figura 73 - TL do modelo III obtida pelo MMT com fator de correção de Davies variando a velocidade de escoamento

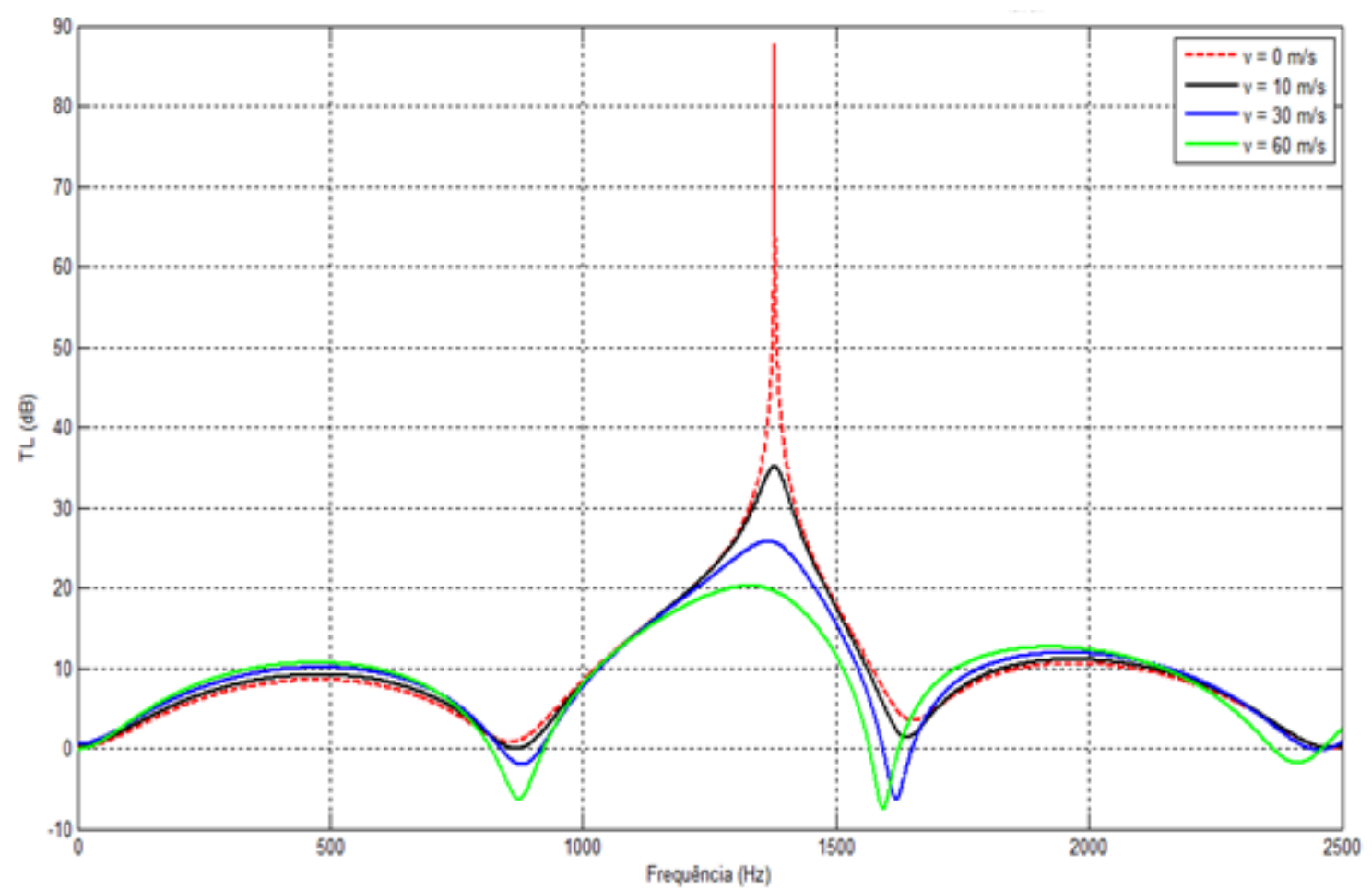

Figura 74 - TL do modelo III obtida pelo MMT com fator de correção de Karal variando a velocidade de escoamento 


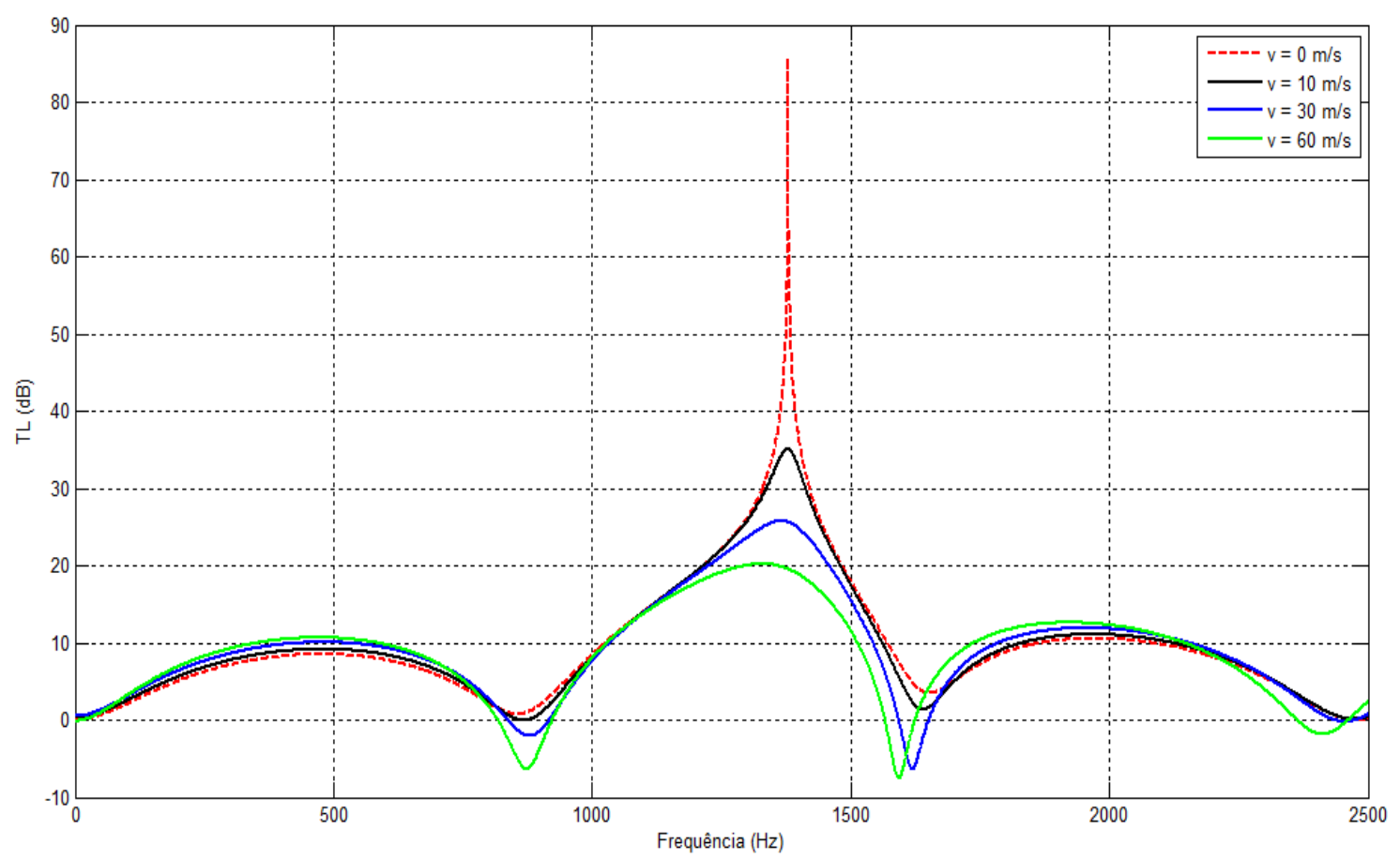

Figura 75 - TL do modelo III obtida pelo MMT com fator de correção de Torregrossa variando a velocidade de escoamento

Nos três casos observa-se um padrão: à medida que a velocidade aumenta, a amplitude dos domos da curva aumenta enquanto que a amplitude do pico de atenuação reduz significativamente. Dessa forma, os resultados obtidos pelo MMT mostram que o desempenho do modelo III é influenciado pela presença e velocidade de escoamento.

A Figura 76 compara os resultados, para a mesma velocidade $(10 \mathrm{~m} / \mathrm{s})$, obtidos com os diferentes fatores de correção.

A diferença entre do comportamento da curva sem fator de correção e as demais é evidente. Novamente, as curvas com fatores de Karal e Torregrossa apresentam grande aproximação. Nota-se também que curva de Davies é a única que nesta velocidade apresenta valores negativos. 


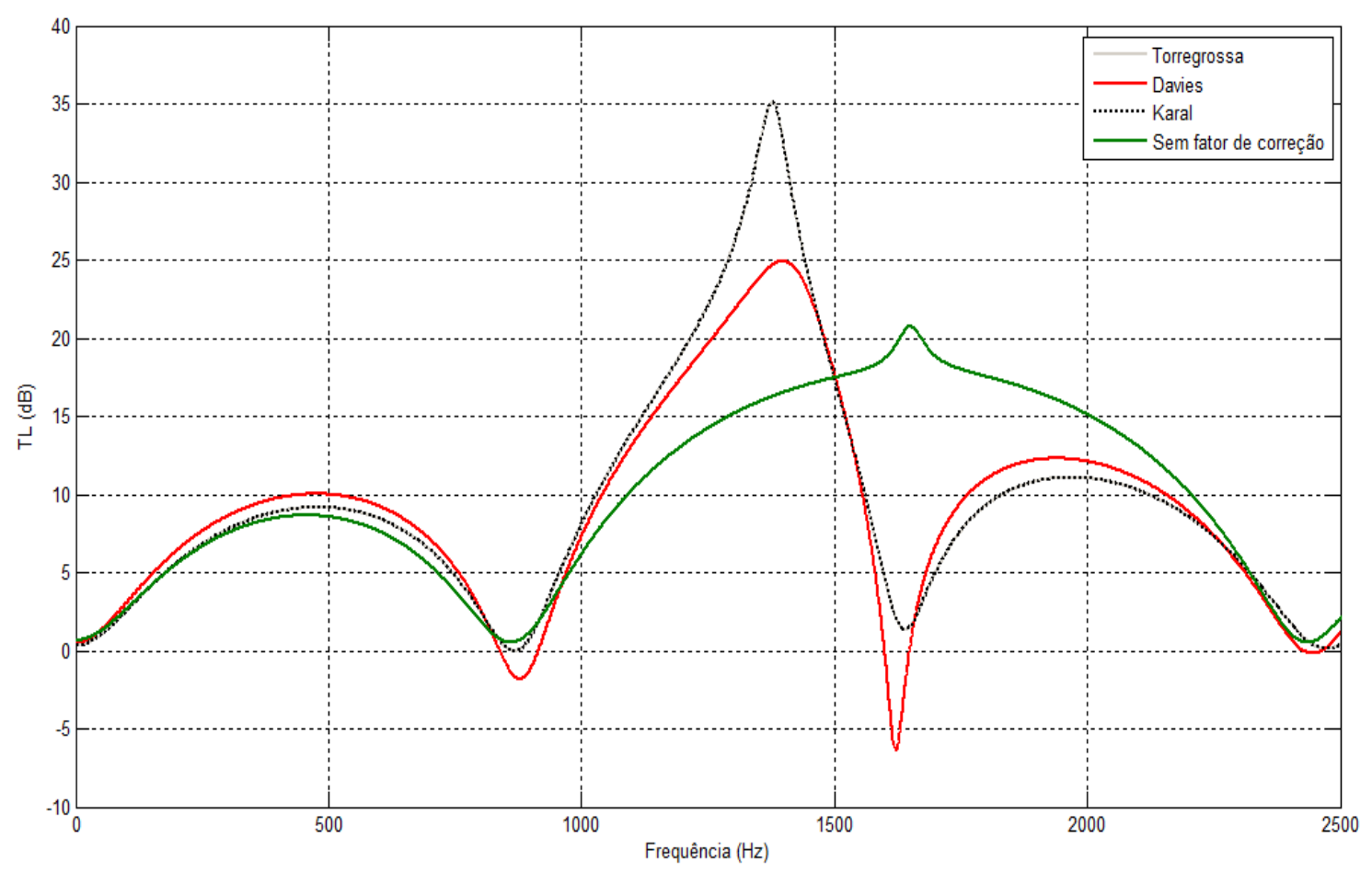

Figura 76 - TL do modelo III obtida pelo MMT para velocidade de $10 \mathrm{~m} / \mathrm{s}$

\subsubsection{Modelo IV}

A Figura 77 exibe as curvas de perda de transmissão obtidas pelo MMT sem adotar nenhum fator de correção, variando a velocidade do escoamento. A Figura 78, Figura 79 e Figura 80 mostram os resultados aplicando o fator de correção de Davies, Karal e Torresgrossa, respectivamente. Já os resultados obtidos com o fator de correção de Kang \& Ji e Chaitanya \& Munjal são os mesmo, e são apresentados na Figura 81. 


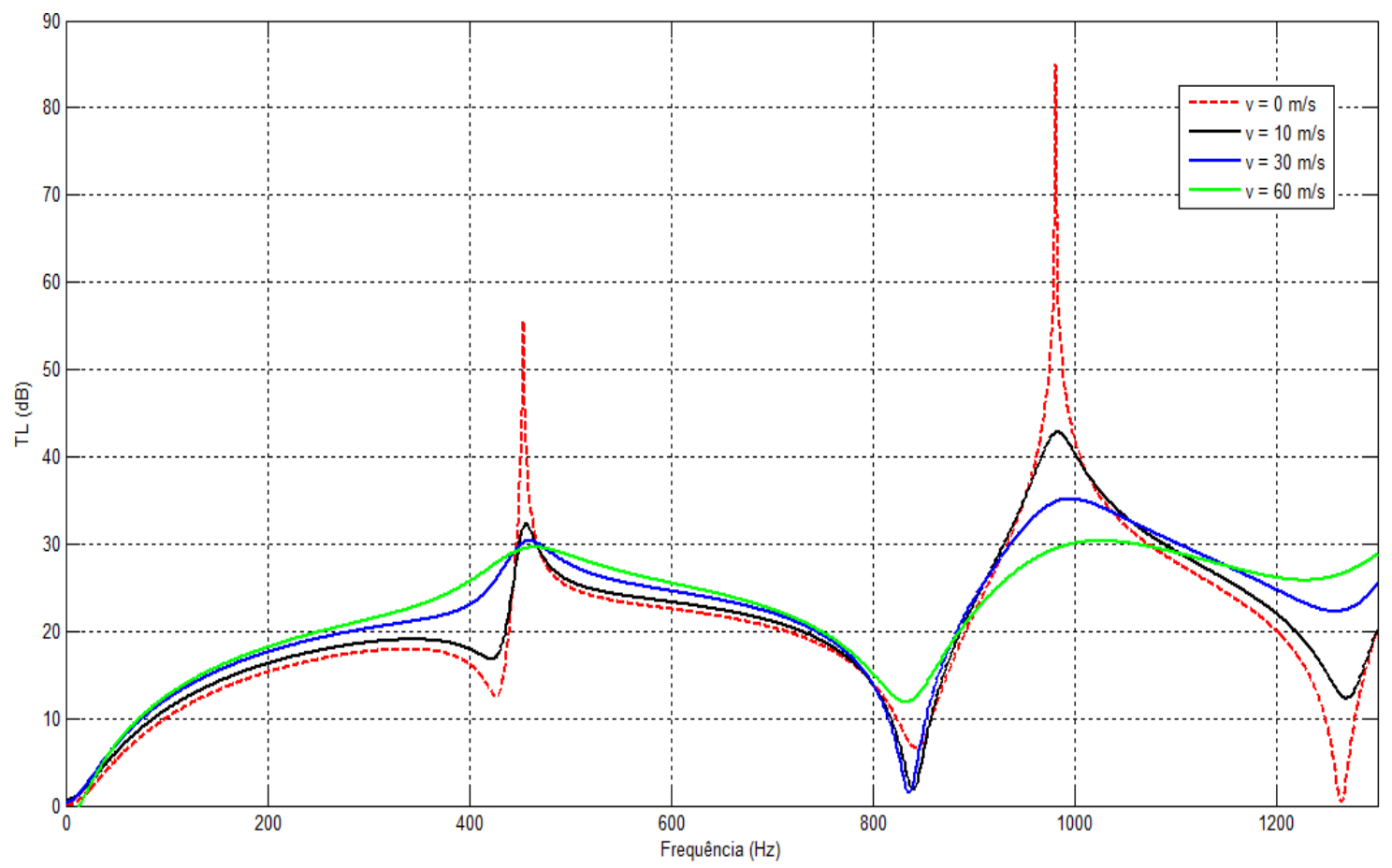

Figura 77 - TL do modelo IV obtida pelo MMT sem fator de correção variando a velocidade de escoamento

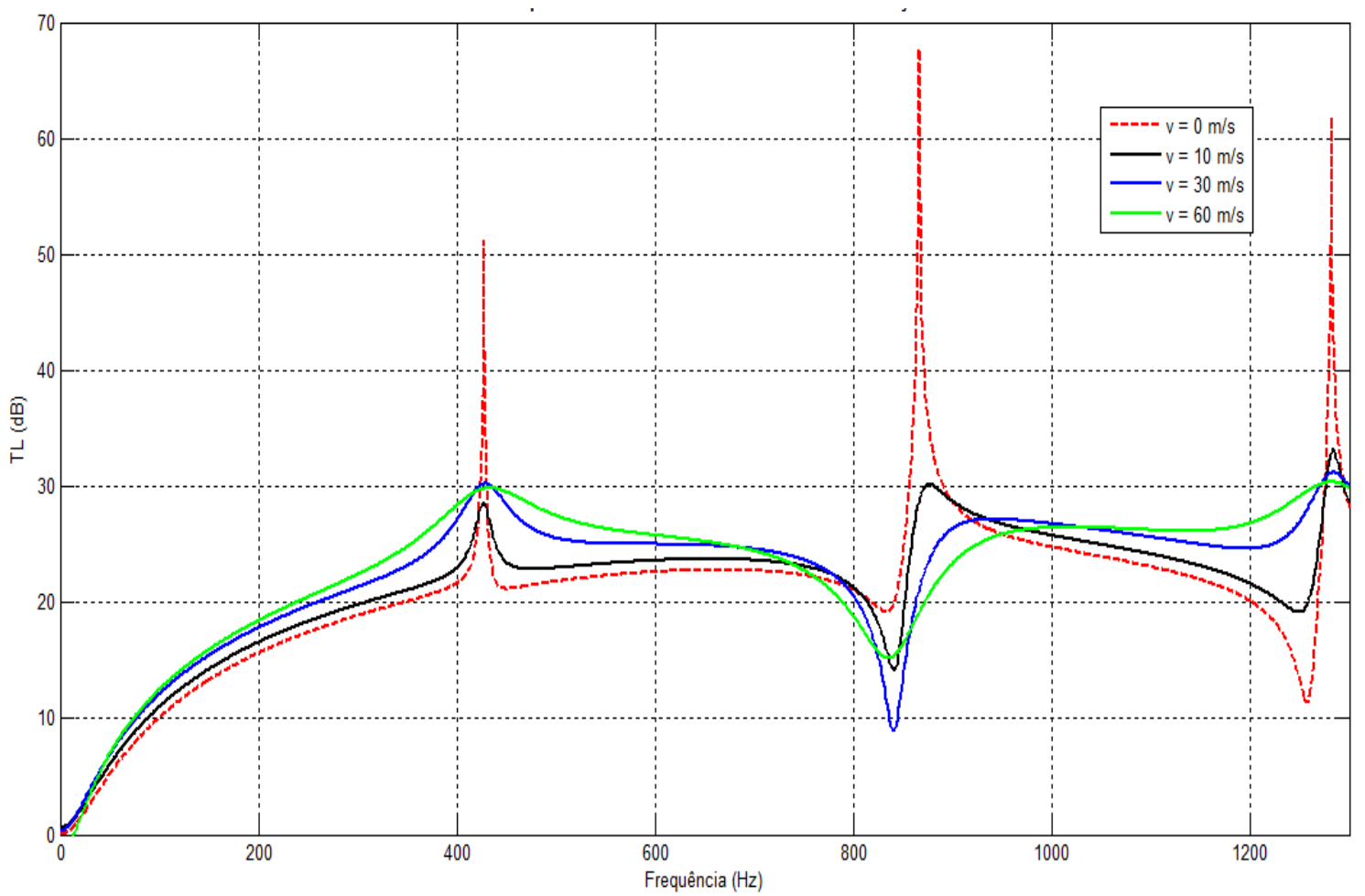

Figura 78 - TL do modelo IV obtida pelo MMT com fator de correção de Davies variando a velocidade de escoamento 


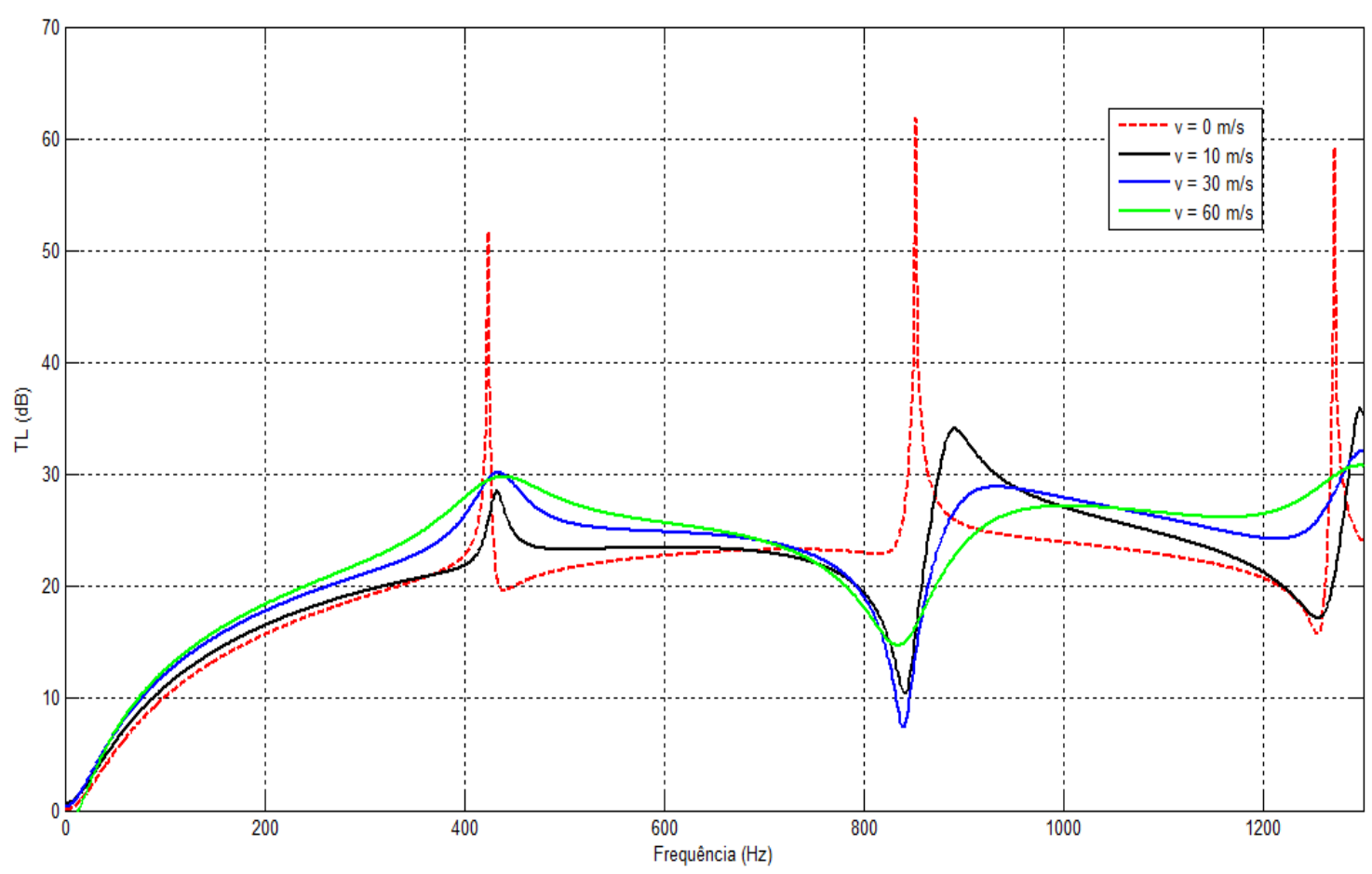

Figura 79 - TL do modelo IV obtida pelo MMT com fator de correção de Karal variando a velocidade de escoamento

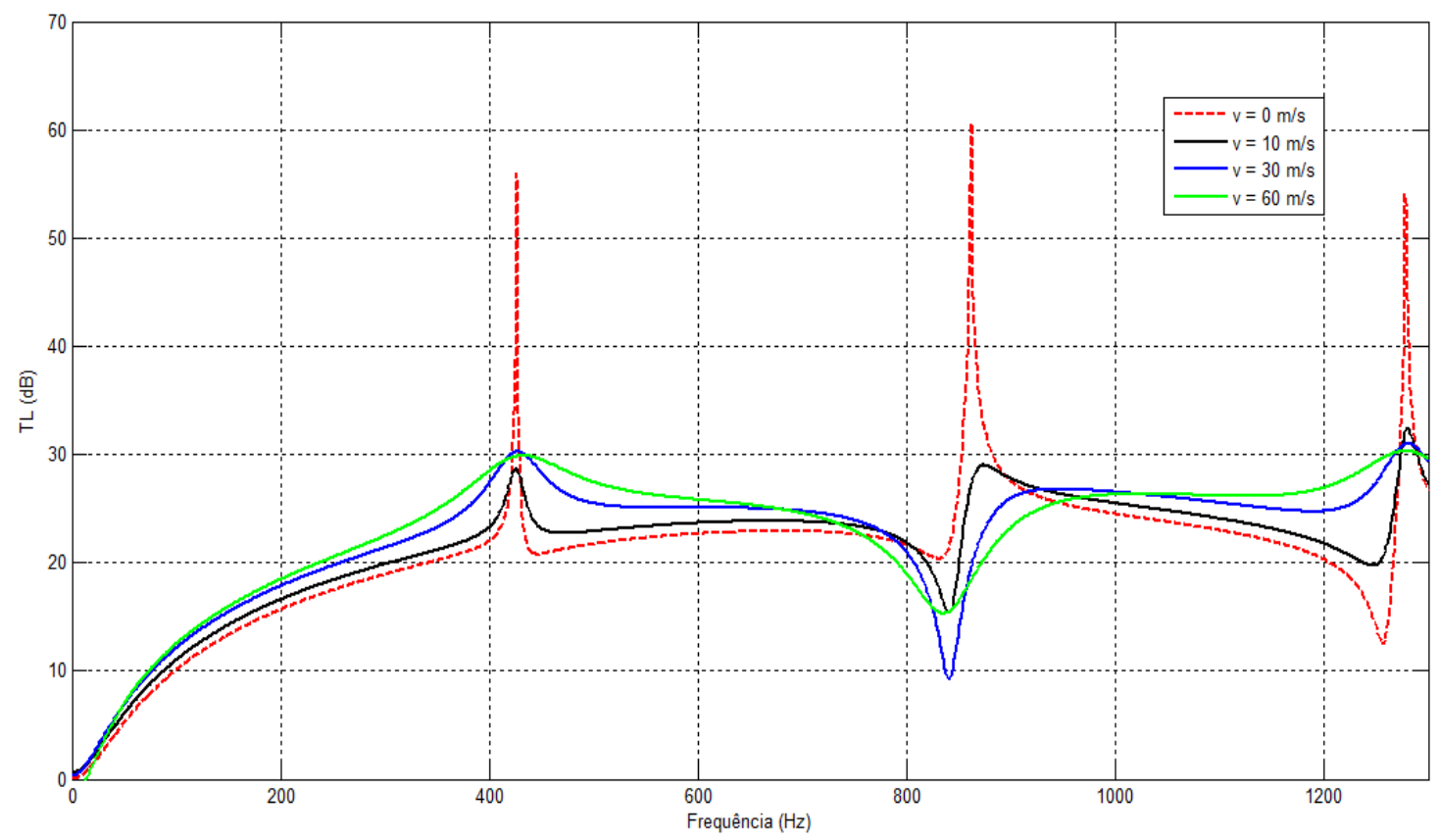

Figura 80 - TL do modelo IV obtida pelo MMT com fator de correção de Torregrossa variando a velocidade de escoamento 


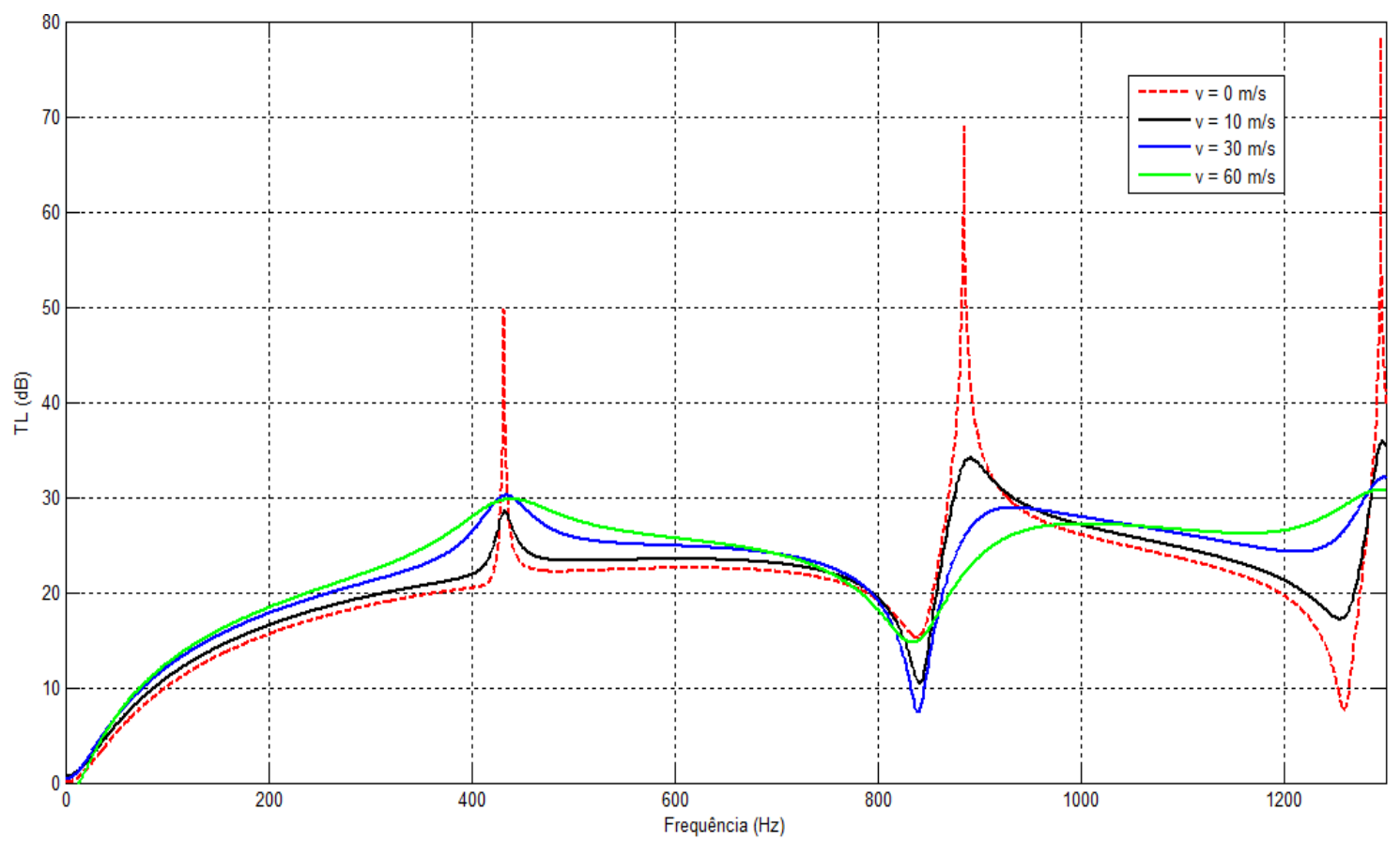

Figura 81 - TL do modelo IV obtida pelo MMT com fator de correção de Kang \& Ji e Chaitanya \& Munjal variando a velocidade de escoamento

Os resultados mostram que a presença de escoamento modifica a curva de perda de transmissão e diminui o valor da amplitude nas frequências em que ocorrem picos de atenuação. A princípio, não é possível estabelecer uma relação direta entre o aumento da velocidade e a redução do desempenho do silenciador.

A Figura 82 compara os resultados, para a mesma velocidade $(10 \mathrm{~m} / \mathrm{s})$, obtidos com os diferentes fatores de correção.

Embora apresente o formato semelhante às demais curvas, a curva sem fator de correção apresenta diferença significativa em amplitude e frequência. Nota-se também que para esta velocidade, as curvas obtidas com os fatores de correção de Torregrossa, Kang \& Ji e Chaitanya \& Munjal são iguais. 


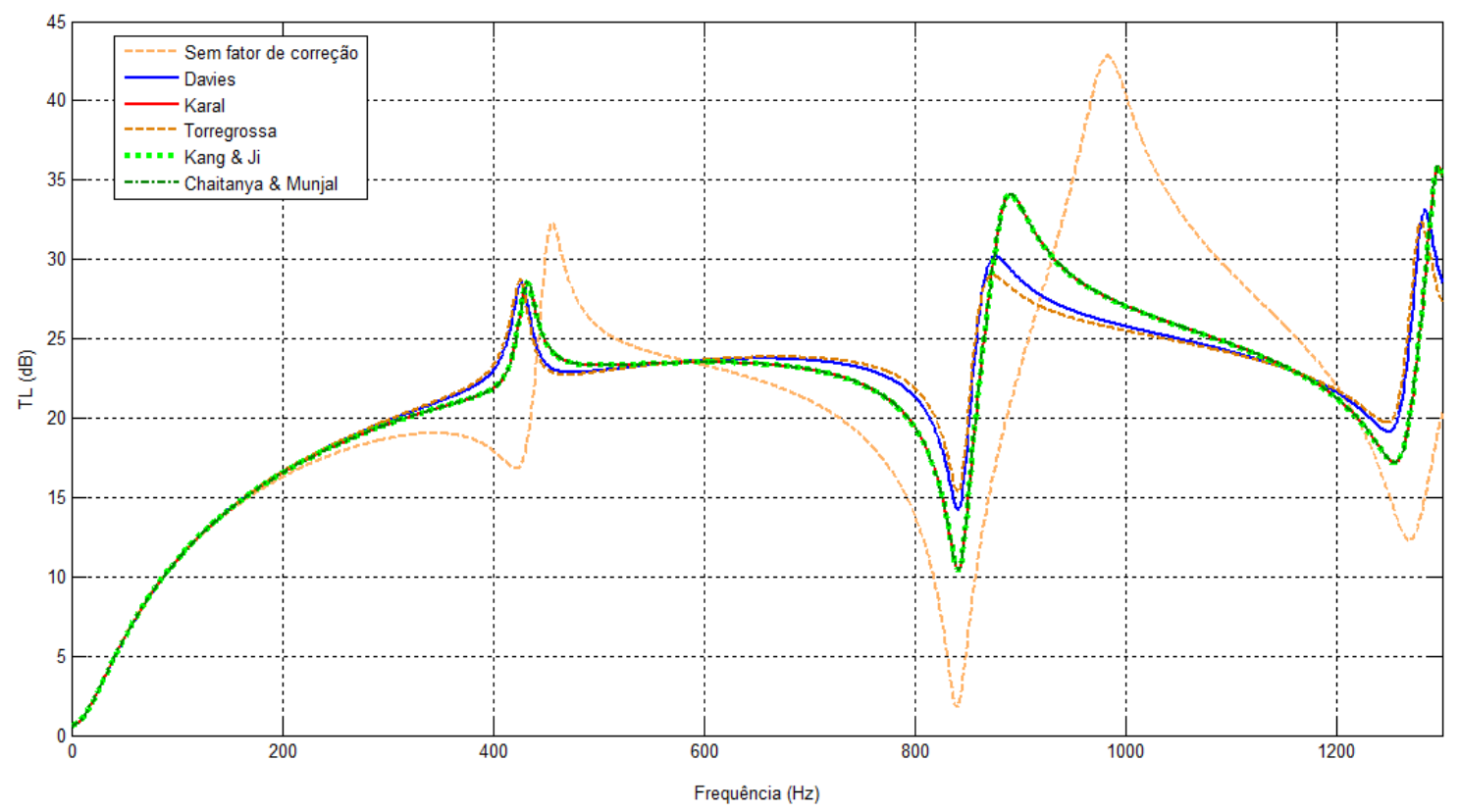

Figura 82 - TL do modelo IV obtida pelo MMT para velocidade de $10 \mathrm{~m} / \mathrm{s}$

\subsubsection{Método Numérico}

O método de elementos finitos é capaz de considerar o efeito do escoamento, assumindo que o campo acústico é sobreposto ao campo de fluxo. Mas isso significa que o fluxo deve ser importado a partir de um cálculo externo [29]. Muitas vezes este cálculo é realizado por uma abordagem simplificada de potencial relativo ao escoamento [37, 63].

Também pode ser realizado através de simulação 3D por dinâmica dos fluidos computacional no domínio do tempo [26, 64]. Dessa forma é possível considerar o efeito viscoso do escoamento na propagação do som. Entretanto, essa abordagem demanda muito custo computacional e ainda exige conhecimento mais aprofundado sobre CFD, o que pode torná-la pouco viável do ponto de vista prático.

Neste contexto, esse trabalho utiliza a análise permanente em CFD, com intuito de obter a velocidade de fluxo detalhada dentro do silenciador e uma distribuição mais realista do que a obtida com a abordagem de potencial de escoamento, porém com custo computacional reduzido e metodologia mais simples, em relação à análise transiente. 
Durante a realização deste trabalho, foi verificado que o software Ansys Mechanical ${ }^{\circledR} 16.0$ (utilizado na análise sem fluxo) apresenta limitações técnicas com relação à modelagem do escoamento, não sendo possível incorporar o resultado da simulação CFD para avaliação acústica de silenciadores. Sendo assim, nesta etapa foi utilizado apenas o software de elementos finitos LMS Virtual.lab ${ }^{\circledR}$.

A metodologia consiste em primeiramente simular o campo de fluxo tridimensional em regime permanente no software Ansys $C F X^{\circledast}$ 16.0. Os valores de velocidade computados para cada nó da malha CFD, são exportados, em formato CGNS (CFD General Notation System) para o software LMS Virtual.Lab $^{\circledR}$, e mapeados na malha acústica. Então, análise harmônica é conduzida pelo MEF, considerando o efeito do campo de fluxo, e em seguida a TL é estimada pelo método da decomposição.

A Figura 83 apresenta um fluxograma com as etapas da metodologia, que serão detalhadas posteriormente. A cor de preenchimento da caixa indica em qual software a etapa foi realizada, sendo que laranja refere-se ao $C F X^{\circledR}$, cinza refere-se ao LMS Virtual.lab ${ }^{\circledR}$ e verde refere-se ao Matlab ${ }^{\circledR}$.

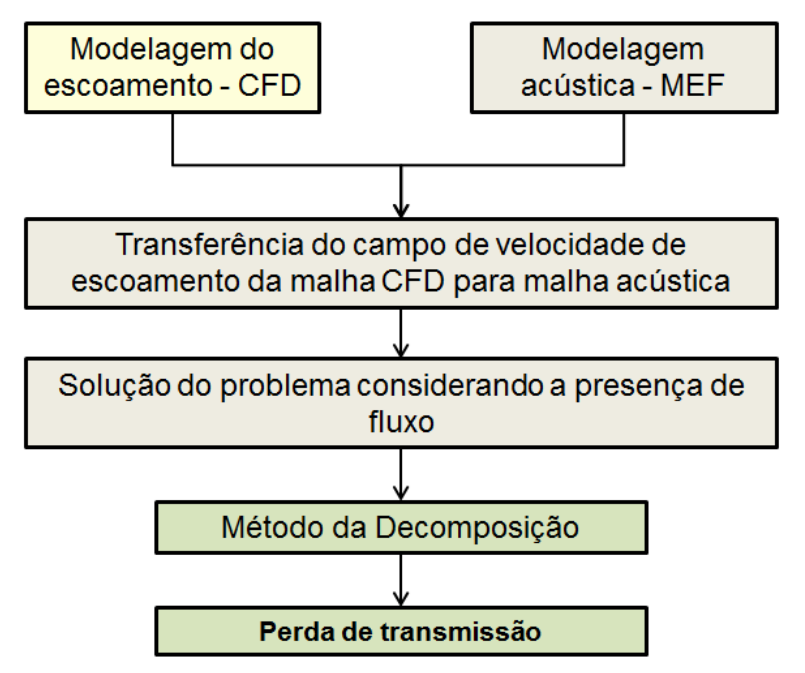

Figura 83 - Fluxograma da metodologia para estimativa da TL em silenciadores reativos considerando a presença de escoamento 
O número de Reynolds $(R e)$ é um parâmetro adimensional para o cálculo do regime de escoamento de determinado fluido dentro de um tubo ou sobre uma superfície, dado por [38]:

$R e=\frac{\rho \cdot v \cdot D}{\mu}$

em que $\rho$ é a massa específica do fluído, $v$ é a velocidade do escoamento, $D$ é o diâmetro do tubo e $\mu$ é a viscosidade dinâmica do fluido. A Tabela 26 apresenta os números de Reynolds calculados considerando o diâmetro do duto de entrada e das câmaras de expansão, em função da velocidade de escoamento. Foi adotado $\rho=1,21 \mathrm{~kg} / \mathrm{m}^{3}$ e $\mu=17,4 \times 10^{-6} \mathrm{~Pa} \cdot \mathrm{s}$.

Tabela 26 - Número de Reynolds para cada modelo de câmara de expansão em função da velocidade do escoamento

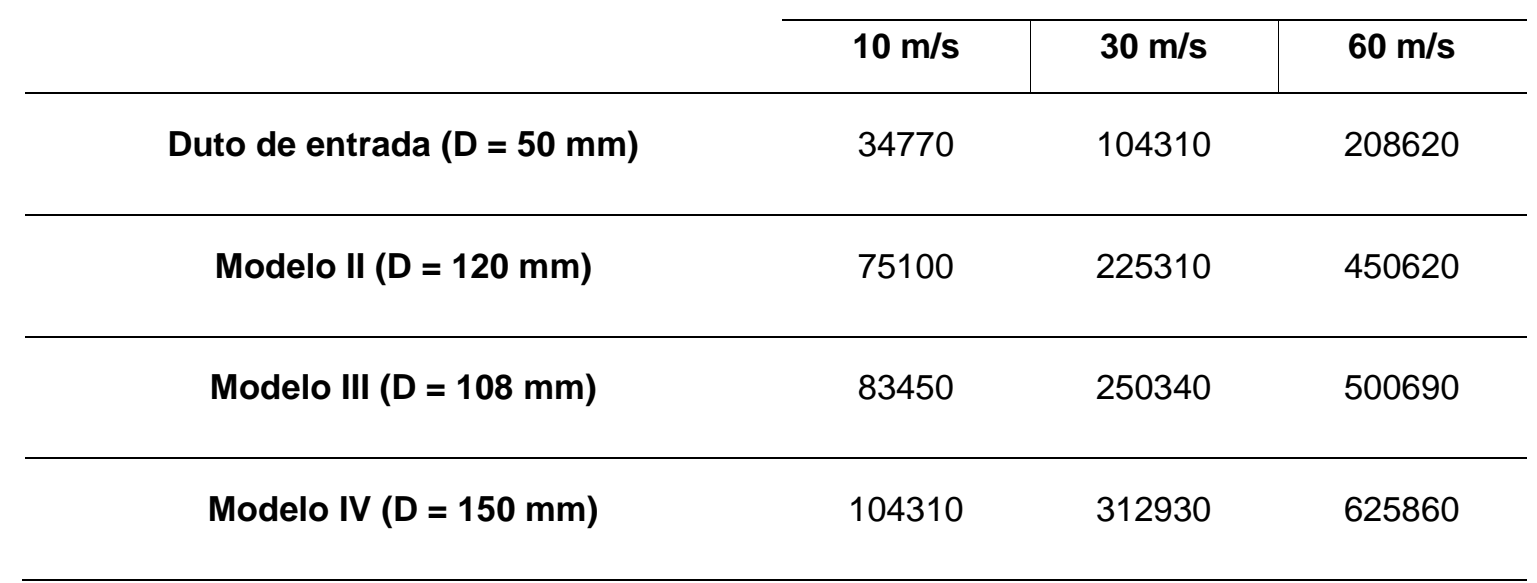

Segundo Fox e McDONALD [38], para $R e>2300$ aproximadamente, o regime de escoamento em um tubo é turbulento. Portanto, este será o regime adotado para todos os casos avaliados. Vale ressaltar que o próprio escoamento turbulento de gases pelo sistema é uma fonte sonora em potencial, a qual não é considerada pela metodologia apresentada neste trabalho. 


\subsubsection{Modelagem CDF do escoamento}

A Tabela 27 apresenta as etapas da metodologia adotada neste trabalho para simulação em CFD do campo de fluxo de silenciadores reativos utilizando o software $\mathrm{CFX}^{\circledR} 16.0$.

Tabela 27- Etapas da metodologia para simulação CFD do escoamento em um silenciador reativo utilizando o $\mathrm{CFX}^{\circledR}$

\begin{tabular}{|c|c|}
\hline Etapa & Descrição \\
\hline $1^{\mathrm{a}}-$ Construir a geometria & $\begin{array}{l}\text { - Fazer a modelagem do volume interno do } \\
\text { silenciador. }\end{array}$ \\
\hline $2^{\mathrm{a}}-$ Construir a malha & $\begin{array}{l}\text { - Dividir o domínio em elementos tetraédricos gerados } \\
\text { automaticamente pelo software. A malha CFD é } \\
\text { bem discretizada e as regiões próximas às paredes } \\
\text { do silenciador são densas a fim de permitir melhor } \\
\text { tratamento das condições de contorno. Esse efeito é } \\
\text { realizado pela função "inflation". }\end{array}$ \\
\hline
\end{tabular}

\begin{tabular}{|c|c|}
\hline $\begin{array}{l}\text { 3a - Definir tipo de fluido e suas } \\
\text { propriedades }\end{array}$ & $\begin{array}{l}\text { O fluido de trabalho é ar a } 25^{\circ} \mathrm{C} \text {, cujas propriedades } \\
\text { estão definidas na biblioteca disponível no software. }\end{array}$ \\
\hline $\begin{array}{l}4^{\mathrm{a}}-\text { Definir modelo de } \\
\text { turbulência do escoamento }\end{array}$ & - Modelo de turbulência $k-\varepsilon[37,63,64]$. \\
\hline $\begin{array}{l}\text { 5a - Definir condições de } \\
\text { contorno }\end{array}$ & $\begin{array}{l}\text { - Na seção transversal da extremidade do duto de } \\
\text { entrada foi definida velocidade de entrada na } \\
\text { direção z } \\
\text { - Na seção transversal da extremidade do duto de } \\
\text { saída foi definida pressão estática constante, nesse } \\
\text { caso } 0 \mathrm{~Pa} \text {, relativo à pressão atmosférica } \\
\text { - As demais paredes do silenciador são assumidas } \\
\text { como estáticas, sem deslizamento e adiabática. }\end{array}$ \\
\hline $5^{\mathrm{a}}$ - Definir tipo de análise & - Definir a análise como regime permanente. \\
\hline $\begin{array}{l}\text { 6ª - Definir parâmetros de } \\
\text { convergência da simulação }\end{array}$ & $\begin{array}{l}\text { - Definir número máximo de iterações. Foi adotado o } \\
\text { valor de } 10.000 \text { iterações } \\
\text { - Definir o fator de erro residual. Foi adotado o valor } \\
\text { de } 10^{-6} \text {. }\end{array}$ \\
\hline
\end{tabular}


7ํ - Resolver o modelo

8 - Exportar dados de velocidade
- A simulação é feita até que um dos critérios de convergência seja atingido.

- Os valores de velocidade em cada nó devem ser exportados em arquivo no formato .CGNS.

A simulação em CFD do campo de escoamento foi realizada para cada um dos modelos de câmara de expansão, variando a velocidade de entrada em $10 \mathrm{~m} / \mathrm{s}, 30 \mathrm{~m} / \mathrm{s}$ e $60 \mathrm{~m} / \mathrm{s}$. As geometrias construídas para cada silenciador são mostradas na Figura 84.

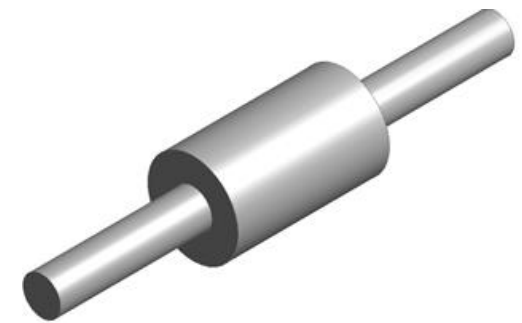

(a)

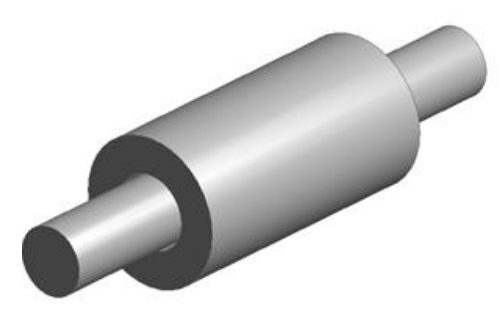

(b)

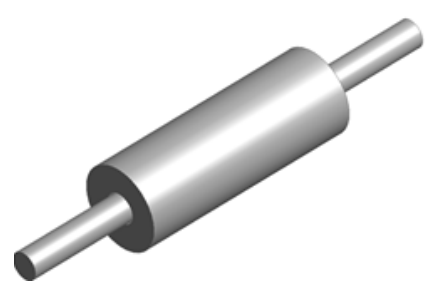

(c)

Figura 84 - Geometria dos silenciadores no DesignModeler (a) modelo II (b) modelo III e (c) modelo IV

A Figura 85, Figura 86 e Figura 87 mostram as vistas isométricas e em corte das malhas geradas para cada silenciador. Na vista em corte é possível observar como a densidade da malha aumenta nas regiões próximas das paredes do tubo.

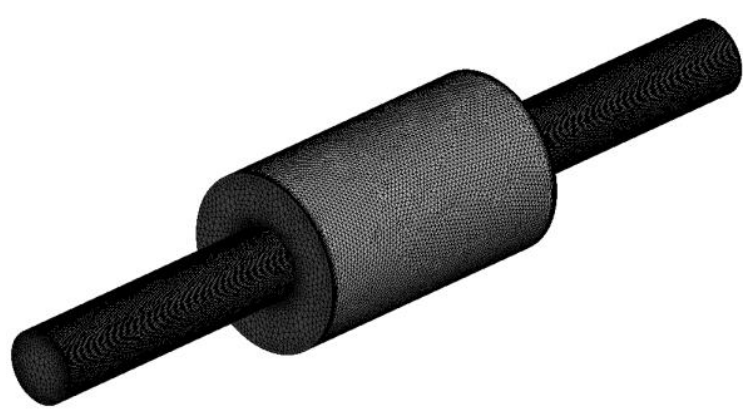

(a)

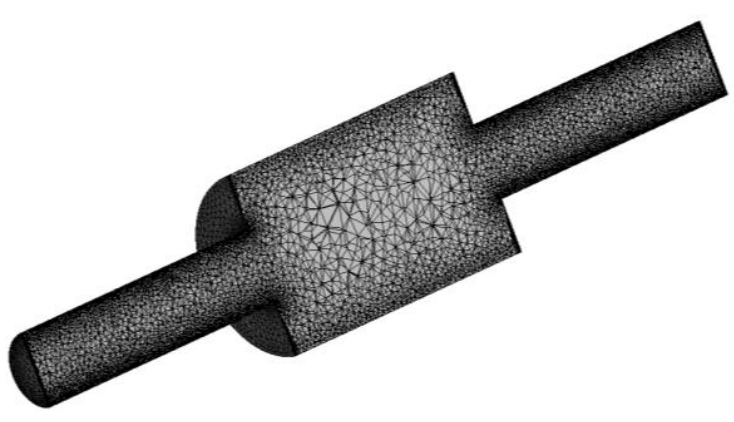

(b)

Figura 85 - Malha em CFD do modelo II (a) vista isométrica e (b) vista em corte 


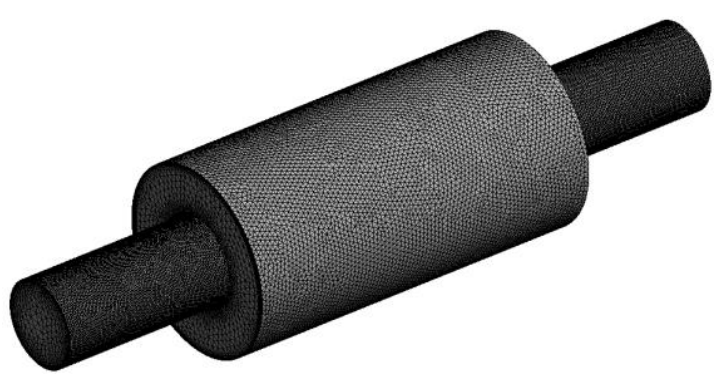

(a)

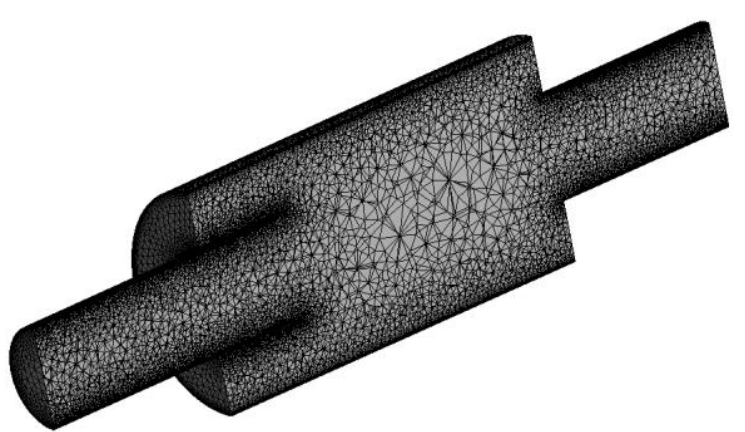

(b)

Figura 86 - Malha em CFD do modelo III (a) vista isométrica e (b) vista em corte

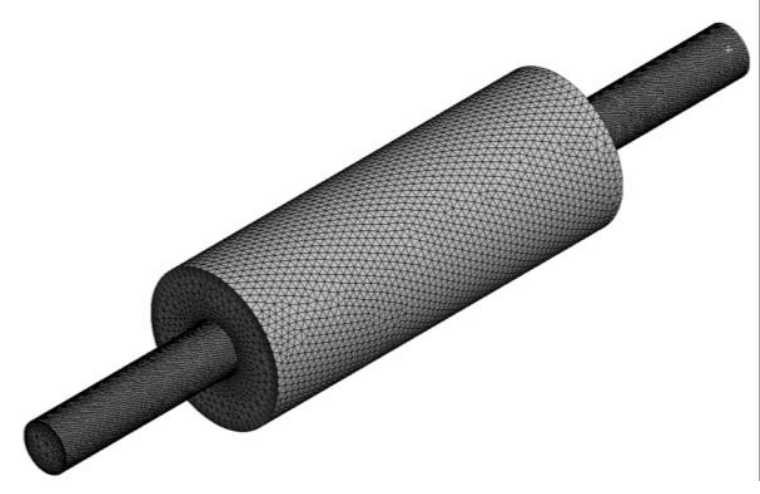

(e)

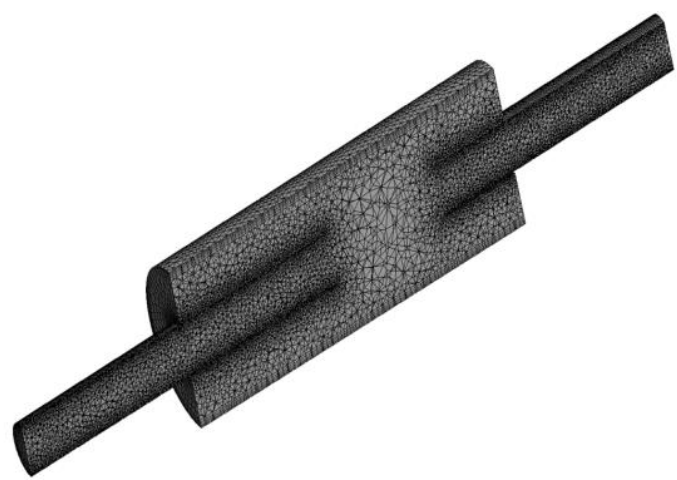

(f)

Figura 87 - Malha em CFD do modelo IV (a) vista isométrica e (b) vista em corte

Os números de nós e elementos que constituem cada malha são apresentados na Tabela 28.

Tabela 28- Composição da malha CFD de cada modelo de silenciador

\begin{tabular}{ccc}
\hline Modelo de silenciador & Nós & Elementos \\
\hline Modelo II & 1605806 & 1080418 \\
\hline Modelo III & 2926111 & 1490305 \\
\hline Modelo IV & 1228358 & 689909
\end{tabular}

A Tabela 29 registra o tempo consumido por cada simulação, em função da velocidade de entrada. Em todos os casos, a convergência dos resultados se deu pelo critério de erro residual. 
Tabela 29 - Tempo de simulação CFD em função da velocidade de entrada

\begin{tabular}{|c|c|c|c|}
\hline Modelo de silenciador & $10 \mathrm{~m} / \mathrm{s}$ & $30 \mathrm{~m} / \mathrm{s}$ & $60 \mathrm{~m} / \mathrm{s}$ \\
\hline Modelo II & 1h18min47s & $2 \mathrm{~h} 03 \mathrm{~min} 24 \mathrm{~s}$ & Oh59min14s \\
\hline Modelo III & $1 \mathrm{~h} 22 \mathrm{~min} 38 \mathrm{~s}$ & 2h08min57s & $1 \mathrm{~h} 51 \mathrm{~min} 50 \mathrm{~s}$ \\
\hline Modelo IV & 1h39min17s & $1 \mathrm{~h} 21 \mathrm{~min} 01 \mathrm{~s}$ & $1 \mathrm{~h} 48 \mathrm{~min} 07 \mathrm{~s}$ \\
\hline
\end{tabular}

Como resultado da análise, é possível obter o contorno de velocidade ao longo do silenciador, que é apresentado na Figura 88, Figura 89 e Figura 90 para o modelo II, modelo III e modelo IV, respectivamente.

Nota-se que o aumento da velocidade não altera sua distribuição no interior do silenciador. Em todos os modelos, os dutos de saída registram os valores mais elevados de velocidade. Os valores mais baixos ocorrem próximos às paredes das câmaras de expansão.

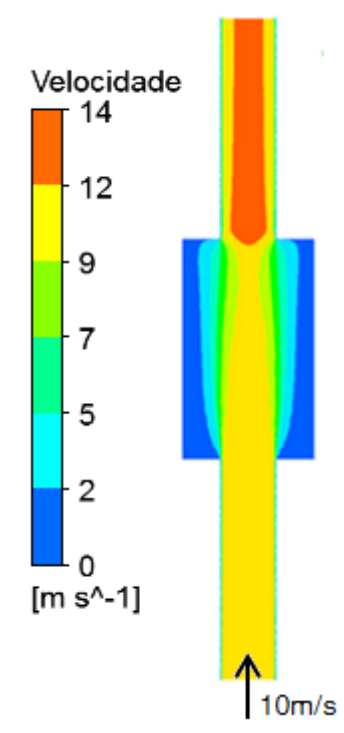

(a)

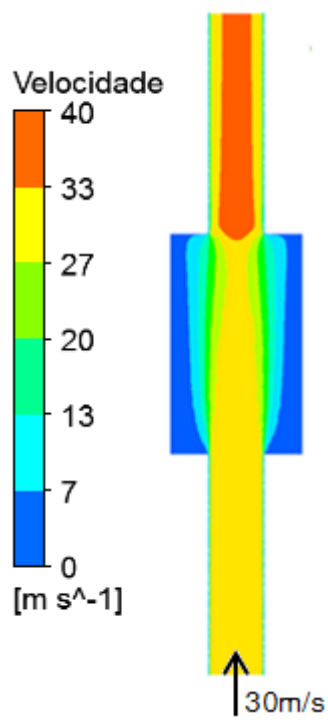

(b)

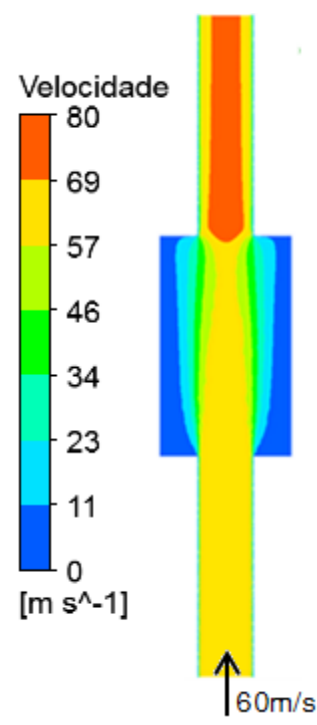

(c)

Figura 88 - Contorno de velocidade obtido para o modelo II com velocidade de entrada de (a) $10 \mathrm{~m} / \mathrm{s}$ (b) $30 \mathrm{~m} / \mathrm{s}$ e (c) $60 \mathrm{~m} / \mathrm{s}$ 


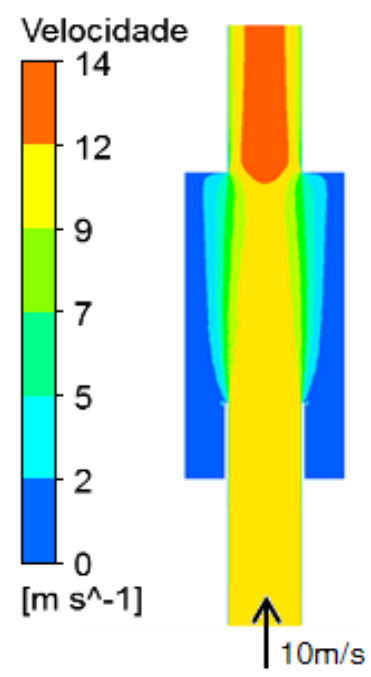

(a)

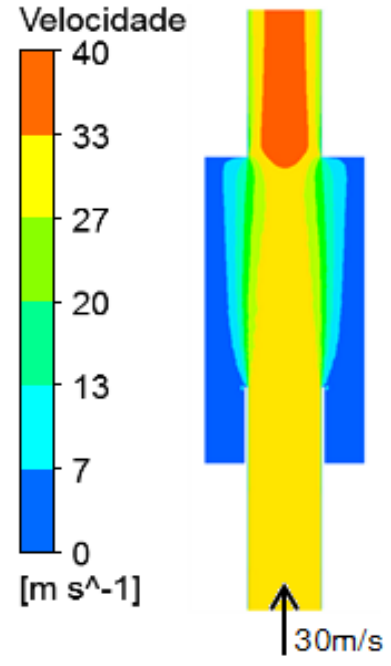

(b)

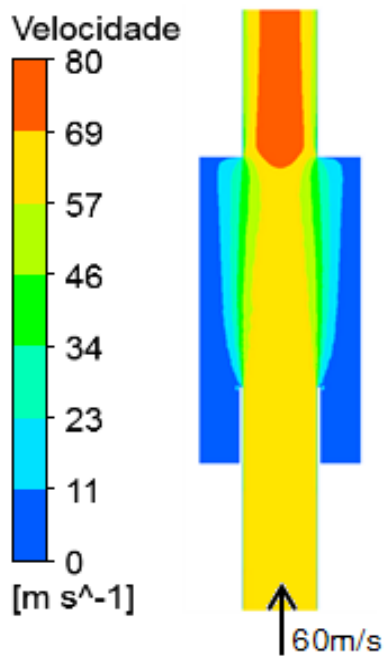

(c)

Figura 89- Contorno de velocidade obtido para o modelo III com velocidade de entrada de (a) $10 \mathrm{~m} / \mathrm{s}$ (b) $30 \mathrm{~m} / \mathrm{s}$ e (c) $60 \mathrm{~m} / \mathrm{s}$

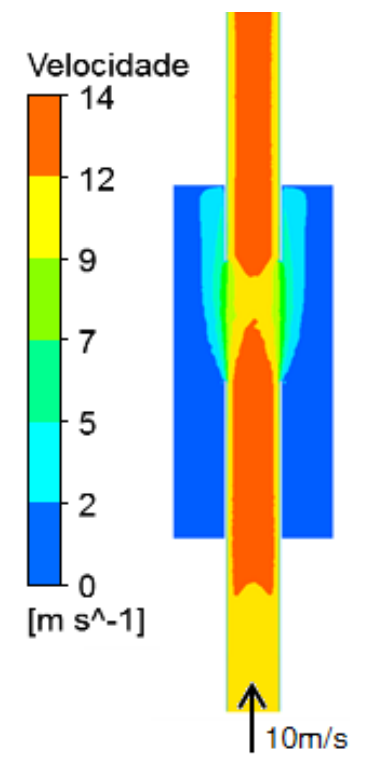

(a)

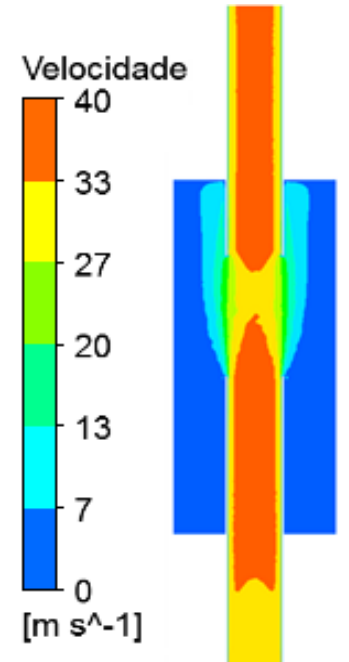

$\uparrow_{30 \mathrm{~m} / \mathrm{s}}$

(b)

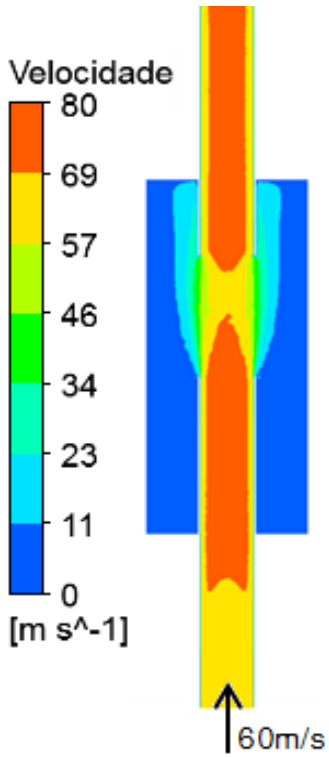

(c)

Figura 90 - Contorno de velocidade obtido para o modelo IV com velocidade de entrada de (a) $10 \mathrm{~m} / \mathrm{s}$ (b) $30 \mathrm{~m} / \mathrm{s}$ e (c) $60 \mathrm{~m} / \mathrm{s}$

\subsubsection{Modelagem acústica - MEF}

Conforme mostra o fluxograma da Figura 83, a modelagem acústica deve ser iniciada no Virtual.lab ${ }^{\circledR}$ em paralelo à simulação no CFX. 
Esta modelagem é a mesma daquela utilizada para estimativa da TL no Virtual.lab ${ }^{\circledast}$ sem presença de escoamento. Portanto, os modelos da análise sem fluxo foram também utilizados aqui.

4.2.2.3. Transferência do campo de velocidade de fluxo da malha CFD para malha acústica

Com resultado da simulação no CFX deve-se obter um arquivo em formato .CGNS que contém informações sobre a posição dos nós da malha CFD e o valor de velocidade de fluxo associado a cada um deles. Esses dados são importados no Virtual.lab ${ }^{\circledR}$ onde serão transferidos para malha acústica. Essa transferência é realizada pela função Data Transfer que o software dispõe.

Como a malha CFD é muito mais refinada que a malha acústica, não existe uma correspondência direta entre os nós, e por isso é necessário um algoritmo de mapeamento, realizado pela função Mesh Mapping. Neste trabalho, foi empregado o Algoritmo de Distância Máxima (Maximmum Distance Algorithm), comumente adotado para fazer o mapeamento entre duas malhas com diferentes densidades de nós [29].

Para este algoritmo são necessários dois parâmetros: 1) número de nós $(N)$ : é o número máximo de nós da malha de origem (CFD) que é considerado para o mapeamento com um nó da malha alvo (malha acústica) e 2) a distância máxima $(R)$ : apenas os nós da malha CFD que se encontram dentro de uma esfera com raio $R$, centrado no nó da malha acústica, são considerados.

Dessa forma, o valor de velocidade atribuído ao nó da malha acústica é uma média ponderada do valor para os $N$ nós da malha CFD. $O$ fator de ponderação é o inverso da distância entre os nós, dado por [61]:

$$
W_{i}=\frac{1 / d_{i}}{\sum_{i=1}^{N}\left(1 / d_{i}\right)}
$$


O valor da velocidade transferido para malha acústica é então:

$v^{\text {acústica }}=\frac{\sum_{i=1}^{N}\left(v_{i}^{C F D} / d_{i}\right)}{\sum_{i=1}^{N}\left(1 / d_{i}\right)}$

em que $d_{i}$ é a distância entre o nó da malha de origem e o nó da malha de destino e $v^{C F D}$ é o valor da velocidade no nó da malha CFD.

Valores apropriados para $N$ e $R$ são dados automaticamente quando as malhas CFD e acústica são introduzidas na função Data Transfer.

Para exemplificar, a Figura 91 compara o contorno de velocidade da malha CFD e da malha acústica do modelo III, para velocidade de entrada de $60 \mathrm{~m} / \mathrm{s}, \mathrm{com} N=8$ e $R=22.4 \mathrm{~mm}$.

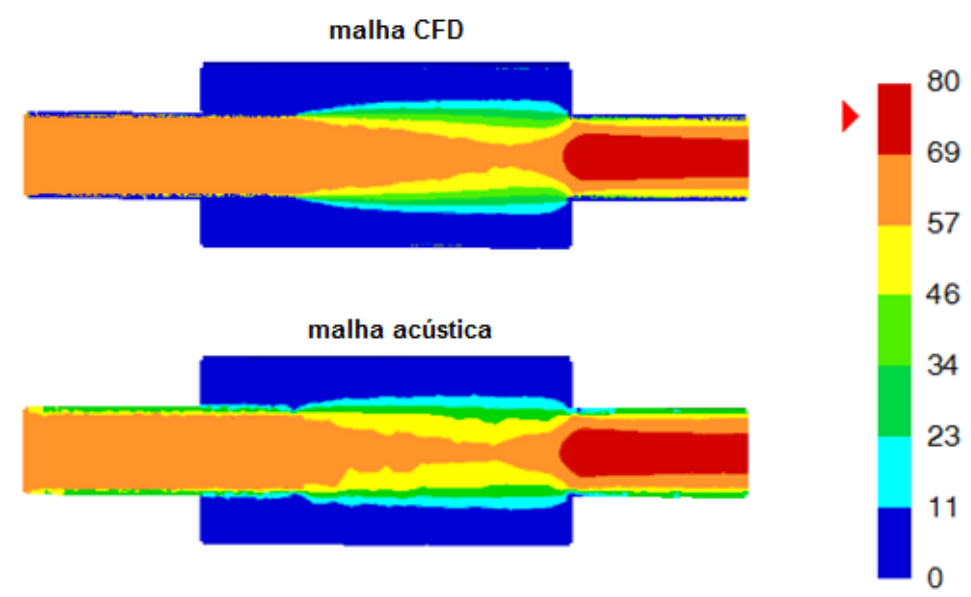

Figura 91 - Comparação entre o contorno de velocidade na malha CFD e malha acústica para o modelo III

Nota-se diferença na região próxima às paredes do duto de entrada e saída, provavelmente relacionado ao adensamento da malha CFD que não é reproduzida na malha acústica. Mas, considerando que a malha acústica é significativamente mais grosseira do que a malha CFD, o resultado da transferência de velocidade é satisfatório, visto que de forma geral a distribuição de velocidade é preservada. 
4.2.2.4. Solução do problema considerando a presença de escoamento

Em seguida, parte-se para solução da equação de onda pelo método de elementos finitos, com a presença de escoamento, conforme Eq.(22). Para isso, deve ser realizada a análise harmônica, na faixa de frequência de interesse, ativando no Virtual.lab ${ }^{\circledR}$ a opção de considerar a presença de fluxo e associá-la ao resultado da transferência do campo de velocidade da malha CFD para acústica.

Ao final da análise harmônica, é necessário obter o valor da pressão sonora em três pontos para estimar a TL pelo método da decomposição, conforme já descrito nas etapas 8 e 9 da Tabela 15.

A Figura 92 apresenta as curvas de TL do modelo II variando a velocidade de fluxo. Para comparação, é mostrada também a curva obtida com a análise sem fluxo $(\mathrm{v}=0 \mathrm{~m} / \mathrm{s})$.

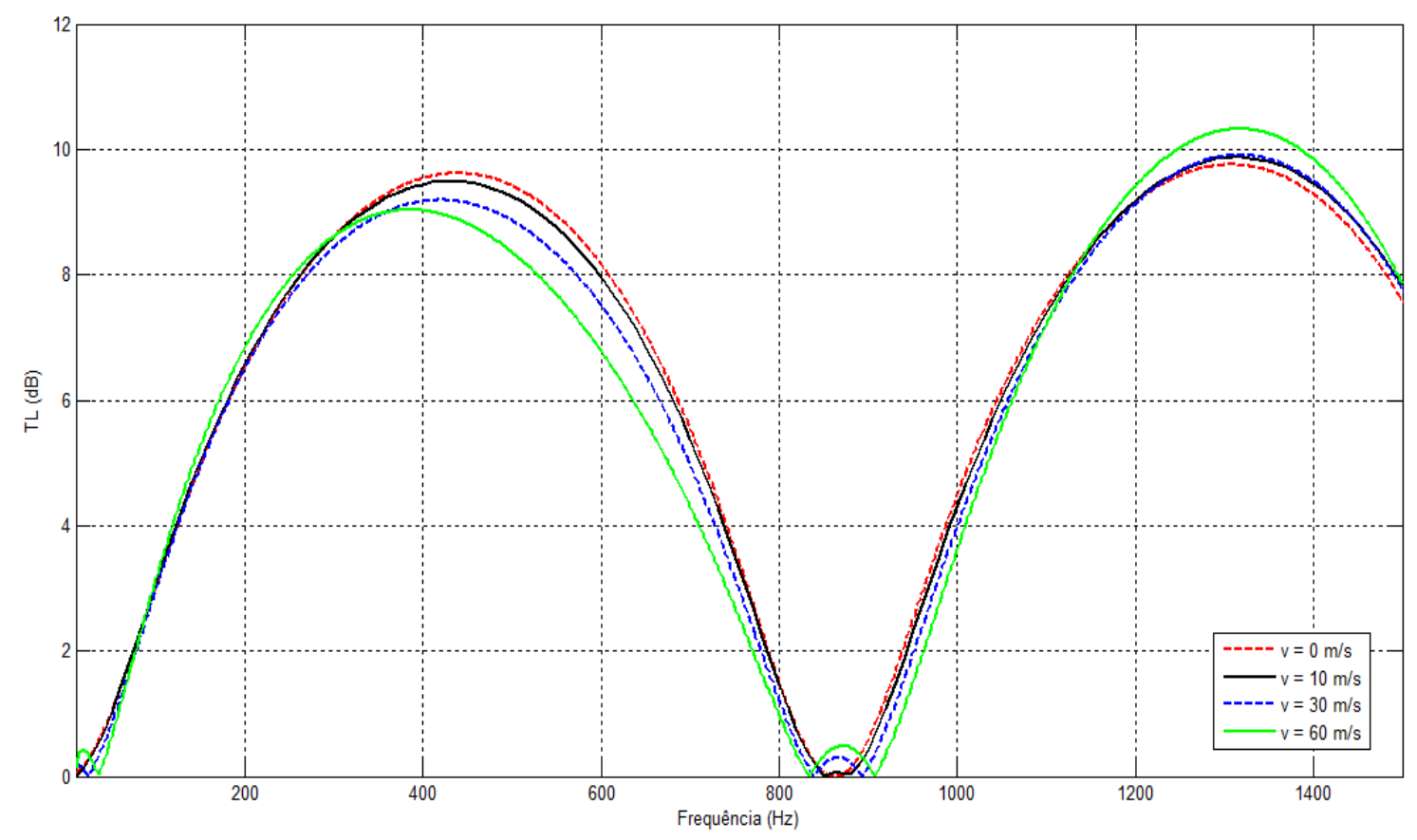

Figura 92 - TL do modelo II variando a velocidade de escoamento

Observa-se que aproximadamente entre $240 \mathrm{~Hz}$ e $1140 \mathrm{~Hz}$ o aumento da velocidade de fluxo reduz a atenuação dos silenciadores. Comparando, por 
exemplo, a curva de $60 \mathrm{~m} / \mathrm{s}$ com a curva sem escoamento, a redução é de até $1,41 \mathrm{~dB}$, em $626 \mathrm{~Hz}$. Nota-se também que o fluxo provoca o surgimento de um novo domo de baixa amplitude.

Já a partir de $1140 \mathrm{~Hz}$, a presença de escoamento aumenta a amplitude das curvas, principalmente para velocidade de $60 \mathrm{~m} / \mathrm{s}$, cujo aumento em relação à curva sem fluxo é de até $0,59 \mathrm{~dB}$ em $1358 \mathrm{~Hz}$.

O comportamento descrito acima não foi notado nos resultados obtidos pelo método da matriz de transferência. Como foi mostrado no item 4.2.1.1, na análise 1D ocorreu aumento da amplitude de atenuação do silenciador, em toda a faixa de frequência, à medida que a velocidade de fluxo cresceu.

Para efeito de comparação, a Figura 93 mostra a TL obtida pelo MEF e pelo MMT, considerando os diferentes fatores de correção, para velocidade de fluxo de $10 \mathrm{~m} / \mathrm{s}$.

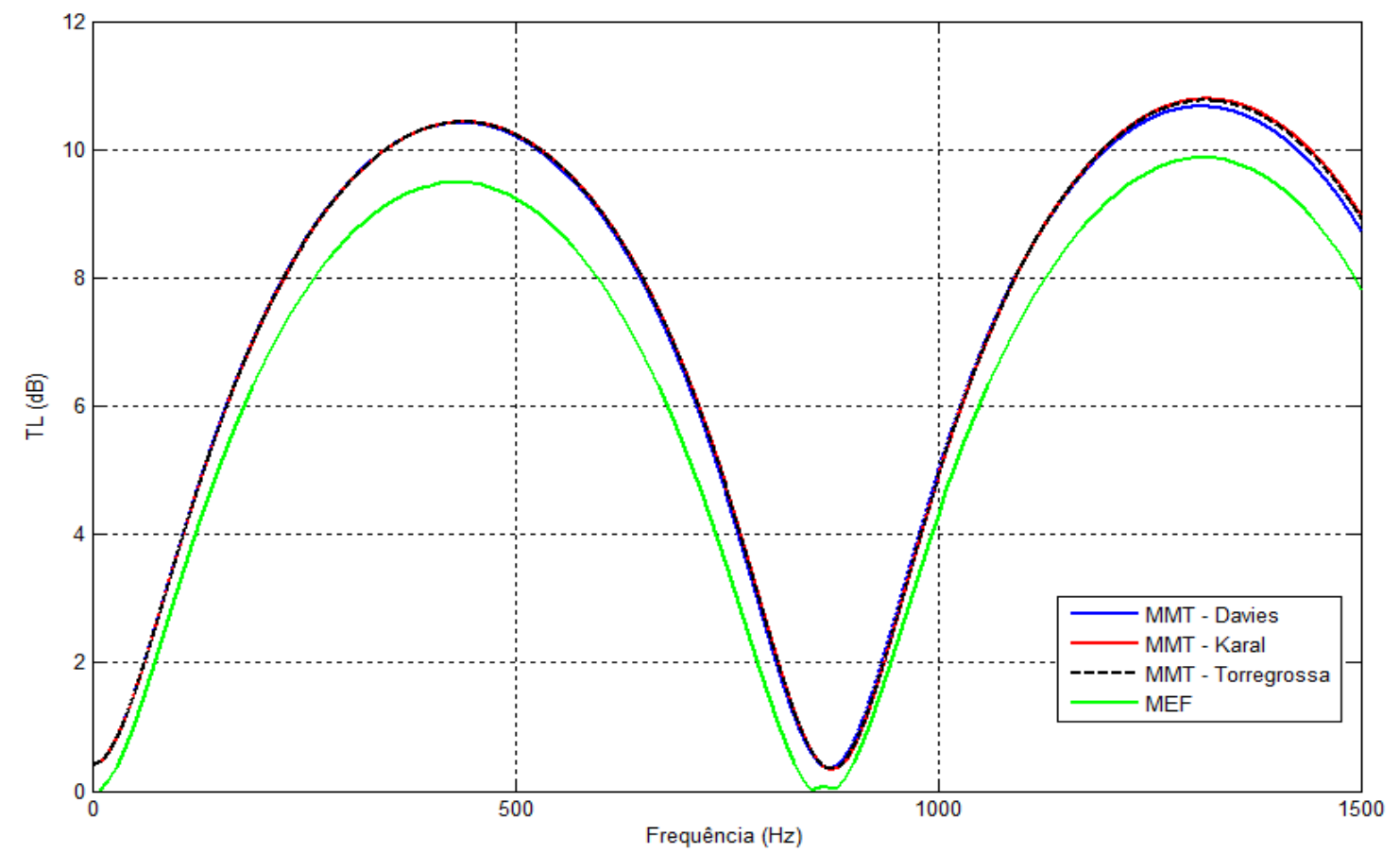

Figura 93 - Comparação da TL obtida pelo MMT e MEF para o modelo II com velocidade de fluxo de $10 \mathrm{~m} / \mathrm{s}$ 
Observa-se que a amplitude da curva estimada pelo MMT é significativamente maior que a estimada pelo MEF. Portanto, para o modelo II, na presença de fluxo, a análise unidimensional não apresentou boa concordância com análise tridimensional proposta neste trabalho.

A Figura 94 ilustra a distribuição da amplitude da pressão sonora em 626 $\mathrm{Hz}$ no modelo II, para as velocidades de fluxo avaliadas. Verifica-se que a distribuição da pressão sonora ao longo do silenciador é semelhante nos quatro casos avaliados.

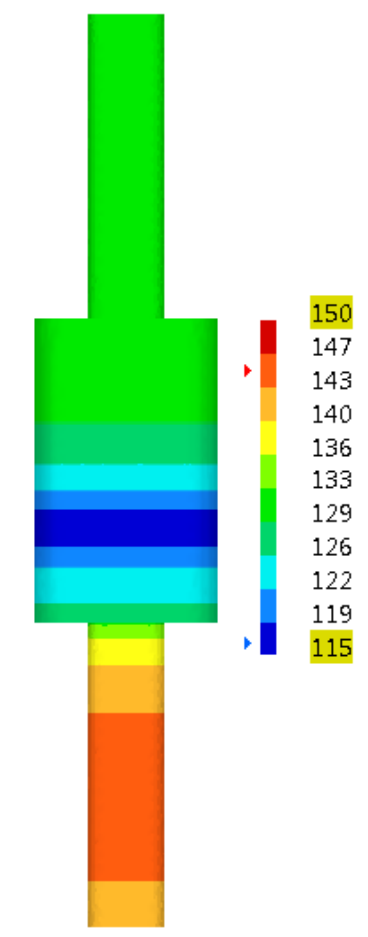

(a)

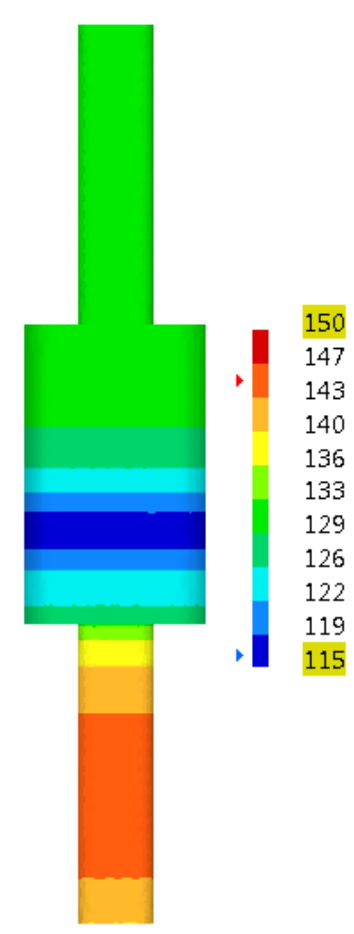

(b)

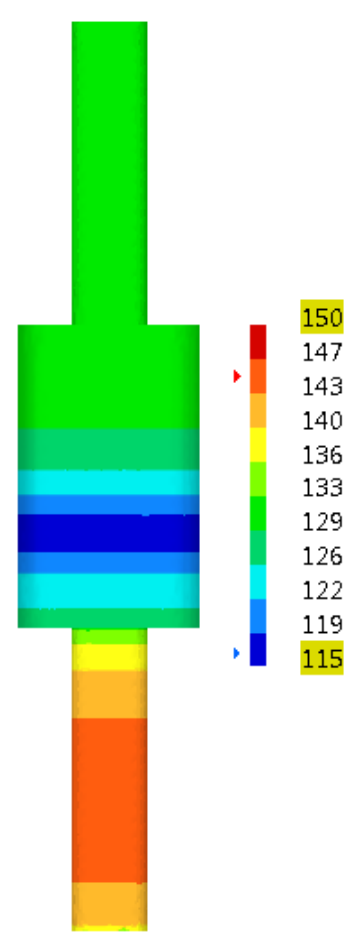

(c)

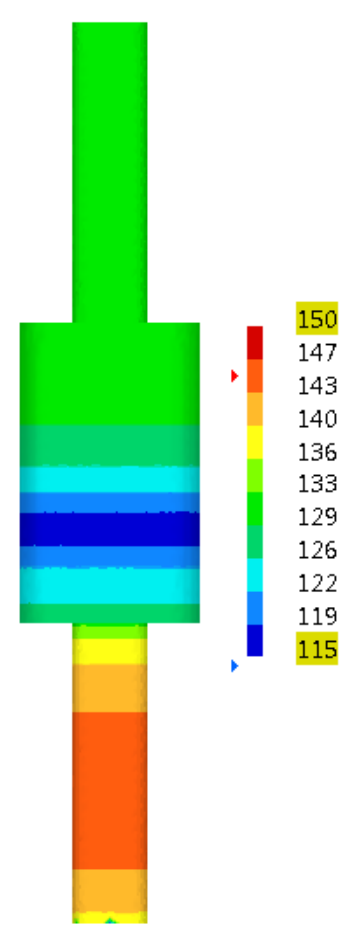

(d)

Figura 94 - Distribuição da pressão sonora (dB) do modelo II em $1398 \mathrm{~Hz}(\mathrm{a})$ sem escoamento e com velocidade de fluxo de (b) $10 \mathrm{~m} / \mathrm{s}$, (c) $30 \mathrm{~m} / \mathrm{s}$ e (d) $60 \mathrm{~m} / \mathrm{s}$

A Figura 95 apresenta as curvas de TL do modelo III variando a velocidade de fluxo. Para comparação, é mostrada também a curva obtida com a análise sem fluxo $(\mathrm{v}=0 \mathrm{~m} / \mathrm{s})$. E a Tabela 30 registra os valores de frequência e amplitude em que ocorre a atenuação máxima. 


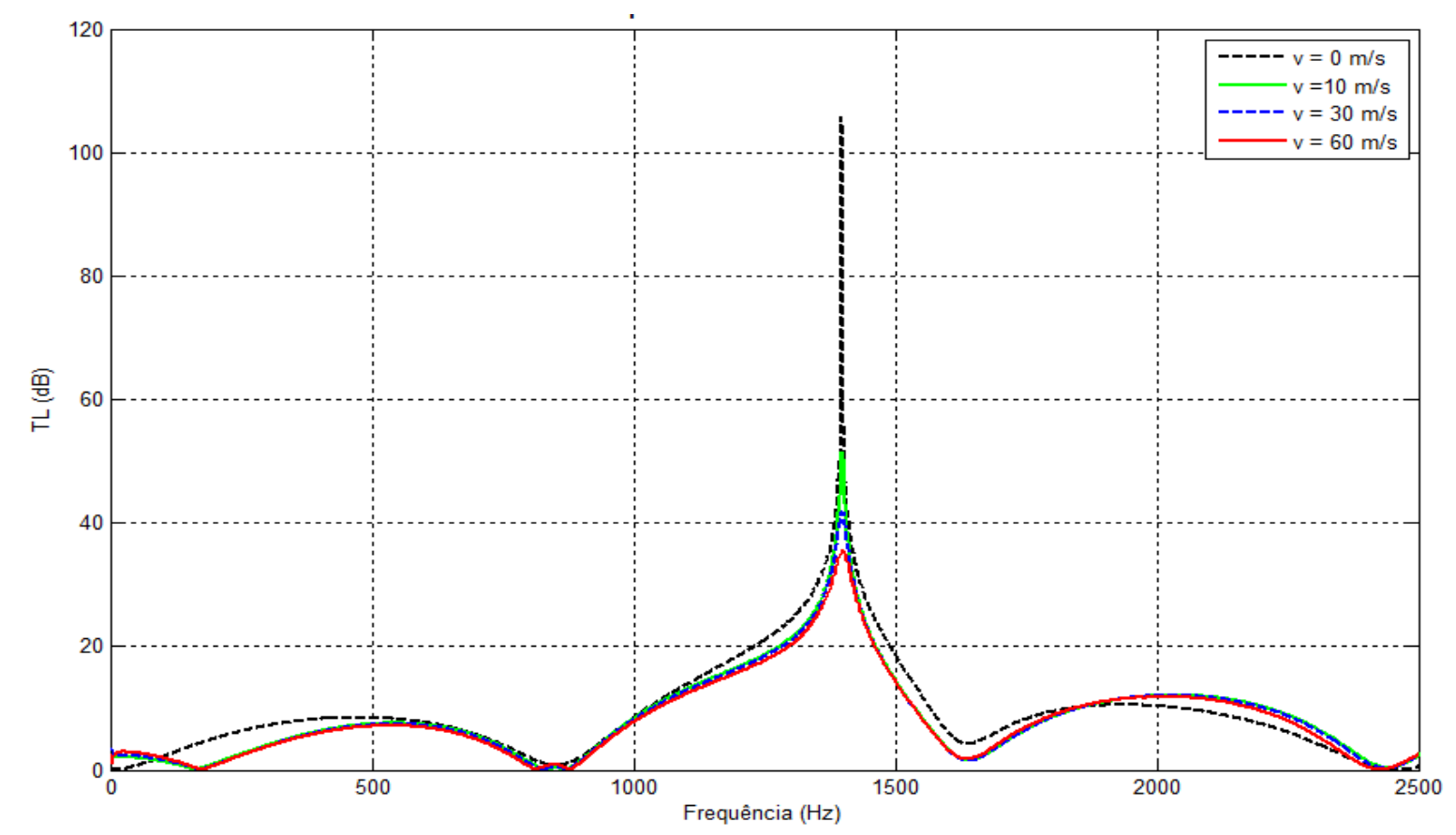

Figura 95 - TL do modelo III variando a velocidade de escoamento

Tabela 30- Valores de frequência e amplitude do pico de atenuação da TL do modelo III

\begin{tabular}{ccc}
\hline Velocidade de fluxo & Frequência & Amplitude \\
\hline Sem fluxo & $1398 \mathrm{~Hz}$ & $105,7 \mathrm{~dB}$ \\
\hline $10 \mathrm{~m} / \mathrm{s}$ & $1398 \mathrm{~Hz}$ & $51,38 \mathrm{~dB}$ \\
\hline $30 \mathrm{~m} / \mathrm{s}$ & $1398 \mathrm{~Hz}$ & $41,83 \mathrm{~dB}$ \\
\hline $60 \mathrm{~m} / \mathrm{s}$ & $1398 \mathrm{~Hz}$ & $35,33 \mathrm{~dB}$ \\
\hline
\end{tabular}

Observa-se que a frequência de ressonância se manteve a mesma nos quatro casos avaliados, mas os valores de amplitude são consideravelmente reduzidos com o aumento da velocidade de fluxo. Ao comparar a atenuação máxima da curva sem fluxo, com a curva para velocidade de $60 \mathrm{~m} / \mathrm{s}$, tem-se uma redução de aproximadamente $66 \%$ no desempenho do silenciador.

Como mostrado no item 4.2.1.2, os resultados obtidos com o método da matriz de transferência também registraram a tendência de redução da TL com o aumento da velocidade de fluxo. Entretanto, a frequência de atenuação também foi modificada pela presença do escoamento. 
A Figura 96 mostra a TL obtida pelo MEF e pelo MMT, considerando os diferentes fatores de correção, para velocidade de fluxo de $10 \mathrm{~m} / \mathrm{s}$. Observa-se que nenhuma das curvas da análise 1D obteve boa aproximação com a curva obtida pela análise 3D. A amplitude obtida pelo MMT foi subestimada em relação ao MMT.

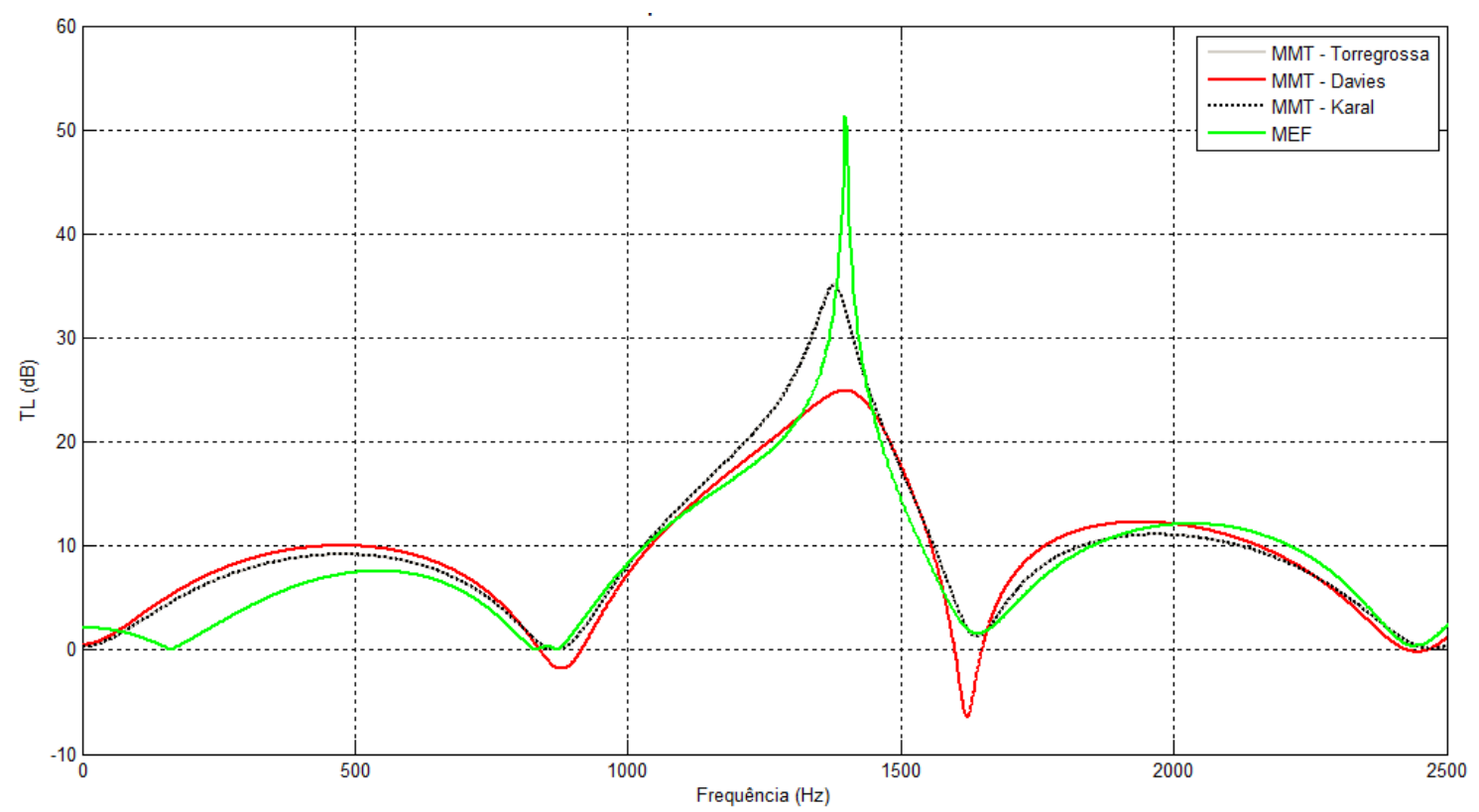

Figura 96 - Comparação da TL obtida pelo MMT e MEF para o modelo III com velocidade de fluxo de $10 \mathrm{~m} / \mathrm{s}$

A Figura 97 ilustra a distribuição da amplitude da pressão sonora em $1398 \mathrm{~Hz}$, para as velocidades de fluxo avaliadas.

A distribuição da pressão sonora ao longo do silenciador é semelhante nos quatro casos avaliados. Nota-se, porém, que os modelos com velocidade de fluxo de $10 \mathrm{~m} / \mathrm{s}$ e $30 \mathrm{~m} / \mathrm{s}$ apresentam valores de amplitude mais baixos na região da câmara de expansão. 


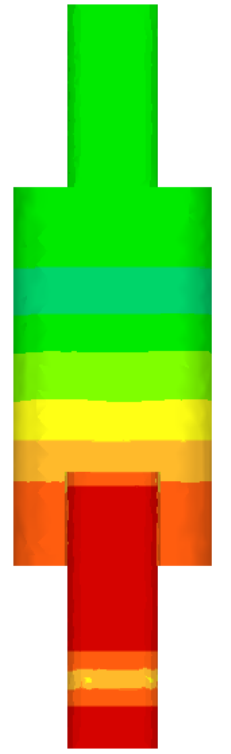

(a)

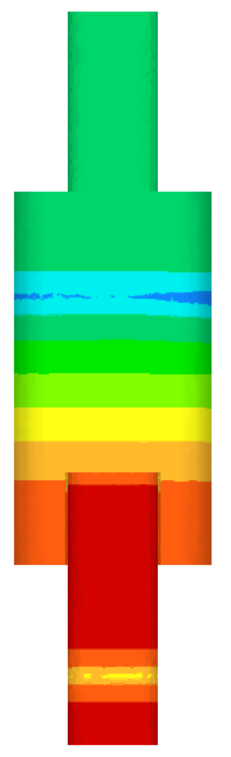

(b)

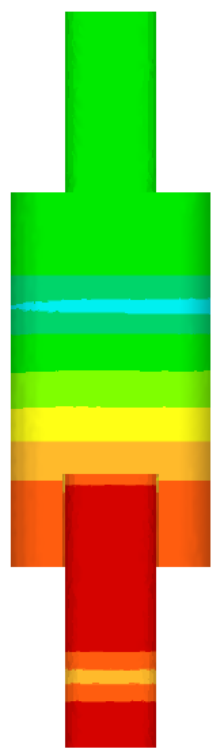

(c)

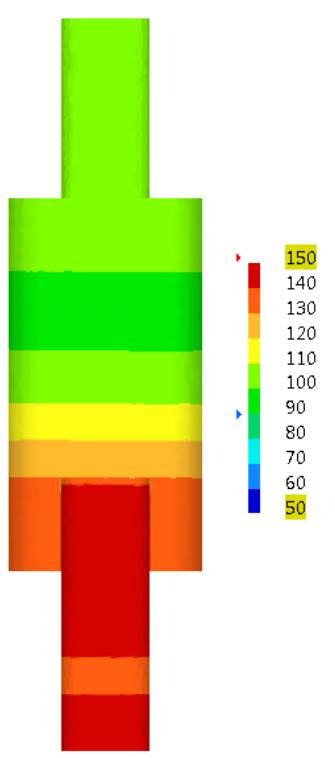

(d)

Figura 97 - Distribuição da pressão sonora (dB) no modelo III em $1398 \mathrm{~Hz}(\mathrm{a})$ sem escoamento e com velocidade de fluxo de (b) $10 \mathrm{~m} / \mathrm{s}$, (c) $30 \mathrm{~m} / \mathrm{s} \mathrm{e} \mathrm{(d)} 60 \mathrm{~m} / \mathrm{s}$

A Figura 98 apresenta as curvas de TL do modelo IV variando a velocidade de fluxo. Para comparação, é mostrada também a curva obtida com a análise sem fluxo $(\mathrm{v}=0 \mathrm{~m} / \mathrm{s})$. E a Tabela 31 registra os valores de frequência e amplitude em que ocorrem os picos de atenuação.

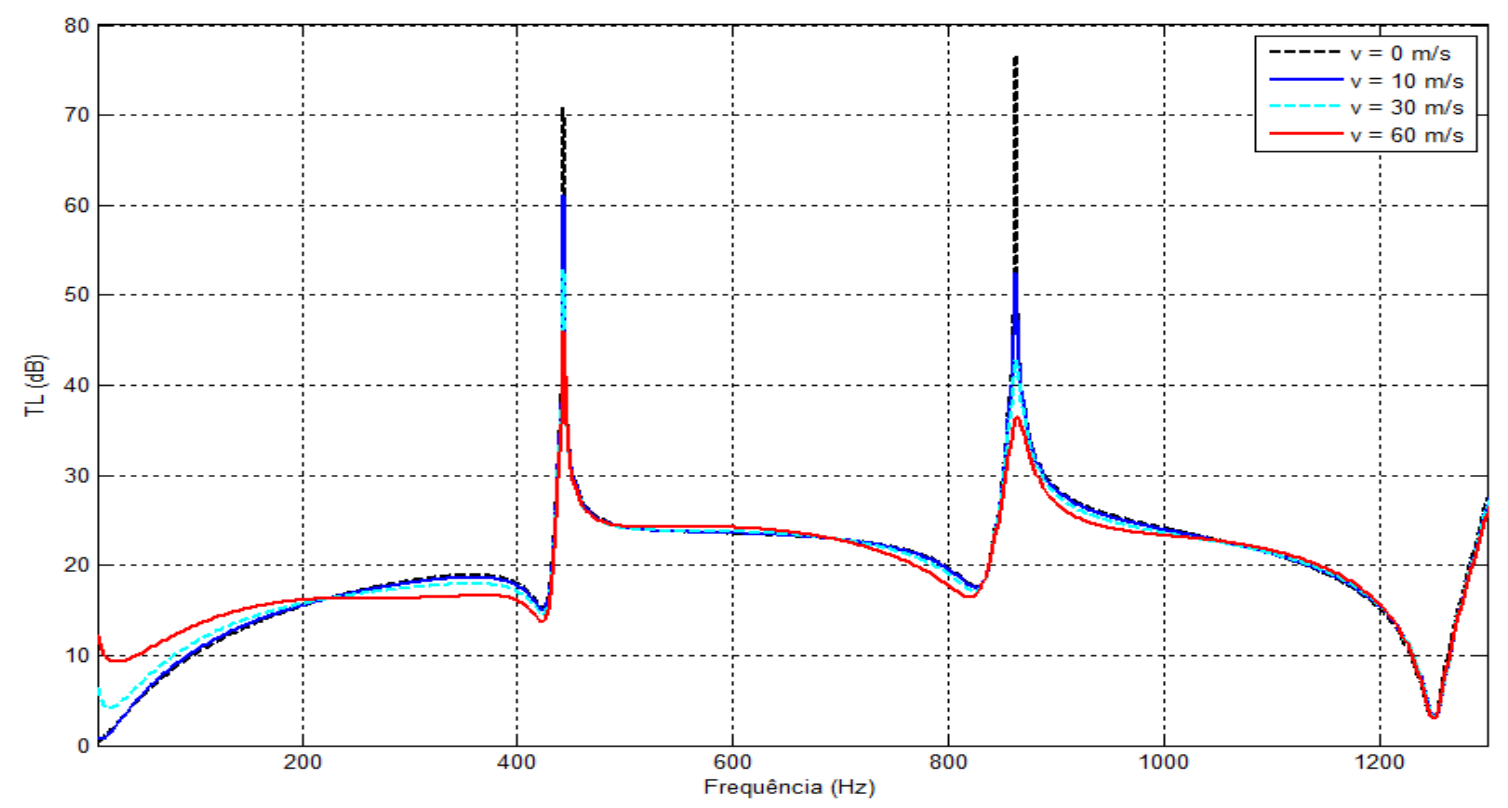

Figura 98 - TL do modelo IV variando a velocidade de escoamento 
Tabela 31- Valores de frequência e amplitude dos picos de atenuação da TL do modelo IV

\begin{tabular}{c|cc|cc}
\cline { 2 - 5 } & \multicolumn{2}{c}{ 10 $^{\text {10 }}$} & \multicolumn{2}{c}{ 20 $^{\mathbf{0}}$ pico } \\
\hline Velocidade de fluxo & Frequência & Amplitude & Frequência & Amplitude \\
\hline Sem fluxo & $442 \mathrm{~Hz}$ & $70,75 \mathrm{~dB}$ & $862 \mathrm{~Hz}$ & $76,75 \mathrm{~dB}$ \\
\hline $10 \mathrm{~m} / \mathrm{s}$ & $442 \mathrm{~Hz}$ & $61,10 \mathrm{~dB}$ & $862 \mathrm{~Hz}$ & $52,51 \mathrm{~dB}$ \\
\hline $30 \mathrm{~m} / \mathrm{s}$ & $442 \mathrm{~Hz}$ & $52,79 \mathrm{~dB}$ & $862 \mathrm{~Hz}$ & $42,79 \mathrm{~dB}$ \\
\hline $60 \mathrm{~m} / \mathrm{s}$ & $442 \mathrm{~Hz}$ & $45,99 \mathrm{~dB}$ & $862 \mathrm{~Hz}$ & $36,54 \mathrm{~dB}$ \\
\hline
\end{tabular}

Observa-se que as frequências em que ocorrem os picos de atenuação se mantiveram as mesmas nos quatro casos avaliados. Mas os valores de amplitude são consideravelmente reduzidos com o aumento da velocidade de fluxo. Ao comparar a curva sem fluxo, com a curva para velocidade de $60 \mathrm{~m} / \mathrm{s}$, tem-se uma redução de aproximadamente $35 \%$ na atenuação promovida em $442 \mathrm{~Hz}$ e $52 \%$ em $862 \mathrm{~Hz}$.

Como mostrado no item 4.2.1.3, os resultados obtidos com o método da matriz de transferência também registraram a tendência de redução da TL com o aumento da velocidade de fluxo. Entretanto, as frequências de atenuação também foram modificadas pela presença do escoamento.

A Figura 99 mostra a TL obtida pelo MEF e pelo MMT, considerando os diferentes fatores de correção, para velocidade de fluxo de $10 \mathrm{~m} / \mathrm{s}$. Observa-se que nenhuma das curvas da análise unidimensional obteve boa aproximação com a curva obtida pela análise 3D. A amplitude obtida pelo MMT foi subestimada em relação ao MMT.

A Figura 100 ilustra a distribuição da amplitude da pressão sonora em $432 \mathrm{~Hz}$, para as velocidades de fluxo avaliadas.

A distribuição da pressão sonora ao longo do silenciador é semelhante nos quatro casos avaliados. Porém, a amplitude da pressão no tubo de saída reduz de forma relevante e gradativa com o aumento da velocidade de escoamento. 


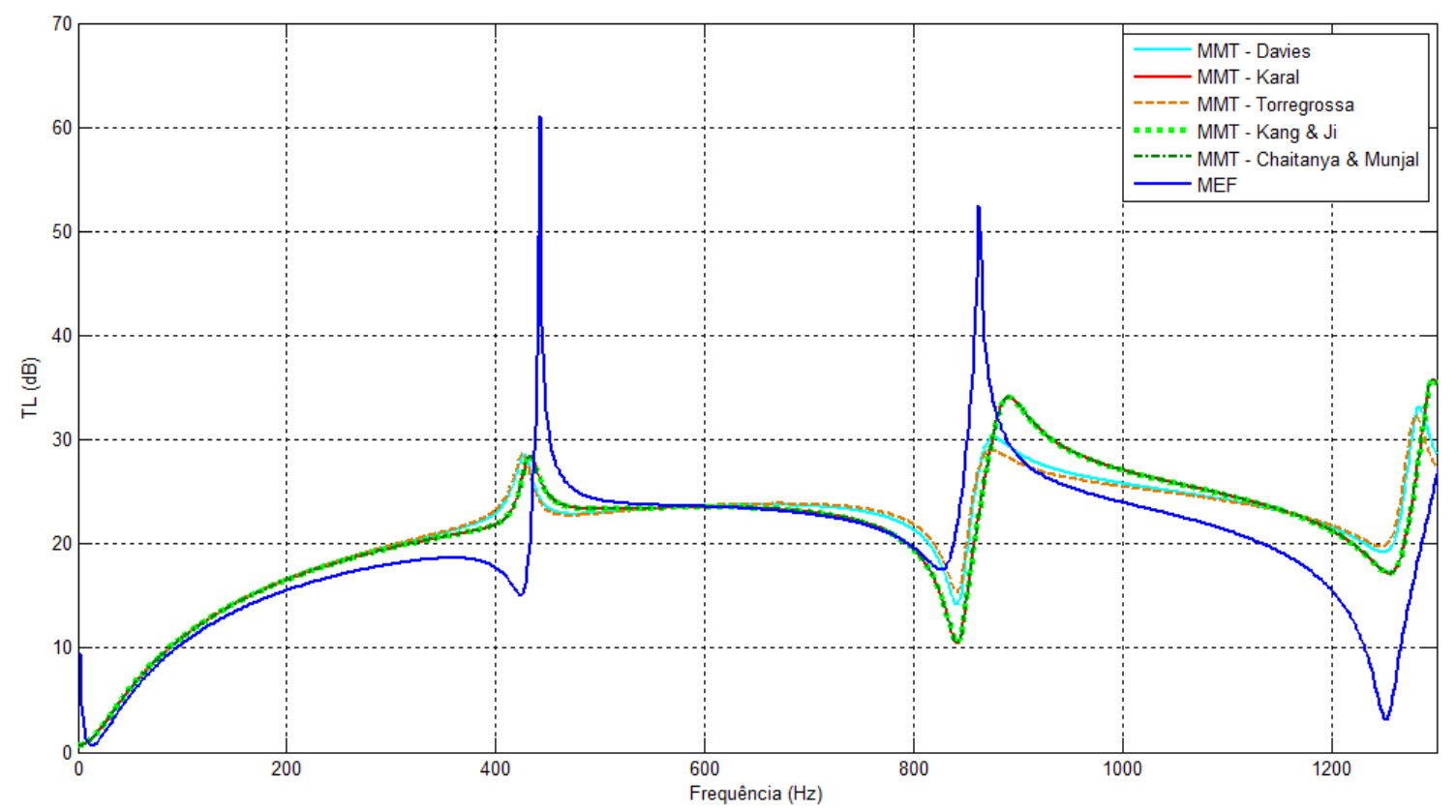

Figura 99 - Comparação da TL obtida pelo MMT e MEF para o modelo IV com velocidade de fluxo de $10 \mathrm{~m} / \mathrm{s}$

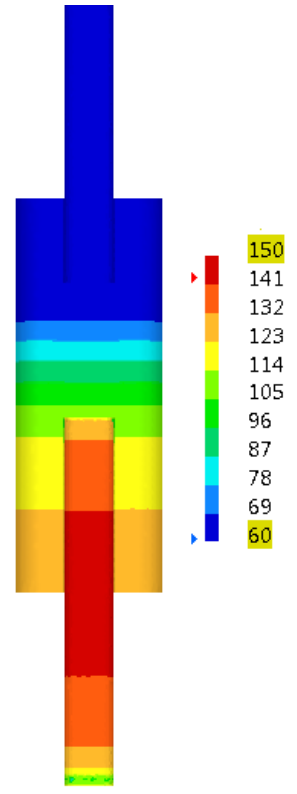

(a)

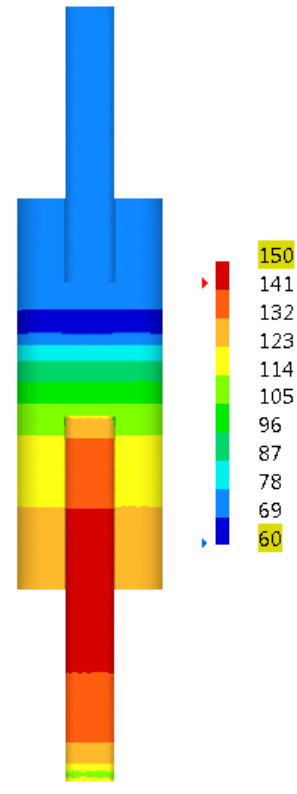

(b)

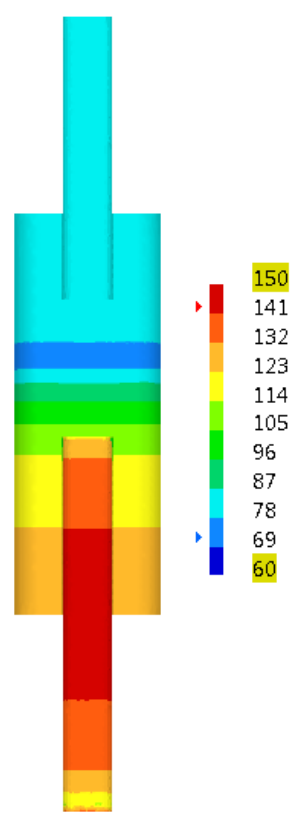

(c)

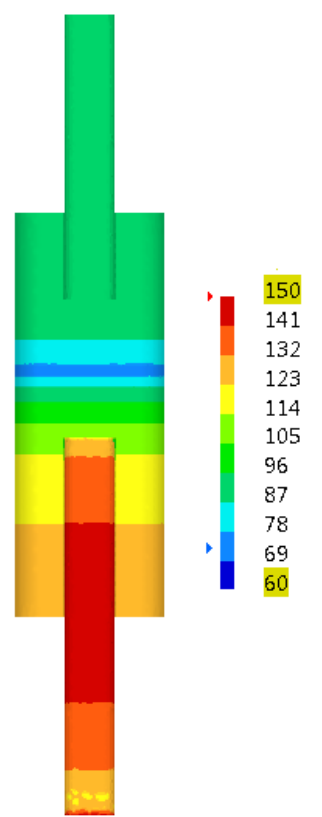

(d)

Figura 100 - Distribuição da pressão sonora (dB) no modelo IV em $432 \mathrm{~Hz}$ (a) sem escoamento e com velocidade de fluxo de (b) $10 \mathrm{~m} / \mathrm{s}$, (c) $30 \mathrm{~m} / \mathrm{s} \mathrm{e} \mathrm{(d)} 60 \mathrm{~m} / \mathrm{s}$ 


\section{CONCLUSÃO}

Este trabalho apresentou uma metodologia para estimativa da perda de transmissão de silenciadores reativos. Quatro modelos clássicos de silenciadores foram avaliadas:

1. Modelo I: Quarter-wave-tube;

2. Modelo II: Câmara de expansão simples;

3. Modelo III: Câmara de expansão com duto de entrada estendido;

4. Modelo IV: Câmara de expansão com dutos estendidos.

$\mathrm{Na}$ primeira etapa, todas as configurações acima citadas foram avaliadas sem presença de escoamento. A análise unidimensional foi realizada pelo método da matriz de transferência. Foram aplicados diferentes fatores de correção, disponíveis na literatura, para as regiões onde ocorrem mudanças súbitas na seção transversal dos tubos. Verificou-se que os fatores de correção afetam diretamente a frequência e amplitude das curvas de TL. Portanto devem ser bem selecionados antes de uma análise 1D.

Em seguida, o desempenho dos silenciadores foi estimado usando o método de elementos finitos utilizando os softwares comerciais Ansys Mechanical ${ }^{\circledR} 16.0$ e LMS Virtual.lab ${ }^{\circledR} 13.5$.

No Ansys ${ }^{\circledR}$ foram realizadas análises 2D, 3D e, para os modelos de câmara de expansão também foi feita a modelagem 3D fracionada, que consiste em $1 / 6$ do volume completo do silenciador. Os resultados obtidos a partir da simulação 3D apresentaram boa concordância com os resultados obtidos a partir do método da matriz de transferência. Para alguns fatores de correção, as curvas apresentam melhor aproximação.

A modelagem 2D reduziu o gasto de tempo computacional em até $97 \%$ em comparação com o modelo 3D completo. Porém, apenas a curva de TL do modelo I apresentou boa concordância com a curva da simulação 3D. Nos demais casos, ainda que as curvas apresentassem a forma típica de atenuação 
da câmara de expansão avaliada, não apresentaram boa aproximação em frequência máxima de atenuação e amplitude com os demais resultados.

A simulação 3D fracionada também proporcionou uma redução expressiva no tempo de processamento em relação ao modelo 3D - de até $98 \%$ na simulação da câmara de expansão simples, por exemplo. Os resultados apresentaram concordância satisfatória com as curvas da simulação 3D completa, em especial com relação à frequência máxima de atenuação. Percebe-se que os valores de amplitude não seguem uma tendência, ora subestimados ou superestimados em comparação com a análise 3D.

No Virtual.lab ${ }^{\circledR}$ foram realizadas análises 3D e 3D fracionada. Novamente, a simulação 3D fracionada provocou uma redução do tempo de simulação, e os resultados apresentaram boa concordância com as curvas da simulação 3D.

Os dois softwares foram capazes de estimar a perda de transmissão de filtros acústicos reativos sem presença de fluxo de maneira satisfatória. Foi notado que o tempo computacional gasto pelo Virtual.lab ${ }^{\circledR}$ é expressivamente reduzido em relação a simulação no Ansys ${ }^{\circledR}$, o que pode ser muito vantajoso na aplicação industrial. Por outro lado, os resultados obtidos com a análise 3D no Ansys ${ }^{\circledR}$ se aproximaram mais com aqueles obtidos pelo método da matriz de transferência. Por isso, se faz necessário a comparação com resultados experimentais com intuito de validar os resultados numéricos, e avaliar 0 melhor custo-benefício para aplicação prática.

A segunda etapa avaliou a presença de escoamento no desempenho acústico das três configurações de câmara de expansão. Foram avaliadas as velocidades de fluxo de $10 \mathrm{~m} / \mathrm{s}, 30 \mathrm{~m} / \mathrm{s}$ e $60 \mathrm{~m} / \mathrm{s}$. Foi realizada a simulação CFD do escoamento permanente no software CFX ${ }^{\circledast} 16.0$, e os dados de velocidade foram exportados para o software de elementos finitos. Por limitações técnicas do Ansys ${ }^{\circledR}$, nesta etapa foi utilizado apenas o Virtual.lab ${ }^{\circledR}$. 
Esta análise despreza o efeito viscoso do escoamento na propagação do som, que são avaliados em análise transiente. E não considera o ruído gerado pelo fluxo turbulento de massa, pois para a predição dos níveis de pressão sonora emitidos por esta fonte, devem-se utilizar os modelos de simulação numérica de aeroacústica. Porém fornece informações mais detalhadas sobre a distribuição não uniforme do campo de velocidade no silenciador, de uma maneira que demanda menos tempo computacional, ou ainda conhecimento mais aprofundado em CFD.

Os resultados mostram que a influência do escoamento tende a aumentar com a descontinuidade geométrica do silenciador. Para os dois modelos III e IV, conclui-se que o escoamento não altera as frequências máximas de atenuação, mas diminui a atenuação do silenciador à medida que a velocidade de fluxo aumenta.

Os resultados obtidos pelo MMT, também mostram que a velocidade de fluxo interfere no desempenho do silenciador, porém a amplitude foi superestimada em relação aos resultados numéricos. Este fenômeno pode estra relacionado com o fato de que o comprimento efetivo pode ser fortemente influenciado pelo escoamento de uma forma não prevista pelos fatores de correção adotados neste trabalho. E, além disso, este método não é capaz de capturar os efeitos de escoamentos não uniformes sobre o desempenho acústico do sistema.

Observou-se também que a presença de escoamento altera a pressão sonora na saída do modelo IV, o que, consequentemente, modifica a potência sonora. Entretanto, as avaliações realizadas se referiram apenas ao comportamento acústico, sendo desconsiderada a interação com os demais componentes dos sistemas de exaustão. Assim, os valores da pressão sonora apresentados no presente estudo não correspondem aos existentes em sistemas reais de exaustão. 
Como orientação para trabalhos futuros sugere-se que a metodologia apresentada neste presente trabalho seja aplicada em silenciadores reativos com geometrias mais complexas, por exemplo, com dutos perfurados, a fim de avaliar o efeito do escoamento em seu desempenho. Propõe-se também a construção de uma bancada experimental, em que seja possível controlar a velocidade de fluxo, para avaliação do desempenho de silenciadores acústicos e assim validar os resultados obtidos com a metodologia numérica apresentada neste trabalho.

Cabe também realizar a investigação numérica e experimental da influência da espessura da parede do duto estendido em câmaras de expansão, que como visto, pode influenciar o desempenho do silenciador.

Além disso, para aplicações práticas, é recomendável o estudo da perda de pressão ocasionada pela inserção de atenuadores acústicos em sistemas de exaustão e que tende a aumentar na medida em que geometria torna-se mais complexa. Para isso é necessário avaliar os sistemas de exaustão e a interação entre seus diversos componentes, de forma a possibilitar o cálculo da potência sonora e da perda por inserção, posto ser este o parâmetro que realmente descreve o desempenho acústico de um silenciador em um determinado sistema.

Por fim, sugere-se a investigação da influência do escoamento sobre as regiões onde ocorrem mudanças súbitas na seção transversal dos tubos, para então propor fatores de correção que permitam a avaliação mais precisa de silenciadores na presença de escoamento pelo método da matriz de transferência. 


\section{REFERÊNCIAS}

1. Lima KF. Metodologia de avaliação de filtros acústicos reativos [tese de doutorado]. Florianópolis, Brasil. 2008

2. Burgess Manning Industrial Silencing Internal Combustion Engines, Burgess Manning Industries Company, Dallas, 10-18 (1978) https://www.burgessmanning.com/

3. Silenciador reativo. Acesso em julho de 2015. Disponível em: <http://www.garrysservicecenter.com/services/mufflers-exhaust-systems/>

4. Thieme FA. Atenuação de ruído em silenciadores automotivos: análise numérica pelo método das matrizes de transferência e verificação experimental [dissertação de mestrado] Florianópolis, Brasil, 2000.

5. Young ClJ, Croker MJ. Prediction of transmission loss in mufflers by the finite element method. J Acoust Soc Am 1975, 57, 144-8.

6. Gerges SNY, Jordan R, Thime FA, Coelho JLB, Arenas JP. Muffler Modeling by Transfer Matrix Method and Experimental Verification. J Braz Soc Mech Sci \& Eng 2005; 27(2): 132-140.

7. Young, ClJ, Croker MJ. Acoustical analysis, testing, and design of flow reversing muffler chambers: Prediction of transmission loss in mufflers by the finite element method. J Acoust Soc Am 1976; 60: 1111-8.

8. Silenciador reativo: Acesso em julho de 2015. Disponível em:

<http://www.autoanything.com/exhausts-mufflers/61A3545A0A0.aspx>

9. Alfredson RJ, Davies POAL. Performance of exhaust silencer components. $J$ Sound Vibration 1971; 15(2):175-196.

10. Igarashi J, Toyama M. Fundamentals of acoustic silencers (I). Aeronautical Research Institute, University of Tokyo. 1958; 223-241.

11. Igarashi J, Arai M. Fundamentals of acoustic silencers (III). Aeronautical Research Institute, University of Tokyo.1960; 17-31.

12. Munjal ML. Velocity ratio-transfer matrix method for the evaluation of a muffler with mean flow. J Sound Vibration 1975; 39: 105-119.

13. Munjal ML. Acoustics of ducts and mufflers. Nova York: John Wiley; 1987

14. Munjal ML. Analysis and design of mufflers - an overview of research at the Indian Institute of science. J Sound Vibration 1998; 211 (3): 425-433. 
15. Munjal ML, Behera BK, Thawani PT. Transfer matrix model for the reverseflow, three-duct, open end perforated element muffler. Applied Acoustics 1990; 54(3):229-238.

16. Munjal ML, Gowri S. Theory and design of tuned extended tube chambers and concentric tube resonators. J Acoustic Soc India 2009; 36(2): 53-71.

17. Panigrahi SN, Munjal ML. Plane wave propagation in generalized multiply connected acoustic filters. J Acoust Soc Am 2015; 118: 2860-8.

18. Chen F. Optimization design of muffler based on acoustic transfer matrix and genetic algorithm. $J$ Vibroengineering 2014; 16: 2216-2223.

19. Craggs A. A finite element method for damped acoustic systems: An application to evaluate the performance of reactive mufflers. J Sound Vibration 1976; 48: 377-392.

20- Peat KS. Evaluation of four-pole parameters for ducts with flow by the finite element method. J Sound Vibration 1982; 84(3): 389-395.

21. Zhenlin J., Qiang M,Zhihua Z. Application of the boundary element method to predicting acoustic performance of expansion chamber muffler with mean flow. J Sound Vibration 1994; 173(1): 57-71.

22. Ji ZL, Ma Q, Zhang ZH.. A boundary element scheme for evaluation of fourpole parameters of ducts and mufflers with low Mach number non-uniform flow. J Sound Vibration 1995, 185(1): 107-117.

23. Selamet A, Ji ZL. Acoustic attenuation performance of circular expansion chambers with extended inlet/outlet. J Sound Vibration 1999; 223: 197-212.

24. Selamet A, Ji ZL. Acoustic attenuation performance of expansion chambers with two end-inlet/one side-outlet. J Sound Vibration 2000; 231: 1159-1167

25. Broatch A, Margot X, Gil A, Denia FD. A CFD approach to the computation of the acoustic response of exhaust mufflers. J Compl Acoust 2005; 13: 301316.

26. Liu C, Ji ZL.Computational fluid dynamics-based numerical analysis of acoustic attenuation and flow resistance characteristics of perforated tube silencers. J Vib Acoust 2014; 136(2):1-11.

27. Gardner BK, Mejdi A, Mendonca F. Using CFD flow fields to inform acoustic finite element models of complex mufflers with thermal and flow effects. In:Proceedings of the 44th International Congress and Exposition on Noise Control Engineering 2015; San Francisco, California. 
28. Lee S., Bolton JS. Design of an acoustic silencer with the microperforated elements considering flow effects. In:Proceedings of the 44th International Congress and Exposition on Noise Control Engineering 2015; San Francisco, California.

29. Fan W, Guo L. An investigation of acoustic attenuation performance of silencers with mean flow based on three-dimensional numerical simulation. Shock and Vibration 2015; 2016:1-12.

30. Beranek LL, Ver IL, editors. Noise and Vibration Control Engineering Principles and Applications. 2nd ed. New York, USA: Wiley; 2006.

31. Kumar S. Linear acoustic modeling and testing of exhaust mufflers. [dissertação de mestrado]. Stockholm, Sweden. 2007

32. Gerges SNY. Ruído: fundamentos e controle. Florianópolis Editora: NR LVA; 2000.

33. Tyler W, Le Roy. Muffler characterization with implementation of the finite element method and experimental techniques [dissertação de mestrado]. Michigan, Estados Unidos. 2011.

34. Silenciador dissipativo: Acesso em julho de 2015. Disponível em: $<$ http://b.cdnbrm.com/images/products/rell/exhaust_systems/magnaflow_muffler construction.jpg>

35. Silenciador ativo: Acesso em julho de 2015. Disponível em: $<$ http://soarercentral.com/sc-forum/messages/171174/338741.png>

36 Kinsler, LE, Frey AR, Coppens AB, Sanders JV. Fundamentals of Acoustics. 3.ed. New York: Jhon Wiley \& Sons; 1982.

37. Pascal AM. Análise de sistemas reativos para controle de ruído em dutos pelo método dos elementos finitos [dissertação de mestrado]. Minhas Gerais, Brasil. 2005

38. Fox RW, Mcdonald AT. Introdução à mecânica dos fluidos. 4. ed. Rio de Janeiro : LTC; 1998.

39. Fahy F. Foundations of engineering acoustics. New York: Academic Press; 2001.

40. Nunes, MA. Utilização de síntese modal de componentes e particionamento axial de dutos para controle dos modos acústicos de alta ordem [tese de doutorado]. Uberlândia, Brasil. 2009 
41. Pacheco WS. Ressonador de Helmholtz semi-ativo para controle de ruído em dutos [dissertação de mestrado]. Rio de Janeiro, Brasil. 2006

42. Sullivan JW, Crocker. Analysis of concentric-tube resonators having unpartitioned cavities. J Acoust Soc Am 1978; 64: 207-215.

43. Morse PM, Ingard KU. Theoretical Acoustics . New York: McGraw-Hill; 1968

44. Rayleigh JWS. Theory of Sound. MacMilland and Company. 1980

45. Ingard U. On the theory and design of acoustic resonator. J Acoust Soc Am 1953; 25 (6):1037-1061.

46. Karal FC. The analogous acoustical impedance for discontinuities and constrictions of circular cross section. J Acoust Soc Am 1953; 25: 327-334.

47. Davies POAL. Practical flow duct acoustics. Journal of Sound and Vibration. 1988, 124(1), 91-115.

48. Onorati A. Prediction of the acoustic performance of muffling pipes systems by the method of characteristics. J Sound Vibration 1994; 171(3): 369-395.

49. Torregrossa AJ et al. Numerical estimation of end corrections in extendedduct and perforated-duct mufflers. J Vib Acoust 1999; 121:302-8.

50. Ji ZL. Acoustic length corrections of a closed cylindrical side-branched tube. J Sound Vibration. 2005, 283:1180-6.

51. Chaitanya $P$, Munjal ML. Effect of wall thicknesson the end corrections of the extended inlet and outlet of a double-tuned expansion chamber. Applied Acoustics 2011; 72 (1): 65-70.

52. Coyette JP. Flow acoustics using finite elements. Technical report. LMS Numerical Technologies. Não publicado.

53. Tao Z, Seybert AF. A review of current techniques for measuring muffler transmission loss. SAE International, 2003.

54. Versteeg HK, Malalasekera W. An introduction to computational fluid dynemics - the finite volume method. Longman Scientific \& Technical; 1995

55. Ferziger JH, Peric M. Computational Fluid Dynamics. Springuer; 2002

56. Gonçalves NDF. Método dos volumes finitos em malhas não-estruturadas [dissertação de mestrado]. Porto, Portugal. 2007. 
57. Vasconcellos GLF, Melo AB, Freitas PHA, Hanriot SM, Maia CB. estudo numérico do escoamento ao redor de um cilindro circular em um túnel de vento para baixas velocidades para diferentes rotações. SIMMEC/EMMCOMP 2014 XI Simpósio de Mecânica Computacional II Encontro Mineiro de Modelagem Computacional. Juiz de Fora, Brasil.

58. Kang Z, Ji Z. Acoustic length correction of duct extension into a cylindrical chamber. J Sound Vibration 2008; 310: 782-791

59. Howard CQ, Cazzolact BS. Acoustic analyses using MATLAB and ANSYS. Boca Raton: CRC Press; 2015.

60.ANSYS, Inc. Theory Reference. Release 16.0Documentation for ANSYS. United States of America, 2009

61. LMS International NV, LMS Virtual.Lab Online Help13.5-SL2, LMS International N. V., Leuven, Belgium, 2015.

62. Boij S. Flow effects on the acoustic end correction of a sudden in-duct area expansion. J. Acoust Soc Am 2009;126(3): 995-1004

63. Wang XR, Ji ZL.Boundary element analysis of four pole parameters and transmission loss of silencers with flow. Chinese J Comp Phys 2007; 27(6): 717-724.

64. Ji ZL, Xu HS,. Kang Z.X. Influence of mean flow on acoustic attenuation performance of straight-through perforated tube reactive silencers and resonators. Noise Control Engineering Journal 2010; 58(1):12-17. 